\title{
WestVirginiaUniversity
}

THE RESEARCH REPOSITORY @ WVU

Graduate Theses, Dissertations, and Problem Reports

2020

\section{Solutions to Some Mine Subsidence Research Challenges}

Jian Yang

West Virginia University, jayang@mix.wvu.edu

Follow this and additional works at: https://researchrepository.wvu.edu/etd

Part of the Mining Engineering Commons

\section{Recommended Citation}

Yang, Jian, "Solutions to Some Mine Subsidence Research Challenges" (2020). Graduate Theses, Dissertations, and Problem Reports. 7948.

https://researchrepository.wvu.edu/etd/7948

This Dissertation is protected by copyright and/or related rights. It has been brought to you by the The Research Repository @ WVU with permission from the rights-holder(s). You are free to use this Dissertation in any way that is permitted by the copyright and related rights legislation that applies to your use. For other uses you must obtain permission from the rights-holder(s) directly, unless additional rights are indicated by a Creative Commons license in the record and/ or on the work itself. This Dissertation has been accepted for inclusion in WVU Graduate Theses, Dissertations, and Problem Reports collection by an authorized administrator of The Research Repository @ WVU.

For more information, please contact researchrepository@mail.wvu.edu. 


\title{
Solutions to Some Mine Subsidence Research Challenges
}

\author{
Jian Yang
}

\author{
Dissertation submitted \\ to the \\ Benjamin M. Statler College of Engineering and Mineral Resources \\ at West Virginia University \\ in partial fulfillment of the requirements \\ for the degree of \\ Doctor of Philosophy \\ in \\ Mining Engineering \\ Yi Luo, Ph.D., Chair \\ Ihsan B Tulu, Ph.D. \\ Qingqing Huang, Ph.D. \\ Ming Gu, Ph.D. \\ Lihong Zhou, PhD.
}

Department of Mining Engineering

Morgantown, West Virginia

2020

Keywords: Surface and Subsurface Subsidence Prediction, Inactive Room-and-Pillar Mine, Dewatering, Longwall Mining, Subsidence Effects, Interstate Highways and Overpass Bridges, Assessment and Mitigation Techniques, Key Strata Theory

Copyright 2020 Jian Yang 


\section{ABSTRACT \\ Solutions to Some Mine Subsidence Research Challenges}

\section{Jian Yang}

The objective of this work is to address three challenging topics, (1) effects of overburden key strata on subsurface subsidence; (2) effects of longwall subsidence on interstate highways and highway bridges; and (3) effects of dewatering mine water on surface subsidence over inactive room-and-pillar mines, in mine subsidence and to continue improvement of mine safety and health by reducing mine-subsidence related hazards.

Surface and subsurface subsidence events induced by underground mining activities are often capable of causing significant disturbances not only to surface structures, but also to subsurface structures. In this work, models and techniques to study three challenging topics in mine subsidence will be developed and detailed as follows.

An accurate subsurface subsidence prediction model is necessary in order to assess the disturbances to various subsurface structures. Decades of research have demonstrated that variations of lithology in the overburden have significant influence on the subsurface strata movements and deformations during ground subsidence process. The key strata theory states that the thick and hard key strata serve as the backbone of the overburden and controls the movements of the overlying thin and soft weak rock strata. A new version of subsurface subsidence prediction model considering the key strata effects on subsurface strata movements and deformations is developed. The influence function method, proven to be accurate and versatile for surface subsidence prediction, is employed to predict the subsidence on each of the overburden strata from mining horizon progressively upward to ground surface with the assumption that the predicted subsidence on a given stratum serves as the subsidence source for the stratum immediately above. The new subsurface subsidence prediction model is demonstrated with an actual case to show its applicability and improvement.

Surface subsidence events induced by underground longwall mining operations can cause various problems to interstate highways and their bridges, ranging from structural integrity and stability to functionality. Accurate subsidence predictions, correct influence assessments and effective mitigation measures are the keys to ensure the continuous service of interstate highways, safety of travelers and smooth mining operations. Highway bridges, as a kind of special road construction that can only tolerate smaller movements and deformations than road pavements, are particularly susceptible to severe influence caused by subsidence-induced ground movements and deformations. The techniques to use the predicted final and dynamic surface subsidence to assess their influences on the integrity, stability and functionality of highway structures (e.g., road surface pavements, concrete slabs, transverse joints, etc.), bridge structures, vehicle dynamics, comfort and drivability are presented. Mitigation measures to protect the highway and bridge structures and to ensure traffic safety are also proposed along with an application case.

Investigating inactive mine subsidence is often a very difficult task because many factors, both mining- or non-mining-related, can affect the possibility and the formation process of surface subsidence events over inactive room-and-pillar mines. Among them, mine water frequently plays an important role in causing such subsidence events. However, mine water could also serve the purpose of preventing subsidence. The dewatering of inactive room-and-pillar mines has been identified as the main cause for a number of serious mine subsidence events in the past. In this 
work, the mechanism of mine water to prevent surface subsidence over inactive room-and-pillar coal mines is studied. Two mathematical models are proposed to quantify the potential effects of mine water on the structural stability of mine pillars and roof, as well as the potential for causing surface subsidence. The models are validated with a documented subsidence case. 


\section{ACKNOWLEDGEMENT}

I would like to express my deepest appreciation to my committee chair, Dr. Yi Luo for his invaluable instructions, encouragement, and support during this research and throughout my graduate study. Without his guidance and persistent help this dissertation would not have been possible.

Special thanks are given to the committee members, Dr. Berk I. Tulu, Dr. Qingqing Huang, Dr. Ming Gu, and Dr. Lihong Zhou for the time and the expertise contributed to the enhancement of this research.

Special thanks are also given to all the faculty and staff members in the Mining Engineering Department for their kindness, friendship and assistance shown to me during my time in WVU.

I would like to give my sincere thanks and wishes to my fellow graduate students: Hua Jiang, Yinan Zhang, Yuting Xue, Haochen Zhao, Deniz Tuncay, Deniz Talan, Qinwen Shi and other graduate students in the Department of Mining Engineering at WVU, for their great assistances during this research.

Finally, sincere gratitude goes to my family members, my father, Ximing Yang, and mother, Herong Han, my elder sister, Qianqian Yang. Special thanks are given to my beloved wife, Danqing Gao, and my daughter Tracy Gao Yang. Without their endless love, constant support, patience and understanding, I would never have finished the study in WVU. 


\section{TABLE OF CONTENTS}

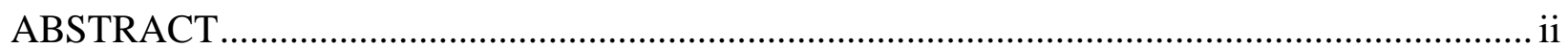

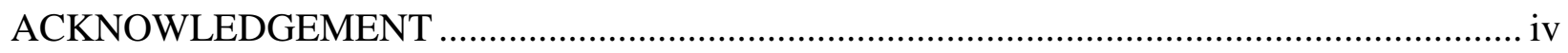

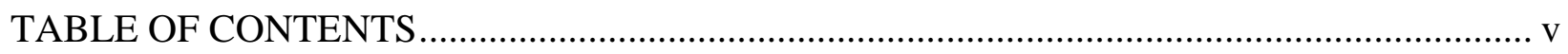

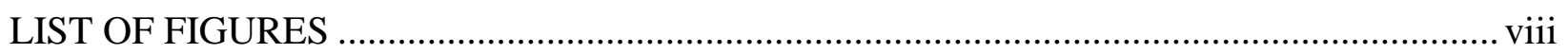

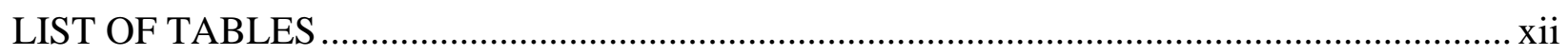

LIST OF ABBREVIATIONS AND SYMBOLS ........................................................... xiii

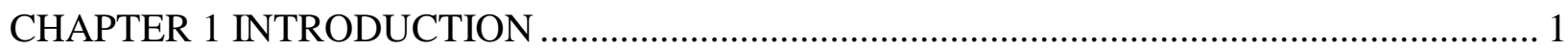

1.1 Mine Subsidence Background and Development ................................................. 1

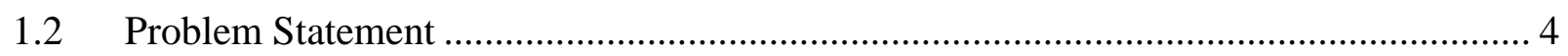

1.3 Objective and Research Methods ......................................................................... 7

CHAPTER 2 LITERATURE REVIEW ................................................................. 9

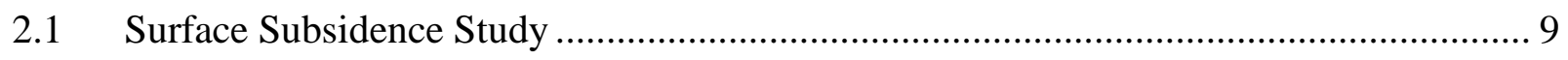

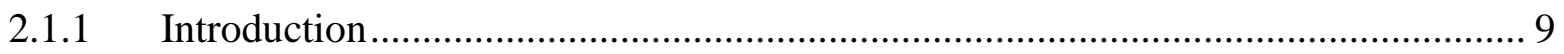

2.1.2 Final Surface Subsidence ......................................................................... 10

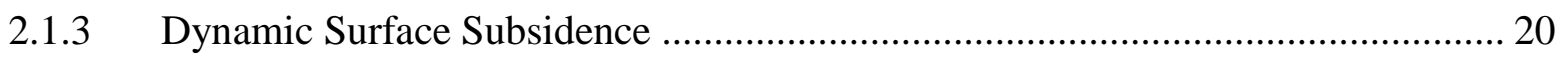

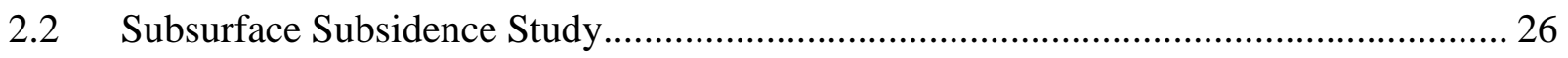

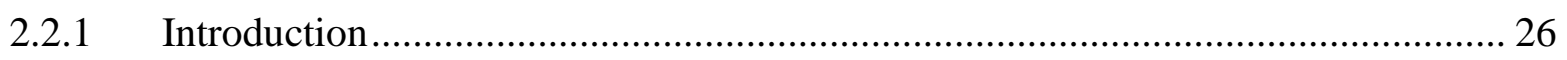

2.2.2 Final Subsurface Subsidence Prediction ........................................................ 26

2.3 Mine Subsidence-Related Research ..................................................................... 31

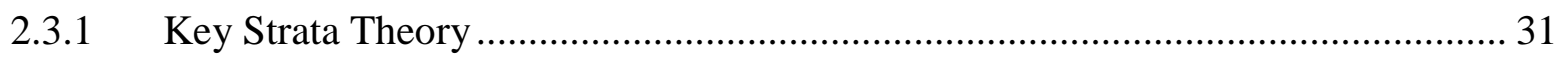

2.3.2 Interstate Highways and Bridges .......................................................... 35

2.3.3 Mine Water in Inactive Room-and-Pillar Mines ................................................ 38

CHAPTER 3 ENHANCED SUBSURFACE SUBSIDENCE PREDICTION MODEL INCORPORATING KEY STRATA THEORY ............................................................ 41

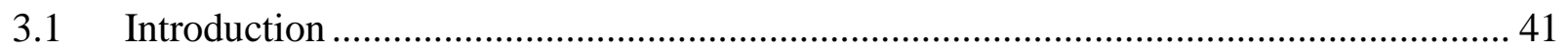

3.2 Enhanced Mathematical Model......................................................................... 43

3.2.1 Influence functions for subsurface subsidence and horizontal displacement ........ 44

3.2.2 Final subsurface movements ......................................................................... 46

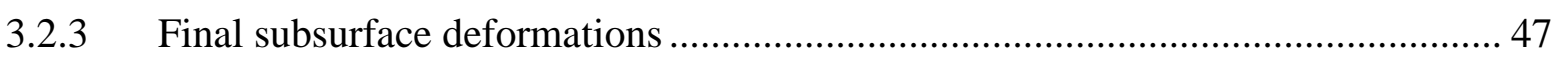

Final Subsurface Subsidence Parameters ................................................................ 47 


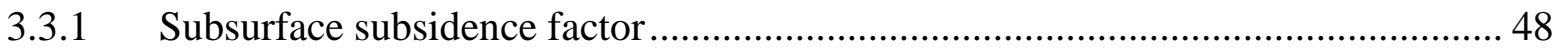

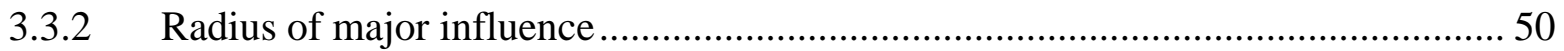

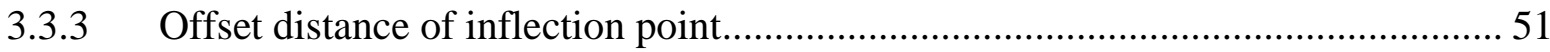

$3.4 \quad$ Strength of Common Coal Measure Rocks .............................................................. 52

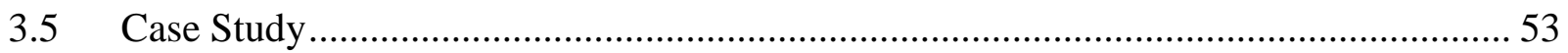

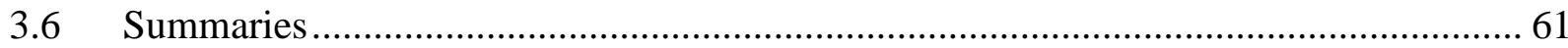

CHAPTER 4 TECHNIQUES FOR ASSESSING AND MITIGATING LONGWALL

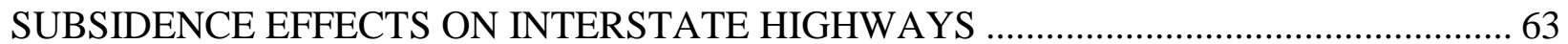

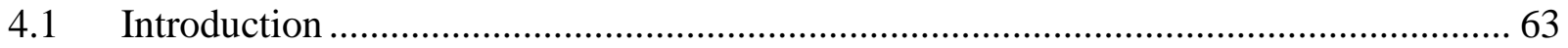

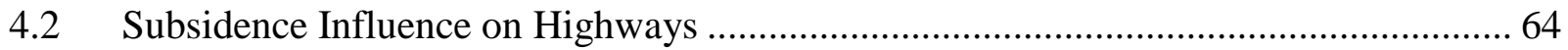

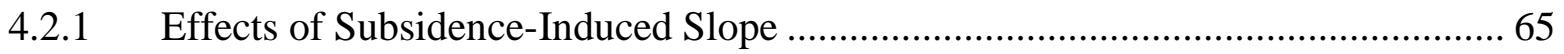

4.2.2 Effects of Subsidence-Induced Strain ................................................................ 69

4.2.3 Effects of Subsidence-Induced Curvature .......................................................... 70

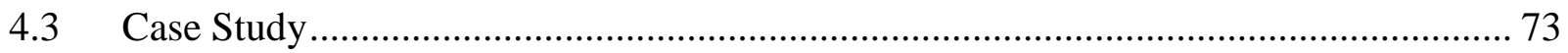

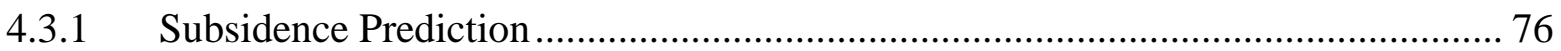

4.3.2 Assessment of Subsidence Influence on Highway …………………………....... 77

4.3.3 Mitigation Measures for Highway Pavements.......................................................... 79

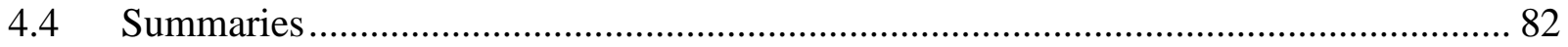

CHAPTER 5 TECHNIQUES FOR ASSESSING AND MITIGATING LONGWALL

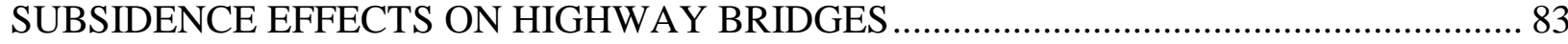

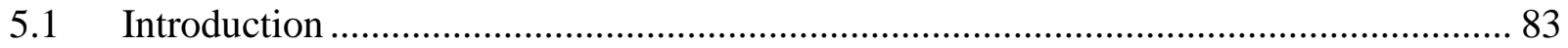

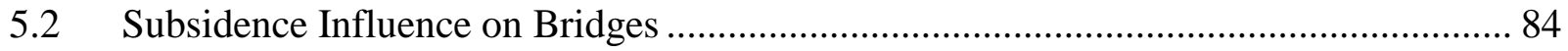

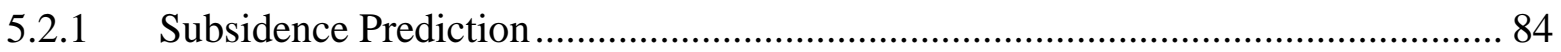

5.2.2 Separation or Closure between End Abutments .................................................... 85

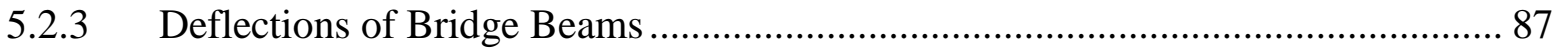

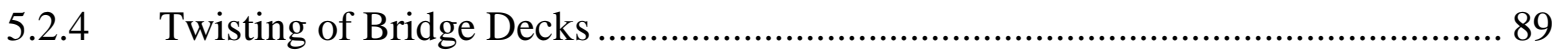

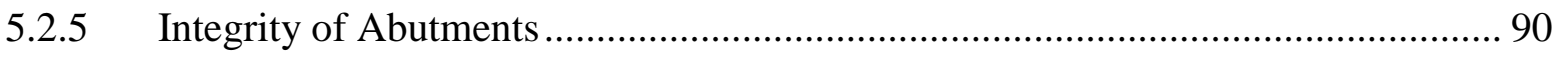

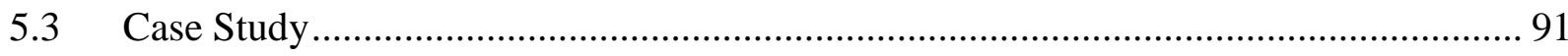

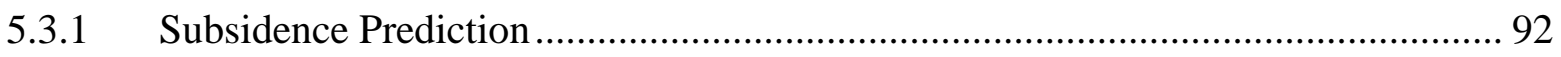

5.3.2 Assessment of Subsidence Influence on Bridges................................................. 99

5.3.3 Recommended Mitigation Measures for Bridges ................................................... 103

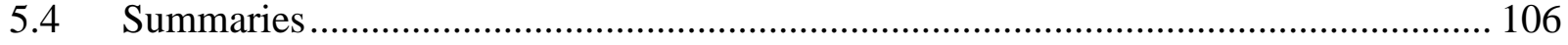

CHAPTER 6 EFFECTS OF DEWATERING FLOODED INACTIVE ROOM-AND-PILLAR

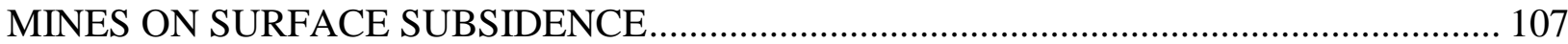




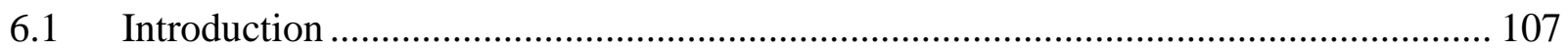

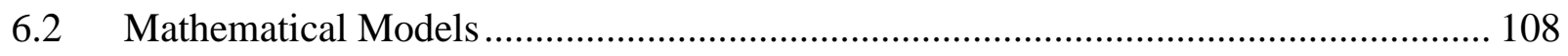

6.2.1 Pillar Stability Model ....................................................................................... 108

6.2.2 Roof Stability Model................................................................................ 112

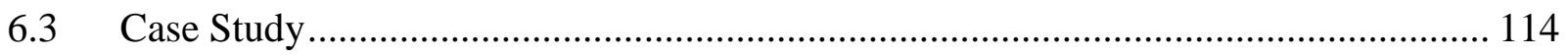

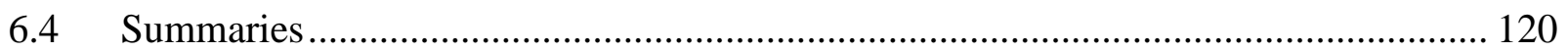

CHAPTER 7 CONCLUSIONS AND RECOMMENDATIONS ......................................... 121

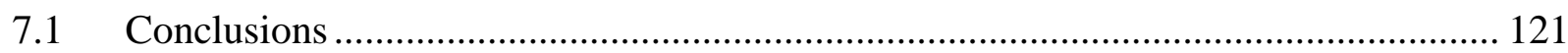

7.2 Research Significance and Outcomes ............................................................. 123

7.3 Recommendations for Future Research ........................................................... 123

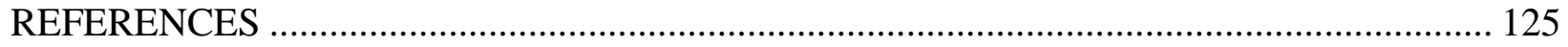

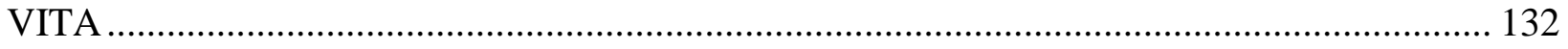




\section{LIST OF FIGURES}

Figure 1.1 Schematic of roof strata movements due to longwall face retreat (Peng, 2020) .......... 2

Figure 2.1 Types of mine subsidence and their effects (after PADEP, 2020a) ......................... 9

Figure 2.2 Definition of surface movements and deformations (after Luo, 2020b) .................. 13

Figure 2.3 Relationship among subsidence terminologies and subsidence trough (Luo, 1989)... 14

Figure 2.4 Schematic of influence functions for subsidence and horizontal displacement (Luo,

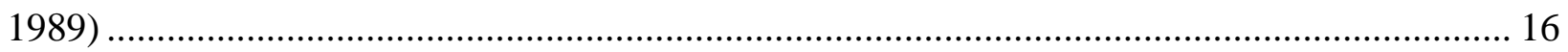

Figure 2.5 Schematic for calculating final subsidence along a major cross-section (Luo, 2020a) 17

Figure 2.6 Schematic for calculating final horizontal displacement along a major cross-section

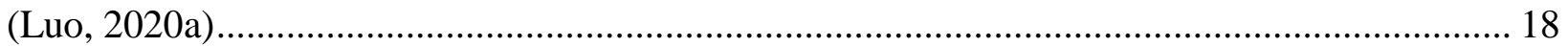

Figure 2.7 Surface and subsurface subsidence factors in CISPM (after Luo and Peng, 2000) .... 19

Figure 2.8 Surface subsidence factor in SDPS (after Karmis et al., 1987) .............................. 20

Figure 2.9 Dynamic subsidence profiles in the initial stage of mining a longwall panel (Luo, 2020a)

Figure 2.10 Dynamic subsidence profiles in the normal stage of mining a longwall panel (Luo,

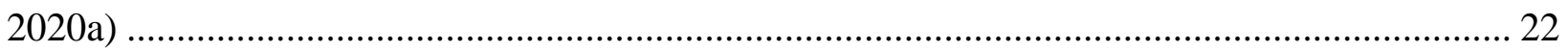

Figure 2.11 Development and distribution of residual (creep) subsidence (Luo, 2020a)........... 23

Figure 2.12 Normal and long-term dynamic subsidence development process (Luo, 2020b) ..... 23

Figure 2.13 Coordinate systems for dynamic subsidence prediction (Luo, 1989) .................... 24

Figure 2.14 Second version of subsurface subsidence prediction model (Luo and Qiu, 2012) ... 27

Figure 2.15 Schematic of influence function method for subsurface subsidence prediction ....... 28

Figure 2.16 Determination of the radius of major influence (Luo and Qiu, 2012)................... 30

Figure 2.17 Schematic of key strata in the overburden ...................................................... 32 
Figure 2.18 Typical construction of interstate highways (after Oglesby and Hicks, 1982) ........ 36 Figure 2.19 Typical construction of highway bridges from front view (top) and cross-section view

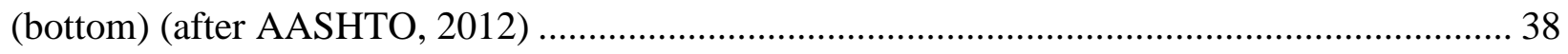

Figure 2.20 Observed subsidence events on interstate I-70 over an abandoned coal mine (after

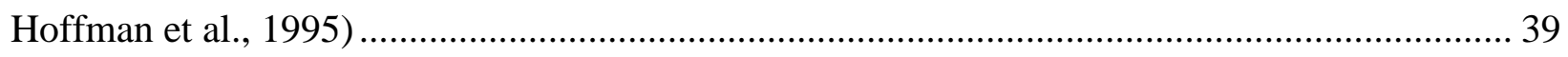

Figure 3.1 Principle of the influence function method for subsurface subsidence prediction...... 45

Figure 3.2 Schematic of the focal point theory showing relationship between influence functions

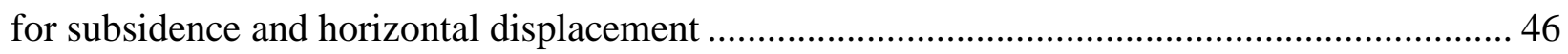

Figure 3.3 Linear regression for ratios and percent of hard rock........................................ 49

Figure 3.4 Determination of the radius of major influence. ............................................... 50

Figure 3.5 Longwall layout showing the location of the boreholes (left) and stratigraphic section at the borehole site with the mechanical anchors (right) (Plot Not to Scale) ............................ 54

Figure 3.6 Final subsurface subsidence profiles formed at different levels above the longwall panel

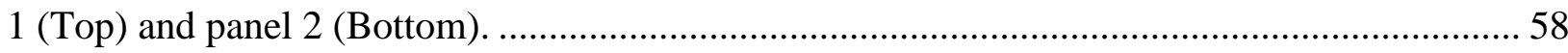

Figure 3.7 Distribution of final subsurface void intensity above the longwall panel 1 (top) and

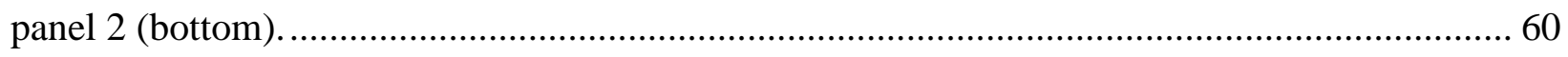

Figure 4.1 Effect of subsidence-induced slope on vehicle dynamics .................................... 66

Figure 4.2 Height of uplift of concrete slabs under influence of compressive strain ................ 70

Figure 4.3 Schematic of highway crest vertical curve ................................................... 72

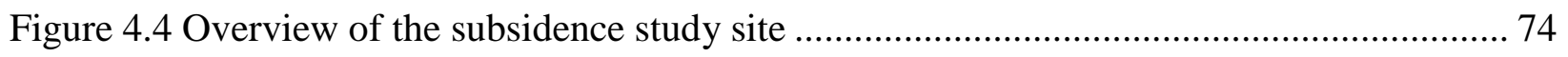

Figure 4.5 Highway surface elevations before and after subsidence .................................... 75

Figure 4.6 Highway gradient profiles before and after subsidence ..................................... 76

Figure 4.7 Highway vertical curvature profiles before and after subsidence ........................... 76 
Figure 4.8 Bump (Ground already) formed on I-79 in the Maximum Compression Zone 81

Figure 4.9 Vertical curve induced by subsidence and open lane for traffic on each direction ..... 81

Figure 5.1 Schematic of movements of corresponding points in end abutments 86

Figure 5.2 Typical types of bearings for bridges: (a) sliding bearings; (b) rocker bearings; (c) roller bearings; (d) elastomeric bearings; (e) curved bearings; (f) pot bearings; (g) disk bearings ....... 86

Figure 5.3 Schematic of bridge beams convex (a) and concave (b) deflections........................ 89

Figure 5.4 Twisting condition that occurred on the bridge deck (Fuller et al., 2000) ............... 90

Figure 5.5 Schematic of integrity of abutment ............................................................ 91

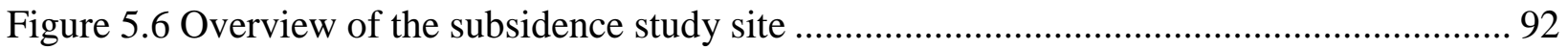

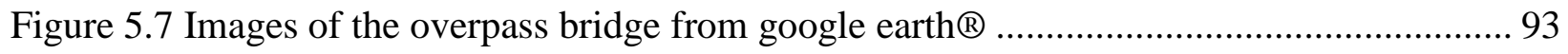

Figure 5.8 Development curves of dynamic subsidence for the eastbound overpass bridge ....... 95

Figure 5.9 Differential subsidence between paired points (steel beams) on the eastbound bridge

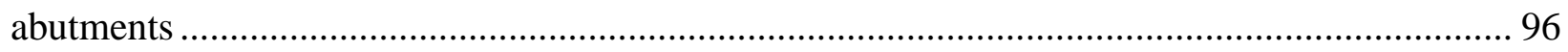

Figure 5.10 Development curves of dynamic horizontal displacement for the eastbound overpass

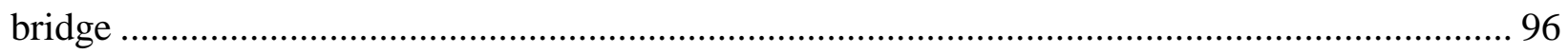

Figure 5.11 Differential horizontal displacement between paired points on end abutments....... 98

Figure 5.12 Development curves of dynamic strain on abutments for the eastbound overpass bridge 98

Figure 5.13 Dynamic curvature developed on the end abutments and pier caps...................... 99

Figure 5.14 Predicted separation/closure between the paired points on eastbound bridge abutments 100

Figure 5.15 Development curves of maximum deflection of steel beam at intermediate piers.. 102 Figure 5.16 Development curves of twisting conditions on the bridge decks . 103 
Figure 5.17 Dynamic strain developed on the end abutments 103

Figure 6.1 Schematic of hydrostatic pressure and tributary load method. 109

Figure 6.2 Change in safety factor vs. percent change in variables.

Figure 6.3 A beam with fixed ends for assessing mine roof stability in abandoned room-and-pillar mine. 112

Figure 6.4 Map view of the sinkhole subsidence on the eastbound of I-70 (road stations 4830048500) in Ohio (after Guy et al., 2003) 115

Figure 6.5 A Geologic column constructed from drill log data along the southern edge of the I-70 115

Figure 6.6 Roof deflection profile for the 25 -ft long and $15-\mathrm{ft}$ thick shale layer with and without hydrostatic pressure effect 118 Figure 6.7 Strain profiles for the $25-\mathrm{ft}$ long and 15 -ft thickness shale layer with and without hydrostatic pressure effect 118 Figure 6.8 Roof deflection profile for the 45 -ft long and 15 -ft thick shale layer with and without hydrostatic pressure effect 119 Figure 6.9 Strain profiles for the 45 -ft long and 15-ft thickness shale layer with an without hydrostatic pressure effect 119 


\section{LIST OF TABLES}

Table 2.1 Shapes of final surface subsidence basin over a single opening (after Luo, 2020a) .... 11

Table 3.1 Subsidence factors calculated using Eq. 3.5 ................................................. 48

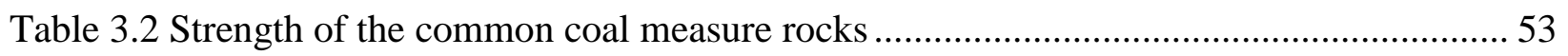

Table 3.3 Relative height of each anchor in $\mathrm{BH}$ land $\mathrm{BH} 2$ with respect to the Redstone Coalbed 55

Table 3.4 Geological stratification of overburden with rock properties .................................. 57

Table 4.1 Maximum grades along the axial direction for rural and urban highways (AASHTO,

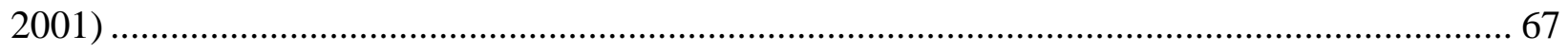

Table 4.2 Minimum radius of vertical curve and maximum curvature for highway .................. 73

Table 4.3 Predicted final surface movements and deformations across the highway section ...... 77

Table 5.1 Ranges of predicted final surface movements and deformations across the bridge

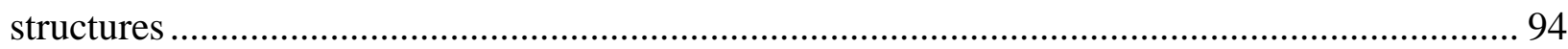

Table 5.2 Original elevations of contact points on eastbound bridge abutments .................... 101

Table 6.1 Ranges of independent variables in sensitivity study ........................................ 111

Table 6.2 Physical and mechanical properties of coal measure rocks in dry condition (Zhao, 2020) 


\section{LIST OF ABBREVIATIONS AND SYMBOLS}

\section{List of Symbols}

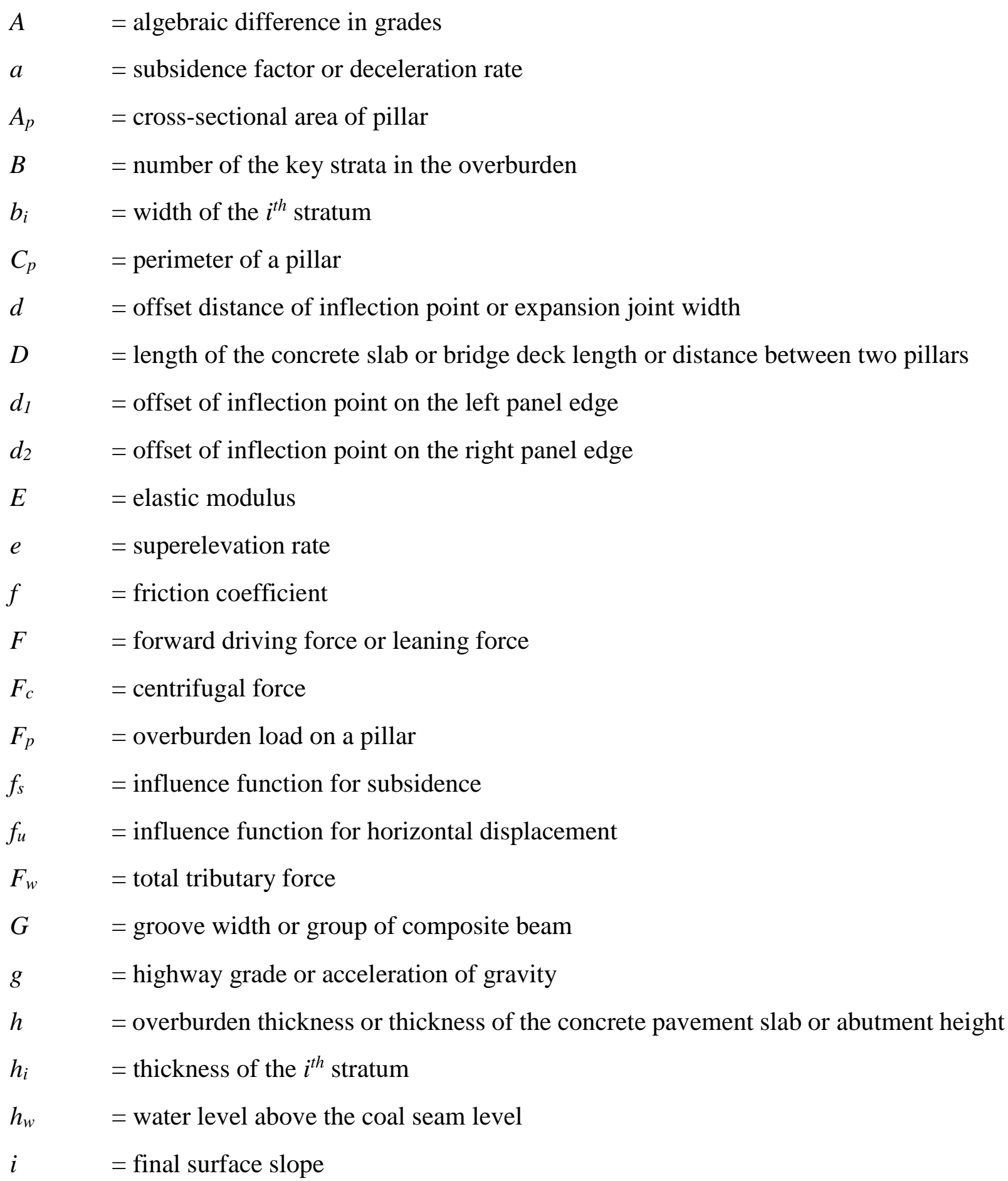




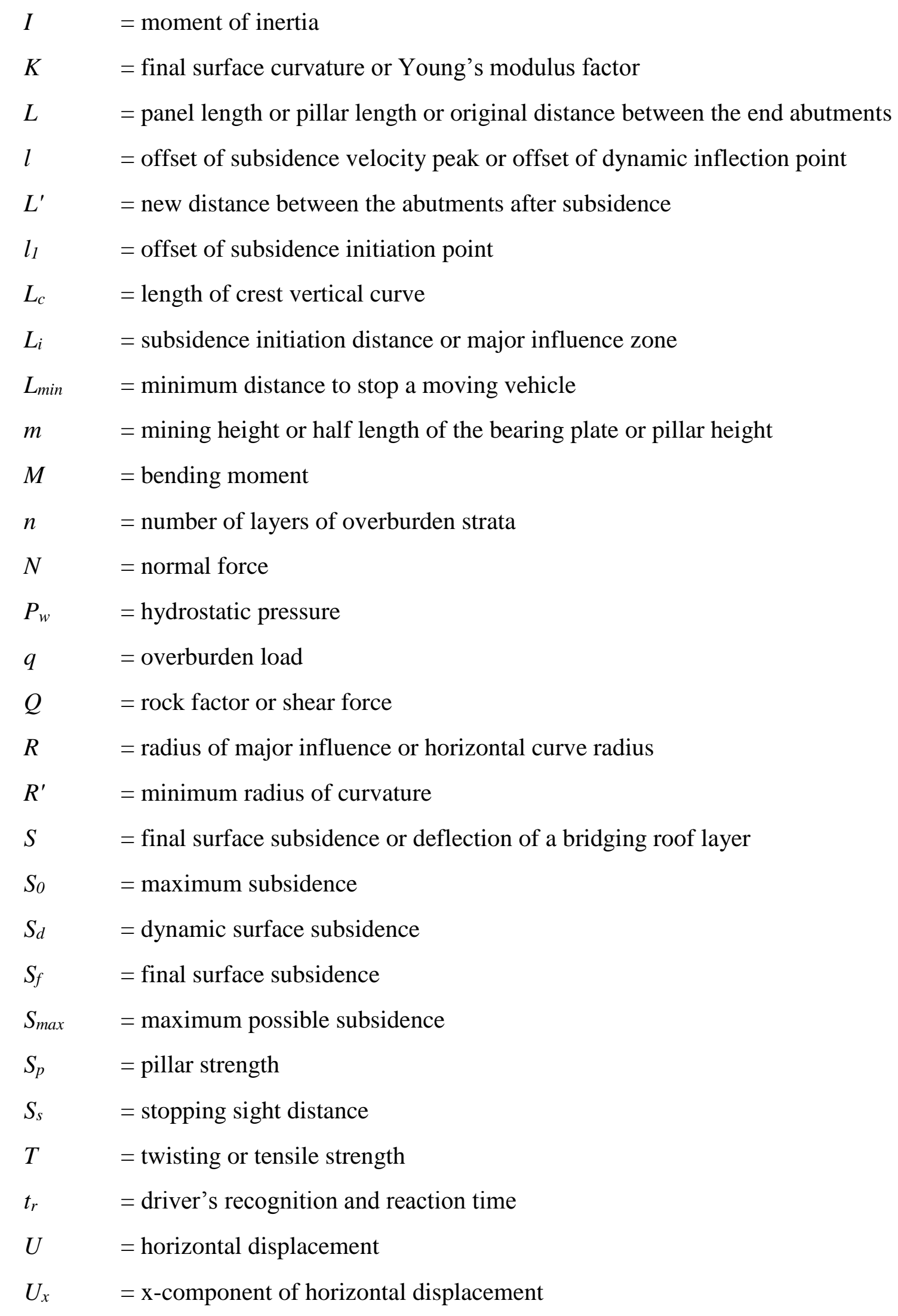




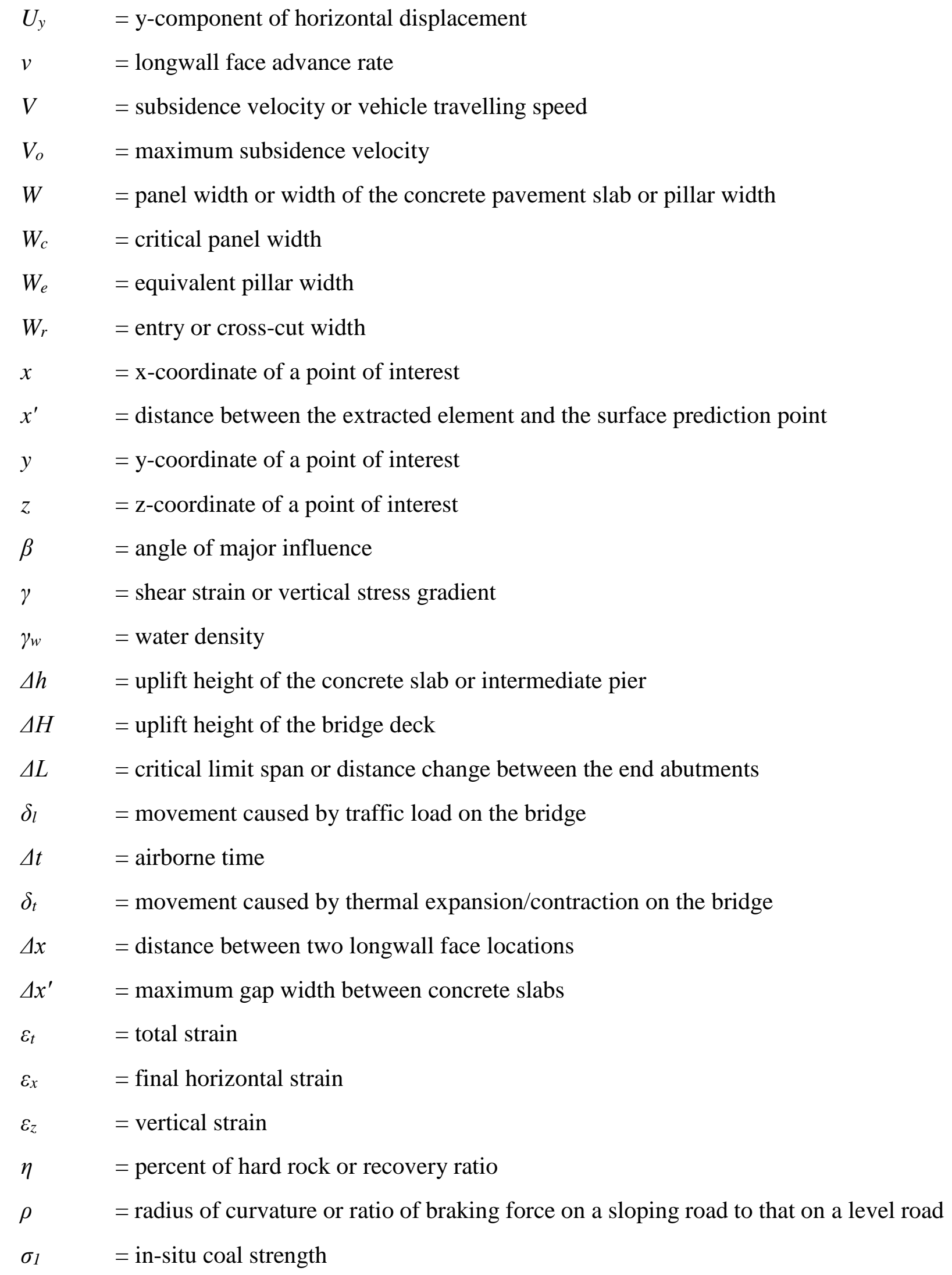




$$
\begin{array}{ll}
\sigma_{p} & =\text { pillar stress } \\
\Phi & =\text { angle between } U \text { and } U x \\
1 \mathrm{ft} & =0.3048 \mathrm{~m} \\
1 \mathrm{psi} & =0.0069 \mathrm{MPa} \\
1 \mathrm{mph} & =1.61 \mathrm{~km} / \mathrm{h}
\end{array}
$$

\section{List of Abbreviations}

CISPM = Comprehensive and Integrated Subsidence Prediction Model

PISI = Protodyakonov Impact Strength Index

SDPS $=$ Surface Deformation Prediction System

SF $\quad=$ Safety Factor

UCS = Uniaxial Compressive strength

VPC = Vertical Point of Curvature

VPI = Vertical Point of Intersection

VPT $=$ Vertical Point of Tangency 


\section{CHAPTER 1 \\ INTRODUCTION}

\subsection{Mine Subsidence Background and Development}

The study of mine subsidence is one of the important branches in the research areas related to underground coal mining activities. Room-and-pillar mining method without pillar extraction, though designed for not causing subsidence, could still induce unexpected mine subsidence under some conditions. Full-extraction mining methods employed in underground coal mines, such as longwall mining and room-and-pillar mining with pillar extraction, can normally cause immediate mine subsidence.

The potential for room-and-pillar mining operations to induce surface subsidence is mainly dependent on the recovery ratio in the underground mines that directly relates to the stability of pillars. The higher the recovery ratio is, the higher is the probability for the pillars to fail, roof to collapse and surface subsidence to occur. The traditional belief is that if the recovery ratio is less than $50 \%$, the mine pillars are strong enough to support the overburden strata and less likely to collapse. When the recovery ratio is between $50 \%$ and $70 \%$, the mine pillars could be loaded to near their critical conditions and, therefore, the surface subsidence is uncertain to develop. However, if the recovery ratio is greater than $70 \%$, the pillars are too small to support the overburden strata and can cause immediate surface subsidence.

When full-extraction mining methods are used, they produce a large void in the coal seam and disturb the equilibrium conditions of the surrounding strata (Fig. 1.1). When the excavated area expands to a sufficient size, the roof strata will cave. As a result, the overlying strata continue to bend and break until the piles of the fallen rock fragments are sufficiently high to support the 
overhanging strata. At this time, the overhanging strata no longer cave, but bend and rest on the underlying strata. Overburden strata movements and deformations develop upwards from the excavation level, through the overburden strata, to the surface. The entire overburden strata and the surface subsidence basin will further go through a period of compaction and gradually become stabilized. Eventually, subsurface and surface subsidence events will be formed over the mined areas (Peng, 1992).

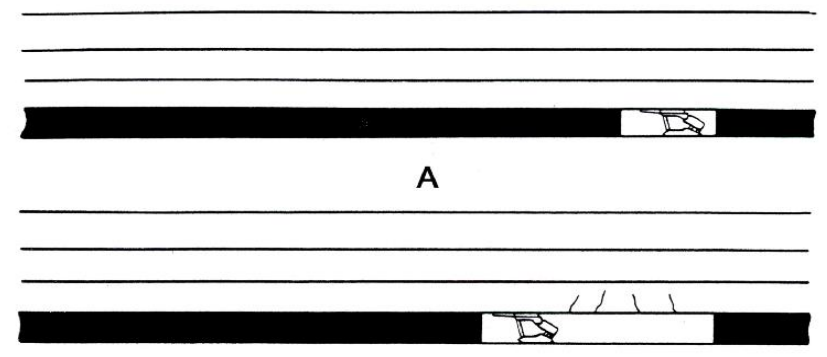

B

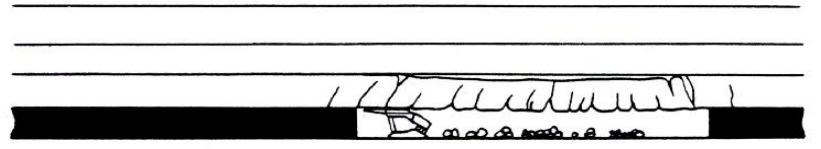

C

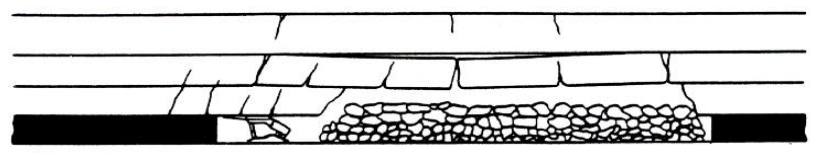

D

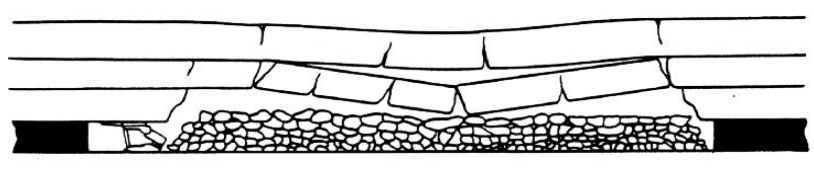

E

Figure 1.1 Schematic of roof strata movements due to longwall face retreat (Peng, 2020)

Surface subsidence process can cause adverse influences on surface structures such as residential and industrial buildings, water, gas, oil and sewage pipelines, towers, etc., and on environment like conditions change in surface water bodies (Peng, 1992). While subsurface subsidence, which describe overburden strata movements and deformations associated with underground mining activities, are often capable of causing significant disturbances to subsurface structures such 
as gas, oil and water wells, aquifers, mine structures in multi-seam mining operations, etc. (Luo and Peng, 2000).

In order to protect subsurface and surface structures and water resources, it is important to predict subsurface and surface movements and deformations accurately. Furthermore, experience shows that accurate prediction of mine subsidence and correct assessment of its influence on structures are the key to designing and implementing effective and efficient mitigation measures in the effort to reduce the severity of the subsidence disturbances and the subsequent consequences (Peng, 2008).

In the past four decades, extensive mine subsidence researches were conducted by government agencies, academic institutions, coal companies, and consulting companies all over the world, which result in many mine subsidence prediction theories and mathematics models being developed. The Comprehensive and Integrated Subsidence Prediction Model (CISPM), developed by Luo (Luo, 1989; Luo and Peng, 1989; Peng and Luo, 1992), is one of the most popular, versatile and accurate surface subsidence prediction programs for the US mining conditions. The program is based on the principles of the influence function method and it uses a number of mathematical models, and empirical formulas for optimizing the required subsidence parameters. The program has been proven to be accurate through numerous applications in the US coal mining industry and in a number of major coal producing countries (Peng, 2008; Luo, 2015b). On the basis of accurate surface subsidence prediction, hundreds of surface structures have been protected successfully by properly assessing surface subsidence influences and effectively designing and implementing the mitigation measures. The surface structures can be categorized into: (1) residential and farm structures such as houses and garages (Luo and Peng, 1991), (2) industrial and public structures such as large workshops, telecommunication towers, office and school buildings etc. (Luo et al., 2003; 
2005; Luo, 2008), (3) linear structures such as railroads, overland conveyors, buried pipelines etc. (Luo et al., 1997; 2010; Qiu and Luo, 2013; Luo and Peng, 1994), and (4) surface water bodies (Luo and Peng, 2010).

Since surface subsidence is observable, measurable and easier to study, majority efforts were focused on surface subsidence studies in the early stages, making surface subsidence research more mature than subsurface subsidence study. With the rapid development of mine subsidence research, however, attention is being paid to the investigation of subsurface subsidence due to the high maturity of surface subsidence study. In the past two decades, two versions (first and second as referred in this work) of subsurface subsidence prediction models have been developed. The first version treats the entire overburden strata as uniform materials and expands the successful influence function method used in surface subsidence prediction for subsurface subsidence prediction. Due to the simplification, this model is easy to use and can predict both final and dynamic subsurface subsidence over longwall panels in underground coal mines (Luo and Peng, 2000). The second version is much more complicated because it has the capability to consider the stratification of the overburden strata, such as massive hard rock layers, in subsurface subsidence prediction. The effects of the stratification are reflected through the derivation of the empirical formulas for final subsidence parameters used in the model (Luo and Qiu, 2012).

\subsection{Problem Statement}

As underground coal mining operations were conducted gradually closer to suburban, even urban, areas where inhabitants and infrastructures are concentrated, mine subsidence-induced disturbances to surface and subsurface structures and water resources have attracted more and more public attention and concerns. As a result, regulations from federal and state agencies for surface and subsurface subsidence control were enacted and increasingly tightened. In response to these 
subsidence control laws requirement, many subsidence research programs were initiated in the US in the late 1970s (Peng, 2006).

After four decades of dedicated research in various subjects in mine subsidence (i.e., theories, prediction models, influence assessments, mitigation technologies, and investigation techniques) by our group and other researchers, most of the major mine subsidence-induced problems have been successfully addressed. However, a few challenging topics in the field of mine subsidence research have not been adequately addressed and require further research attention, including:

(1) Effects of overburden key strata on subsurface subsidence. To assess mine subsidence disturbances to subsurface structures accurately and to design effective and efficient mitigation measures, it is necessary to develop an accurate prediction model for subsurface strata movements and deformations. Decades of research have demonstrated that variations of lithology in the overburden have significant influence on the subsurface strata movements and deformations during ground subsidence process. However, the first version subsurface subsidence prediction model (Luo and Peng, 2000) did not take the variations of overburden stratification and lithology into consideration. This model assumed that the variations of the overburden strata have insignificant or little influences on the subsurface subsidence. While in the second version subsurface subsidence prediction model (Luo and Qiu, 2012), the entire overburden strata are equally divided into a finite number of layers and the percent of hard rocks (i.e., limestone and sandstone) in each layer is used as an additional input to consider the lithology of the overburden. However, the equal division approach for the overburden strata can separate a massive hard rock stratum into two or more layers that could reduce its bridging 
effect to its overlying strata during ground subsidence process. Therefore, improvements should be made in the subsurface subsidence prediction model when significant stratification variation exists in the overburden strata.

(2) Effects of longwall subsidence on interstate highways and their bridges. Although the surface subsidence influences on most of surface structures have been studied, the effects of longwall subsidence on interstate highways and their bridges have not been studied adequately. Surface subsidence events induced by underground longwall mining operations can cause various disturbances to interstate highways and their bridges ranging from integrity and stability to functionality problems. The specific damages that the subsidence-induced slope, strain and curvature would cause to the interstate highways and their bridges have not been systematically studied according to the design standards of the interstate highways and their bridges. Also, greater efforts should be made to design effective and efficient mitigation measures to reduce, even eliminate, the longwall subsidence disturbances to the interstate highways and bridges.

(3) Effects of dewatering mine water on surface subsidence over inactive room-and-pillar mines. Surface subsidence events over inactive underground room-and-pillar mines are often unexpected and difficult to predict because many factors can affect their possibility and formation process. Among them, mine water frequently plays an important role in causing such subsidence events. However, mine water could also serve the purpose of preventing subsidence. The dewatering of inactive room-and-pillar mines has been identified as the main cause for several serious mine subsidence events in the past. The mechanisms of mine water to prevent and cause surface subsidence over inactive room-and-pillar coal mines are still not clear. 


\subsection{Objective and Research Methods}

According to the aforementioned three challenging topics in mine subsidence, the objective of this work is to address these challenging topics for improving mine safety and health. The objective will be realized through developing: (1) an improved subsurface subsidence prediction model to enhance the prediction accuracy, (2) techniques for assessing and mitigating the surface subsidence influence on interstate highways and highway bridges, and (3) mechanical models to assess the effects of mine water in preventing or causing surface subsidence over inactive roomand-pillar coal mines. The research efforts should be continually devoted to addressing the three challenging topics including the key strata effects on the subsurface subsidence, longwall subsidence effects on interstate highways and their bridges, and mine water effects on surface subsidence. The research methods that will be used in this work are listed as follows:

(1) In order to improve the subsurface subsidence prediction model, the concept of the key strata theory was introduced (Chien, 1981). The key strata theory states that the thick and hard key strata serve as the backbone of the overburden and controls the movements of the thin and soft weak rock strata located above them. An algorithm will be carried out to determine the locations and number of the key strata. A new version subsurface subsidence prediction model will be developed by incorporating the key strata theory. This model will consider the variations of the overburden stratification and lithology in a better way according to the concept of rock mechanics by using a new division scheme for the overburden strata. In addition, the empirical formulae for the final subsurface subsidence parameters have been derived by incorporating the past subsidence research and the key strata effects. 
(2) In order to reduce the longwall subsidence impacts on highway and bridge structures and traffic, accurate subsidence prediction is the first and most important step. Based on accurate final and dynamic surface subsidence prediction made by CISPM programs, subsidence influence on highway and bridge structures will be assessed accurately. Accordingly, efficient and effective mitigation measures will be designed and implemented during subsidence process to ensure the continuous service of highways and bridges, safety of the travelers and smooth mining operations.

(3) In this part of research, the mechanisms of dewatering mine water to prevent or cause surface subsidence over inactive room-and-pillar coal mines will be studied. Specifically, two mathematical models will be proposed to quantify the potential effects of mine water on the structural stability of mine pillars and roof, as well as the potential for causing surface subsidence. 


\section{CHAPTER 2 \\ LITERATURE REVIEW}

\subsection{Surface Subsidence Study}

\subsubsection{Introduction}

Surface subsidence events are the sudden sinking or gradual downward settling of the ground surface due to underground mining activities. Two main mining methods, room-and-pillar and longwall, are practiced in US underground coal mines. The disturbance intensities to the overburden strata by the two mining methods are significantly different and so are the surface subsidence events. Generally, coal mining activities could cause two types of surface subsidence events, sinkhole subsidence and trough subsidence as shown in Fig. 2.1.

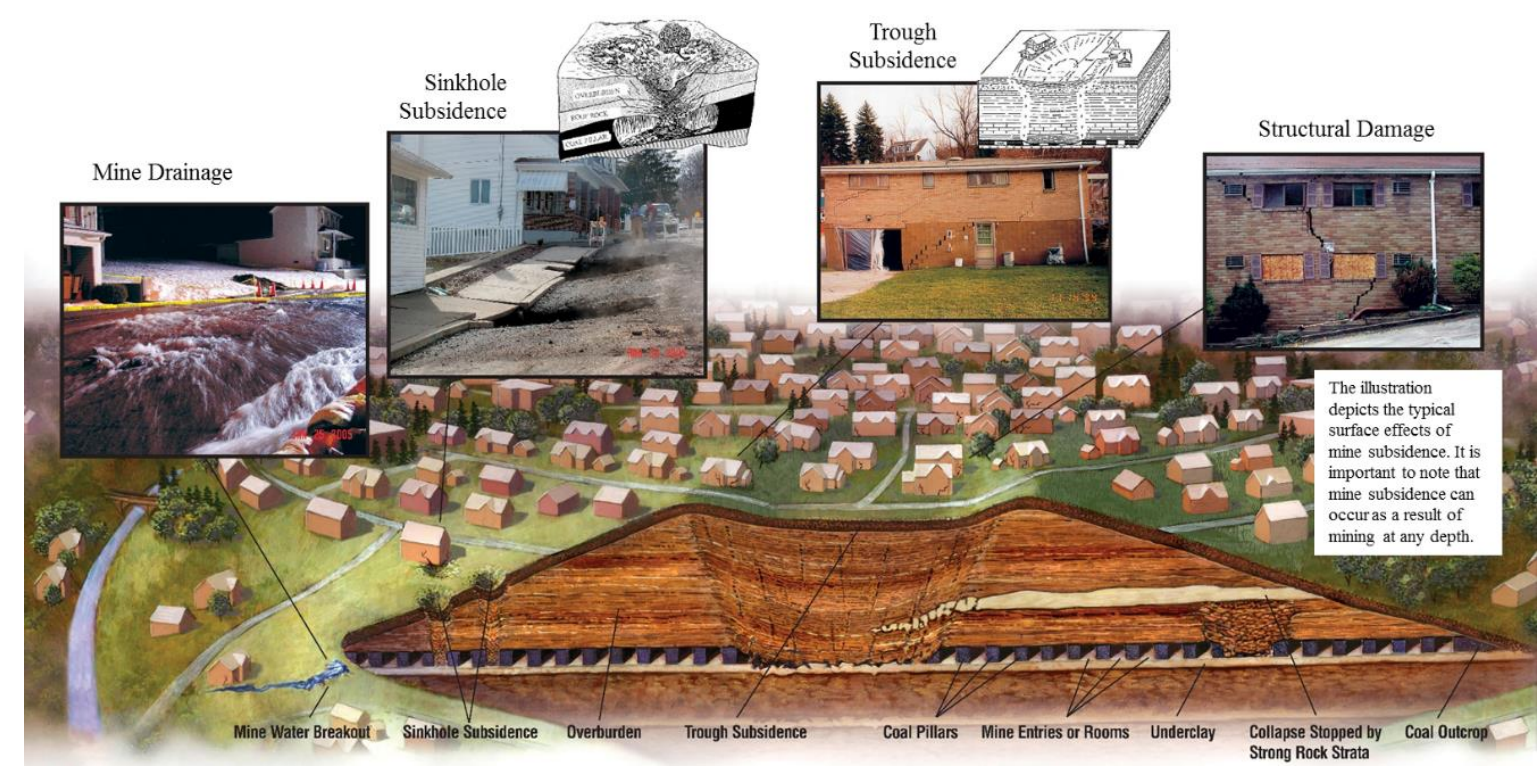

Figure 2.1 Types of mine subsidence and their effects (after PADEP, 2020a)

Sinkhole subsidence, often cone-shaped, is an abrupt depression zone at the ground surface as overburden strata collapse into the mine void such as a room or an intersection. Sinkhole subsidence generally develops at the locations where the overburden strata above a mine are weak and thin so that the caving of the mine roof can propagate all the way to the ground surface. Erosion 
from surface water can help the process, while competent strata above the mine can restrict the sinkhole development process. Matheson and Eckert-Clift (1986) found that sinkholes are likely to occur when the ratio of overburden thickness $(h)$ to mining height $(m)$ is less than 5 . When $h / m$ is between 5 and 11, the potential occurrence of sinkholes decreases rapidly. When $\mathrm{h} / \mathrm{m}$ is more than 11 , fewer than $10 \%$ of the mine openings that collapse will induce sinkholes on the surface (Peng, 1992). Due to the abrupt and rapid nature, sinkhole subsidence often causes much severer damages to the surface structures than trough subsidence.

Trough subsidence is a shallow, often broad, dish-shaped depression resulted from the sagging overburden strata toward a large mine opening such as longwall panel gob or room-and-pillar mining with pillar extraction area, or crushing of mine pillars or punching of pillars into the mine floor or roof in a large contiguous area. To form a trough-type subsidence, the dimension of the contiguous subsidence source should be larger than an effective width of about one-third of overburden depth. Normally, a trough subsidence forms when the overburden above a mine is thick and the ratio of $h / m$ is greater than 11 . Trough subsidence progressively increases from the trough edges until reaches the greatest usually located at the center of the trough.

\subsubsection{Final Surface Subsidence}

Final surface subsidence is the result of a fairly complicated dynamic subsidence process and forms long after the underground mining has been completed. Generally, the fact that sinkhole subsidence is happened suddenly and unpredictable results in research difficulty. However, trough

subsidence is normally expected and has some common characteristics. In the past, majority of research effort is devoted to study trough subsidence. The research results will be discussed in details. 


\subsubsection{Final Surface Subsidence Basin}

The trough subsidence events are normally associated with longwall and room-and-pillar with pillar extraction mining methods. Normally, the width and length of the underground opening should be greater than one-third of the overburden depth. The final surface subsidence basin is the surface depression zone formed over the mined area long after the extraction and its magnitude and distribution will no longer change with time.

Different types and sizes of a single opening can cause different shapes of final surface subsidence basin as shown in Table 2.1. In this table, $L$ and $W$ are the opening length and width, respectively. And $W_{c}$ stands for the critical panel width which is defined as the minimum width of a square underground opening that the surface movements and deformations above which can be fully developed. Expansion of the opening further only affects the distributions of the surface movements and deformations but will not their maximum magnitudes.

Table 2.1 Shapes of final surface subsidence basin over a single opening (after Luo, 2020a)

\begin{tabular}{|c|c|c|c|}
\hline $\begin{array}{l}\text { Opening } \\
\text { Type }\end{array}$ & Size & Shape & $\begin{array}{c}\text { Type of Subsidence } \\
\text { Basin }\end{array}$ \\
\hline Square & $\begin{array}{l}\mathrm{L} \leq W_{c} \\
\mathrm{~L}>W_{c}\end{array}$ & $\begin{array}{c}\text { Circular } \\
\text { Square with rounded corners }\end{array}$ & $\begin{array}{c}\text { Subcritical or critical } \\
\text { Supercritical }\end{array}$ \\
\hline Rectangular & $\begin{array}{c}\mathrm{L} \leq W_{c} \\
\mathrm{~W} \leq W_{c}, \mathrm{~L}>W_{c} \\
\mathrm{~W}>W_{c}\end{array}$ & $\begin{array}{l}\text { Elliptical } \\
\text { Rectangular with rounded ends } \\
\text { Rectangular with rounded corners }\end{array}$ & $\begin{array}{l}\text { Subcritical } \\
\text { Semi-critical } \\
\text { Supercritical }\end{array}$ \\
\hline
\end{tabular}

Based on the previous research on surface subsidence, seven indexes of the surface movements and deformations are defined as follows (Luo, 1989):

1. Subsidence, $S$. It is the vertical component of surface movement at a surface point (Fig. 2.2a). Maximum subsidence $\left(S_{o}\right)$ is the maximum amount of subsidence measurable in 
a subsidence basin and is generally located over the center of the extraction. When the panel width exceeds the critical panel width, the maximum subsidence reaches its maximum possible value $\left(S_{\max }\right)$.

2. Horizontal displacement, $U$. It is the horizontal component of surface movement at a surface point within the $360^{\circ}$ horizontal plane. The horizontal displacement at a surface point in a subsidence basin is a vector of which its magnitude $(U)$ varies with direction $(\Phi)$ as shown in Fig. 2.2b. It can be defined by its $x$ - and $y$-components ( $U_{x}$ and $U_{y}$ ).

3. Slope, $i$. It is the differential subsidence over a horizontal distance of a unit length and is the first derivative of the subsidence (Fig. 2.2a).

$$
i \approx \frac{S_{b}-S_{a}}{x_{b}-x_{a}}=\frac{d S}{d x}
$$

4. Horizontal strain, $\varepsilon_{x}$. It is the differential horizontal displacement over a horizontal distance of a unit length and is the first derivative of the horizontal displacement (Fig. 2.2a).

$$
\varepsilon_{x} \approx \frac{U_{b}-U_{a}}{x_{b}-x_{a}}=\frac{d U}{d x}
$$

5. Curvature, $K$. It is the differential slope over a horizontal distance of a unit length and is the second derivative of the subsidence (Fig. 2.2c).

$$
K \approx \frac{i_{b}-i_{a}}{x_{b}-x_{a}}=\frac{d i}{d x}=\frac{d^{2} s}{d x^{2}}
$$

6. Twisting, $T$. It is the differential slope along two parallel line sections separated by a horizontal distance of a unit length (Fig. 2.2d). 


$$
T \approx \frac{i_{b}-i_{a}}{y_{2}-y_{1}}=\frac{d i_{x}}{d y}=\frac{d^{2} s}{d x d y}
$$

7. Shear strain, $\gamma$. It is the differential horizontal displacement along two parallel line sections separated by a horizontal distance of a unit length (Fig. 2.2e).

$$
\gamma \approx \frac{U_{b}-U_{a}}{y_{2}-y_{1}}=\frac{d U_{x}}{d y}
$$

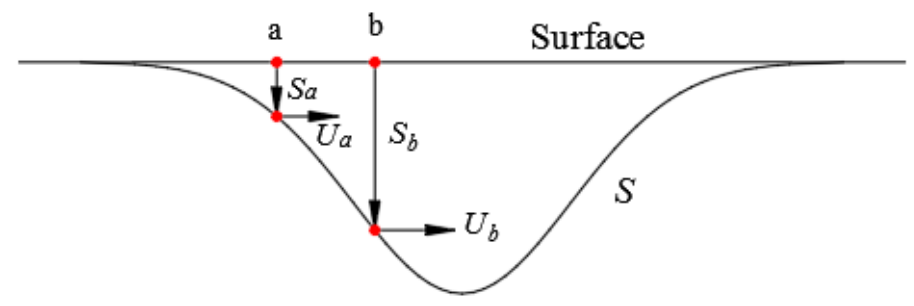

\section{Gob}

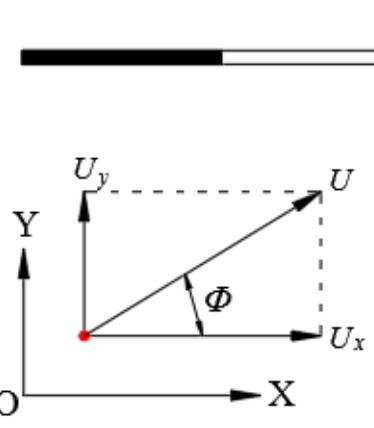

(b)

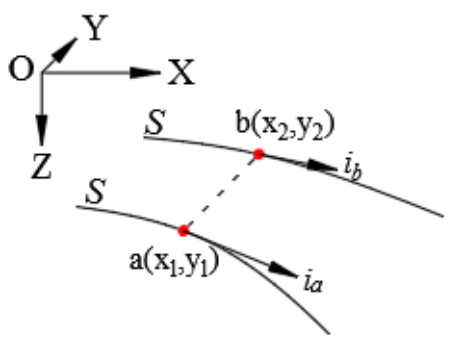

(d)

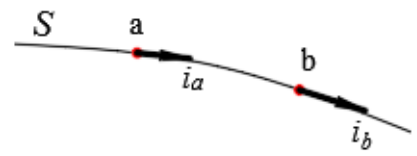

(c)

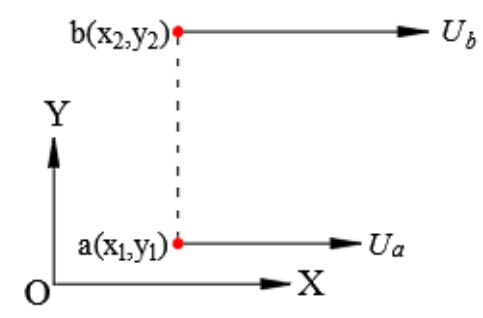

(e)

Figure 2.2 Definition of surface movements and deformations (after Luo, 2020b) 
In order to numerically characterize the final subsidence basin, three most important subsidence parameters including subsidence factor $(a)$, offset distance of inflection point $(d)$ and radius of major influence $(R)$ or angle of major influence $(\beta)$ have been defined as shown in Fig. 2.3 (Luo, 1989). Subsidence factor is defined as the ratio of the maximum possible subsidence $\left(S_{\max }\right)$ to the mining height $(h)$ of the coal seam. Offset distance of inflection point $(d)$ is the horizontal distance between the panel edge and the inflection point. Inflection point is the surface point where surface bending turns from convex to concave of the subsidence profile. Radius of major influence $(R)$ is defining the extent of the major influence zone where the major amount of changes in movements and deformations occur in the final subsidence basin. Angle of major influence $(\beta)$ is the angle between the horizontal line at the mining level and the line connecting the vertically projected point of the inflection point on the coal seam and the edge of radius of major influence. Each of the three parameters affects one of the three aspects of the final subsidence basin formed over a mine gob. Subsidence factor affects the depth of the subsidence basin. Offset distance of inflection point dedicates the location of the subsidence basin in relation to the edge of the mined gob. Radius of major influence determines the shape of the subsidence basin (Luo, 1989).

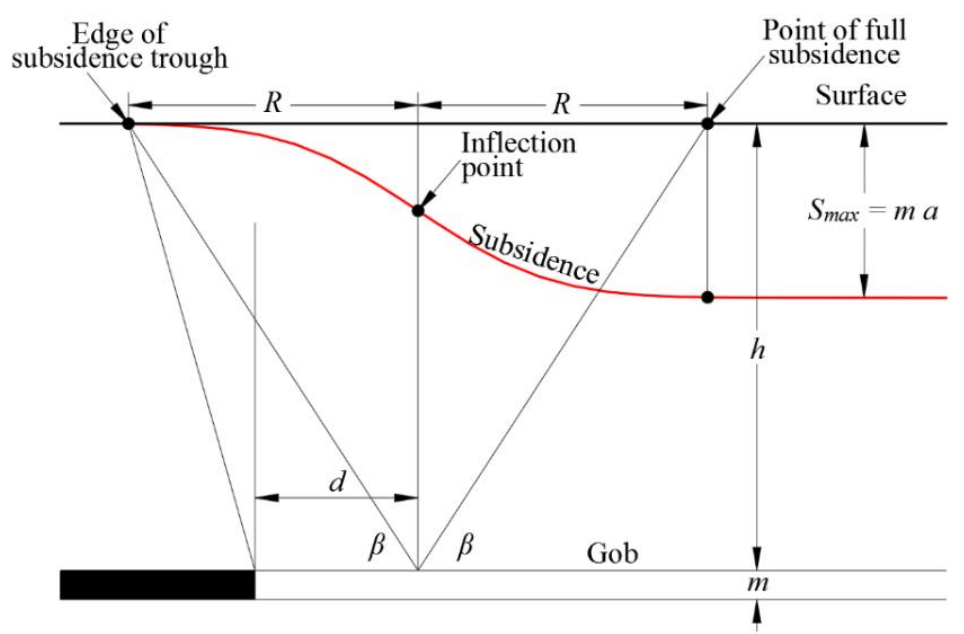

Figure 2.3 Relationship among subsidence terminologies and subsidence trough (Luo, 1989). 


\subsubsection{Final Surface Subsidence Prediction}

Accurate prediction of surface subsidence has great significance to land planning in mining areas, mine design of coal resources, safety evaluation of surface facilities in mining areas, prevention of geological disasters and realization of sustainable development (Han et al., 2019). During the last four decades of research on surface subsidence, many surface subsidence prediction theories and mathematics models have been developed all over the world. In this work, only the influence function method will be discussed in details here because it is one of the most widely used and accurate subsidence prediction methods (Liu, 1981; VPI\&SU, 1987; Luo, 1989).

\section{Mathematical Model}

During the past four decades, several different influence functions were developed by subsidence researchers to build mathematical models for surface subsidence prediction (Bals, 1932; Beyer, 1945; Knothe, 1957). Among these influence functions, the most popular and versatile influence functions for surface subsidence prediction was proposed by Knothe (1957). The principle of Knothe's influence function is that the extraction of an elemental area of an underground coal seam will cause surface to subside in a particular manner and the distribution of the subsidence can be expressed by a modified normal probability distribution function (Fig. 2.4). Based on the Knothe's theory, the influence function for subsidence can be derived as follows:

$$
f_{S}\left(x^{\prime}\right)=\frac{S_{\max }}{R} e^{-\pi\left(\frac{x^{\prime}}{R}\right)^{2}}
$$

In this equation, $x^{\prime}$ is the distance between the extracted element and the surface point where final subsidence to be calculated. 


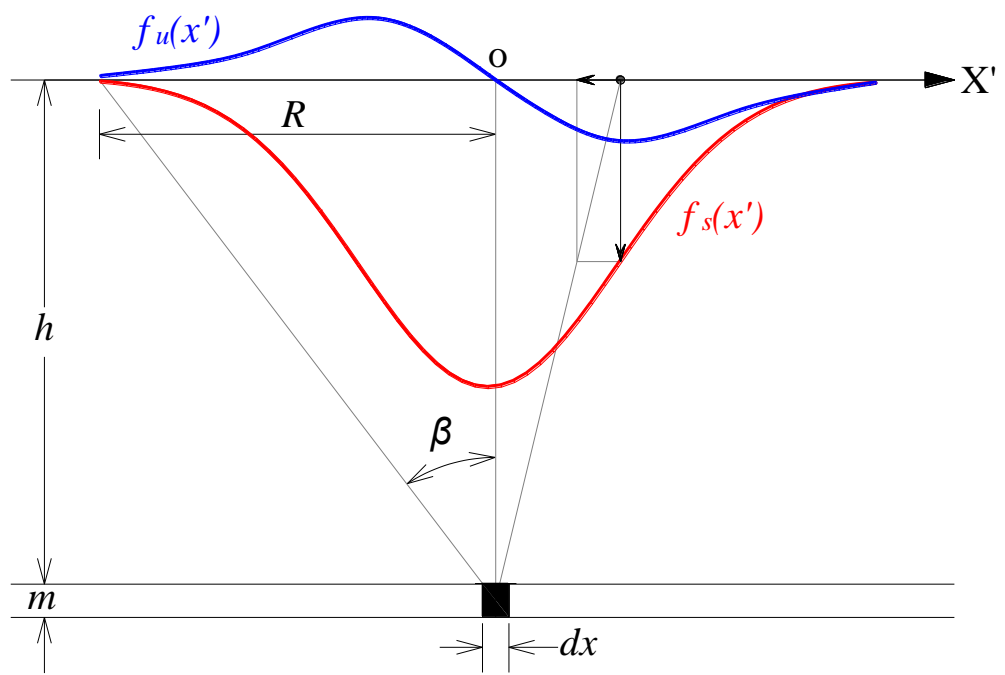

Figure 2.4 Schematic of influence functions for subsidence and horizontal displacement (Luo, 1989)

Based on the employed influence function for surface subsidence prediction, the focal point theory is employed to derive the influence function for surface horizontal displacement. The focal point theory states that the extraction of an element of coal seam will pull the ground surface to move toward this extracted element (Fig. 2.4). Based on the focal point theory and field calibrations, the influence function for horizontal displacement is mathematically expressed in the following equation (Luo, 1989).

$$
f_{u}\left(x^{\prime}\right)=-\frac{2 \pi s_{\max }}{R h} x^{\prime} e^{-\pi\left(\frac{x^{\prime}}{R}\right)^{2}}
$$

The final surface subsidence and horizontal displacement at a prediction point are determined by integrating their respective influence functions between the left and right inflection points (Figs. 2.5 and 2.6). The mathematical expressions for the final subsidence and horizontal displacement at a prediction point along a major cross-section are shown in Eqs. 2.8 and 2.9, respectively.

$$
S(x)=\frac{S_{\max }}{R} \int_{d_{1}-x}^{W-d_{2}-x} e^{-\pi\left(\frac{x^{\prime}}{R}\right)^{2}} d x^{\prime}
$$




$$
U(x)=\frac{R S_{\max }}{h}\left[e^{-\pi\left(\frac{d_{1}-x}{R}\right)^{2}}-e^{-\pi\left(\frac{W-d_{2}-x}{R}\right)^{2}}\right]
$$

The final slope can be determined as:

$$
i(x)=\frac{d S(x)}{d x}=\frac{S_{\max }}{R}\left[e^{-\pi\left(\frac{d_{1}-x}{R}\right)^{2}}-e^{-\pi\left(\frac{W-d_{2}-x}{R}\right)^{2}}\right]
$$

The final strain can be calculated as:

$$
\varepsilon(x)=\frac{d U(x)}{d x}=\frac{2 \pi S_{\max }}{h}\left[\frac{d_{1}-x}{R} e^{-\pi\left(\frac{d_{1}-x}{R}\right)^{2}}-\frac{W-d_{2}-x}{R} e^{-\pi\left(\frac{W-d_{2}-x}{R}\right)^{2}}\right]
$$

The final curvature can be expressed as:

$$
K(x)=\frac{d^{2} S(x)}{d x^{2}}=\frac{2 \pi S_{\max }}{R^{2}}\left[\frac{d_{1}-x}{R} e^{-\pi\left(\frac{d_{1}-x}{R}\right)^{2}}-\frac{W-d_{2}-x}{R} e^{-\pi\left(\frac{W-d_{2}-x}{R}\right)^{2}}\right]
$$

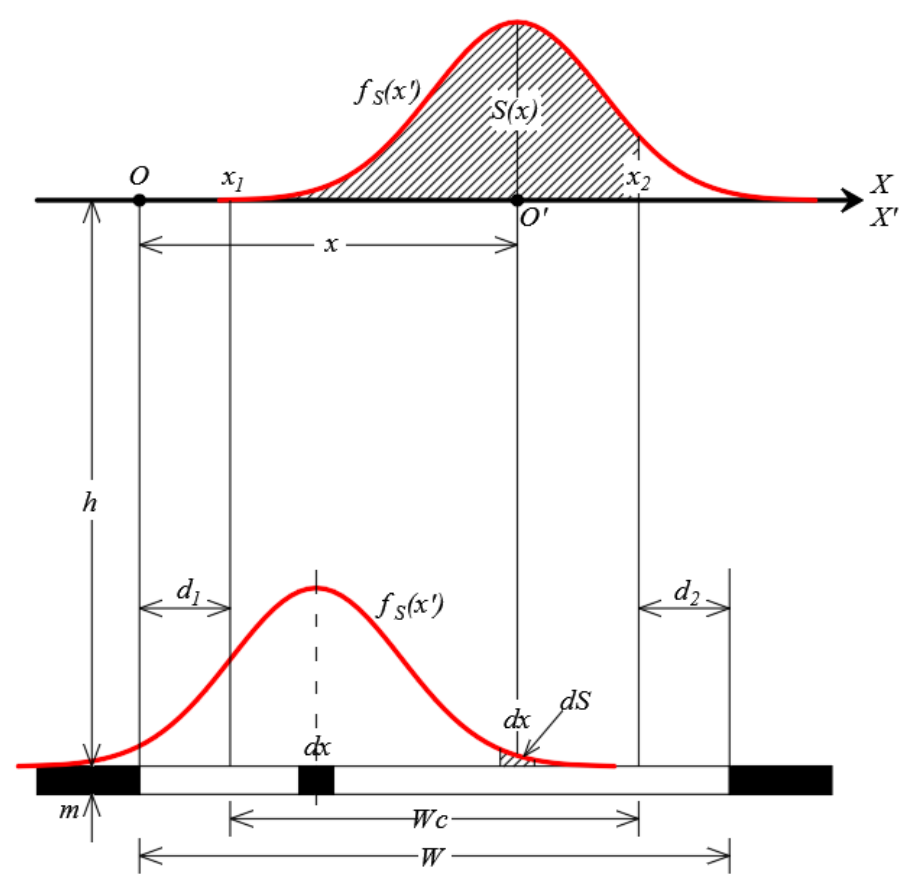

Figure 2.5 Schematic for calculating final subsidence along a major cross-section (Luo, 2020a) 


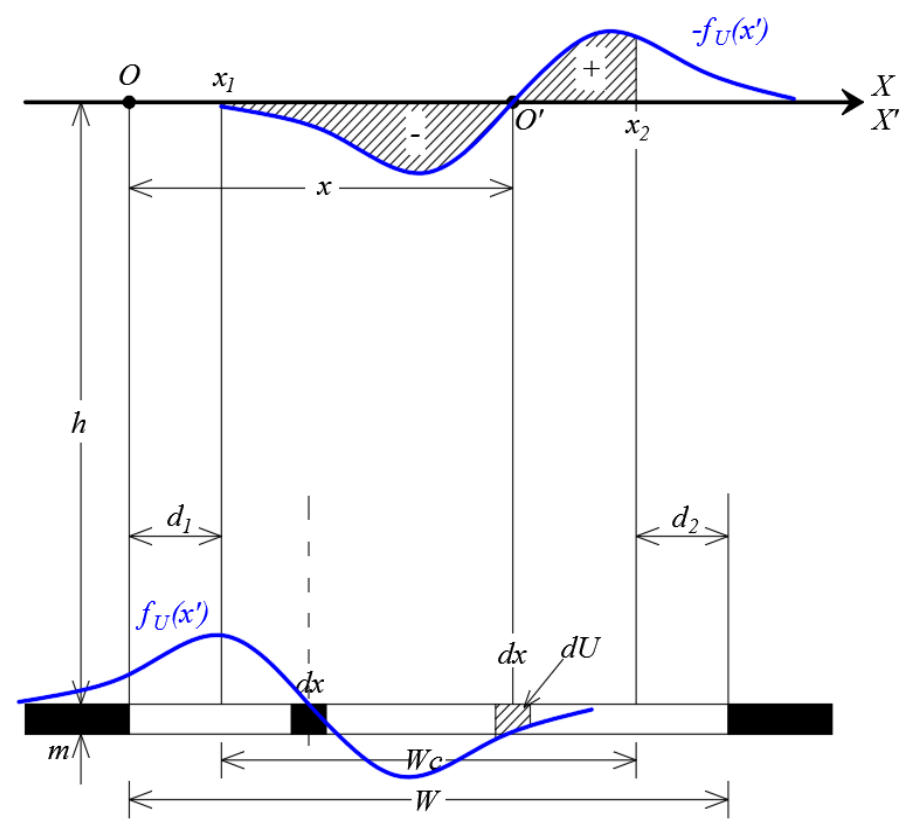

Figure 2.6 Schematic for calculating final horizontal displacement along a major cross-section (Luo, 2020a)

\section{Final Subsidence Parameters}

Like any other prediction models, the accuracy of the subsidence prediction model depends equally on the mathematical model and the required subsidence parameters used in the model.

Subsidence factor plays the most important role in predicting surface subsidence. Previous studies on the subsidence factors are based on the regression study of the collected case data. In CISPM, an empirical formula (Eq. 2.13) was proposed to relate the overburden depth $(h)$ and the subsidence factor based on a nonlinear regression performed on 135 subsidence data sets, including 22 subsurface subsidence case data and 113 surface subsidence case data as shown in Fig. 2.7 (Luo and Peng, 2000). In this equation, it should be noted that the subsidence factor just depends on the overburden depth and does not take the subsurface strata mechanical properties into account.

$$
a_{C I S P M}=1.9381(h+23.4185)^{-0.1884}
$$




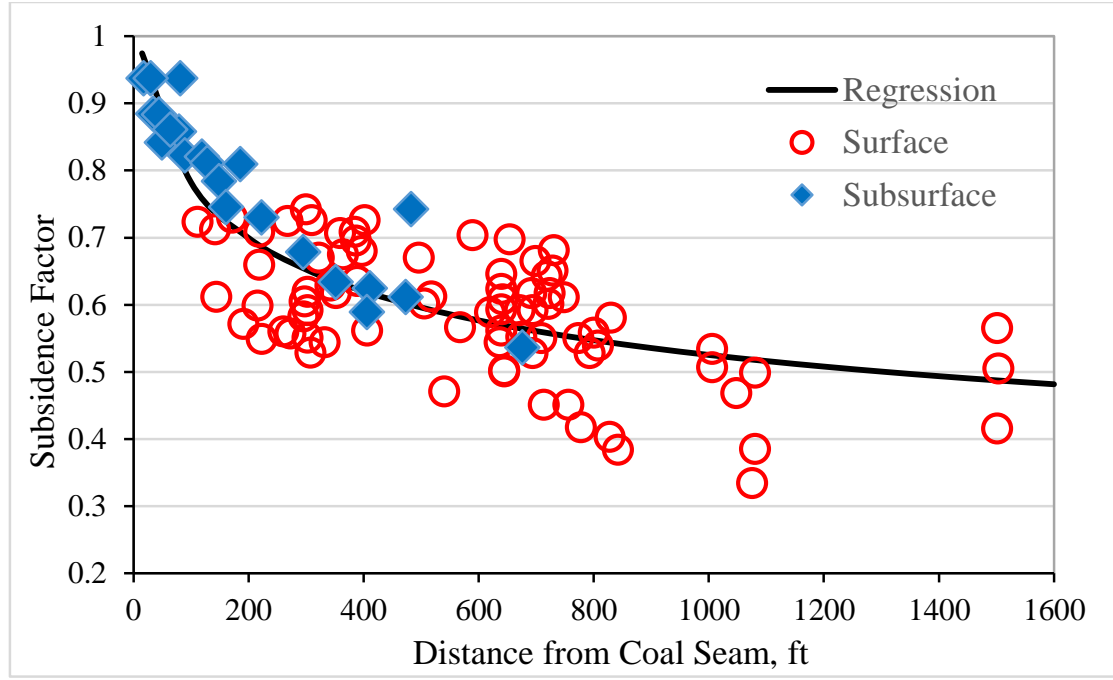

Figure 2.7 Surface and subsurface subsidence factors in CISPM (after Luo and Peng, 2000)

In the US coal fields, the overburden strata for underground coal mines in the central Appalachian coal fields normally have much higher percentage of hard rock (i.e., sandstone and limestone) strata, usually above $60 \%$ and many hard rock formations are also in thick layers. Such strong overburden strata make the characteristics of the mine subsidence events in this particular area significantly distinct from those of other coal fields in the US (Luo, 1989). In the Surface Deformation Prediction System (SDPS) developed by Virginia Tech, another empirical formula (Eq. 2.14) was determined as well to calculate the subsidence factor based on the collected subsidence data in the central Appalachian coal fields as shown in Fig. 2.8 (Karmis et al., 1987). In this equation, $\eta$ stands for percent of hard rock in the overburden. For example, $35 \%$ hard rock should be input as $\eta=35$.

$$
a_{S D P S}=\left[1.017-\frac{0.03}{\frac{W}{h}-0.43}\right] \times\left(0.12+0.66 \cdot e^{-0.00034 \eta^{2}}\right)
$$




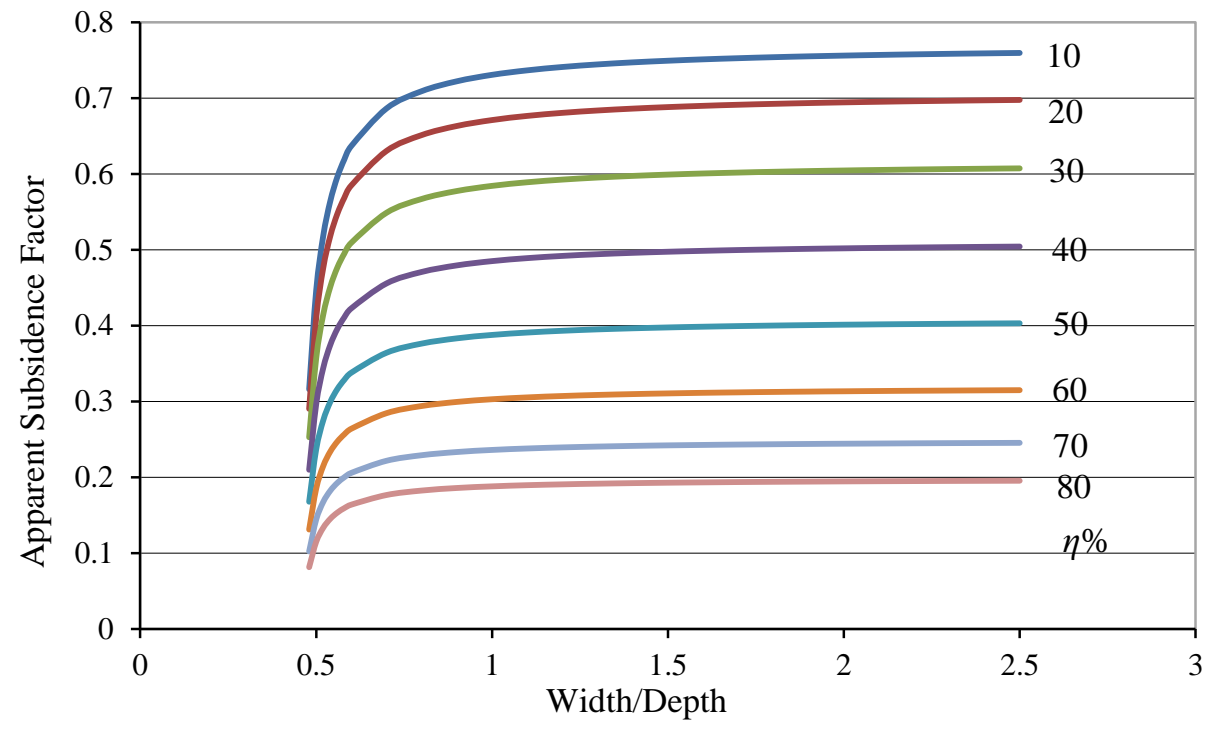

Figure 2.8 Surface subsidence factor in SDPS (after Karmis et al., 1987)

Based on the analysis of the collected longwall subsidence cases, Peng et al. (1995) found that the offset distance of the inflection point is a function of the overburden depth (Eq. 2.15) and is applicable to most US coal fields.

$$
\frac{d}{h}=0.382075 \times 0.999253^{h}
$$

Finally, the relationship between the angle of major influence and the radius of major influence can be defined as in Eq. 2.16. Based on the analysis of the collected longwall subsidence cases, Peng et al. (1995) found that using 3.0 for $\tan \beta$ or $71.6^{\circ}$ for $\beta$ is good approximation for most of the US coal fields.

$$
R=\frac{h}{\tan \beta}
$$

\subsubsection{Dynamic Surface Subsidence}

The dynamic surface subsidence describes the time-dependent development process of surface movements and deformations at a surface point of interest before the final surface subsidence 
at this point is reached. In a supercritical final subsidence basin, the central portion subsides uniformly and there is no horizontal displacement. Thus, any structures located there are not subjected to any final permanent surface deformations. However, as the working face moves, the structures will undergo dynamic deformations associated with the dynamic subsidence basin. Therefore, knowledge of dynamic surface subsidence is particularly important for those structures located on or in the vicinity of the flat bottom portion of the final subsidence basin (Peng, 1992).

\subsubsection{Dynamic subsidence process}

The dynamic surface subsidence process associated with underground longwall mining operations can be divided into the following four basic phases (Peng and Luo, 1988; Luo and Peng, 1992).

Subsidence Initiation and Development Phase: In the initial stage of mining a longwall panel, surface will not move or the movement is very insignificant until the longwall face has reached a critical distance away from the panel setup entry. This distance is called subsidence initiation distance $\left(L_{i}\right)$. A sudden and rapid movement will follow when the critical distance is reached. The subsidence process gradually slows down and enters the normal stage when the face has reached a distance about 1.5 to 2 times of the overburden depth (Fig. 2.9).

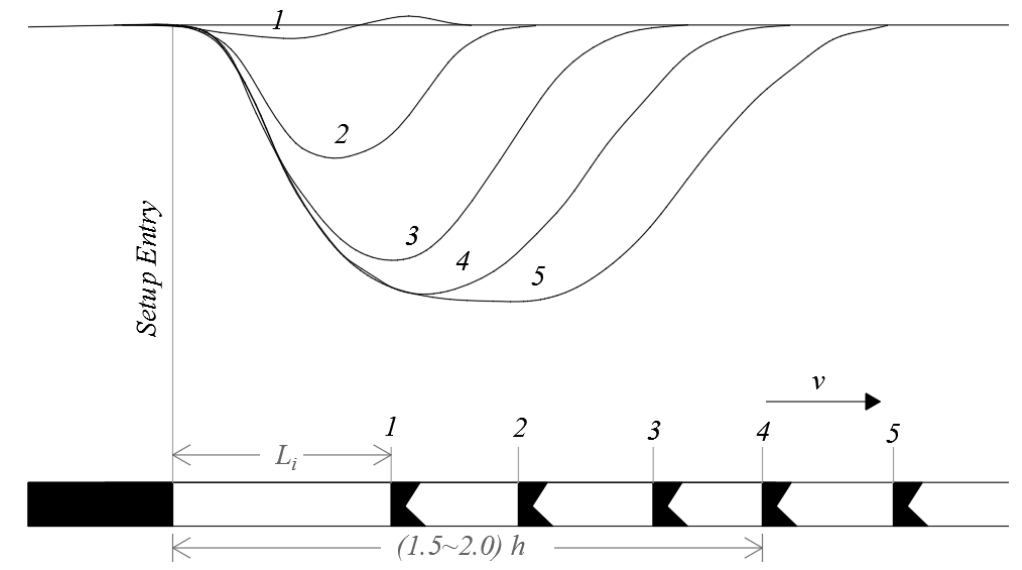

Figure 2.9 Dynamic subsidence profiles in the initial stage of mining a longwall panel (Luo, 2020a) 
Normal Dynamic Subsidence Phase: When the face advances at a fairly constant rate (varying in a range of $\pm 40 \%$ of the average rate), the shape of the half subsidence basin on the advancing longwall face side remains basically unchanged and will advance with the longwall face at the same pace (Fig. 2.10). This phase ends when the longwall face stops for an extended period or the mining in the longwall panel is completed.

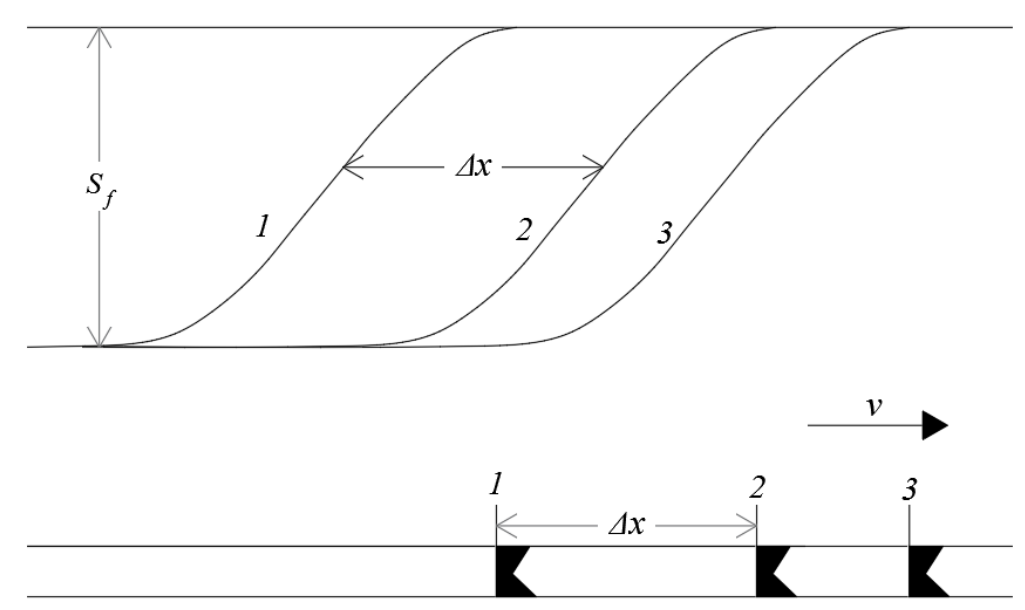

Figure 2.10 Dynamic subsidence profiles in the normal stage of mining a longwall panel (Luo, 2020a)

Residual (Creep) Subsidence Phase: When the longwall face has stopped advancing, the surface movement will not stop immediately and it will continue subsiding for a period of time. The transitional subsidence process occurred between the subsidence profile at the time of face stop $(t=0), S_{d}$, and the final subsidence profile $(t=\infty), S_{f}$, is the residual or creep subsidence phase (Fig. 2.11).

Long-Term Subsidence: The long-term subsidence is referred as the subsidence occurred long after the normal dynamic subsidence period (Fig. 2.12). The most possible causes for such long-term subsidence are the failure of mine structures due to insufficient structural designs, weathering or flooding, creep deformation of the remnant mine structures, and re-compaction of overburden strata, etc. 


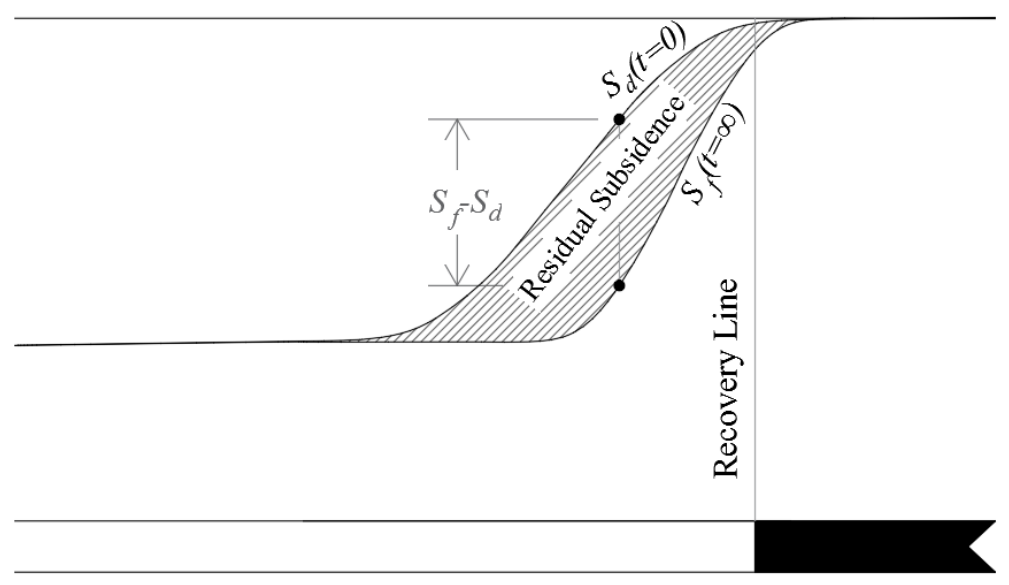

Figure 2.11 Development and distribution of residual (creep) subsidence (Luo, 2020a)

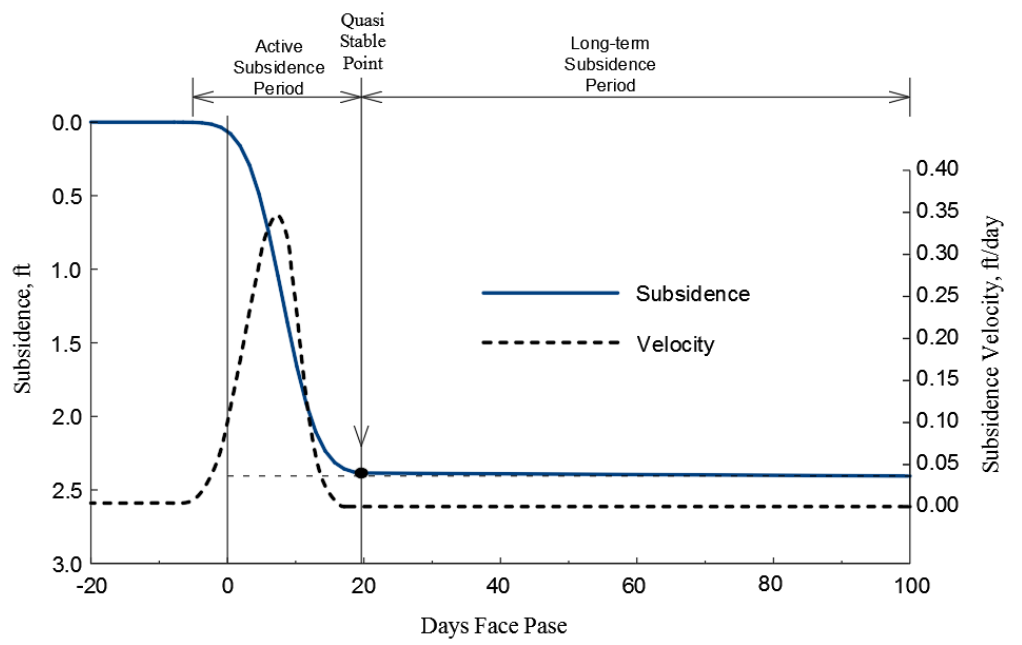

Figure 2.12 Normal and long-term dynamic subsidence development process (Luo, 2020b)

\subsubsection{Dynamic Surface Subsidence Prediction}

In the dynamic surface subsidence prediction, only the normal dynamic subsidence phase will be studied here because this phase is the most important phase for the studies of dynamic subsidence process and encountered most in longwall mining operation. Knowledge of this phase is required for prediction in the other phases.

\section{Mathematical Model}

For dynamic subsidence prediction, determining the development curve of subsidence velocity is the most important and first step (Peng and Luo, 1988; Luo and Peng, 1992). Field 
observations show that the distribution of subsidence velocity at a surface point resembles a shape of normal probability distribution if the face advances at a fairly constant rate, $v$ (Fig. 2.13). Subsidence velocity is the incremental subsidence at a surface point over a unit of time and can be expressed as:

$$
V\left(x^{\prime}, y\right)=V_{o}(x, y) e^{-2\left(\frac{x^{\prime}+l}{l+l_{1}}\right)^{2}}=\sqrt{\frac{2}{\pi}} \frac{v \cdot S_{f}(x, y)}{l+l_{1}} e^{-2\left(\frac{x^{\prime}+l}{l+l_{1}}\right)^{2}}
$$

In this equation, $l$ is the offset of subsidence velocity peak or offset of dynamic inflection point and $l_{1}$ is the offset of subsidence initiation point where about $2 \%$ of the final subsidence has accumulated. $V_{o}(x, y)$ is the maximum subsidence velocity at the prediction point (Fig. 2.13). $S_{f}(x, y)$ is the final subsidence at the point of interest and can be calculated using Eq. 2.8.

The dynamic subsidence at the prediction point is the accumulation of the incremental subsidence received, which can be expressed in Eq. 2.18.

$$
S_{d}\left(x^{\prime}, y\right)=\frac{1}{2} S_{f}(x, y)+\sqrt{\frac{2}{\pi}} \frac{S_{f}(x, y)}{l+l_{1}} \int_{x_{p}}^{-l} e^{-2\left(\frac{x^{\prime}+l}{l+l_{1}}\right)^{2}} d x^{\prime}
$$

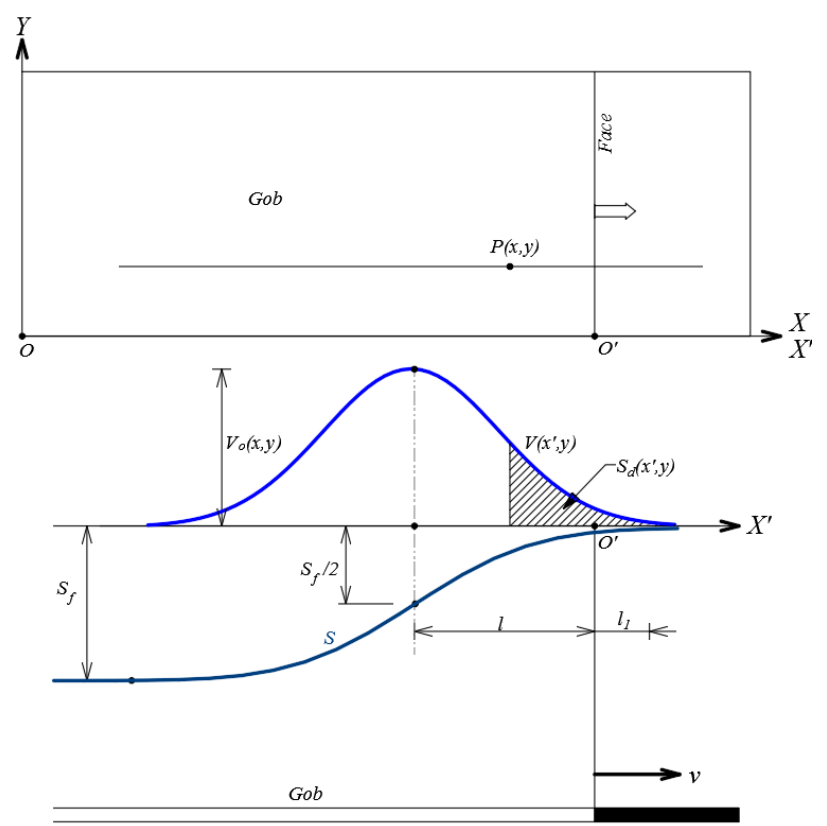

Figure 2.13 Coordinate systems for dynamic subsidence prediction (Luo, 1989) 
The normal dynamic slope can be determined as:

$$
i_{d}\left(x^{\prime}, y\right)=\frac{d s_{d}}{d x^{\prime}}=-\sqrt{\frac{2}{\pi}} \frac{s_{f}(x, y)}{l+l_{1}} e^{-2\left(\frac{x^{\prime}+l}{l+l_{1}}\right)^{2}}
$$

The normal dynamic curvature can be expressed as:

$$
K_{d}\left(x^{\prime}, y\right)=\frac{d^{2} s_{d}}{d x^{\prime 2}}=-4 \frac{x^{\prime}+l}{\left(l+l_{1}\right)^{2}} \cdot i_{d}\left(x^{\prime}, y\right)=4 \sqrt{\frac{2}{\pi}} \frac{s_{f}(x, y)}{\left(l+l_{1}\right)^{3}}\left(x^{\prime}+l\right) e^{-2\left(\frac{x^{\prime}+l}{l+l_{1}}\right)^{2}}
$$

According to the characteristics found in final surface subsidence prediction, horizontal displacement is proportional to the slope with a scale factor of $R^{2} / h$. Therefore, the normal dynamic horizontal displacement at a prediction point can be calculated as:

$$
U_{d}\left(x^{\prime}, y\right)=\frac{R^{2}}{h} \cdot i_{d}\left(x^{\prime}, y\right)=-\sqrt{\frac{2}{\pi}} \frac{R^{2}}{h} \frac{S_{f}(x, y)}{l+l_{1}} e^{-2\left(\frac{x^{\prime}+l}{l+l_{1}}\right)^{2}}
$$

The normal dynamic strain can be calculated as:

$$
\varepsilon_{d}\left(x^{\prime}, y\right)=\frac{d U_{d}}{d x^{\prime}}=\frac{R^{2}}{h} \cdot K_{d}\left(x^{\prime}, y\right)=4 \sqrt{\frac{2}{\pi}} \frac{R^{2}}{h} \frac{S_{f}(x, y)}{\left(l+l_{1}\right)^{3}}\left(x^{\prime}+l\right) e^{-2\left(\frac{x^{\prime}+l}{l+l_{1}}\right)^{2}}
$$

\section{Dynamic Subsidence Parameters}

The accuracy of the dynamic subsidence prediction model depends on the approximation of dynamic subsidence parameters. In this model, there are two important dynamic subsidence parameters: offset of subsidence initiation point, $l_{l}$; and offset of subsidence velocity peak or offset of dynamic inflection point, $l$. A large number of longwall dynamic subsidence cases have been collected and those two dynamic subsidence parameters were derived for each of the cases. Regression studies on the parameters resulted in the following two formulas. In the equations, $v$ is the average advance rate of the longwall in $\mathrm{ft}$. per day. 


$$
\begin{aligned}
& l=h \times 0.382075 \times 0.999253^{h} \times\left(1+1.5731 \times 10^{-4} \times v^{1.967}\right) \\
& l_{1}=\frac{0.113 h}{1+0.1825 \sqrt{v}}
\end{aligned}
$$

\subsection{Subsurface Subsidence Study}

\subsubsection{Introduction}

Subsurface subsidence process associated with underground longwall mining operations is often capable of causing significant disturbances to subsurface structures such as gas, oil and water wells, underground water bodies, multi-seam mining structures, etc. (Luo and Peng, 2000). Therefore, having a profound understanding of the characteristics of subsurface strata movements and deformations is essential for accurately accessing the influence on those subsurface structures and for properly designing and implementing effective and efficient mitigation measures to reduce, or even eliminate subsidence-induced disturbances.

\subsubsection{Final Subsurface Subsidence Prediction}

As mentioned previously, two versions of final subsurface subsidence prediction models have been developed. The first version deals with uniform overburden strata and is simple to use (Luo and Peng, 2000). The second version can consider the variation of overburden stratification but the model is much more complicated (Luo and Qiu, 2012). In this work, only the second version model is detailed.

\section{Mathematical Model}

In this model, the overburden strata over a longwall gob are divided into a finite number (n) of layers of equal thickness. The layers are numbered from the immediate roof stratum to the surface by $1,2 \ldots n$ as shown in Fig. 2.14. The subsidence on the top surface of a given layer can 
be determined by the following procedure: (1) transforming the overburden load above it into a uniform equivalent load on the layer; (2) defining the subsidence influence function at a prediction point using the equivalent load $\left(q_{i}\right)$, layer thickness $(h / n)$, percent of hard rock $\left(\eta_{i}\right)$ in the layer and vertical movement at the layer bottom $\left(S\left(x, z_{i-1}\right)\right)$ directly under the prediction point; (3) integrating the influence function within a proper horizontal interval for the final subsidence on the top of the layer. This procedure is repeated from the mining horizon, layer by layer upwards, until the ground surface is finally reached (Luo and Qiu, 2012).

The first step in applying the influence function method to determine strata movements at a given point on the top surface of the $i^{\text {th }}$ layer is to define the influence functions for vertical and horizontal displacements, respectively (Fig. 2.15). The influence functions for subsidence and horizontal displacement along a major cross section are shown in Eqs. 2.25 and 2.26 respectively.

$$
\begin{array}{ll}
f_{S}\left(x^{\prime}, z_{i}\right)=\frac{S\left(x+x^{\prime}, z_{i-1}\right) \cdot a_{i}}{R_{i}} e^{-\pi\left(\frac{x^{\prime}}{R_{i}}\right)^{2}} & i=1,2, \cdots, n \\
f_{u}\left(x^{\prime}, z_{i}\right)=-2 \pi \frac{S\left(x+x^{\prime}, z_{i-1}\right) \cdot a_{i} \cdot n}{R_{i} \cdot h} x^{\prime} e^{-\pi\left(\frac{x^{\prime}}{R_{i}}\right)^{2}} & i=1,2, \cdots, n
\end{array}
$$

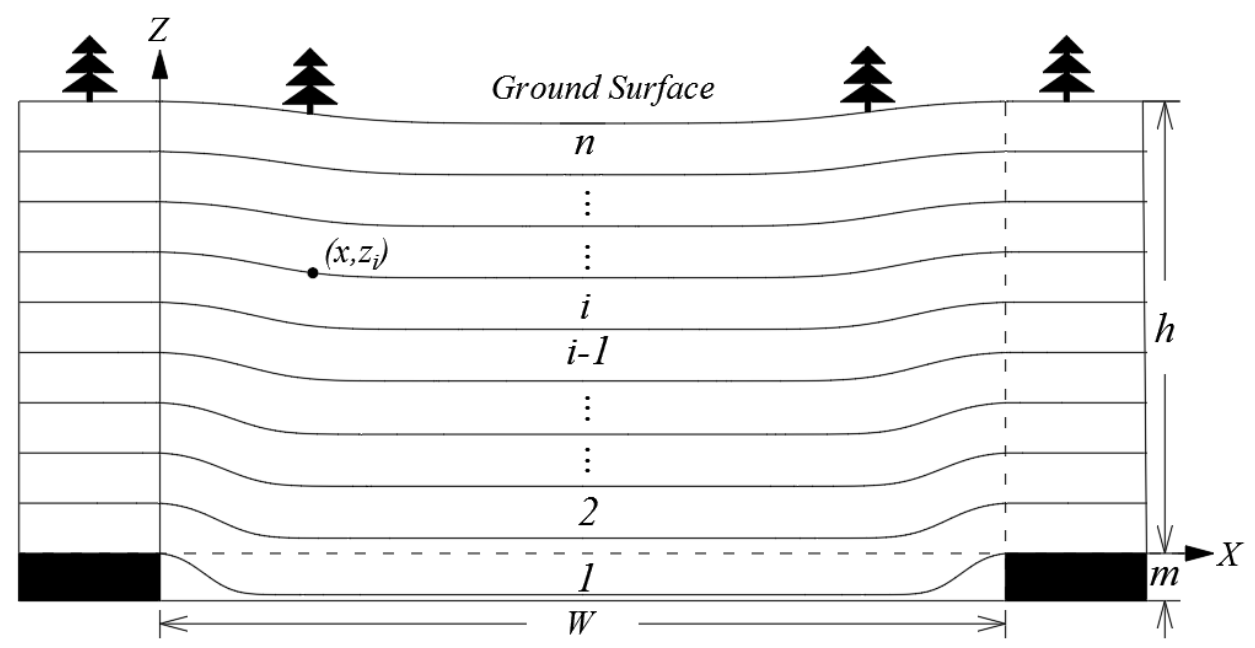

Figure 2.14 Second version of subsurface subsidence prediction model (Luo and Qiu, 2012) 
In these equations, $x$ is the horizontal distance between the left panel edge and the prediction point; $x^{\prime}$ is the horizontal distance between the prediction point and the subsidence source point while $z_{i}$ is the vertical distance between the top surface of the $i^{t h}$ layer and the mined coal seam as shown in Fig. 2.14. The term $S\left(x+x^{\prime}, z_{i-1}\right)$ is the predicted final subsidence on top surface of the underlying layer located $x^{\prime}$ distance on the left of the prediction point. For the first layer immediately above the mined coal seam, the mining height, $m$, should be used in the place of $S\left(x+x^{\prime}, z_{i-1}\right)$ in the influence functions. Final subsidence parameters $a_{i}$ and $R_{i}$ are the subsidence factor and radius of major influence for the $i^{\text {th }}$ layer, respectively.

The final subsurface subsidence and horizontal displacement at a prediction point $\left(x, z_{i}\right)$ on top surface of the $i^{\text {th }}$ layer can be determined by integrating the respective influence functions between the left and right inflection points as shown in Eqs. 2.27 and 2.28, respectively. In these two equations, $W$ is the rib-to-rib width of the mined longwall panel. The terms $d_{i 1}$ and $d_{i 2}$ are the offset distances of inflection points on the left and right sides of panel for the $i^{\text {th }}$ layer, respectively. The methods to determine the final subsidence parameters $\left(a_{i}, R_{i}, d_{i 1}\right.$ and $\left.d_{i 2}\right)$ will be discussed later.

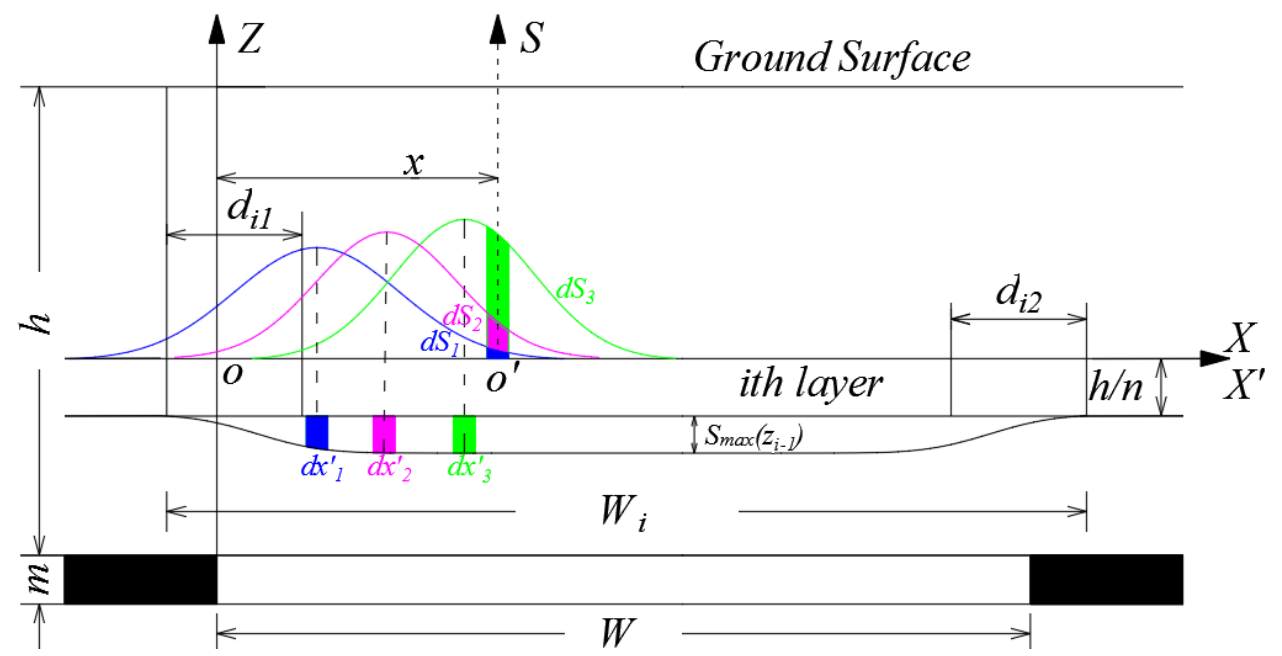

Figure 2.15 Schematic of influence function method for subsurface subsidence prediction (Luo and Qiu, 2012) 


$$
\begin{aligned}
& S\left(x, z_{i}\right)=\frac{a_{i}}{R_{i}} \int_{d_{i 1}-x}^{W-d_{i 2}-x} S\left(x+x^{\prime}, z_{i-1}\right) e^{-\pi\left(\frac{x^{\prime}}{R_{i}}\right)^{2}} d x^{\prime} \quad i=1,2, \cdots ; n \\
& U\left(x, z_{i}\right)=\frac{2 \pi a_{i} n}{R_{i} h} \int_{d_{i 1}-x}^{W-d_{i 2}-x} S\left(x+x^{\prime}, z_{i-1}\right) x^{\prime} e^{-\pi\left(\frac{x^{\prime}}{R_{i}}\right)^{2}} d x^{\prime} \quad i=1,2, \cdots ; n
\end{aligned}
$$

Deformations could be formed in the subsurface strata due to the resulting differential strata movements in both horizontal and vertical directions. In addition to the traditional deformation indexes, such as slope, horizontal strain and curvature, used for surface subsidence study, vertical and total strains in the overburden strata could be more useful for assessing the influences of subsidence to subsurface structures.

The horizontal strain $\left(\varepsilon_{x}\right)$ is defined as the first derivative of horizontal displacement with respect to $x$ (Eq. 2.29 or Eq. 2.2). High horizontal strain could cause vertical fractures or even cracks in the strata. The vertical strain $\left(\varepsilon_{z}\right)$ is defined as the first derivative of subsurface subsidence with respect to $h$ (Eq. 2.30). Sufficient vertical strain could cause bed separations along the strata bedding planes or even step cracks. The total strain $\left(\varepsilon_{t}\right)$, defined in Eq. 2.31, is an indicator of the severity of expansion or contraction of a volume of rock strata under the influence of subsidence process (Luo and Qiu, 2012).

$$
\begin{aligned}
& \varepsilon_{x}(x, h)=\frac{d U(x, h)}{d x} \\
& \varepsilon_{z}(x, h)=\frac{d S(x, h)}{d x} \\
& \varepsilon_{t}(x, h)=\varepsilon_{x}+\varepsilon_{z}+\varepsilon_{x} \cdot \varepsilon_{z}
\end{aligned}
$$

\section{Final Subsidence Parameters}

The accuracy of this subsurface subsidence prediction model largely depends on the accuracy of final subsurface subsidence parameters, $a_{i}, R_{i}, d_{i 1}$ and $d_{i 2}$. Based on previous subsidence 
research (Luo, 1989; Peng et al, 1995) and mechanical analysis, empirical formulas for final subsurface subsidence parameters were proposed (Luo and Qiu, 2012).

The following empirical equation was derived to relate subsidence factor of a given layer with the thickness $(h / n)$ and percent of hard rock $\left(\eta_{i}\right)$ in it.

$$
a_{i}=1.0032 \times\left(\frac{h}{n}\right)^{-0.009} e^{0.00005\left(35-\eta_{i}\right)} \quad i=1,2, \cdots ; n
$$

To determine the radius of major influence of the $i^{\text {th }}$ layer, the layer is regarded as an overhang beam with a thickness of $h / n$ (Fig. 2.16). The left side of the beam is restricted by an elastic fixed end in the vertical direction while the right side is limited by the maximum possible subsidence on the top surface of the immediate underlying layer, $S_{\max }\left(z_{i-1}\right)$. The analytically derived formula was modified to accommodate the empirically derived values on ground surface with similar condition and depth. Eq. 2.33 shows the recommended empirical formula for radius of major influence for the $i^{\text {th }}$ layer.

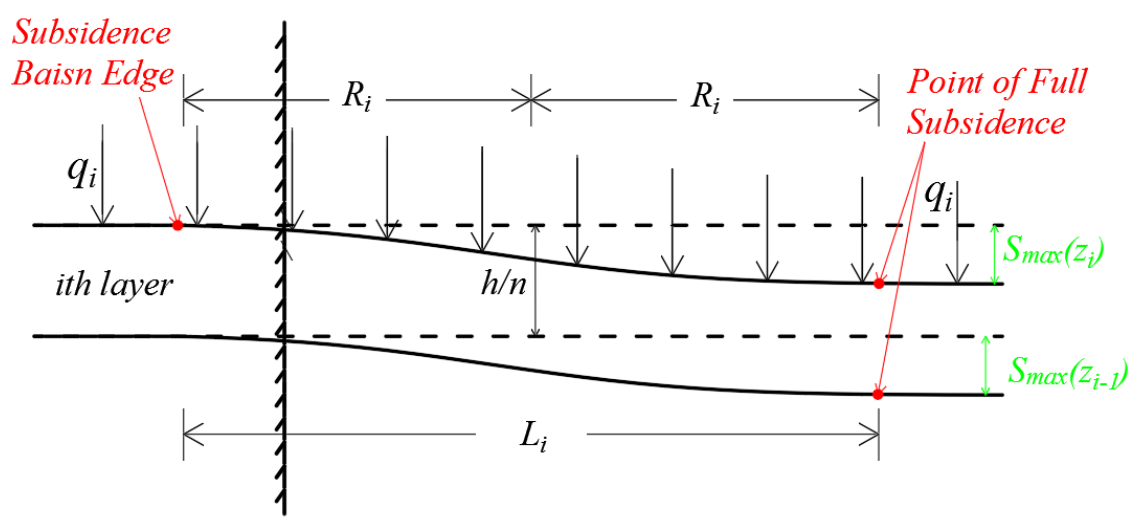

Figure 2.16 Determination of the radius of major influence (Luo and Qiu, 2012)

$$
R_{i}=0.5\left\{\left[\frac{2 \cdot S_{\max }\left(z_{i-1}\right) \cdot a_{i}\left(\frac{h}{n}\right)^{3} \frac{K}{Q_{i}^{2}}}{3 q_{i}}\right]^{0.25}+0.13 \frac{i \cdot h}{n}\right\} \quad i=1,2, \cdots, n
$$


In Eq. 2.33, $q_{i}$ is the magnitude of the overburden load for the $i^{\text {th }}$ layer and can be defined by Eq. 2.34. $K$ is a factor related to the Young's modulus of the rock strata, which can be estimated to be 0.49 times the average Young's modulus of the rock strata. The rock factor for the $i^{\text {th }}$ layer, $Q_{i}$, can be calculated by Eq. 2.35. In Eq. 2.34, $\gamma$ is the average density of the overburden strata in pounds per cubic feet. If the determined radius of major influence for $i^{\text {th }}$ layer $\left(R_{i}\right)$ is smaller than that for the underlying layer $\left(R_{i-1}\right), R_{i}$ will be set as the summation of $R_{i-1}$ and $0.2 h / n$.

$$
\begin{array}{ll}
q_{i}=\frac{\gamma \cdot h \cdot(n+i) \cdot(n-i+1)}{288 \cdot n \cdot i} & i=1,2, \cdots ; n \\
Q_{i}=\sqrt{\frac{\left(0.08 \cdot \eta_{i}\right)^{2}+\left[0.7 \cdot\left(1-\eta_{i}\right)\right]^{2}}{\eta_{i}^{2}+\left(1-\eta_{i}\right)^{2}}} & i=1,2, \cdots ; n
\end{array}
$$

The offset distance of inflection point of the $i^{\text {th }}$ layer can be determined by the following empirical formula.

$$
d_{i}=0.382075 \times 0.999253^{\frac{i h}{n}} \times \frac{i h}{n} \quad i=1,2, \cdots, n
$$

\subsection{Mine Subsidence-Related Research}

\subsubsection{Key Strata Theory}

Overburden lithology has significant influence on the subsurface strata movements and deformations during ground subsidence process (Liu, 1981; Karmis et al., 1987; Qian et al., 1996; Wang et al., 2009). One of the methods to address such influence is the key strata theory. The key strata theory states that the thick and hard key strata band serves as the backbone of the overburden and controls the movements of the thin and soft weak rock strata bands located above them (Fig. 2.17). Furthermore, the key strata also have the following characteristics. First, for an overburden containing $n$ strata, each key stratum and its overlying weak strata moves and deforms 
synchronously. Second, after subsidence process is over, each key stratum regains the equilibrium condition through forming a structural model and continues supporting its overlying weak strata.

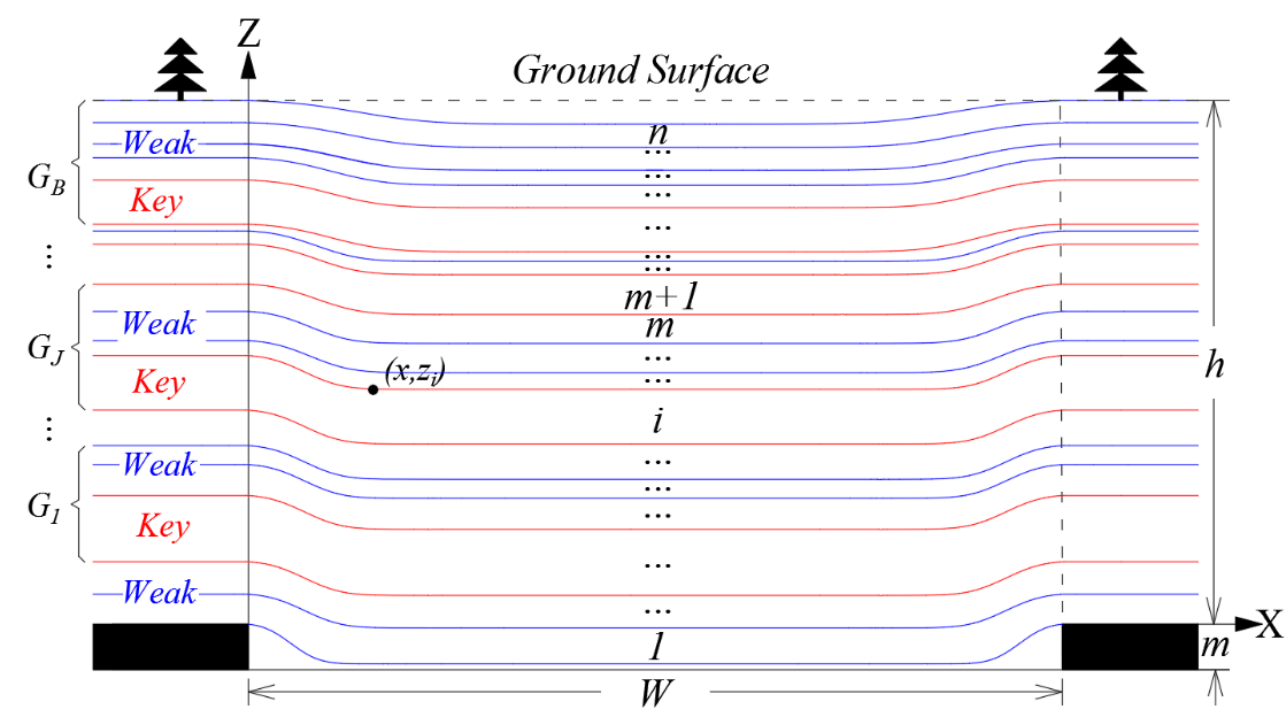

Figure 2.17 Schematic of key strata in the overburden

\section{Algorithm for Determining Key Strata}

According to the principles of the composite beam theory and the key strata theory, the key strata can be identified using the following algorithm (Xu and Qian, 2000). It is assumed that the first key stratum is the $i^{\text {th }}$ stratum and the overlying weak strata controlled by the first key stratum is up to the $m(m<n)$ stratum. Therefore, the strata from $i$ to $m$ can be treated as a composite beam which will move and deform synchronously. The shear force $Q$ and bending moment $M$ of the composite beam are the summation of the shear force and bending moment of each stratum from $i$ to $m$. The relationship can be expressed as:

$$
\begin{aligned}
& Q_{i \sim m}=Q_{i}+Q_{i+1}+\cdots+Q_{m} \\
& M_{i \sim m}=M_{i}+M_{i+1}+\cdots+M_{m}
\end{aligned}
$$


Based on the mechanics of materials, the relationship among the curvature $K_{j}$, the radius of curvature $\rho_{j}$, moment $M_{j}$, elastic modulus $E_{j}$ and moment of inertia $I_{j}$ of the $j^{\text {th }}$ stratum under the action of dead load is presented as:

$$
K_{j}=\frac{1}{\rho_{j}}=\frac{M_{j}}{E_{j} I_{j}} \quad j=i, i+1, \ldots, m
$$

Since the composite beam consisting of the strata from $i$ to $m$ moves and deforms synchronously, the curvatures of those strata in the composite beam have little differences. Therefore, the strata in the composite beam would behave according to the following relationships.

$$
\frac{M_{i}}{E_{i} I_{i}}=\frac{M_{i+1}}{E_{i+1} I_{i+1}}=\cdots=\frac{M_{m}}{E_{m} I_{m}}
$$

Eq. 2.40can be transformed into the following format.

$$
\frac{M_{i}}{M_{i+1}}=\frac{E_{i} I_{i}}{E_{i+1} I_{i+1}}, \frac{M_{i}}{M_{i+2}}=\frac{E_{i} I_{i}}{E_{i+2} I_{i+2}}, \cdots, \frac{M_{i}}{M_{m}}=\frac{E_{i} I_{i}}{E_{m} I_{m}}
$$

Substitute Eq. 2.41 into Eq. 2.38, then the Eq. 2.38 can be rewritten as:

$$
M_{i \sim m}=M_{i}\left(\frac{E_{i} I_{i}+E_{i+1} I_{i+1}+\cdots+E_{m} I_{m}}{E_{i} I_{i}}\right)
$$

Move $M_{i}$ to the left side of the equation, then Eq. 2.42 becomes:

$$
M_{i}=M_{i \sim m}\left(\frac{E_{i} I_{i}}{E_{i} I_{i}+E_{i+1} I_{i+1}+\cdots+E_{m} I_{m}}\right)
$$

It is well known that the shear stress $Q$ is defined as the first derivative of the bending moment $M$ with respect to $x$ and the dead load $q$ is the first derivative of the shear stress $Q$ with respect to $x$. Therefore, Eq. 2.43 can be written as:

$$
q_{i}=q_{i \sim m}\left(\frac{E_{i} I_{i}}{E_{i} I_{i}+E_{i+1} I_{i+1}+\cdots+E_{m} I_{m}}\right)
$$

Where: 


$$
\begin{aligned}
& q_{i \sim m}=\gamma_{i} h_{i}+\gamma_{i+1} h_{i+1}+\cdots+\gamma_{m} h_{m} \\
& I_{i}=\frac{b_{i} h_{i}^{3}}{12}, I_{i+1}=\frac{b_{i+1} h_{i+1}^{3}}{12}, \cdots, I_{m}=\frac{b_{m} h_{m}^{3}}{12}
\end{aligned}
$$

In Eqs. 2.45 and 2.46, $\gamma_{j}, h_{j}$ and $b_{j}$ are the vertical stress gradient, thickness and width of the $j^{\text {th }}$ stratum. The stratum is simplified as a beam with a unit width, therefore, $b_{j}$ is set as a unit. Substituting Eqs. 2.45 and 2.46 into Eq. 2.44, the equation for determining the total load caused by the overlying weak strata up to $m$ stratum which is applied on the first stratum can be derived as:

$$
\left(q_{m}\right)_{i}=q_{i}=\frac{E_{i} h_{i}^{3}\left(\gamma_{i} h_{i}+\gamma_{i+1} h_{i+1}+\cdots+\gamma_{m} h_{m}\right)}{E_{i} h_{i}^{3}+E_{i+1} h_{i+1}^{3}+\cdots+E_{m} h_{m}^{3}}
$$

Similarly, the load on the other strata can be calculated. Based on the clamped beam theory in material mechanics, the critical limit span $\left(\Delta L_{j}\right)$ of the $j^{\text {th }}$ rock stratum for the first breaking can be determined as:

$$
\Delta L_{j}=h_{j} \sqrt{\frac{2 T_{j}}{q_{j}}} \quad j=i, i+1, \ldots, m
$$

In this equation, $T_{j}$ and $q_{j}$ are the tensile strength and total load of the $j^{\text {th }}$ rock stratum, respectively.

If the $m+1$ stratum is another key stratum supporting its overlying weak strata, the following two requirements must be satisfied. The first one is the load requirement. The total load caused by the overlying weak strata up to $m+1$ stratum applied on the previous key stratum $\left(q_{m+1}\right)_{i}$ must be smaller than that caused by the overlying strata up to $m$ stratum applied on the previous key stratum $\left(q_{m}\right)_{i}$. The other one is the strength requirement. The critical limit span of the key stratum $\left(\Delta L_{m+1}\right)$ must be longer than that of the previous key stratum $\left(\Delta L_{i}\right)$. 


$$
\begin{aligned}
& \left(q_{m}\right)_{i}>\left(q_{m+1}\right)_{i} \\
& \Delta L_{i}<\Delta L_{m+1}
\end{aligned}
$$

If the $m+1$ stratum cannot control the movements and deformations up to the ground surface, there must be one or more key strata above the $m+1$ stratum. The same procedures used for determining the key stratum at the $m+1$ stratum should be used to determine all the other key strata in the overburden.

\subsubsection{Interstate Highways and Bridges}

As of 2016, the US interstate highway system had a total length of 48,191 miles and connected 48 contiguous states. Furthermore, about one-quarter of all vehicle miles driven in the country used the interstate highway system (OHPI, 2017). Taking I-79 as an example, its annual average daily traffic is 36,846 for 2017 (PADOT, 2017). Therefore, the interstate highway system is one of the most important transportation modes in the US. Highway bridges, as a key element in the transportation system, are built to connect a disconnected road and to span physical obstacles such as a body of water, valley, or road, for the purpose of providing passage over the obstacles (BTH, 2020). Therefore, ensuring the functionality and safety of interstate highways and their bridges is vital to the travelers and vehicles.

\subsubsection{Basics of Highway Designs}

The interstate highways normally have two or more lanes in each direction separated by a median. Generally, the interstate highway pavements are originally built with concrete slabs overlying on the base courses while asphalt is used in repaving and repairing the highway surface afterwards. Immediately under the base course, subbase is constructed on subgrade, which is built 
on the original ground surface. Figure 2.18 shows the typical constructions of interstate highways (Oglesby and Hicks, 1982).

The length $(D)$, width $(W)$, and thickness $(h)$ of the concrete pavement slabs normally are 20, 12, and $0.5 \mathrm{ft}$, respectively, as shown in Fig. 2.18 (Oglesby and Hicks, 1982). The concrete slabs are laid side by side forming the highway surface pavement. Longitudinal and transverse joints, either sawed or formed, are left on the concrete pavement to control the stresses induced by weather and uneven traffic loads. The normal groove is $5 / 8$ in. wide and $15 / 8$ in. deep and the gap is filled with sealant. At the joints, steel load transfers or deformed tiebars are cemented at the half depth of the slabs. When sufficient tension or compression develops, cracks are likely to occur at the joints instead of in random pattern.

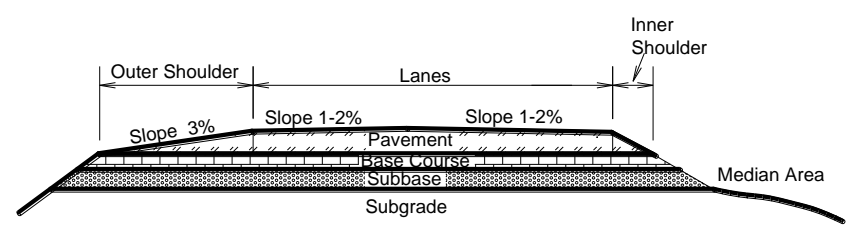

(a) Typical Cross-section of Interstate Highway

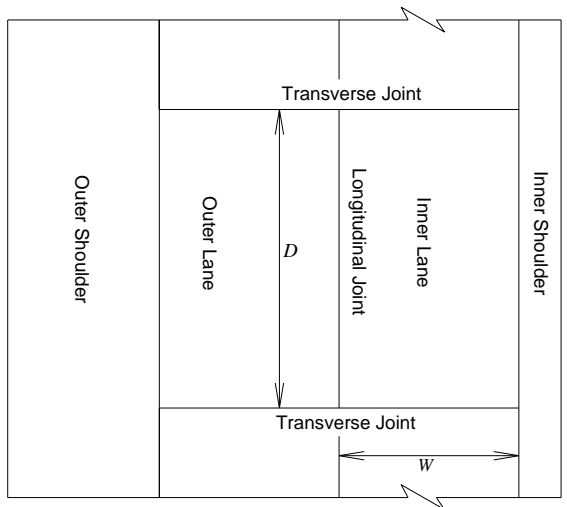

(b) Pavement Dimension

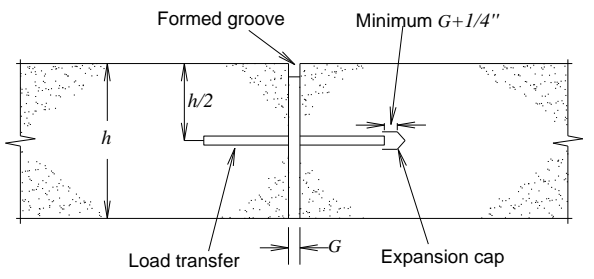

(c) Transverse Joint

Figure 2.18 Typical construction of interstate highways (after Oglesby and Hicks, 1982) 


\subsubsection{Basics of Highway Bridges}

The beam bridges are most often used for highway and railroad constructions for spanning relatively small distances. The typical structural components of a beam bridge are shown in Fig. 2.19 (AASHTO, 2012). At the top surface of the bridge deck, barriers are placed along each edge of the bridge pavements along the axial direction to prevent vehicles from entering the opposite lane and going off the edges (Zain and Mohammed, 2015). The deck is the surface of a bridge and is normally constructed from concrete, steel, or wood. Sometimes, the deck is repaved and repaired with asphalt. The bridge deck is mounted on top of the beams which resist loads transferred from the bridge decks. A beam typically responds to forces by bending in reaction to its support points, which are typically the end abutments and the intermediate piers. The beams and abutments/intermediate piers are connected through bearings which are bolted in beams and abutments/intermediate pier caps. The purpose of the bearing system is to allow controlled bridge movement and thereby reduce high stress concentrations. Normally, one or more piers are erected to support a pier cap. At a pier bottom, a concrete foundation is built to improve the stability of the pier. At the ends of the bridge, approach slabs are paved to connect bridge decks and road surface pavement. Expansion joints are left between the bridge decks and approach slabs to compensate the expansion or contraction of bridge decks.

It is well known that surface subsidence process induced by underground longwall mining operations can cause various disturbances on surface structures. While the surface subsidence influences on most of surface structures have been studied, the research on the effects of subsidence influence on interstate highways and highway bridges is few and incomplete due to the high standard design criteria for highways and bridges. Past experience shows that the surface subsidenceinduced slope, strain and curvature could cause cracks or bumps on the highway pavements, 
steepen the highway gradients, reduce the stopping sight distance of the travelling vehicles, induce deflection on the bridge beams and twisting conditions on the bridge decks, and even cause the bridge collapse (Gutierrez et al., 2010; Adelsohn, 2019; Alke and Thompson, 1984; Jones, 1988; Ma et al., 2011). Almost all of the literatures are about case study and do not have systematic theoretical analysis to study how the subsidence process causes damages to the interstate highways and highway bridges.
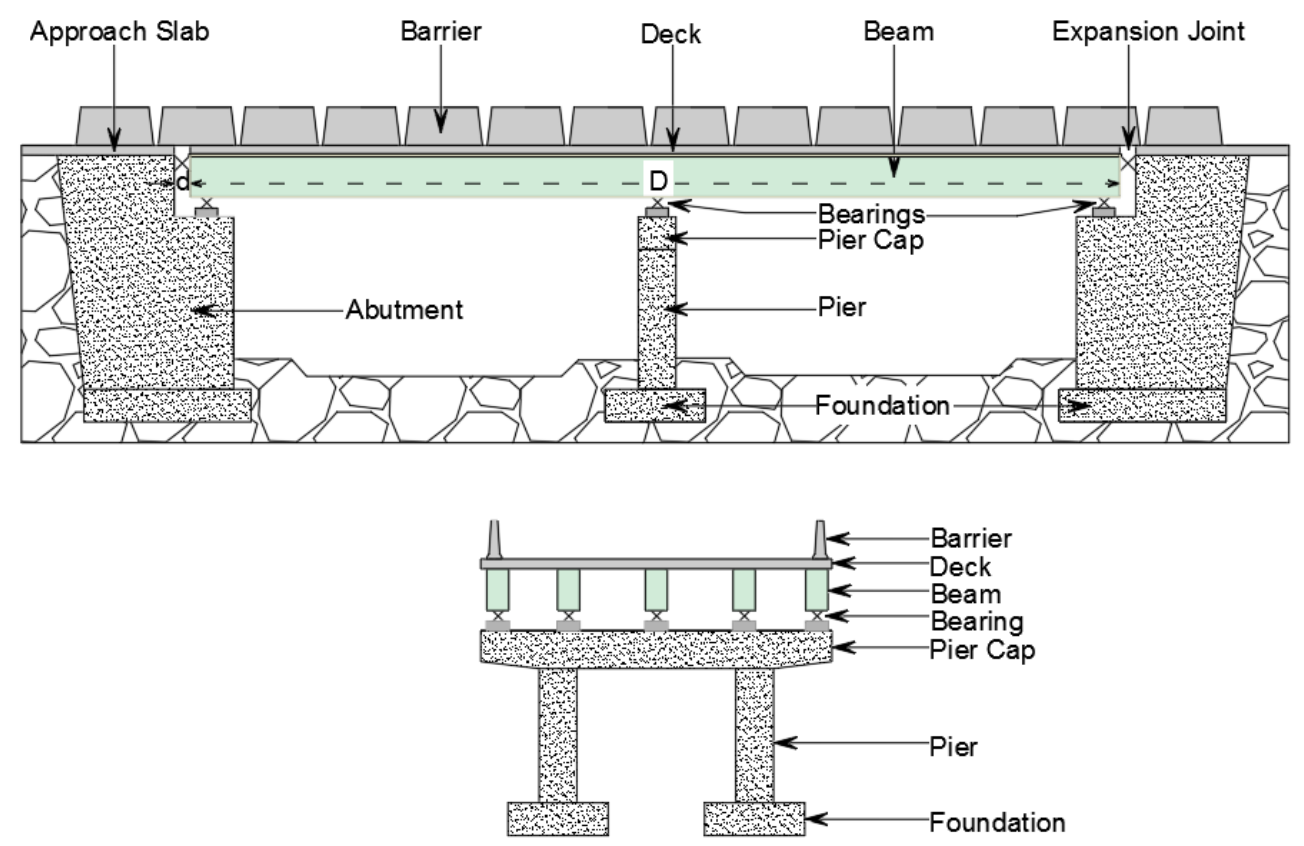

Figure 2.19 Typical construction of highway bridges from front view (top) and cross-section view (bottom) (after AASHTO, 2012)

\subsubsection{Mine Water in Inactive Room-and-Pillar Mines}

When an abandoned room-and-pillar mine or part of an active room-and-pillar mine is sealed, water will gradually seep from surrounding rock strata through cracks and fill into the underground mine openings. The mine water may come from groundwater, rivers, lakes, wetland or rainwater. When the mine openings are filled with mine water, water will continue accumulating above the mining level, until reach the ground surface. Reopening a sealed mine or building a new 
mine encountering to a sealed mine will result in prolific mine water flowing out the sealed mine. Experience shows that mine water frequently plays an important role in causing mine subsidence over inactive room-and-pillar mines and, however, could also serve the purpose of preventing such subsidence events (PADEP, 2020b).

Figure 2.20 shows a documented subsidence case. Started in March 1994, a 2,000 linear feet section of Interstate 70 (I-70) in eastern Ohio experienced sinkhole type subsidence events within the travel lanes, shoulders and adjacent right of way areas (Hoffman et al., 1995). The sinkholes were about $10 \mathrm{ft}$ in depth and width with the most catastrophic one occurred on the eastbound travel lane presenting a hazardous condition to highway traffic. In addition, multiple depressions zones were observed on the highway pavements. The subsidence occurred after the dewatering of an abandoned underground room-and-pillar mine during the auger mining operations near the site. This section of I-70 was closed for 180 days for emergency remediation activities that costed about $\$ 3.8$ million and the traffic was re-routed to the nearby local roads during that time.

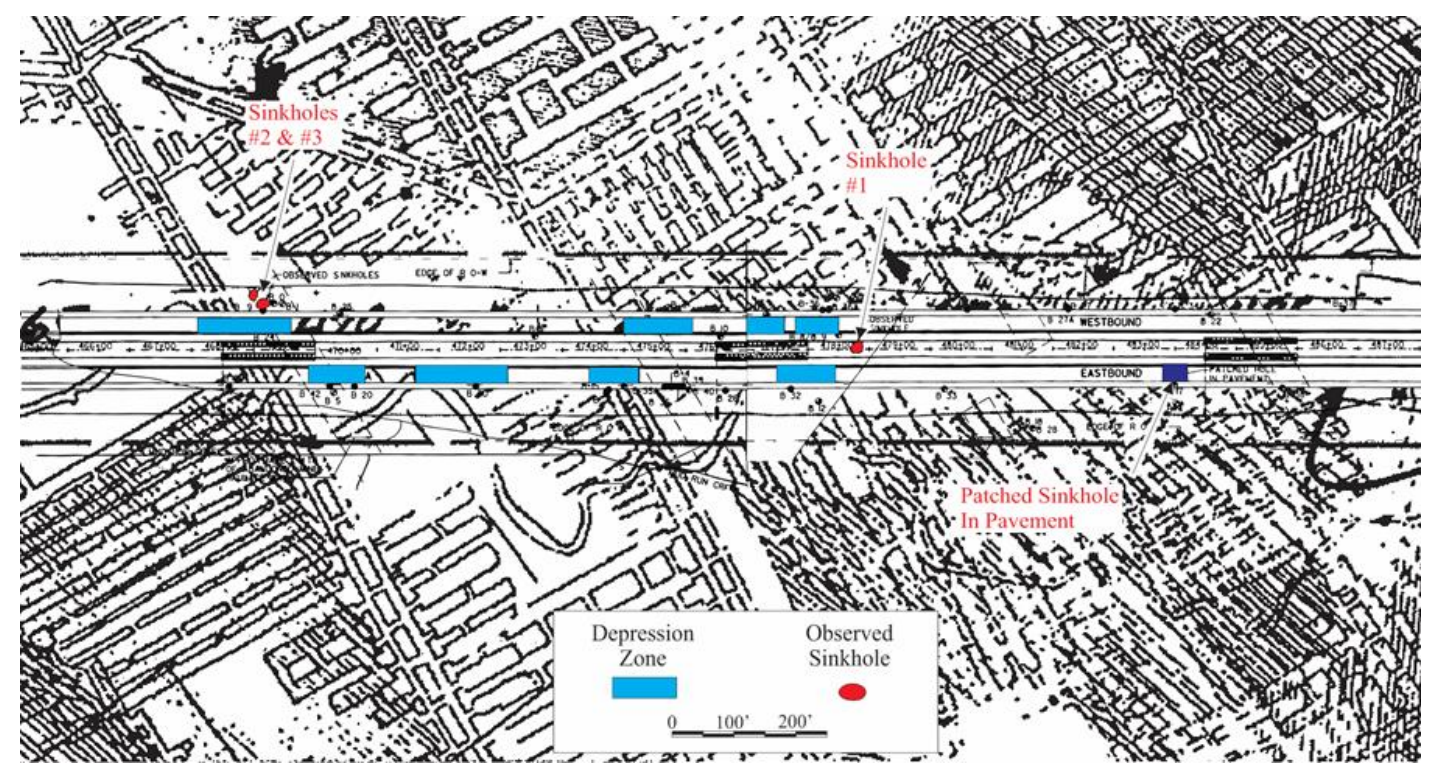

Figure 2.20 Observed subsidence events on interstate I-70 over an abandoned coal mine (after Hoffman et al., 1995) 
Due to the facts that inactive room-and-pillar mines are no longer accessible and the conditions of the underground mine structures are unknown, the mechanisms of the effects of mine water on the stability of mine pillars and immediate roof, as well as the potential for causing surface subsidence over inactive room-and-pillar coal mines are not studied adequately and are still not clear. 


\section{CHAPTER 3 \\ ENHANCED SUBSURFACE SUBSIDENCE PREDICTION MODEL INCORPORATING KEY STRATA THEORY}

\subsection{Introduction}

Large movements and deformations occur in the overburden strata from the immediate roof up to ground surface in response to the longwall mining operations in underground coal mines. The movements and deformations in the overburden strata could cause disturbances to the multiple seam mine structures stability (Mark, 2007), ground water storage and flow mechanism (Du, 2010) and coalbed methane desorption and diffusion mechanism (Guo et al., 2009). Therefore, a good understanding of the subsurface subsidence process is required in order to correctly access those disturbances to various coal mining activities. However, field measurements are costly and timeconsuming, the research on subsurface subsidence has been far less than that on surface subsidence. Based on the success of using the surface subsidence prediction-assessment-mitigation systematic approach, developing an accurate subsurface subsidence prediction model is the first step for properly assessing the subsurface subsidence influences and for designing and implementing the effective mitigation measures. Only through such efforts, the anticipated subsurface subsidence influences caused by longwall mining can be greatly reduced or even eliminated.

Decades of research have indicated that variations of stratification and lithology in the overburden have significant influence on the subsurface strata movements and deformations during ground subsidence process (Liu, 1981; Karmis, 1987; Qian et al., 1996; Wang et al., 2009). The first version subsurface subsidence prediction model (Luo and Peng, 2000) can predict final and dynamic subsurface subsidence over a longwall panel. However, this model did not take the variations of overburden stratification and lithology and strata properties into consideration. This 
model assumed that the variations of the overburden strata have insignificant or little influences on the subsurface subsidence, the subsidence at a point of subsurface stratum is the same as that on a surface point with the same overburden depth with the other conditions being equal. However, the overburden strata often consist of not only thick and hard layers but also thin and weak layers. The different rock properties between hard and weak layers can affect the behavior of strata movement, consequently the final subsidence parameters and the accuracy of the subsidence prediction. More than a decade later, the second version subsurface subsidence prediction model considering overburden stratification was introduced (Luo and Qiu, 2012). In this model, the entire overburden strata are equally divided into a finite number of layers and the percent of hard rocks (i.e., limestone and sandstone) in each layer is used as an additional input to consider the lithology of the overburden. However, the equal division approach for the overburden strata can separate a massive hard rock stratum into two or more layers that could reduce its bridging effect to its overlying strata during ground subsidence process. Besides, a thick stratum other than limestone and sandstone such as strong shale will register for zero percent of hard rock in this model but may create a greater effect on the overlying strata movements than that by strata of low percent of limestone and sandstone. Therefore, the previous approach, through the first attempt to consider stratification, could result in inaccurate subsurface subsidence prediction.

A new subsurface subsidence prediction model is proposed in an effort to improve the mathematical model and the required subsidence parameters used in the previous versions by incorporating the key strata theory (Chien, 1981). This model considers the variations of the overburden stratification and lithology in a better way according to the concept of rock mechanics by using a new division scheme for the overburden strata. The overburden strata are subdivided into a finite number of individual groups according to the numbers of the identified key strata in the 
overburden for subsurface subsidence prediction. The key strata can be identified based on the rock properties of each actual layer and the composite beam theory as stated in section 2.3.1.

The proposed concept is that the subsidence on the top surface of a given layer is regarded as the subsidence source for the immediate overlying layer (Luo and Qiu, 2012). Therefore, the subsidence on the top surface of a given layer can be determined from that on the top surface of its underlying layer using the principle of influence function method. The rock properties of each layer and the composite beam theory are used to derive a set of final subsidence parameters for each layer required by influence function method. This concept makes it possible that the subsidence of each layer can be calculated using repetitive method progressively from immediate roof upward to ground surface. A computer program has been developed in Excel for implementing the proposed mathematical model.

At the end of the chapter, a subsidence case study where surface and subsurface strata movements were monitored using mechanical grouting method was used to demonstrate the applicability and improvement of the new subsurface subsidence prediction model.

\subsection{Enhanced Mathematical Model}

After determining the locations and number ( $B$ as shown in Fig. 2.17) of the key layers, the overburden strata can be subdivided into $B$ groups of composite beams $\left(G_{1} \ldots G_{B}\right.$ in Fig. 2.17). In each group, the bottom is the key layer while the remaining are weak layers. The weight of the overlying layers of a given layer can be considered as load acting on the given layer. It should be noted that the layers in a given group just takes the load from their overlying layers in that group. The higher position a layer is in a given group, the less load it has to take from its overlying layers. Therefore, the top layer in each group does not take load expect for its own weight. 
The thickness of each layer can be obtained from the drill log record while their rock properties (i.e., $U C S, T, E$, and $\gamma$ ) can be estimated or determined from the core samples obtained in the mine exploration. The subsidence on the top surface of a given layer in a given group can be determined with the following modified procedures (Luo and Qiu, 2012): (1) transforming the weight of its overlying layers in a given group into a uniform equivalent load on the layer; (2) defining the subsidence influence functions and the required final subsidence parameters at a prediction point on the top surface of the layer according to the equivalent load, layer thickness, UCS and subsidence at the point directly under the prediction point on the top surface of its immediate underlying layer; (3) integrating the influence functions in a proper horizontal interval for the final subsidence on top of the layer. The procedures are implemented repeatedly from the mining horizon layer by layer upwards, until the ground surface is reached.

\subsubsection{Influence functions for subsurface subsidence and horizontal displacement}

For a mathematical model developed based on the influence function method, defining the influence functions is the first and most important step. Since the influence functions used for predicting final surface subsidence have been proven to be accurate and accepted widely, the influence functions are extended for subsurface subsidence prediction. The principle of the influence function method is that the extraction of an element of coal seam or the subsidence at a the underlying layer will induce a point on the top surface of overlying layer to subside certain amount as shown in Fig. 3.1. Generally, the point on the top surface of the overlying layer located directly above the subsided element receives the most amount of subsidence. The farther the point is away from the subsided element horizontally, the less amount of influence to be received by the point. The influence function for subsidence on the top surface of the $i^{\text {th }}$ layer along a major cross-section of a longwall panel is shown as follows: 


$$
f_{S}\left(x^{\prime}, z_{i}\right)=\frac{s\left(x+x^{\prime}, z_{i-1}\right) \cdot a_{i}}{R_{i}} e^{-\pi\left(\frac{x^{\prime}}{R_{i}}\right)^{2}} \quad i=1,2, \cdots, n
$$

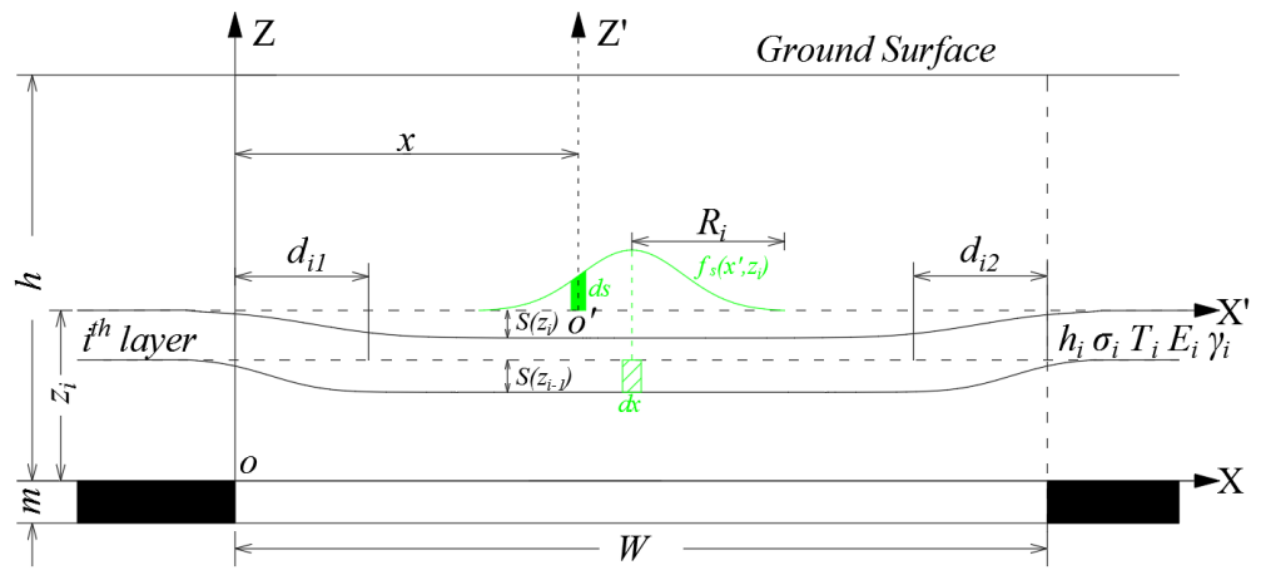

Figure 3.1 Principle of the influence function method for subsurface subsidence prediction

In this equation, $x$ is the horizontal distance between the left panel edge and the point of interest while $x^{\prime}$ is the distance between the point of interest and the subsidence source element. Term $z_{i}$ is the vertical distance between the top surface of the $i^{\text {th }}$ layer and the mining level (Fig. 2.17). Term $S\left(x+x^{\prime}, z_{i-1}\right)$ is the predicted final subsidence for the point located $x^{\prime}$ distance to the right of the point of interest on the top surface of the $(i-1)^{t h}$ layer. The two final subsidence parameters $a_{i}$ and $R_{i}$ are the subsidence factor and the radius of major influence for the $i^{\text {th }}$ layer, respectively. The third final subsidence parameters $d_{i 1}$ and $d_{i 2}$ shown in Fig. 3.1 are the offset distances of inflection points for the $i^{\text {th }}$ layer on the left and right sides of the panel, respectively, and are used to determine the integration boundaries of the influence functions.

Based on the employed influence function for subsidence on the top surface of the $i^{\text {th }}$ layer, the focal point theory is employed to derive the influence function for horizontal displacement on the top surface of the $i^{\text {th }}$ layer. The focal point theory states that the extraction of an elemental area of coal seam or the subsidence at a point on the underlying layer will pull the overburden layers to move toward the extracted or subsided element (Fig. 3.2). Based on the focal point theory and field 
calibration, the influence function for horizontal displacement on the top surface of the $i^{\text {th }}$ layer along a major cross-section of a longwall panel is deduced from the influence function for vertical subsidence as shown in the following equation.

$$
f_{u}\left(x^{\prime}, z_{i}\right)=-2 \pi \frac{S\left(x+x^{\prime}, z_{i-1}\right) \cdot a_{i}}{R_{i} \cdot h_{i}} x^{\prime} e^{-\pi\left(\frac{x^{\prime}}{R_{i}}\right)^{2}} \quad i=1,2, \cdots ; n
$$

\section{Ground Surface}

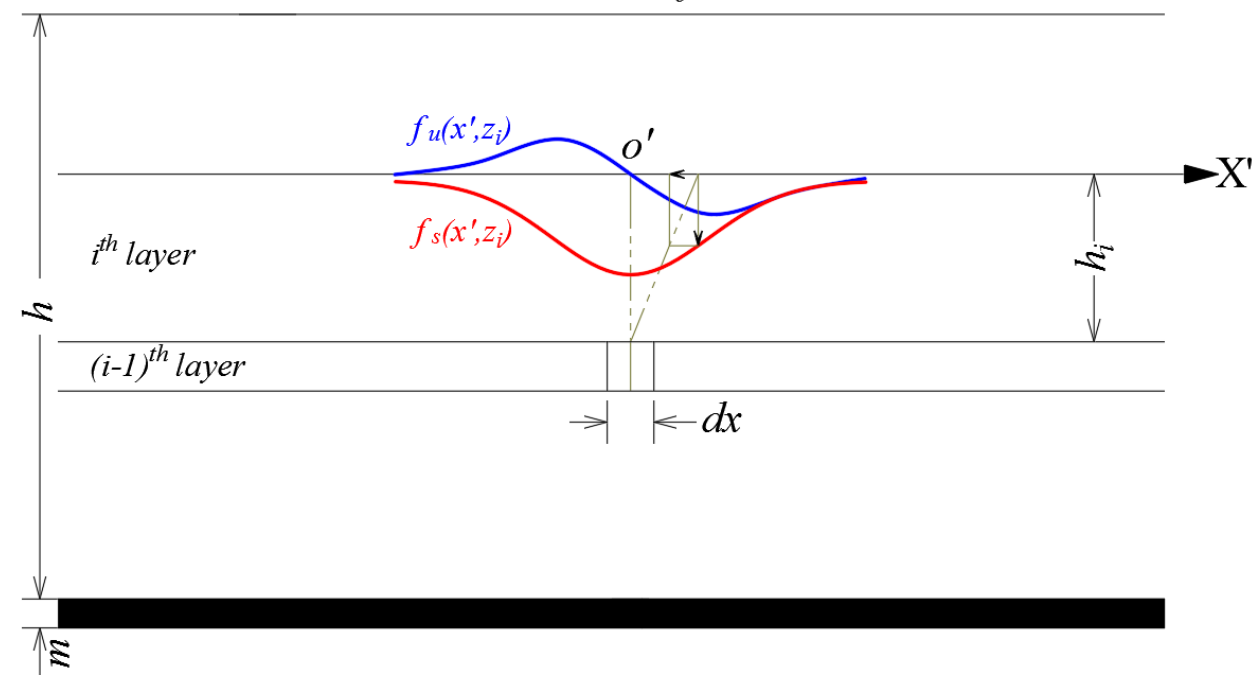

Figure 3.2 Schematic of the focal point theory showing relationship between influence functions for subsidence and horizontal displacement

\subsubsection{Final subsurface movements}

The final subsurface movements which include vertical subsidence and horizontal displacement at a point of interest can be determined by integrating the respective influence functions between the left and right inflection points on the given layer (Fig. 3.1). Therefore, the final subsurface vertical subsidence at a point of interest $\left(x, z_{i}\right)$ on the top surface of the $i^{\text {th }}$ layer can be calculated by the following equation. In the equation, $W$ is the rib-to-rib width of the mined longwall panel.

$$
S\left(x, z_{i}\right)=\frac{a_{i}}{R_{i}} \int_{d_{i 1}-x}^{W-d_{i 2}-x} S\left(x+x^{\prime}, z_{i-1}\right) e^{-\pi\left(\frac{x^{\prime}}{R_{i}}\right)^{2}} d x^{\prime} \quad i=1,2, \cdots ; n
$$


Similarly, the final subsurface horizontal displacement at a point of interest $\left(x, z_{i}\right)$ on the top surface of the $i^{\text {th }}$ layer can also be calculated by integrating the influence function for horizontal displacement between the left and right inflection points of the $i^{t h}$ layer as shown in the following equation.

$$
U\left(x, z_{i}\right)=-\frac{2 \pi a_{i}}{R_{i} h_{i}} \int_{d_{i 1}-x}^{W-d_{i 2}-x} S\left(x+x^{\prime}, z_{i-1}\right) x^{\prime-\pi\left(\frac{x^{\prime}}{R_{i}}\right)^{2}} d x^{\prime} \quad i=1,2, \cdots ; n
$$

\subsubsection{Final subsurface deformations}

Horizontal, vertical and total strains for the subsurface deformations have been introduced in section 2.2.2 and can be calculated by Eqs. 2.29, 2.30 and 2.31, respectively.

\subsection{Final Subsurface Subsidence Parameters}

The accuracy of the new subsurface subsidence prediction model is heavily dependent on two main components: the mathematical model and the required subsidence parameters. A good mathematical model should be flexible and versatile so that it is able to represent the resulting subsidence basin under various possible conditions. The influence function method has been proven to meet the stated criteria for the surface subsidence prediction - a special case for subsidence process of entire overburden strata. Therefore, the mathematical model used for surface subsidence prediction can be expanded for predicting the subsurface subsidence with a good confidence. On the other hand, the required subsidence parameters in the mathematical model play important roles to ensure the accuracy of the prediction for the subsurface strata movements and deformations and to address the site-specific variations. The most important three subsurface subsidence parameters are final subsurface subsidence factor $\left(a_{i}\right)$, radius of major influence $\left(R_{i}\right)$ and offset distance of inflection point $\left(d_{i}\right)$. In this section, the empirical formulae for the three final 
subsurface subsidence parameters have been derived from the past subsidence research (Peng et al., 1995; Luo and Peng, 2000; Luo and Qiu, 2012).

\subsubsection{Subsurface subsidence factor}

For calculating subsurface subsidence factor, the empirical formula (Eq. 2.13) in CISPM just depends on the overburden depth while the empirical formula (Eq. 2.14) in SDPS is only influenced by the percent of hard rock in the overburden when the panel is in supercritical condition. In order to take the combination effects of the overburden depth and percent of hard rock in the overburden into consideration on subsurface subsidence factor, a method is proposed. When the panel is in supercritical condition, Eq. 2.14 can be simplified as follows:

$$
a_{S D P S}=0.12+0.66 \cdot e^{-0.00034 \eta^{2}}
$$

For the percent of hard rock ranging from 10 to 80 with an interval of 10, eight subsidence factors can be calculated and also listed in Table 3.1. Experience shows that the percent of hard rock in the overburden for the north Appalachian coal field is about 30\%. Ratios of the subsidence factors for percent of hard rock ranging from 10 to 80 to the subsidence factor when percent of hard rock being $30 \%$ are also calculated and listed in Table 3.1. The linear regression is performed on the ratios data set and one of the best formulas is selected to relate the ratios and the percent of hard rock as shown in Eq. 3.6. The resulted coefficient of determination $\left(R^{2}\right)$ for this regression is up to 0.9924 as shown in Fig. 3.3.

Table 3.1 Subsidence factors calculated using Eq. 3.5

\begin{tabular}{|c|c|c|c|c|c|c|c|c|}
\hline$H R(\eta)$ & 10 & 20 & 30 & 40 & 50 & 60 & 70 & 80 \\
\hline$a$ & 0.758 & 0.696 & 0.606 & 0.503 & 0.402 & 0.314 & 0.245 & 0.195 \\
\hline Ratios & 1.251 & 1.149 & 1.000 & 0.830 & 0.664 & 0.518 & 0.404 & 0.322 \\
\hline
\end{tabular}

Ratios $=1.4013-0.0141 \cdot \eta$ 


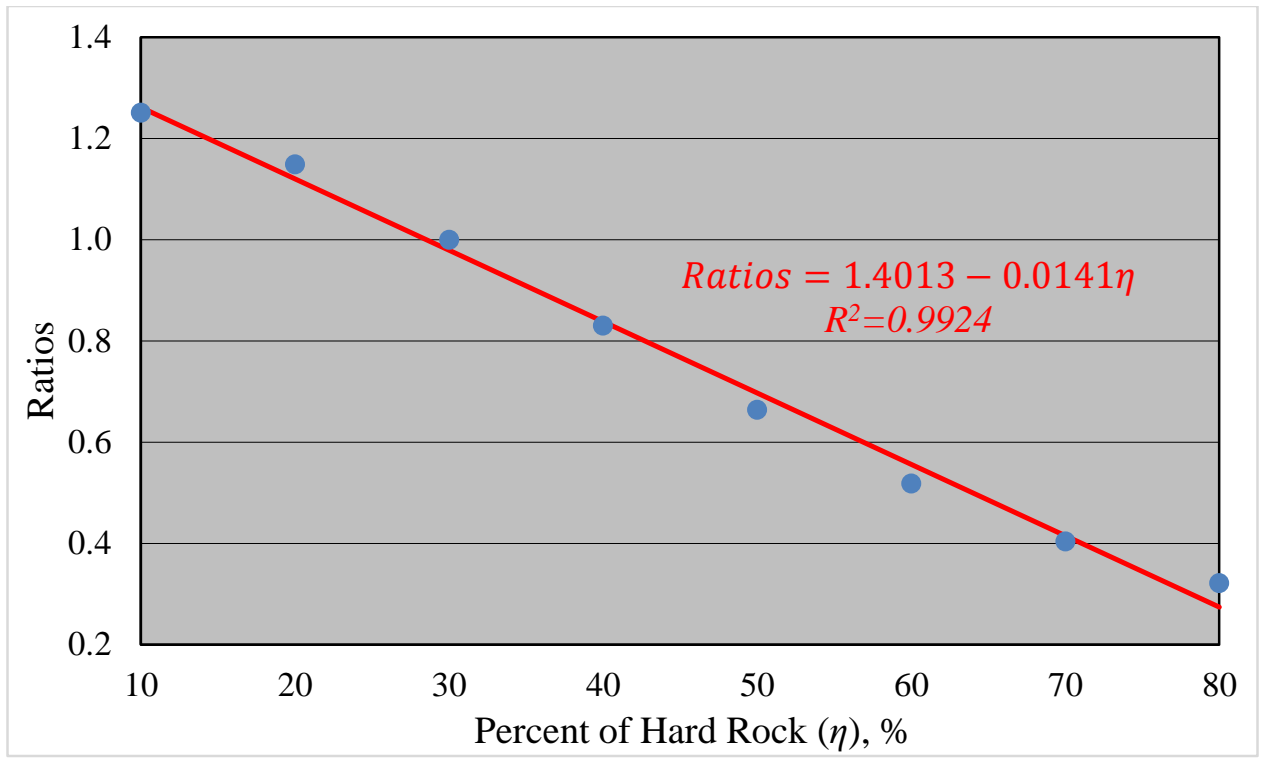

Figure 3.3 Linear regression for ratios and percent of hard rock

Combining Eqs. 2.13 and 3.6, a new empirical equation for determining the surface subsidence factor is resulted in Eq. 3.7 with considering the combination effect of the overburden depth and the percent of hard rock.

$$
a=1.9381(h+23.4185)^{-0.1884} \cdot(1.4013-0.0141 \cdot \eta)
$$

In Eq. 3.7, the percent of hard rock is an indicator of the stiffness of a strata group which also can be presented by the combination effect of the Protodyakonov Impact Strength Index (PISI) of each layer (Brook and Misra, 1970). The PISI for a given rock type is also an index of the stiffness of the rock, which is defined as one-tenth of its UCS in MPa. Therefore, an assumption is made that the numerical value of the percent of hard rock for a given layer is equal to the UCS of the rock type in the layer. If the UCS of a rock type is greater than $100 \mathrm{MPa}$, it forces the UCS to be $100 \mathrm{MPa}$. Through this strength approach, the hard rocks include not only sandstone and limestone but also hard shale. The modified equation for calculating the subsurface subsidence factor at the top surface of the $i^{\text {th }}$ layer is presented as: 


$$
a_{i}=1.9381\left(z_{i}+23.4185\right)^{-0.1884} \frac{\sum_{k=1}^{i} h_{k} \cdot\left(1.4013-0.0141 \cdot U C S_{k}\right)}{z_{i}}
$$

\subsubsection{Radius of major influence}

Based on the key strata theory, the entire overburden strata can be divided into several groups by the key strata. In each group, the major influence zone in each layer is treated as an overhanging beam model to determine the radius of major influence. The left end of the major influence zone of the $i^{\text {th }}$ layer is vertically restricted by an elastically fixed end, while the right end is restricted by the maximum possible subsidence on the top surface of the immediate underlying layer $S_{\max }\left(z_{i-1}\right)$ as shown in Fig. 3.4. For the first layer, the mining height is used as the deflection at the right end. The total load applied on the $i^{\text {th }}$ layer caused by the weight of the overlying layers up to the $m^{\text {th }}$ layer causes the $i^{\text {th }}$ layer to deflect. The maximum deflection of the $i^{\text {th }}$ layer can be determined using Eq. 3.9 based on the beam theory.

$$
S_{\max }\left(z_{i-1}\right)=\frac{3\left(\sum_{k=i}^{m} \gamma_{k} h_{k}\right) L_{i}^{4}}{2 E_{i} h_{i}^{3}}
$$

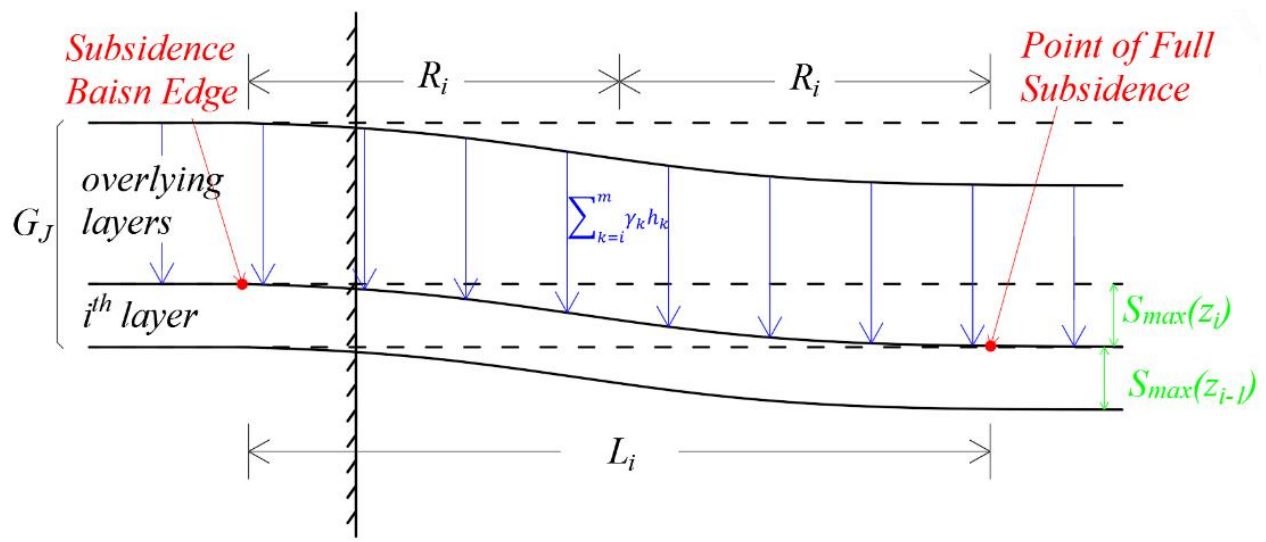

Figure 3.4 Determination of the radius of major influence.

In this equation, $L_{i}$ is the minimum length of the major influence zone that has the maximum deflection at the right end of $S_{\max }\left(z_{i-1}\right)$ under the overlying load. The radius of major influence 
of the $i^{\text {th }}$ layer is the half length of the major influence zone. Therefore, after adjusting Eq. 3.9, the proposed formula for radius of major influence for the $i^{\text {th }}$ layer is shown in Eq. 3.10.

$$
R_{i}=0.5\left(\frac{2 S_{\max }\left(z_{i-1}\right) E_{i} h_{i}^{3}}{3 \sum_{k=i}^{m} \gamma_{k} h_{k}}\right)^{0.25}
$$

However, due to the intensive mining disturbance to the caving zone, the radius of major influence of the rock strata in the caving zone has to be modified to fit the empirically derived values. The proposed empirical formula for the radius of major influence for the rock strata in the caving zone is shown as follows.

$$
R_{i}=\frac{z_{i}}{3} \cdot \frac{z_{i}}{\sum_{k=1}^{i} h_{k} \cdot\left(1.4013-0.0141 \cdot U C S_{k}\right)}
$$

\subsubsection{Offset distance of inflection point}

According to the assumption that the subsidence on the top surface of a given layer is the subsidence cause for the layer immediately above. The offset distance of inflection point of the $i^{\text {th }}$ layer was assumed as the summation of the offset distance of inflection point of each layer from the first up to the $i^{\text {th }}$ layer. Therefore, the following formula was derived to calculate the offset

distance of the inflection point $\left(d_{i}\right)$ of the $i^{t h}$ layer with considering the rock properties of the overburden strata (Luo and Peng, 2000).

$$
\frac{d_{i}}{z_{i}}=0.382075 \cdot 0.999253^{z_{i}} \frac{z_{i}}{\sum_{k=1}^{i} h_{k} \cdot\left(1.4013-0.0141 \cdot U C S_{k}\right)}
$$

It should be noted that the units for overburden depth $(h)$, layer thickness $\left(h_{i}\right)$, panel width $(W)$, vertical distance $\left(z_{i}\right)$, radius of major influence $\left(R_{i}\right)$ and offset distance of inflection point $\left(d_{i}\right)$ in the empirical equations $3.7,3.8,3.11$ and 3.12 are in feet $(\mathrm{ft})$ and $1 \mathrm{ft}=0.3048 \mathrm{~m}$. 


\subsection{Strength of Common Coal Measure Rocks}

Rock properties have been studied ever since the subject of rock mechanics began in the 1950s (Peng, 2008). Rock properties are generally considered to be representatives of rock types. Past experience shows that rock properties can vary considerably from sample to sample of the same rock type. Mark and Barton (1997) compiled more than 4,000 individual UCS tests of coals covering more than 60 seams and showed that the UCS varies with coal seam, ranging from 539 to 6,844 psi. Sun and Peng (1993) developed a rock properties data bank for common coal measure rocks. The data bank consists of data for more than 4,000 rock samples from 50 coal seams in 90 mines from all the coalfields in the US. The data bank shows the compressive strength of coal ranges from 500 to $9,900 \mathrm{psi}$, fireclay from 2,500 to $5,500 \mathrm{psi}$, shale from 50 to $16,000 \mathrm{psi}$, siltstone from 7,000 to 17,500 psi, sandstone from 3,000 to 24,000 psi, and limestone from 12,500 to 25,000 psi. In addition, it also shows that the average tensile strength for coal ranges from 40 to 1,000 psi, shale from 300 to 1,640 psi, and sandstone from 480 to 1,500 psi. It can be seen that the ranges of rocks' strength overlap each other and that the average strength in ascending order are fireclay, coal, shale, siltstone, sandstone and limestone. Luo (1989) classified the coal measure rocks into five common types (i.e., sandstone, limestone, shale, coal and clay). The relative hardness of each type of rock is divided into seven ranges (i.e., extremely hard, very hard, hard, regular, soft, very soft and extremely soft) with different UCS values.

In order to easily access of the strength of the common coal measure rocks and provide a reference for the program users, the uniaxial compressive strength (UCS in ksi) and tensile strength ( $T$ in ksi) of the common coal measure rocks are listed in Table 3.2 based on a similar classification method and the comprehensive consideration of the ranges of the coal measure rocks' strength 
extracted from previous studies. It should be noted that in addition to the five common rock types, the rock properties of siltstone are also listed in Table 3.2.

Table 3.2 Strength of the common coal measure rocks

\begin{tabular}{|c|c|c|c|c|c|c|c|}
\hline \multirow{2}{*}{\multicolumn{2}{|c|}{ Hardness }} & \multicolumn{6}{|c|}{ Type of Rock } \\
\hline & & \multirow{2}{*}{$\begin{array}{c}\text { Limestone } \\
>14.5\end{array}$} & \multirow{2}{*}{$\frac{\text { Sandstone }}{>12.8}$} & \multirow{2}{*}{$\begin{array}{c}\text { Siltstone } \\
>11.5\end{array}$} & \multirow{2}{*}{$\begin{array}{l}\text { Shale } \\
>10.0\end{array}$} & \multirow{2}{*}{$\frac{\text { Coal }}{>4.0}$} & \multirow{2}{*}{$\begin{array}{l}\text { Clay } \\
>2.7\end{array}$} \\
\hline Extremely & $U C S$ & & & & & & \\
\hline Hard & $T$ & $>3.6$ & $>3.0$ & $>2.2$ & $>1.6$ & $>1.0$ & $>0.5$ \\
\hline \multirow{2}{*}{ Very Hard } & $U C S$ & $13.3-14.5$ & $11.4-12.8$ & $10.0-11.5$ & $8.5-10.0$ & $3.5-4.0$ & $2.3-2.7$ \\
\hline & $T$ & $3.0-3.6$ & $2.52-3.0$ & $1.85-2.2$ & $1.35-1.6$ & $0.83-1.0$ & $0.42-0.5$ \\
\hline \multirow{2}{*}{ Hard } & $U C S$ & $11.9-13.3$ & $10.0-11.4$ & $8.9-10.0$ & $6.4-8.5$ & $3.0-3.5$ & $2.0-2.3$ \\
\hline & $T$ & $2.5-3.0$ & $2.05-2.52$ & $1.51-1.85$ & $1.09-1.35$ & $0.65-0.83$ & $0.34-0.42$ \\
\hline \multirow{2}{*}{ Regular } & $U C S$ & $10.6-11.9$ & $8.5-10.0$ & $7.3-8.9$ & $4.3-6.4$ & $2.5-3.0$ & $1.7-2.0$ \\
\hline & $T$ & $1.9-2.5$ & $1.5-2.05$ & $1.15-1.51$ & $0.83-1.09$ & $0.47-0.65$ & $0.26-0.34$ \\
\hline \multirow{2}{*}{ Soft } & $U C S$ & $9.2-10.6$ & $7.0-8.5$ & $6.0-7.3$ & $2.8-4.3$ & $1.5-2.5$ & $1.0-1.7$ \\
\hline & $T$ & $1.3-1.9$ & $1.04-1.5$ & $0.8-1.15$ & $0.56-0.83$ & $0.3-0.47$ & $0.18-0.26$ \\
\hline \multirow{2}{*}{ Very Soft } & $U C S$ & $7.8-9.2$ & $6.4-7.0$ & $4.7-6.0$ & $1.4-2.8$ & $1.0-1.5$ & $0.4-1.0$ \\
\hline & $T$ & $0.7-1.3$ & $0.58-1.04$ & $0.44-0.8$ & $0.3-0.56$ & $0.15-0.3$ & $0.1-0.18$ \\
\hline \multirow{2}{*}{$\begin{array}{c}\text { Extremely } \\
\text { Soft }\end{array}$} & $U C S$ & $<7.8$ & $<6.4$ & $<4.7$ & $<1.4$ & $<1.0$ & $<0.4$ \\
\hline & $T$ & $<0.7$ & $<0.58$ & $<0.44$ & $<0.3$ & $<0.15$ & $<0.1$ \\
\hline
\end{tabular}

\subsection{Case Study}

In order to demonstrate the enhanced subsurface subsidence prediction model, a subsidence case over two adjacent longwall panels in a shallow coal mine where surface and subsurface strata movements were monitored is presented. The mine site is in the north-central region of West Virginia. The overburden in the area rarely exceeds $300 \mathrm{ft}(91.4 \mathrm{~m})$ in the mountainous region and generally is about $110 \mathrm{ft}(33.5 \mathrm{~m})$ in the valleys. Each of the two adjacent longwall panels was 500 $\mathrm{ft}(152.4 \mathrm{~m})$ wide and 3,550 ft $(1,082 \mathrm{~m})$ long. The redstone coal seam was extracted with the average mining height being about $6.0 \mathrm{ft}(1.83 \mathrm{~m})$. Two vertical boreholes (BH1 and $\mathrm{BH} 2)$ were drilled, before mining, along the center line over the two longwall panels to the coal seam or immediate roof as shown in Fig. 3.5. The overburden depths at BH1 and BH2 were $211 \mathrm{ft}(64.3 \mathrm{~m})$ 
and $215 \mathrm{ft}(65.5 \mathrm{~m})$, respectively. The distances of the boreholes from the panel setup were $700 \mathrm{ft}$ (275 m) and $2500 \mathrm{ft}(762 \mathrm{~m})$, respectively (Khair, 1987).
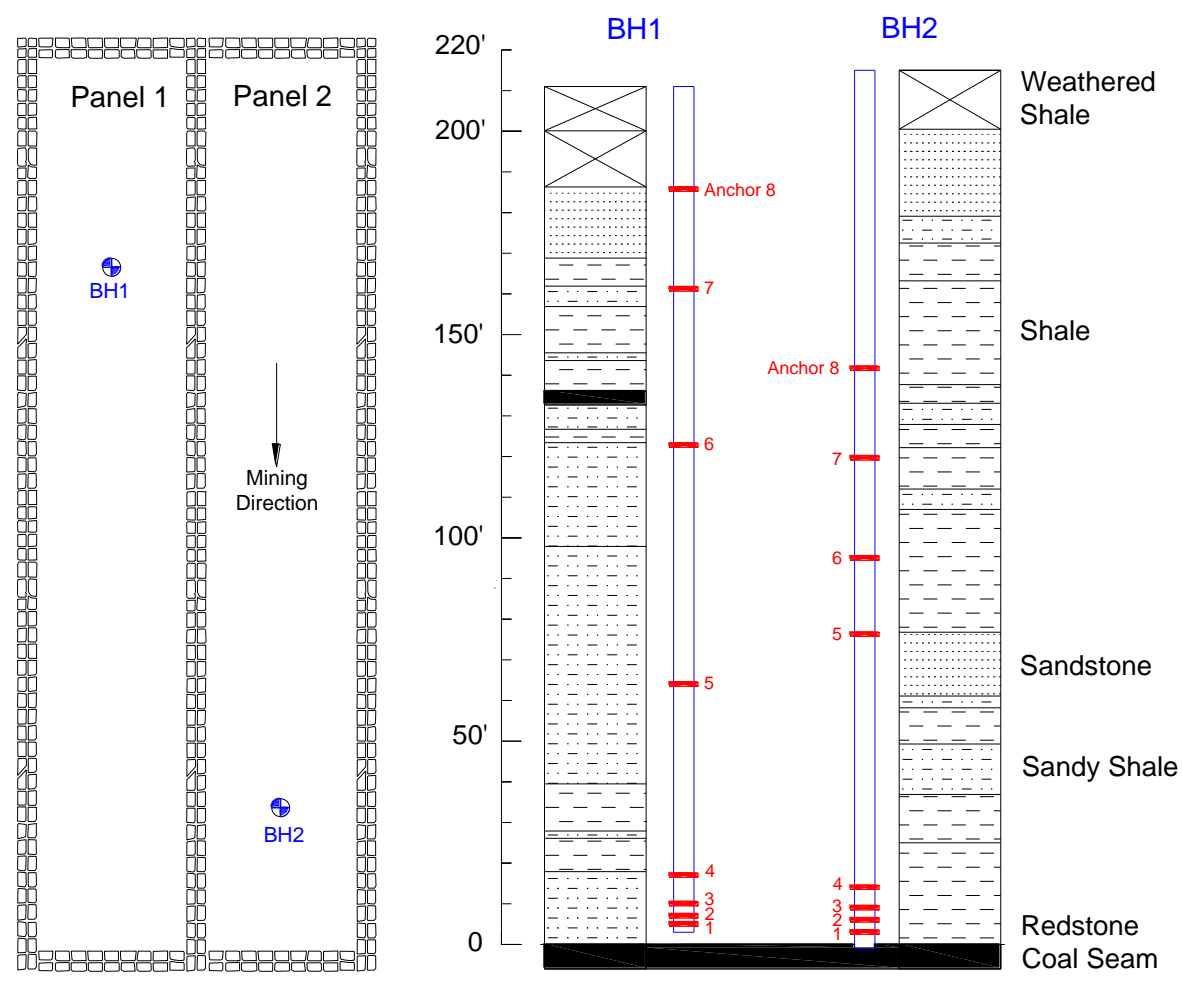

Figure 3.5 Longwall layout showing the location of the boreholes (left) and stratigraphic section at the borehole site with the mechanical anchors (right) (Plot Not to Scale)

The subsurface strata movements were measured by the multi-wire borehole instrumentation system consisting of mechanical anchors installed at different horizons in the boreholes between surface and coal seam. The general information about each of the anchors for each borehole are shown in Table 3.3 and also plotted in Fig. 3.5. The geological stratification of the overburden with respective rock properties at the borehole are listed in Table 3.4 and also plotted in Fig. 3.5. The overburden strata consist of an interbedded succession of sandy shale, shale, weathered shale and sandstone, making up roughly $51.4 \%, 24.1 \% 13.4 \%$ and $11.1 \%$, respectively at the borehole 
BH1. These rock types were found to be $19.9 \%, 59.3 \%, 5.1 \%$ and $15.7 \%$, respectively at the borehole BH2. The immediate roof of the Redstone Coal seam consists of shale and sandy shale while the floor is the Weston Sandstone formation.

Table 3.3 Relative height of each anchor in $\mathrm{BHl}$ and $\mathrm{BH} 2$ with respect to the Redstone Coalbed

\begin{tabular}{|ccccc|}
\hline $\begin{array}{c}\text { Anchor No. } \\
\text { in BH1 }\end{array}$ & $\begin{array}{c}\text { Height Above } \\
\text { Coal Seam (ft) }\end{array}$ & $\begin{array}{c}\text { Measured Sub- } \\
\text { sidence (ft) }\end{array}$ & $\begin{array}{c}\text { Predicted Sub- } \\
\text { sidence (ft) }\end{array}$ & $\begin{array}{c}\text { Difference } \\
\text { (ft) }\end{array}$ \\
1 & 5 & 4.63 & 5.91 & $27.5 \%$ \\
2 & 7 & 4.48 & 5.87 & $30.9 \%$ \\
3 & 10 & 4.38 & 5.81 & $32.8 \%$ \\
4 & 17 & 4.32 & 5.68 & $31.6 \%$ \\
5 & 64 & 4.18 & 4.78 & $14.3 \%$ \\
6 & 119 & 4.05 & 4.41 & $8.9 \%$ \\
7 & 156 & 4.01 & 4.20 & $4.9 \%$ \\
8 & 179 & 3.98 & 4.00 & $0.7 \%$ \\
Surface & 211 & 3.97 & 3.90 & $-1.7 \%$ \\
\hline & & & & \\
Anchor No. & Height Above & Measured Sub- & Predicted Sub- & Difference \\
in BH2 & Coal Seam (ft) & sidence (ft) & sidence (ft) & (ft) \\
1 & & & & $-11.2 \%$ \\
2 & 3 & 6.62 & 5.87 & $-4.5 \%$ \\
3 & 6 & 6.02 & 5.75 & $-1.4 \%$ \\
4 & 9 & 5.70 & 5.62 & $-0.3 \%$ \\
5 & 14 & 5.43 & 5.41 & $3.4 \%$ \\
6 & 75 & 3.99 & 4.13 & $6.2 \%$ \\
7 & 95 & 3.76 & 3.99 & $5.0 \%$ \\
8 & 116 & 3.73 & 3.92 & $-2.8 \%$ \\
Surface & 138 & 3.66 & 3.85 & 3.51 \\
\hline
\end{tabular}

To perform the subsurface subsidence prediction using the new program, the key layers in the overburden should be determined first using the approach stated in the "Algorithm for Determining Key Strata" section. It was determined that there is one and two key layers in the overburden over longwall panels 1 and 2, respectively, as shown in Table 3.4. For the key layer over panel 1, the layer is No. 5 and the rock mass is sandy shale with the thickness of $58.4 \mathrm{ft}(17.8 \mathrm{~m})$, UCS of $4.5 \times 10^{3}$ Psi (31 MPa) and elasticity modulus of $1.5 \times 10^{6} \mathrm{Psi}(10.3 \mathrm{GPa})$. While for the two key layers over panel 2, the layers are Nos. 6 and 7. The layer No. 6 consists of sandstone with the 
thickness of $15.6 \mathrm{ft}$ (4.8 m), UCS of $9.3 \times 10^{3}$ Psi (64 MPa) and elasticity modulus of $2.8 \times 10^{6}$ Psi (19.3 GPa) while the layer No. 7 is composed of shale with the thickness of $30.2 \mathrm{ft}(9.2 \mathrm{~m})$, UCS of $5.4 \times 10^{3}$ Psi (37.2 MPa) and elasticity modulus of $1.1 \times 10^{6} \mathrm{Psi}(7.6 \mathrm{GPa})$. Although sandy shale and shale in the key layers have relatively lower UCS and elasticity modulus compared to sandstone, the combined effect of large thicknesses and their respective rock properties would result in stronger bridging effects than the sandstone strata of Nos. 15 and 16 over panels 1 and 2, respectively. The thick sandy shale and shale key layers could cause little influence on the surrounding layers in the previous model because they do not contribute any percent of hard rocks in a layer, while in the new model they serve as the key layers in the overburden. The key layers control the movements of the weak layers overlying them while the first key layer will be collapsed into the void created after the coal seam extracted.

In the new program, the proposed empirical equations are used to determine the final subsurface subsidence parameters at the top of each layer. Substituting the calculated final subsurface subsidence parameters into the influence functions, integrating the subsidence influence functions within the two inflection points of each layer will result in the final movements at a point on the top of a given layer. Using this approach progressively from first strata layer upward to ground surface, the complete distribution of final subsurface movements and deformations can be obtained. The profiles of the predicted final subsidence on the top surface of the overburden strata over two panels are plotted in Fig. 3.6.

Due to the symmetrical nature of the subsidence profiles along a given panel transverse cross-section, only one half of the subsidence profiles are plotted over the two longwall panels in the figure. In order to make prediction readable, the predicted subsidence for each layer was exaggerated by five times when Fig. 3.6 was plotted. 
Table 3.4 Geological stratification of overburden with rock properties

\begin{tabular}{|c|c|c|c|c|c|c|c|c|}
\hline \multicolumn{9}{|c|}{ BH1 } \\
\hline $\begin{array}{l}\text { Layer } \\
\text { No. }\end{array}$ & Rock Type & $\begin{array}{l}\text { Thickness } \\
\text { (ft) }\end{array}$ & $\begin{array}{c}\text { Depth } \\
\text { (ft) }\end{array}$ & $\begin{array}{l}\text { UCS } \\
\text { (Psi) }\end{array}$ & $\begin{array}{l}\text { Elasticity } \\
\text { Modulus } \\
\quad \text { (Psi) }\end{array}$ & $\begin{array}{l}\text { Specific } \\
\text { Weight } \\
\text { (Psi/ft) }\end{array}$ & $\begin{array}{c}\text { Tensile } \\
\text { Strength } \\
\text { (Psi) }\end{array}$ & $\begin{array}{c}\text { Key } \\
\text { Layer }\end{array}$ \\
\hline 17 & Weathered Shale & 10.9 & 10.9 & $2.1 \mathrm{E}+03$ & $5.0 \mathrm{E}+01$ & 0.69 & $3.7 \mathrm{E}+02$ & \\
\hline 16 & Weathered Shale & 13.8 & 24.7 & $2.1 \mathrm{E}+03$ & $5.0 \mathrm{E}+01$ & 0.69 & $3.7 \mathrm{E}+02$ & \\
\hline 15 & Sandstone & 17.5 & 42.2 & $9.3 \mathrm{E}+03$ & $2.8 \mathrm{E}+06$ & 1.11 & $1.2 \mathrm{E}+03$ & \\
\hline 14 & Shale & 6.9 & 49.1 & $5.4 \mathrm{E}+03$ & $1.1 \mathrm{E}+06$ & 1.11 & $9.4 \mathrm{E}+02$ & \\
\hline 13 & Sandy Shale & 5.0 & 54.1 & $4.5 E+03$ & $1.5 \mathrm{E}+06$ & 1.08 & $7.0 \mathrm{E}+02$ & \\
\hline 12 & Shale & 11.4 & 65.6 & $5.4 \mathrm{E}+03$ & $1.1 \mathrm{E}+06$ & 1.11 & $9.4 \mathrm{E}+02$ & \\
\hline 11 & Sandy Shale & 1.9 & 67.5 & $4.5 E+03$ & $1.5 E+06$ & 1.08 & $7.0 \mathrm{E}+02$ & \\
\hline 10 & Shale & 7.5 & 75.0 & $5.4 \mathrm{E}+03$ & $1.1 \mathrm{E}+06$ & 1.11 & $9.4 \mathrm{E}+02$ & \\
\hline 9 & Coal & 3.4 & 78.4 & $2.7 \mathrm{E}+03$ & $9.0 \mathrm{E}+05$ & 0.63 & $5.7 \mathrm{E}+02$ & \\
\hline 8 & Sandy Shale & 6.0 & 84.4 & $4.5 E+03$ & $1.5 \mathrm{E}+06$ & 1.08 & $7.0 \mathrm{E}+02$ & \\
\hline 7 & Shale & 3.3 & 87.7 & $5.4 \mathrm{E}+03$ & $1.1 \mathrm{E}+06$ & 1.11 & $9.4 \mathrm{E}+02$ & \\
\hline 6 & Sandy Shale & 25.5 & 113.1 & $4.5 \mathrm{E}+03$ & $1.5 \mathrm{E}+06$ & 1.08 & $7.0 \mathrm{E}+02$ & \\
\hline 5 & Sandy Shale & 58.4 & 171.6 & $4.5 \mathrm{E}+03$ & $1.5 \mathrm{E}+06$ & 1.08 & $7.0 \mathrm{E}+02$ & Key \\
\hline 4 & Shale & 11.6 & 183.2 & $5.4 \mathrm{E}+03$ & $1.1 \mathrm{E}+06$ & 1.11 & $9.4 \mathrm{E}+02$ & \\
\hline 3 & Sandy Shale & 1.8 & 185.0 & $4.5 E+03$ & $1.5 \mathrm{E}+06$ & 1.08 & $7.0 \mathrm{E}+02$ & \\
\hline 2 & Shale & 8.2 & 193.2 & $5.4 \mathrm{E}+03$ & $1.1 \mathrm{E}+06$ & 1.11 & $9.4 \mathrm{E}+02$ & \\
\hline 1 & Sandy Shale & 17.8 & 211.0 & $4.5 \mathrm{E}+03$ & $1.5 \mathrm{E}+06$ & 1.08 & $7.0 \mathrm{E}+02$ & \\
\hline & Coal & 6.0 & 217.0 & $2.7 \mathrm{E}+03$ & $9.0 \mathrm{E}+05$ & 0.63 & $5.7 \mathrm{E}+02$ & \\
\hline \multicolumn{9}{|c|}{ BH2 } \\
\hline $\begin{array}{l}\text { Lay- } \\
\text { erNo. }\end{array}$ & Rock Type & $\begin{array}{l}\text { Thickness } \\
\text { (ft) }\end{array}$ & $\begin{array}{c}\text { Depth } \\
\text { (ft) }\end{array}$ & UCS (Psi) & $\begin{array}{l}\text { Elasticity } \\
\text { Modulus } \\
\text { (Psi) }\end{array}$ & $\begin{array}{l}\text { Specific } \\
\text { Weight } \\
\text { (Psi/ft) }\end{array}$ & $\begin{array}{c}\text { Tensile } \\
\text { Strength } \\
\text { (Psi) }\end{array}$ & $\begin{array}{c}\text { Key } \\
\text { Layer }\end{array}$ \\
\hline 17 & Weathered Shale & 14.5 & 14.5 & $2.1 \mathrm{E}+03$ & $5.0 \mathrm{E}+01$ & 0.69 & $3.7 \mathrm{E}+02$ & \\
\hline 16 & Sandstone & 21.4 & 35.9 & $9.3 \mathrm{E}+03$ & $2.8 \mathrm{E}+06$ & 1.11 & $1.2 \mathrm{E}+03$ & \\
\hline 15 & Sandy Shale & 6.6 & 42.5 & $4.5 \mathrm{E}+03$ & $1.5 \mathrm{E}+06$ & 1.08 & $7.0 \mathrm{E}+02$ & \\
\hline 14 & Shale & 9.3 & 51.8 & $5.4 \mathrm{E}+03$ & $1.1 \mathrm{E}+06$ & 1.11 & $9.4 \mathrm{E}+02$ & \\
\hline 13 & Shale & 25.5 & 77.3 & $5.4 \mathrm{E}+03$ & $1.1 \mathrm{E}+06$ & 1.11 & $9.4 \mathrm{E}+02$ & \\
\hline 12 & Shale & 4.6 & 81.9 & $5.4 \mathrm{E}+03$ & $1.1 \mathrm{E}+06$ & 1.11 & $9.4 \mathrm{E}+02$ & \\
\hline 11 & Sandy Shale & 5.2 & 87.1 & $4.5 \mathrm{E}+03$ & $1.5 \mathrm{E}+06$ & 1.08 & $7.0 \mathrm{E}+02$ & \\
\hline 10 & Shale & 5.7 & 92.8 & $5.4 \mathrm{E}+03$ & $1.1 \mathrm{E}+06$ & 1.11 & $9.4 \mathrm{E}+02$ & \\
\hline 9 & Shale & 10.3 & 103.0 & $5.4 \mathrm{E}+03$ & $1.1 \mathrm{E}+06$ & 1.11 & $9.4 \mathrm{E}+02$ & \\
\hline 8 & Sandy Shale & 5.0 & 108.0 & $4.5 \mathrm{E}+03$ & $1.5 \mathrm{E}+06$ & 1.08 & $7.0 \mathrm{E}+02$ & \\
\hline 7 & Shale & 30.2 & 138.2 & $5.4 \mathrm{E}+03$ & $1.1 E+06$ & 1.11 & $9.4 \mathrm{E}+02$ & Key \\
\hline 6 & Sandstone & 15.6 & 153.9 & $9.3 \mathrm{E}+03$ & $2.8 E+06$ & 1.11 & $1.2 \mathrm{E}+03$ & Key \\
\hline 5 & Sandy Shale & 3.0 & 156.8 & $4.5 \mathrm{E}+03$ & $1.5 \mathrm{E}+06$ & 1.08 & $7.0 \mathrm{E}+02$ & \\
\hline 4 & Shale & 8.9 & 165.7 & $5.4 \mathrm{E}+03$ & $1.1 \mathrm{E}+06$ & 1.11 & $9.4 \mathrm{E}+02$ & \\
\hline 3 & Sandy Shale & 12.4 & 178.1 & $4.5 \mathrm{E}+03$ & $1.5 \mathrm{E}+06$ & 1.08 & $7.0 \mathrm{E}+02$ & \\
\hline 2 & Shale & 11.9 & 190.0 & $5.4 \mathrm{E}+03$ & $1.1 \mathrm{E}+06$ & 1.11 & $9.4 \mathrm{E}+02$ & \\
\hline \multirow[t]{2}{*}{1} & Shale & 25.0 & 215.0 & $5.4 \mathrm{E}+03$ & $1.1 \mathrm{E}+06$ & 1.11 & $9.4 \mathrm{E}+02$ & \\
\hline & Coal & 6.0 & 221.0 & $2.7 \mathrm{E}+03$ & $9.0 \mathrm{E}+05$ & 0.63 & $5.7 \mathrm{E}+02$ & \\
\hline
\end{tabular}

It is apparent that the subsidence profiles formed at all layers exhibit the supercritical nature of the flat basin bottom as the panels have high width-to-depth ratios of 2.37 and 2.33, respectively, significantly higher than critical width of 1.2 times of depth (Peng, 1992). The predicted subsurface 
subsidence phenomenon that the closer the layer is to the coal seam, the larger differential subsidence at the panel edge and the wider the flat bottom portion will be, is consistent with the actual situation. In order to demonstrate the applicability and improvement of the new program, the predicted subsurface subsidence was compared with the measured subsurface subsidence at the locations of the installed mechanical anchors in the boreholes drilled over the center of the longwall panels.
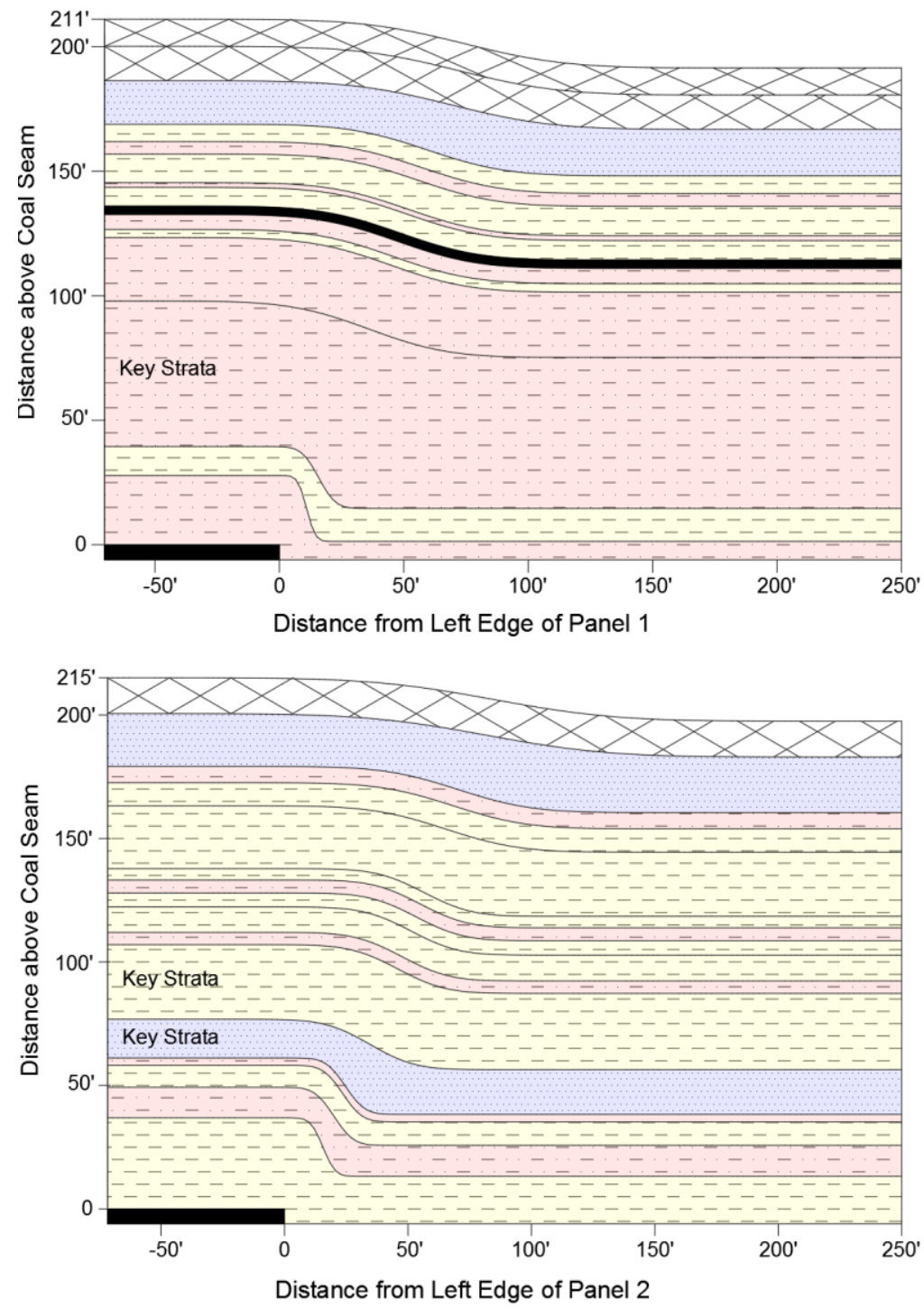

Figure 3.6 Final subsurface subsidence profiles formed at different levels above the longwall panel 1 (Top) and panel 2 (Bottom). 
In each borehole, 8 anchors were installed at different levels above the coal seam to measure the lowering of the subsurface strata with respect to the ground surface at the hole. By adding the measured surface subsidence at the locations of boreholes, the subsurface subsidence in a borehole at different anchor points can be determined. The predicted and measured subsidence as well as the relative error at each anchor point in each borehole are listed in Table 3.3. It should be noted that the lowest four anchor points in each borehole were very close to the coal seam and should be located in the caving zone. Due to the intensive caving process after longwall face retreated, the rock wall of the borehole could have been heavily fractured and unable to anchor the measurement points. The slippage of the anchors in the caving zone resulted in inaccurate measured strata subsidence and caused the prediction errors. The fact that the measured subsidence at anchor \#1 in BH1 (only $5.0 \mathrm{ft}$ or $1.5 \mathrm{~m}$ above the mined coal seam), $4.63 \mathrm{ft}(1.41 \mathrm{~m})$, is unreasonably small compared to the mining height of $6 \mathrm{ft}$ also indicates the occurrence of anchor slippage in the lower strata. Same can be observed from the measured subsidence at anchor \#1 in BH2 of $6.62 \mathrm{ft}$ (2.02 $\mathrm{m})$ even exceeding the mining height of $6 \mathrm{ft}(1.83 \mathrm{~m})$. Therefore, the inaccurate measurements have resulted in the relatively large errors for those anchors in the caving zone. However, for the anchors \#5 to \#8 above the caving zone, the predicted final subsurface subsidence matched very well with the measured ones in both boreholes. Figure 3.6 also shows the changes of the major influence zone where most deformations occur at different levels above the coal seam. The bridging effects of the identified key strata on altering the upward propagation of the strata movements as well as the shape changes in the influence zones can be also observed from the graphs.

Based on Eq. 2.31, the predicted final total strain in the overburden is plotted in Fig. 3.7. In the figure, the total strain distribution patterns vary considerably in locations of thick and hard 
key layers at the depths from 30 to $80 \mathrm{ft}(9.1$ to $24.4 \mathrm{~m})$ above the coal seam for the panel 1 and at the depths from 65 to $85 \mathrm{ft}$ (19.8 to $25.9 \mathrm{~m}$ ) above the coal seam for the panel 2 .
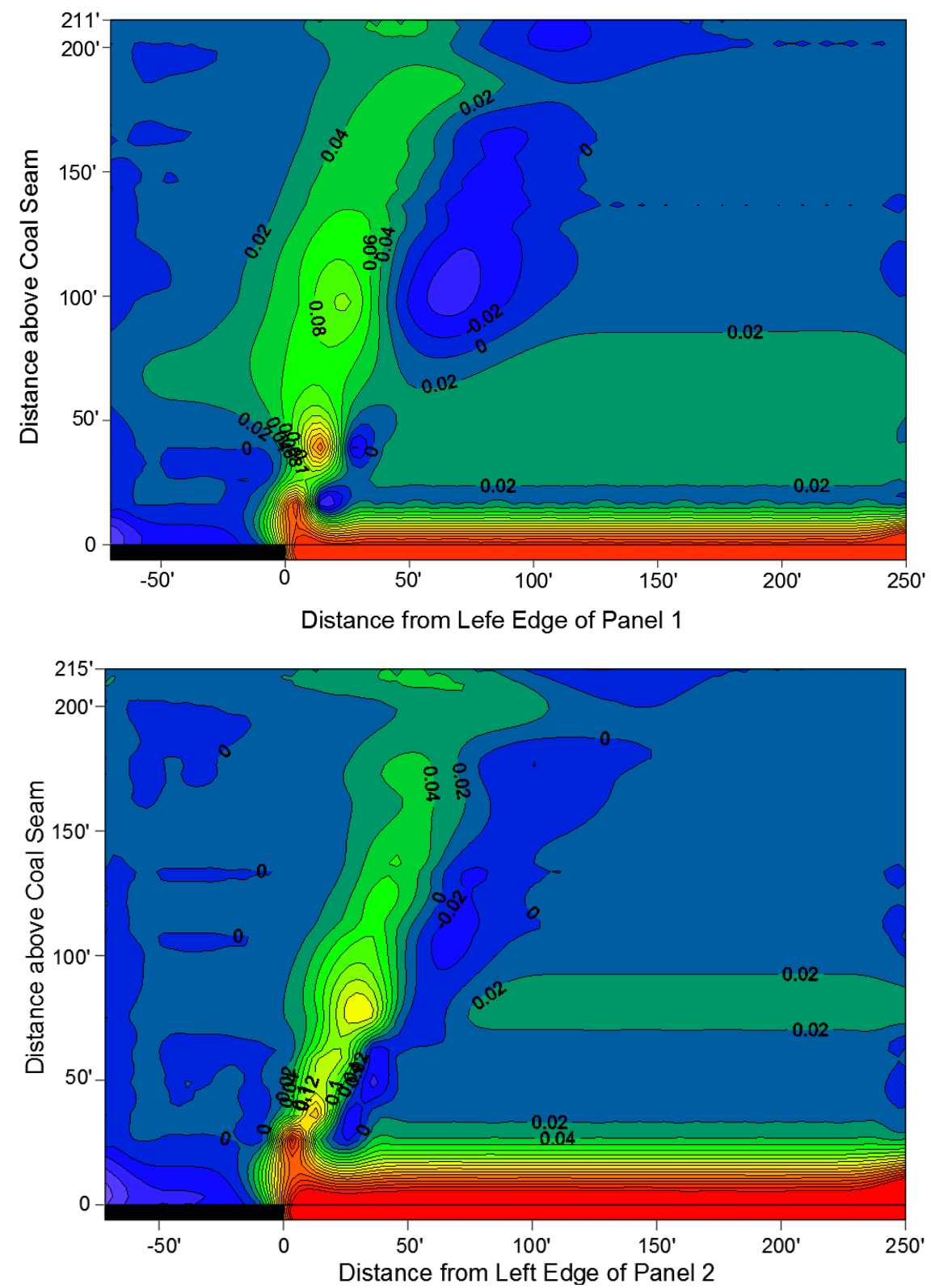

Figure 3.7 Distribution of final subsurface void intensity above the longwall panel 1 (top) and panel 2 (bottom).

It can be seen that the magnitude and distribution ranges of subsidence-induced total compressive strain (in cool colors) are smaller than that of total tensile strain (in warm colors). An Lshaped total tensile strain zone formed over the half side of the panel with its turning point being 
located a short distance inside the panel edge. Along the horizontal direction, a zone of very high total tensile strain (red color) is located in the immediate roof strata coincident with the caving zone. This zone extends much higher into the overburden strata near the panel edge than that in the central part. On the vertical direction, the zone of total tensile strain skewed toward the panel center. The harder the overburden strata are, the larger the skew angle will be. This vertical tensile zone is the main passage for water seepage from underground aquifers or even surface water bodies and for escapeway of coalbed methane.

The presence of the thick and hard rock strata close to the ground surface will prevent the high total strains developed in the underlying weak layers from propagating directly upward while spreading them in a larger area. When the presence of thick and hard rock strata close to the coal seam, the high total strains developed in the underlying weak layers can propagate and enlarge into the hard rock strata due to the breakage and collapse of the hard rock strata caused by intensive mining disturbance.

\subsection{Summaries}

In order to accurately predict subsurface strata movements and deformations induced by underground longwall mining operations, a new subsurface subsidence prediction model considering variations of lithology and key strata effects on subsurface strata movements and deformations is developed. An algorithm is presented to determine the key strata in the overburden using the input rock properties of each layer. The key strata serve as the backbone of the overburden and control the movements of the weak layers located above them. The overburden strata can be subdivided into several groups of composite beams according to the number of the key strata with each group consisting of a key layer at the bottom and several weak layers overlying it.

The versatile influence function method was employed in this model to predict subsurface strata movements and deformations layer by layer from the mine level to the ground surface. A set 
of empirical formulas were derived for determining the required final subsurface subsidence parameters (i.e., subsidence factor, offset distance of inflection point, radius of major influence) at the top surface of each layer.

The new program was validated with subsurface subsidence data measured in two boreholes over two longwall panels using multi-wire extensometer method with the anchors being attached to the borehole wall at different levels above the mined coal seam. Other than the apparent measurement errors at four anchors in the caving zone due to lost anchorage, the predicted subsurface subsidence agreed well with the measured ones for the remaining anchors and ground surface. The total strain distribution field, useful for estimating the mining impacts to subsurface structures, water bodies and coalbed methane, in the overburden strata produced by the new prediction model can clearly show the effects of the thick and hard key strata to the ground subsidence process. 


\section{CHAPTER 4 TECHNIQUES FOR ASSESSING AND MITIGATING LONGWALL SUBSIDENCE EFFECTS ON INTERSTATE HIGH- WAYS}

\subsection{Introduction}

The US interstate highway system has a total length of 48,191 miles $(77,556 \mathrm{~km})$ and connects 48 contiguous states as of 2016. The official statistics show that about one-quarter of all vehicle miles driven in the country use the interstate highway system (OHPI, 2017). The annual average daily traffic on interstate highway I-70 is 36,846 for 2017 (PADOT, 2017). Therefore, the interstate highway system is one of the most important transportation modes in US. The full length of I-79 goes through the bituminous region of the state of Pennsylvania and the area with mineable coal in the state of West Virginia. I-70 also goes over coal basins with old and active underground coal mines in many states. There are many cases in which underground mining operations have been conducted beneath interstate highways in the past. Surface subsidence associated with underground mining activities, especially active longwall mining operations, can cause significant problems to interstate highways including structural integrity, drivability and driving safety. The difference between mining that occurred years ago and current-day longwall mining is that subsidence may occur from the old mining at any time and without warning, whereas subsidence from longwall mining is planned, controlled, and predictable, allowing highway engineers to address the impacts from subsidence as it occurs. Unplanned subsidence can create road hazards when they are least expected. It would be advisable for highway engineers to investigate old mine maps to determine if hazards exist from abandoned underground mines. 
In order to reduce the impacts on highway structures and traffic, accurate subsidence prediction is the first and most important step. Based on accurate subsidence prediction, the subsidence influences on the highway can be assessed correctly and effective mitigation measures can be designed and implemented to reduce the severity of the anticipated problems. In this chapter, the effects of subsidence-induced surface movements and deformations on highway structures, vehicle dynamics and drivability are analyzed. A section of interstate highway is used as a case study for demonstrating the developed techniques and mitigation measures.

\subsection{Subsidence Influence on Highways}

Common sense indicates that a lower speed limit makes driving safer but results in a lower traffic volume and a longer traveling time. In the US, the maximum speed limits on most interstate highways are designed between 60 and $80 \mathrm{mph}$ (AASHTO, 2001). In the past, the posted speed limits on most of the interstate highways are less than the designed ones. A trend to increase the speed limits has been observed in many states recently due to the lower fuel costs, higher engine energy efficiency, better technologies for improving driving safety, and more efficient traffic regulation enforcement, etc. Based on the dynamics of a moving vehicle, a series of design criteria such as the maximum grade, minimum stopping sight distance and maximum superelevation rate, etc. have been established and used in the highway designs (AASHTO, 2001). However, the potential effects of mine subsidence, especially the large movements and deformations induced by longwall mining operations, are not considered in the original design of the highways. In this section, the methods to assess and mitigate the influence of longwall subsidence on highways and the dynamics of a moving vehicle are presented. 


\subsubsection{Effects of Subsidence-Induced Slope}

The effects of subsidence-induced slope have two kinds of impacts on highways: one is on the vertical alignment while the other on the horizontal alignment. Specifically, the subsidenceinduced slope changes the gradients along the highway axial direction and the superelevation rates along its transverse direction after imposing the subsidence-induced slope on its original axial and transverse elevation profiles.

The subsidence-induced surface slope along the highway axial direction could significantly increase the grade of the highway, which could increase the minimum stopping distance of a travelling vehicle. Depending on overburden depth and mining height, the maximum subsidenceinduced slope over the US longwall mines ranges from $1 \%$ to $7 \%$ with most being less than $3 \%$. The maximum slope occurs at the inflection point of the formed subsidence basins or a distance of around 0.2 times of the overburden depth inside the panel edge as shown in Fig. 4.1. The worst slope influence to the highway grade is when the titling direction of the subsidence-induced slope (i) coincides with that of the original highway grade $(g)$ as shown in Fig. 4.1a. During a vehicle's braking process on a sloping road of $g+i$, not only the traction force between the road surface and the tires, which is the product of normal force $(N)$ and friction coefficient $(f)$, is reduced but also an additional forward driving force of $F$ is generated in comparison to that on a level road. The friction coefficient $(f)$ between the tires and road surface plays an important role in controlling vehicle and can be back-calculated by the achieved deceleration rate $(a)$. Professional drivers frequently achieve deceleration of $32 \mathrm{ft} / \mathrm{s}^{2}\left(9.75 \mathrm{~m} / \mathrm{s}^{2}\right)$ or better while a reasonably skilled driver could easily get deceleration rates in excess of $20 \mathrm{ft} / \mathrm{s}^{2}\left(6.10 \mathrm{~m} / \mathrm{s}^{2}\right)$ without loss of control (NACTO, 2020). However, a very conservative rate of $10 \mathrm{ft} / \mathrm{s}^{2}\left(3.05 \mathrm{~m} / \mathrm{s}^{2}\right)$ is often used in highway design (AASHTO, 2001). Using these documented deceleration rates, the friction coefficient can be 
back-calculated as $1.000,0.625$ and 0.313 for the drivers with the three mentioned different skill levels, respectively.

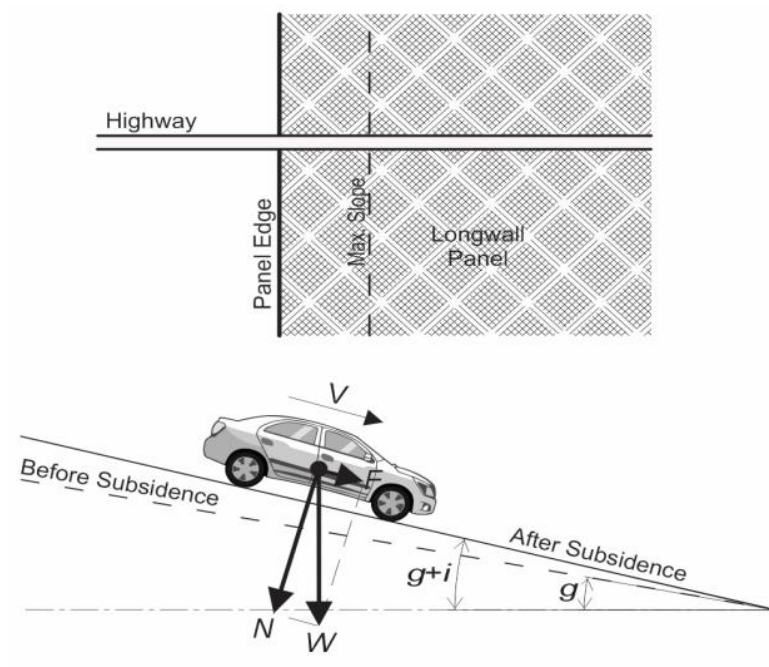

(a)
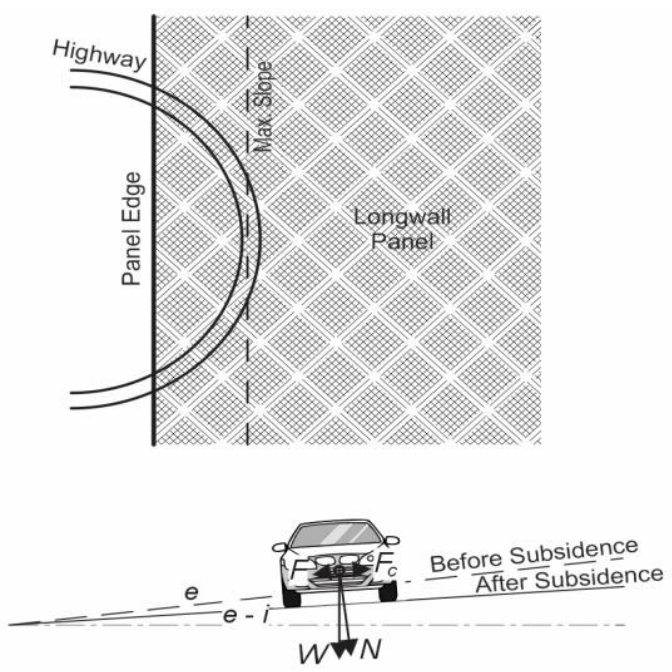

(b)

Figure 4.1 Effect of subsidence-induced slope on vehicle dynamics

Based on the analysis of vehicle dynamics, the ratio of the effective braking force on a sloping road to that on level road $(\rho)$ can be determined by Eq. 4.1. For example, when a vehicle travelling on a road with an $8 \%$ grade and a friction coefficient of 0.313 , the effective braking force is only about $75 \%$ of that on a level road. The reduced effective braking force means to require a longer minimum distance to stop a moving vehicle $\left(L_{m i n}\right)$ travelling at a speed of $V$ mph as shown in Eq. 4.2. For example, it takes a minimum distance of $282 \mathrm{ft}(86 \mathrm{~m})$ or time of 5.5 seconds to completely stop a vehicle driven by a reasonably skilled driver at a speed of $70 \mathrm{mph}$ $(112.7 \mathrm{kph})$ on a road with a down grade of $g=4 \%$. If an average subsidence-induced slope $i=$ $4 \%$ is added on the highway, the minimum stopping distance and time become $303 \mathrm{ft}$ (92 $\mathrm{m}$ ) or 5.9 seconds, respectively. When the other things are equal it requires a minimum distance of 264 $\mathrm{ft}(80 \mathrm{~m})$ or time of 5.1 seconds to stop the vehicle on a level road. It should be noted that the unit of the speed $V$ in the following empirical equation is in $\mathrm{mph}(1 \mathrm{mph}=1.61 \mathrm{~km} / \mathrm{h})$. 


$$
\begin{aligned}
& \rho=\frac{f \cdot \cos (g+i)-\sin (g+i)}{f} \\
& L_{\text {min }}=\frac{0.0336 V^{2}}{f \cdot \cos (g+i)-\sin (g+i)}
\end{aligned}
$$

Based on the AASHTO standard, the maximum design grades along the axial direction for rural and urban highways are presented in Table 4.1 (AASHTO, 2001). The tolerance for maximum grades increases with more rugged terrain while decreases for higher speed limit.

Table 4.1 Maximum grades along the axial direction for rural and urban highways (AASHTO, 2001)

\begin{tabular}{|c|c|c|c|c|c|c|c|c|}
\hline \multirow{2}{*}{ Type of Terrain } & \multicolumn{7}{|c|}{ Design Speed (V), mph } \\
\cline { 2 - 8 } & 50 & 55 & 60 & 65 & 70 & 75 & 80 \\
\cline { 2 - 8 } & \multicolumn{7}{|c|}{ Maximum Grade $(\boldsymbol{g})$, percent } \\
\hline Level & 4 & 4 & 3 & 3 & 3 & 3 & 3 \\
\hline Rolling & 5 & 5 & 4 & 4 & 4 & 4 & 4 \\
\hline Mountainous & 6 & 6 & 6 & 5 & 5 & N/A & N/A \\
\hline
\end{tabular}

It should be noted that during the active longwall subsidence process (about 15 days in typical US mining conditions) it is nearly impossible to repair a section of subsiding highway back to its original condition. The best approach to ensure a safe driving condition before the subsided highway is repaired is to reduce the speed limit and strictly enforce it. Under such condition, a lower speed limit can be determined based on the superimposed grade. For example, for a section of highway in mountainous area with a design speed of $70 \mathrm{mph}(112.7 \mathrm{~km} / \mathrm{h})$ and grade of $5 \%$, if a $1 \%$ subsidence-induced slope is added, the speed limit could be lowered to $50 \mathrm{mph}(80.5 \mathrm{~km} / \mathrm{h})$ based on Table 4.1.

To design a section of highway with a horizontal curve, a superelevation or banking is added on the transverse direction of the roadway so the centrifugal force $F_{c}$ to be experienced by a moving vehicle can be partially compensated by the leaning force $F$ as shown in Fig. 4.1b. The superelevation rate $(e, \%)$ depends on the highway design speed $(V, \mathrm{mph})$, horizontal curve radius 
$(R, \mathrm{ft})$, and the maximum side friction factor $\left(f_{\max }\right)$. The maximum side friction factor decreases as the design speed increases (IDOT, 2013) and can be well represented by a power function in Eq. 4.3.

$$
f_{\max }=2.9345 \cdot V^{-0.792}
$$

Since the superelevation rate of highway is generally smaller than the maximum $8 \%$ regardless of snow or ice conditions (AASHTO, 2001), the subsidence-induced surface slope could significantly change the superelevation rate of a highway surface. The worst influence that a subsidence-induced slope can have on a section of horizontally curved highway is shown in Fig. 4.1b where the dipping direction of the subsidence induced slope $(i)$ is opposite of that of highway superelevation rate $(e)$. The resulting superelevation rate of the road surface becomes $e-i$ and could reduce the lateral stability of a vehicle moving at the designated speed limit. However, for traffic safety, an easy approach is to reduce the speed limit in the section of highway as it experiences the active subsidence process. The maximum speed for a vehicle to safely maneuver through a subsided horizontal curve without losing lateral traction $\left(V_{\max }, \mathrm{mph}\right)$ can be determined using the following equation.

$$
V_{\max }=3.857 \sqrt{R\left[\sin (e-i)+f_{\max } \cdot \cos (e-i)\right]}
$$

Since $f_{\max }$ is a function of vehicle speed $(V)$ as indicated by Eq. 4.3, the maximum speed $\left(V_{\text {max }}\right)$ can be determined through an iterative solution process by combining Eqs. 4.3 and 4.4. For example, for a horizontally curved highway section with a speed limit of $70 \mathrm{mph}(112.7 \mathrm{~km} / \mathrm{h})$, the minimum radius of curvature is $2,331 \mathrm{ft}(710.5 \mathrm{~m})$ when a $4 \%$ superelevation rate is used in designing the transverse surface profile. When a $3 \%$ of subsidence-induced slope is superposed along the transverse direction of the curved highway, the maximum speed is reduced to $64 \mathrm{mph}$ 
(103 km/h). For safety, a significantly lower speed limit, such as $55 \mathrm{mph}(88.5 \mathrm{~km} / \mathrm{h})$, should be enforced.

\subsubsection{Effects of Subsidence-Induced Strain}

In a final subsidence basin formed over a mined longwall panel, the final tension zones are located around the panel edges with the maximum tension occurring a short distance inside the panel edge. Further inside the panel edge, a compression zone can be formed. The subsidence induced surface strains can cause integrity problems to highway structures, mostly to the highway surface pavements. For example, the tensile strain could widen the pre-fabricated stress/thermal compensation joints between the adjacent concrete pavement slabs (Fig. 2.18c). The maximum gap width $\left(\Delta x^{\prime}\right)$ is proportional to the maximum surface tensile strain $\left(\varepsilon_{\max }^{+}\right)$, the slab length $(D)$ and the original width of the compensation joint $(G)$ and can be estimated using Eq. 4.5.

$$
\Delta x^{\prime}=\varepsilon_{\max }^{+} \times D+G
$$

On the other hand, the compressive strain could initially narrow and then close the compensation joints between the concrete slabs. Excessive compressive strain could cause bumps on asphalt pavements and induce significant uplifts on concrete surface pavements. When the concrete pavement slabs are assumed to be rigid, the height of uplift at the joint $(\Delta h)$ can be estimated by Eq. 4.6 as it is a function of the average surface compressive strain along two adjacent slabs $\left(\varepsilon_{a}\right)$, the length of the slab $(D)$, and the width of the compensation joint $(G)$.

$$
\Delta h=\sqrt{D^{2} \varepsilon_{a}\left(2-\varepsilon_{a}\right)-2 D G\left(1-\varepsilon_{a}\right)-G^{2}}
$$

Based on this equation, the determined uplift for slab lengths of 15, 20 and $25 \mathrm{ft}$ (4.6, 6.1 and $7.6 \mathrm{~m})$ and $5 / 8$ inches $(1.59 \mathrm{~cm})$ wide transverse joints for the possible average subsidence- 
induced surface compressive strain has been determined and plotted in Fig. 4.2. The rigid slab approach shows that once the transverse joints are closed completely by the compressive strain (the last point with zero uplift in the figure), a minor amount of extra lateral closure could produce a very significant uplift. However, even with the elastic shortening of the slabs under compressive force, the uplift could be still very high. However, under heavy and dynamic traffic loads, the concrete slabs near the locations of large uplift are likely to crack and break in uncontrolled manner creating unsafe driving condition. However, the solution to prevent such significant uplift could be simply widening the transverse joint to absorb the anticipated closure caused by the compressive strain. For example, by widening a 5/8 inches $(1.59 \mathrm{~cm})$ existing joint to 1.5 inches $(3.81 \mathrm{~cm})$, the uplift shown in Fig. 4.2 can be completely eliminated.

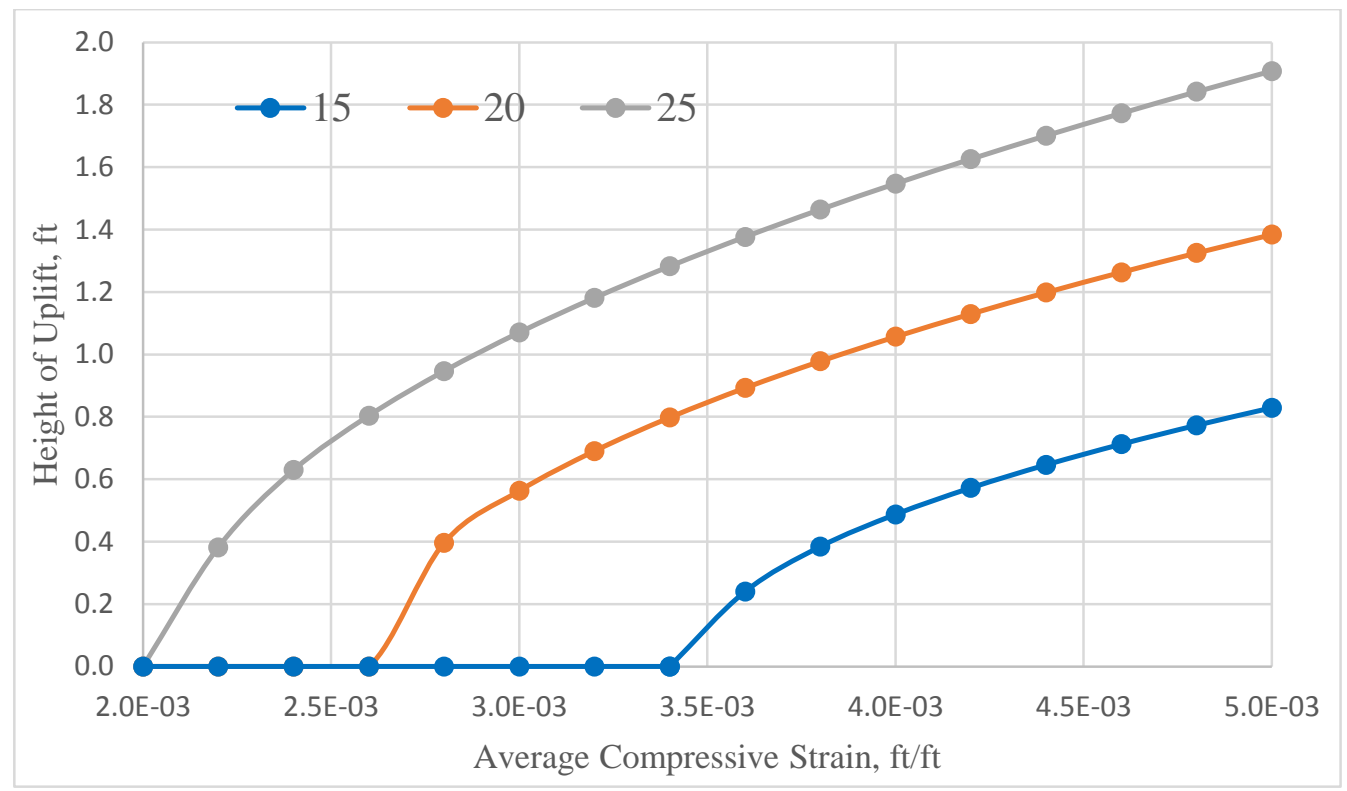

Figure 4.2 Height of uplift of concrete slabs under influence of compressive strain

\subsubsection{Effects of Subsidence-Induced Curvature}

The subsidence-induced surface curvature could be in concave or convex. For the US longwall operations, the maximum curvature could be in the range of $4 \times 10^{-5}$ to $4 \times 10^{-4} 1 / \mathrm{ft}$ $\left(1.31 \times 10^{-4}\right.$ to $\left.1.31 \times 10^{-3} 1 / \mathrm{m}\right)$. The vertical concave curvature generally has little influence on the 
highway pavements and traffic. However, the subsidence-induced vertical convex curvature could further shorten the original radius of vertical convex curvature of the highway and the sight distance. Sight distance is the length of the roadway ahead that is visible to the driver. A section of roadway with vertical curvature should be designed to have a sight distance sufficient for a driver driving at or near the speed limit to recognize a stationary object in the path, to react and to stop vehicle before it reaches the object. The stopping sight distance $\left(S_{s}\right.$, ft), one of several types of sight distances, is most frequently used in road design and is the sum of two distances: driver reaction distance and braking distance. The derived equation for the stopping sight distance is shown as follows (AASHTO, 2001):

$$
S_{s}=1.467 V t_{r}+1.075 \frac{V^{2}}{a}
$$

In the equation, $V$ is the design speed limit, $\mathrm{mph} ; t_{r}$ is the driver's recognition and reaction time (typically 2.5 seconds), $a$ is the design deceleration rate, $\mathrm{ft} / \mathrm{s}^{2}$. As stated previously, the achieved deceleration rate can be $32 \mathrm{ft} / \mathrm{s}^{2}\left(9.75 \mathrm{~m} / \mathrm{s}^{2}\right)$ or better for professional drivers while a reasonably skilled driver could easily get deceleration rates in excess of $20 \mathrm{ft} / \mathrm{s}^{2}\left(6.10 \mathrm{~m} / \mathrm{s}^{2}\right)$ without loss of control. However, a very conservative rate of $10 \mathrm{ft} / \mathrm{s}^{2}\left(3.05 \mathrm{~m} / \mathrm{s}^{2}\right)$ is often used to determine the stopping sight distance in highway design.

For highways in areas with level and moderate surface topography, the original long sight distance makes the longwall subsidence's effects on the drivability of the highway very insignificant. However, in mountainous terrains, the subsidence-induced convex curvature could further increase the original highway crest vertical curve. Considering the design standard for crest vertical curve on highways, it is recommended that crest vertical curves should be designed to provide at least the stopping sight distance for safe and comfortable driving condition. In the rugged terrain 
areas, the high design speed makes it often impractical for the stopping sight distance to be larger than the length of crest vertical curve. Therefore, only the stopping sight distance less than the length of crest vertical curve is considered here. The length of crest vertical curve $\left(L_{c}, \mathrm{ft}\right)$ is related to the algebraic difference in grades $(A, \%)$ and stopping sight distance $\left(S_{s}, \mathrm{ft}\right)$ and can be determined by:

$$
L_{c}=\frac{A S_{S}^{2}}{2158}
$$

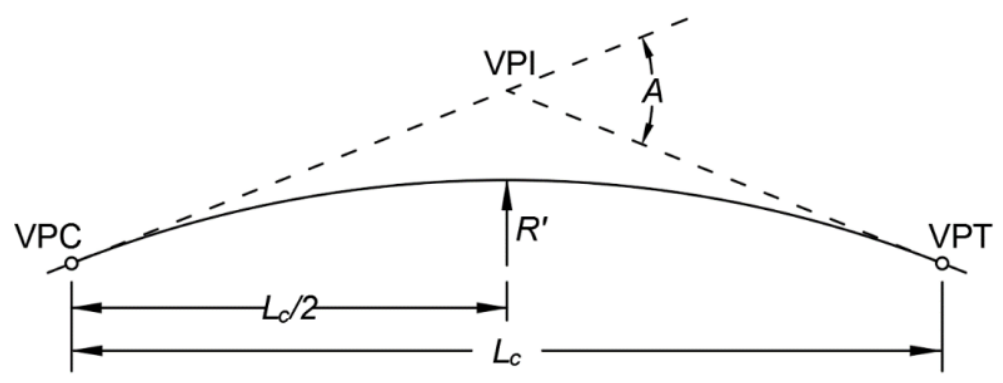

Figure 4.3 Schematic of highway crest vertical curve

For a known length of crest vertical curve, the minimum radius of curvature $\left(R^{\prime}, \mathrm{ft}\right)$ can be determined by Eq. 4.9 using the geometry relationship shown in Fig. 4.3.

$$
R^{\prime}=\frac{L_{c} / 2}{\sin (A / 2)}
$$

Based on Eqs. 4.7, 4.8 and 4.9, the maximum design grades (see Table 4.1) for highways should be used to assess the minimum stopping sight distance and the length of crest vertical curve or the radius of curvature. The minimum stopping sight distance, the maximum length of crest vertical curve, the minimum radius of vertical curve and the maximum vertical curvature for different design speed limit in the mountainous areas are determined and listed in Table 4.2. For the typical highway speed limit ( 65 or $70 \mathrm{mph}, 104.6$ or $112.7 \mathrm{~km} / \mathrm{h}$ ), the magnitude of maximum 
vertical curvature is close to the amount of subsidence-induced convex curvature as stated previously. In addition, it should be noted that the predicted final curvature has to be imposed on the original highway curvature before subsidence in order to assess the subsidence influence on highway. In the scenario that the subsidence-induced convex curvature occurs coincidentally on a crest vertical curvature highway, the superimposed curvature has a great probability beyond the maximum vertical curvature criterion and could cause safety problem.

Table 4.2 Minimum radius of vertical curve and maximum curvature for highway

\begin{tabular}{|c|c|c|c|c|c|}
\hline \multirow{2}{*}{ Design Parameters } & \multicolumn{5}{|c|}{ Speed Limit, mph } \\
\cline { 2 - 6 } & 50 & 55 & 60 & 65 & 70 \\
\hline Min. Stopping Sight Distance $\left(S_{s}\right), \mathrm{ft}$ & 424 & 492 & 566 & 644 & 728 \\
\hline Min. Curve Length $\left(L_{c}\right), \mathrm{ft}$ & 998 & 1,349 & 1,782 & 1,924 & 2,453 \\
\hline Min. Radius of Curvature $\left(R^{\prime}\right), \mathrm{ft}$ & 8,364 & 11,299 & 14,927 & 19,314 & 24,621 \\
\hline Max. Vertical Curvature $(K), 1 / \mathrm{ft}$ & $1.20 \mathrm{E}-04$ & $8.85 \mathrm{E}-05$ & $6.70 \mathrm{E}-05$ & $5.18 \mathrm{E}-05$ & $4.06 \mathrm{E}-05$ \\
\hline
\end{tabular}

\subsection{Case Study}

A case study is shown here to show the subsidence influence on interstate highway. The longwall mining operations in two panels (A and B) have been conducted under a section of I-79 during the time period from 2004 to 2006 (Iannacchione, 2010) as shown in Fig. 4.4. The width of each of the two longwall panels was about 1,266 ft (386 m) while the chain pillar system between these two panels was about $184 \mathrm{ft}(56 \mathrm{~m})$ wide. The average mining height in the Pittsburgh coal seam was about $8.0 \mathrm{ft}(2.4 \mathrm{~m})$ with the average mining depth being $860 \mathrm{ft}(262 \mathrm{~m})$ at the study site. The ratio of the panel width to overburden depth is about 1.47 and results in supercritical subsidence basins (Peng, 1992). The highway passes over the longwall panels in an approximate $65^{\circ}$ with the longitudinal direction of the panels. The speed limit for this section of I-79 at that time was $65 \mathrm{mph}(104.6 \mathrm{~km} / \mathrm{h})$. 


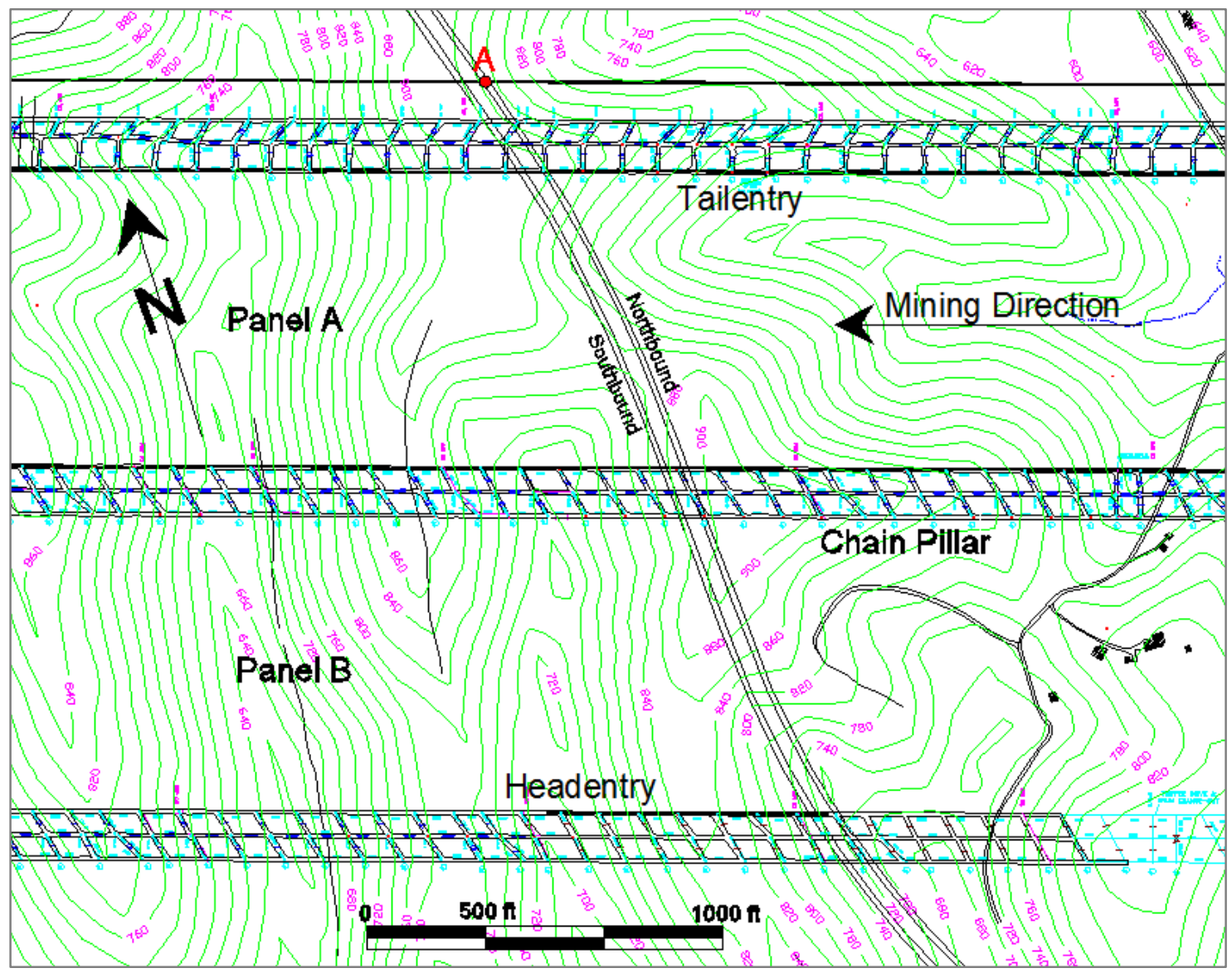

Figure 4.4 Overview of the subsidence study site

Due to the similar surface elevation profiles on both sides of the highway, the northbound highway is selected for analysis. The surface elevation profile of the northbound highway before subsidence is collected and plotted against the distance from the reference point A in Fig. 4.5. The lowest elevation, $1,178 \mathrm{ft}(359 \mathrm{~m})$, is at a distance about 3,900 $\mathrm{ft}(1,189 \mathrm{~m})$ from point A while the highest elevation is $1,342 \mathrm{ft}(409 \mathrm{~m})$ at point $\mathrm{A}$. From point $\mathrm{A}$, the highway section dips toward the south all the way. The gradient of the highway is derived from the surface elevation and plotted in Fig. 4.6. The maximum surface slope on the northbound highway is about $5.5 \%\left(3.15^{\circ}\right)$ occurring at two points over panel B. Based on the AASHTO standard, the maximum design gradient for highway with $65 \mathrm{mph}$ speed limit in the mountainous areas is $5 \%$ as shown in Fig. 4.6 (AASHTO, 2001). It is obvious that there are two short sections of the highway exceeding the 
maximum grade design criterion around 2,200 and 3,200 ft (671 and $975 \mathrm{~m}$ ) from point $\mathrm{A}$, respectively. For northbound highway, a positive gradient in Fig. 4.6 indicates an uphill driving condition but for the southbound it is a downslope driving. The curvature of the northbound highway is derived from the surface slope profile and plotted in Fig. 4.7. A positive curvature represents that the highway forms a crest vertical curve. Based on the design criteria listed in Table 4.2, the maximum design curvature for highway with a crest vertical curve for speed limit of $65 \mathrm{mph}$ is $5.18 \times 10^{-5} 1 / \mathrm{ft}\left(1.70 \times 10^{-4} 1 / \mathrm{m}\right)$ which is plotted in Fig. 4.7 for reference. It is apparent that the curvatures in two sections, a long section and a short section, are higher than the design criterion for $65 \mathrm{mph}$ speed limit even before subsidence. The section closer to point A has the maximum curvature being about $1.0 \times 10^{-4} 1 / \mathrm{ft}\left(3.28 \times 10^{-4} 1 / \mathrm{m}\right)$ located at a distance about $1,500 \mathrm{ft}(457 \mathrm{~m})$ from point A. As it is less comfortable for a driver to drive on a crest vertical curve than on a sag vertical curve, sag vertical curve design is not considered in this chapter.

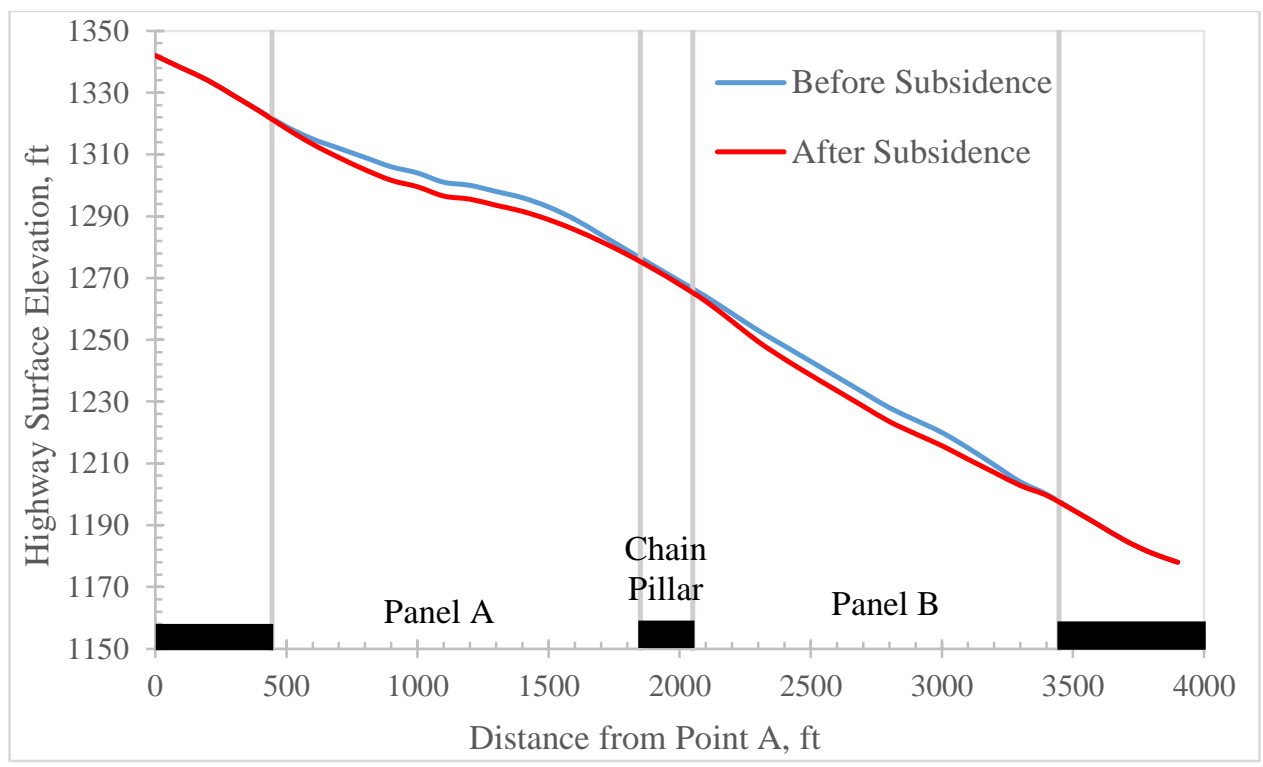

Figure 4.5 Highway surface elevations before and after subsidence 


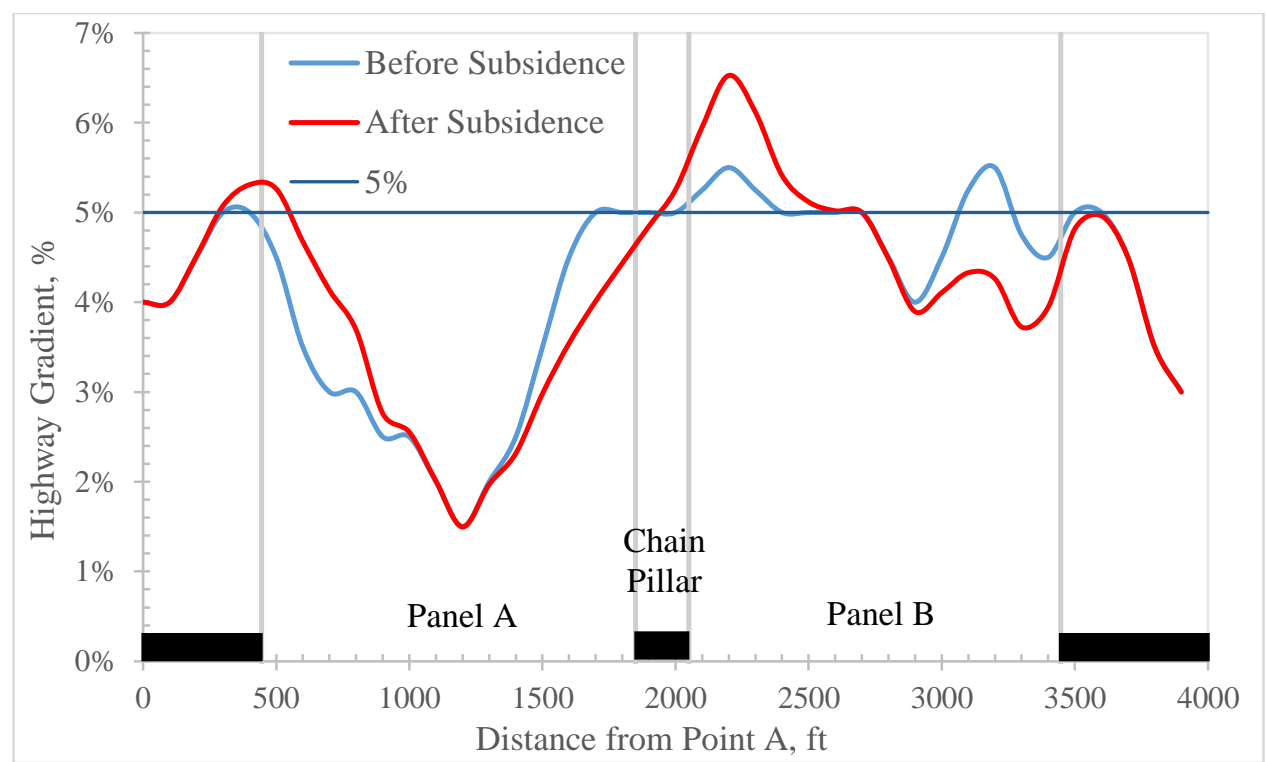

Figure 4.6 Highway gradient profiles before and after subsidence

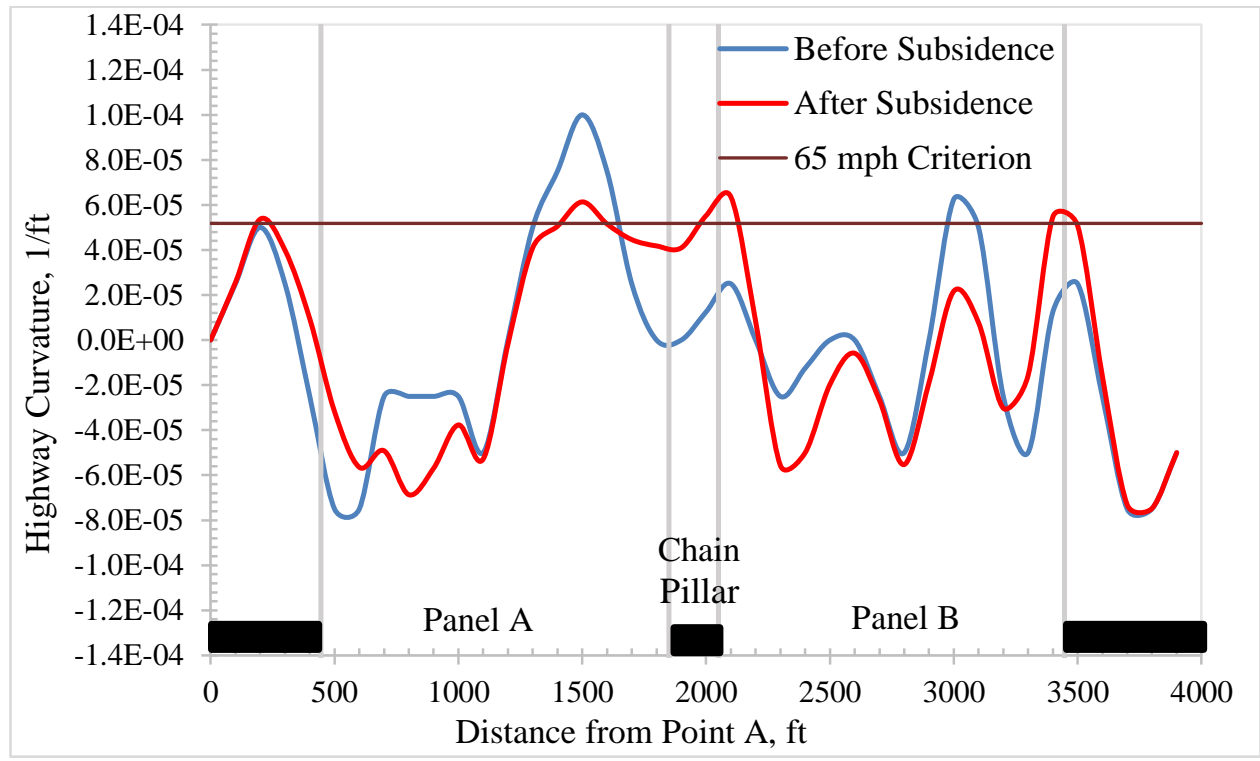

Figure 4.7 Highway vertical curvature profiles before and after subsidence

\subsubsection{Subsidence Prediction}

In order to assess the potential effects of the underground mining operations on the highway structures, the subsidence prediction program package CISPM (Luo, 1989) was used to predict final surface movements and deformations along the highway. For the direction dependent surface movements and deformations, their respective components along the axial direction of the 
highway are predicted. The maximum and minimum values of the predicted subsidence indices are listed in Table 4.3.

Table 4.3 Predicted final surface movements and deformations across the highway section

\begin{tabular}{|l|c|c|c|c|c|}
\hline \multirow{2}{*}{ Item } & Subsidence & H.D. & \multirow{2}{*}{ Slope } & Horizontal Strain & Curvature \\
\cline { 2 - 3 } \cline { 5 - 6 } & $\mathrm{ft}$ & $\mathrm{ft}$ & & $\mathrm{ft} / \mathrm{ft}$ & $1 / \mathrm{ft}$ \\
\hline Min. & 0 & -1.28 & $-1.35 \%$ & $-7.21 \mathrm{E}-03$ & $-6.72 \mathrm{E}-05$ \\
\hline Max & 4.48 & 1.34 & $1.41 \%$ & $7.07 \mathrm{E}-03$ & $6.72 \mathrm{E}-05$ \\
\hline
\end{tabular}

\subsubsection{Assessment of Subsidence Influence on Highway}

In order to assess the subsidence influences on the highway, the predicted final subsidence is imposed on the original elevation profile of the highway. Since the final horizontal displacement is much smaller than the vertical settlement and normally has insignificant influence on the horizontal curvature of the highway, only the influence of the mining-induced ground vertical settlement is assessed.

\subsubsection{Effects of Subsidence-Induced Slope}

The new highway gradient is derived from the new surface elevation after subsidence process and plotted in Fig. 4.6. After subsidence, the maximum highway gradient is increased from $5.5 \%$ to about $6.5 \%$ occurring at 2,200 $\mathrm{ft}(671 \mathrm{~m})$ from point $\mathrm{A}$ - higher than the permissible design grade of $5 \%$ for the speed limit of $65 \mathrm{mph}(104.6 \mathrm{~km} / \mathrm{h})$. Using Eq. 4.2, when an inexperienced driver travels at $65 \mathrm{mph}(104.6 \mathrm{~km} / \mathrm{h})$ speed in the southbound in the subsided $6.5 \%$ downgrade highway section, the minimum stopping distance increases from $541 \mathrm{ft}(165 \mathrm{~m})$ for the designed $5 \%$ grade to $574 \mathrm{ft}(175 \mathrm{~m})$. The gradient in another short section, only about 100 to $200 \mathrm{ft}$ (30.5 to $61 \mathrm{~m})$, located about $500 \mathrm{ft}(152 \mathrm{~m})$ from point $\mathrm{A}$ is increased to $5.4 \%$ - not significantly higher than the critical gradient. The gradient in a section around 3,200 $\mathrm{ft}(975 \mathrm{~m})$ from point A decreases from $5.5 \%$ to $4.3 \%$ - lower than the design gradient. 


\subsubsection{Effects of Subsidence-Induced Strains}

The predicted surface strain is used directly for assessing its influence to the highway pavement. In the tension zone, the maximum width of joint can be estimated to be $0.19 \mathrm{ft}(2.28$ inches or $5.8 \mathrm{~cm})$ using Eq. 4.5 by substituting the predicted maximum tensile strain $\left(7.07 \times 10^{-3} \mathrm{ft} / \mathrm{ft}\right)$ and slab length of $20 \mathrm{ft}(6.1 \mathrm{~m})$. Such wide gaps between the pavement slabs would cause rough driving condition.

In the compression zone, the maximum compressive strain $\left(7.21 \times 10^{-3} \mathrm{ft} / \mathrm{ft}\right)$ could induce compressive stress as high as $2.60 \times 10^{4} \mathrm{psi}(179 \mathrm{MPa})$ on the concrete slab assuming a $3.6 \times 10^{6} \mathrm{psi}$ (24.8 GPa) modulus of elasticity for the concrete (Grübl et al., 1999). The high compressive strain is capable of causing an uplift as high as $2.5 \mathrm{ft}(76 \mathrm{~cm})$ at the joint point of two adjacent concrete slabs based on Eq. 4.6 before the breakage of the slabs.

\subsubsection{Effects of Subsidence-Induced Curvature}

From the new gradient profile after subsidence in Fig. 4.6, the new vertical curvature of the highway is derived and plotted in Fig. 4.7. There would be three short sections where the convex curvatures are higher than the design criterion for speed limit $65 \mathrm{mph}(104.6 \mathrm{~km} / \mathrm{h})$ as shown in Fig. 4.7. However, the peak curvatures in the three sections are even smaller than the respective peak curvatures before subsidence. The sections where the curvature exceeds the critical value are even shorter than those before subsidence. In addition, each of the sections is short, about 100 to $200 \mathrm{ft}$ (30.5 to $61 \mathrm{~m}$ ) long, and the maximum curvature is not significantly higher than the critical value. Therefore, the longwall subsidence associated with the planned mining operations will not affect the drivability of this section of highway to any significant degree in this case. 


\subsubsection{Mitigation Measures for Highway Pavements}

As discussed in the previous sections, ground subsidence induced by longwall mining could steepen the highway grade, widen joint gaps, produce bumps and/or uplifts, decrease side traction on horizontal curve, reduce stopping sight distance on crest curvature, etc. These influences could impact the integrity of highway surface pavements and reduce the drivability and even driving safety of the highway. Many factors such as surface terrain, original design and constructions of the highway, magnitudes and distribution of the subsidence induced surface movements and deformations, posted speed limit, etc. can all affect the severity of subsidence influence to highway structures and traffic. The case study in the previous section shows that the magnitude and extent of subsidence influence to a section of I-79 when it was undermined by two adjacent longwall panels. However, properly designed and implemented mitigation measures could significantly reduce the severity of the anticipated structural disturbances and influence to the highway traffic caused by longwall subsidence. The following simple but effective measures might be considered to mitigate the subsidence influence on highways.

\subsubsection{Traffic Speed Control}

It should be noted that the duration of the dynamic subsidence process for most of the longwall mining operation in the US is well shorter than one mouth and the amount of subsidence is too large for the subsided highway to be repaired back to pre-subsidence condition immediately during the dynamic subsidence process. Therefore, most of the mitigation effort during the active subsidence period should be to maintain the safety of highway traffic. As indicated in the analysis of vehicle dynamics, the safety related highway design criteria, such as the minimum stopping distance, superelevation rate, and sight distance, are related to vehicle travelling speed. Therefore, 
the most effective method to maintain safe driving condition in the subsiding section of the highway is to enforce a reduced speed limit determined from the various design criteria. For the high-

way section in the case study, a speed limit of $45 \mathrm{mph}(72 \mathrm{~km} / \mathrm{h})$ was posted and enforced in a section 5,000 $\mathrm{ft}(1,524 \mathrm{~m})$ beyond both sides of the active longwall panel.

\subsubsection{Measures to Prevent Pavement Damage}

It is a well-known fact that the surface strain in a subsidence process normally is responsible for most of the observed damage to surface structures including highway pavements. When the influence assessment indicated that the subsidence-induced tensile strain could excessively widen the compensation joints or even cause random tension cracks on the concrete pavements, the partially-cut joints could be further deepened to form pre-determined weak plane so that the tension cracks would not propagate into the concrete slabs. The joints should be filled with expansible foam. When the influence assessment indicates that the subsidence-induced compressive strain can cause significant uplift at the joint between concrete pavement slabs, an effective method is to widen the joints to a minor amount as indicated by Eq. 4.6. For asphalt surface pavement, the compressive strain is likely to cause bumps, particularly at the joint locations of underlying concrete pavement as shown in Fig. 4.8. The most effective way is to grind such bumps as it begins to develop.

For implementing such temporary mitigation measures during the active dynamic subsidence process, a service crew was standing by the subsiding section of highway 24 hours a day. The crew checked the traffic, conducted periodic subsidence surveys, monitored structural response and made the necessary repairs.

In order to perform this service work safely, one lane on each direction was kept open for traffic while any emergency and temporary repairs were performed in the other lanes as shown in 
Fig. 4.9. The widened joints in the tension zones were filled with sand and the compression bumps were ground.

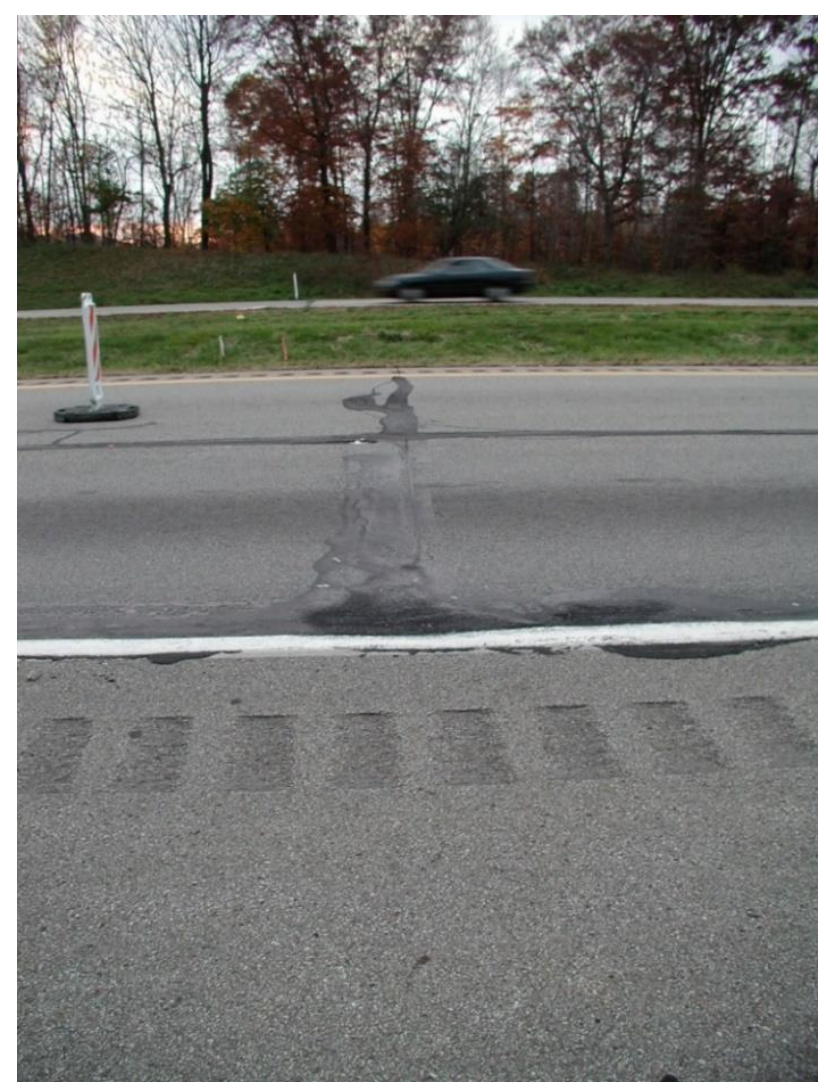

Figure 4.8 Bump (Ground already) formed on I-79 in the Maximum Compression Zone

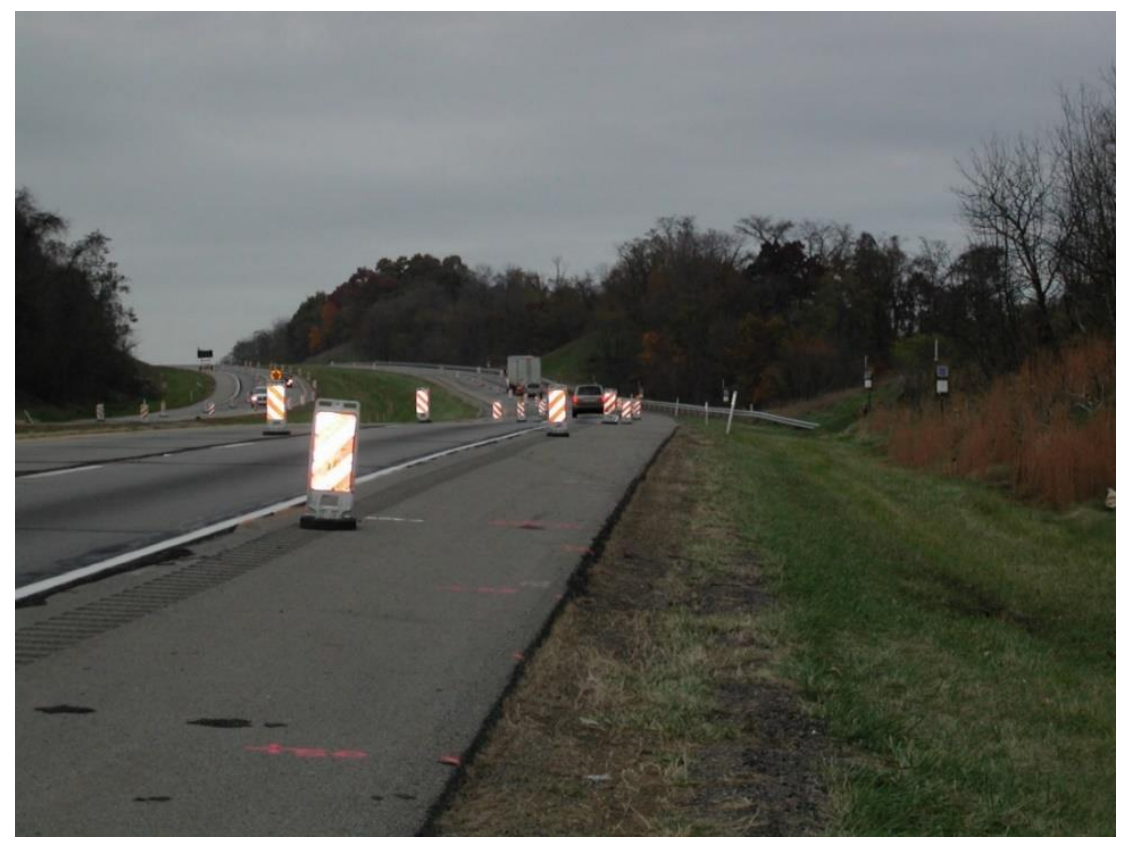

Figure 4.9 Vertical curve induced by subsidence and open lane for traffic on each direction 


\subsubsection{Post-Subsidence Repairs}

Normally, for most US coal mines, the collected subsidence data indicate that the ground regains stable condition and has no additional subsidence after the longwall face has passed the area of interest for one month. After the dynamic subsidence process over one or more longwall panels completes, an elevation survey was performed along the subsided highway section. The measured elevation data can be used to generate a new roadway elevation profile, not necessarily back to the original one, that meets all highway design criteria. Typically, in mountainous area, asphalt road paving material is added only in some short sections to raise the road surface to a predetermined level for the resumption of normal highway traffic.

\subsection{Summaries}

The surface subsidence induced by underground mining activities, especially longwall mining operations, can cause significant influence on interstate highways. In order to maintain the drivers' safety and drivability of the affected highway, the potential subsidence influence should be correctly assessed and properly mitigated based on accurate subsidence prediction. The highway design criteria and the analysis of vehicle dynamics are applied to determine the driving safety related factors such as minimum stopping distance, superelevation rate, sight distance, etc. for the subsided highway. The predicted surface strain is used to assess the integrity of highway pavements. Due to the practical limitations, the mitigation measures can be divided into: (1) temporary mitigation measures to maintain driving safety during the active subsidence period, and (2) permanent adjustment of the subsided section of highway for the resumption of normal traffic after the subsidence event. A case study is presented to demonstrate these influence assessment and mitigation measures. 


\section{CHAPTER 5 \\ TECHNIQUES FOR ASSESSING AND MITIGATING LONGWALL SUBSIDENCE EFFECTS ON HIGHWAY BRIDGES}

\subsection{Introduction}

Bridges, as a key element in the transportation system, are built to connect a disconnected road and to span physical obstacles such as a body of water, valley, or road, for the purpose of providing passage over the obstacles (BTH, 2020). Therefore, ensuring the functionality and safety of bridges is vital to the travelers and vehicles. However, when a bridge is located above an underground coal mine, surface subsidence induced by underground coal mining activities, especially longwall mining operations, can cause various disturbances to the bridge structures including integrity, stability and functionality problems (Jones, 1988). It should be noted that a longwall subsidence process is capable of causing damage or even collapse of a bridge. In order to reduce the severity of the potential surface subsidence influence on bridge structures and to ensure traffic safety, accurate final and dynamic subsidence prediction on the bridge structural parts that have direct contact to ground is the first and the most important step. Based on such accurate ground subsidence prediction at each mining stage, the movements and deformations of the traffic carrying bridge components and their impacts on the bridge structures and traffic can be assessed correctly. Then effective mitigation and remediation measures can be designed and implemented. In this chapter, the techniques to analyze and mitigate the effects of longwall subsidence on beam bridges typically used for bridges of relatively small span has been proposed. An interstate highway overpass bridge located over a rural road is used as a case study for demonstrating these assessment techniques. Mitigation measures are also proposed for this case accordingly. 


\subsection{Subsidence Influence on Bridges}

\subsubsection{Subsidence Prediction}

Correct assessment of potential subsidence influence to a bridge starts with accurate prediction of dynamic and final surface movements and deformations. The prediction points should be carefully selected. All contact points between the bridge beam-deck system (superstructures) and the abutments and piers (substructures), the corner points of approach slabs and the characteristic points of other important bridge structures should be selected as the prediction points. This selection process is based on the assumption that the movements at the contact points on the substructures of the bridge will follow the subsidence-induced movements at the ground points because the contact points on the bridge structural parts (typically not significantly higher than the ground surface) have direct contact to the ground. Therefore, the subsidence prediction on those contact points can be used to assess the subsidence-induced movements and deformations on the superstructures of the bridge which are supported by the substructures. The coordinates $\left(x_{i}, y_{i}, \mathrm{z}_{i}\right)$ of these points before mine subsidence should be surveyed or accurately measured from the mine map and bridge design drawings. For the convenience of applying the subsidence prediction program, the $x$-axis of the Cartesian coordinate system should be along the mining direction. At a given time, the three components of the predicted surface movement at a prediction point $\left(U_{x i}, U_{y i}\right.$, $\left.S_{i}\right)$ can be superimposed on its original coordinates to produce its current spatial location $\left(x_{i}{ }^{\prime}, y_{i}\right.$, $\left.z_{i}{ }^{\prime}\right)$. The coordinates of the points of interest at a given time are used to assess the potential influence on the bridge structures and traffic. 


\subsubsection{Separation or Closure between End Abutments}

Figure 2.19 shows that the distance between the abutments at the top $(L)$ is the sum of the bridge deck length $(D)$ and the two expansion joints width $(d)$. However, the relative locations of the abutments could change under the influence of mining subsidence and a large relative location changes can affect the working condition of the bridge. If the new distance $\left(L^{\prime}\right)$ is considerably larger than its original distance $(L)$, the beam bearings could be pulled off from its bearing plate or even from the abutments or piers leading to possible bridge collapse.

On the other hand, if the new distance becomes smaller and the closure is larger than the total width of the expansion joints, significant compressive force will develop on the bridge beams that could induce significant uplift of the decks. In a worst-case scenario, buckling failure could also develop when the closure is too excessive. Figure 5.1 shows a bridge beam and deck system under the influence of mine subsidence in 3-D. The original distance $(L)$ between a pair of corresponding points on the end abutments under the beam and deck system can be determined from the coordinates of the points $\mathrm{A}$ and $\mathrm{B}$ on the end abutments before subsidence (i.e., $x_{1}, y_{1}, z_{1}$ and $x_{2}, y_{2}, z_{2}$, respectively). At a given time of the subsidence process, the predicted movements at points $\mathrm{A}$ and $\mathrm{B}$ along the $\mathrm{X}, \mathrm{Y}$ and $\mathrm{Z}$ directions are $U_{x l}, U_{y 1}, S_{1}$ and $U_{x 2}, U_{y 2}, S_{2}$, respectively. The new distance $\left(L^{\prime}\right)$ can be determined. The distance change between the two end abutments $(\Delta L)$ at a particular time is determined by Eq. 5.1. In this equation, $\delta_{t}$ and $\delta_{l}$ are the movement caused by thermal expansion/contraction and the traffic load on the bridge, respectively.

$$
\begin{aligned}
& \Delta L=L^{\prime}-L+\delta_{t}+\delta_{l} \\
& =\sqrt{\left[x_{1}-x_{2}+U_{x 1}-U_{x 2}\right]^{2}+\left[y_{1}-y_{2}+U_{y 1}-U_{y 2}\right]^{2}+\left[z_{1}-z_{2}+S_{1}-S_{2}\right]^{2}} \\
& \quad-\sqrt{\left(x_{1}-x_{2}\right)^{2}+\left(y_{1}-y_{2}\right)^{2}+\left(z_{1}-z_{2}\right)^{2}}+\delta_{t}+\delta_{l}
\end{aligned}
$$




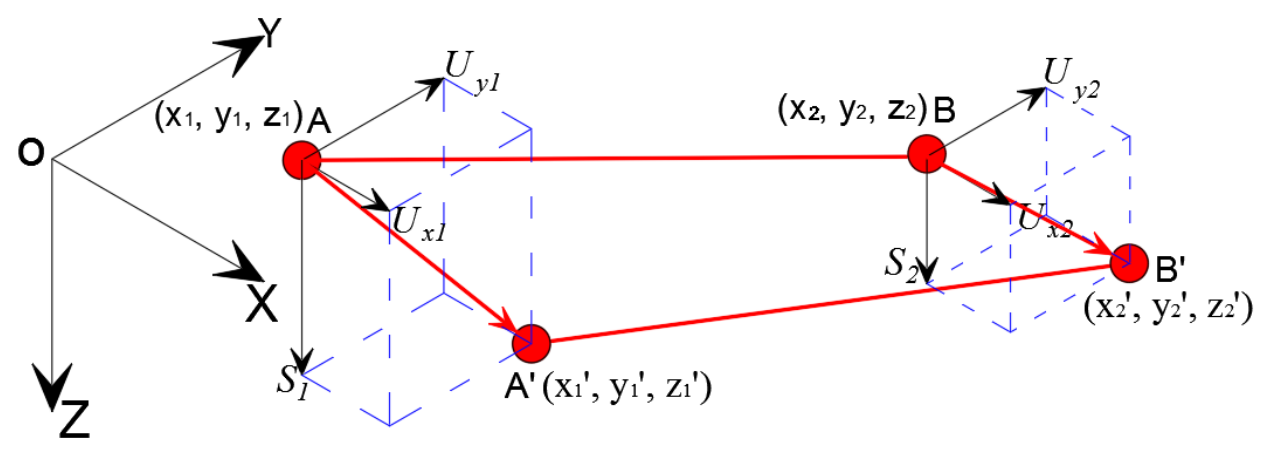

Figure 5.1 Schematic of movements of corresponding points in end abutments

For a beam bridge, the beams are generally bolted to the abutment/pier at one end and their other end are attached to the abutment/pier using a proper type of bearing. There are several types of bridge bearings employed in bridge construction as shown in Fig. 5.2 (The Constructor, 2020). Some of the bearings allow certain amounts of relative translational movements only while the other allow both relative translational and rotational movements caused by thermal expansion and contraction and bridge load. Depending on the bearing type, design, material and size, the allowances for translational or rotational movements could be different. For bridge to be influenced by longwall subsidence, the allowance for translational movement is often the limiting factor.

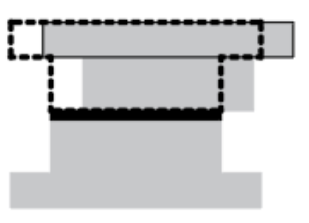

(a)

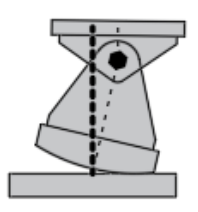

(b)

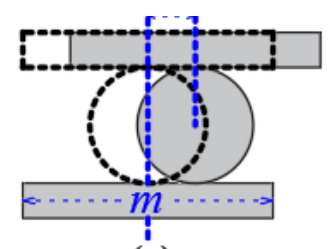

(c)

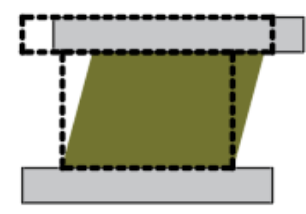

(d)

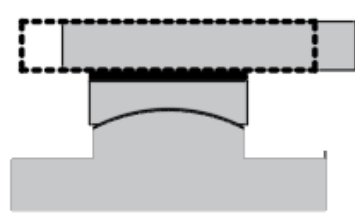

(e)

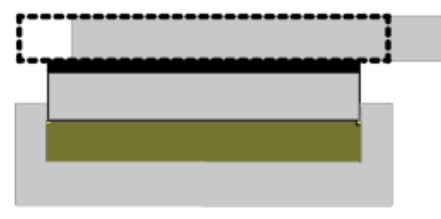

(f)

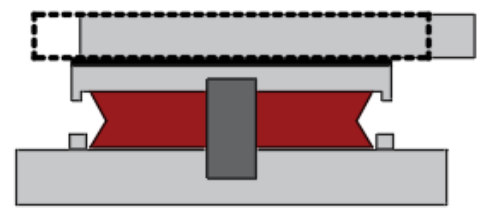

(g)

Figure 5.2 Typical types of bearings for bridges: (a) sliding bearings; (b) rocker bearings; (c) roller bearings; (d) elastomeric bearings; (e) curved bearings; (f) pot bearings; (g) disk bearings 
If a subsidence event causes the two abutments to move closer (negative $\Delta L$ ), the maximum closure should not be larger than the critical closure determined as the smaller value between the total width of the expansion joints and the allowance of translational movement. When the critical closure is exceeded, significant compressive stress can be developed on the bridge decks and beams as well as on the end abutments. It could also damage the bearing structures.

On the other hand, when the two end abutments move away from each other (positive $\Delta L$ ), the maximum separation should be less than the maximum translational movements allowed by the bearing system used on the bridges. Taking the commonly used roller bearing (Fig. 5.2c) in bridge construction as an example, the maximum allowance of the translational movement should be less than the half of the bearing plate length $(m)$. Therefore, in either the closure or separation case, the condition defined by Eq. 5.2 should be met so that the roller is still on the bearings plate for bridge safely. In this expression, the roller is assumed to sit at the center of the bearing plate at the time of construction. The allowances in translational movement for other bearings should be determined based on their designs and performance specifications.

$$
-\operatorname{Min}\left(2 d, \frac{m}{2}\right)<\Delta L<\frac{m}{2}
$$

\subsubsection{Deflections of Bridge Beams}

The bridge beams, sitting on piers and abutments, serve as base support for the bridge decks. They are usually made from steel or reinforced concrete. For single-span bridges, the beams sit on the end abutments and the beam deflection during and after a subsidence process would not be a concern unless it is subjected to significant compression. However, for multi-span bridges, each of the beam is supported not only by the end abutments but also by the intermediate piers. During 
a subsidence process, if the elevation profile of the contact points between each beam and its underlying bearings is not on a straight line, the beam will deflect and cause uneven load distribution among the contact points.

To determine the deflection of a beam at a given mining stage, an imaginary straight line is drawn between the contact points on the subsiding end abutments. The elevations of the contact points on the intermediate piers are checked against the straight line. When the elevation of a contact point on a subsiding intermediate pier is above the straight line, a convex beam deflection would occur and the intermediate pier(s) would be excessively loaded as shown in Fig. 5.3a. Depending on the stiffness of the beam, the beam end sitting on a flexible bearing would likely to detach from its underlying abutment and create a step with a maximum uplift height of $\Delta H$ at the end abutment with flexible bearing which can be determined using Eq. 5.3. In this equation, $x_{i}$ is the horizontal distance between the end abutment and the $i^{\text {th }}$ intermediate pier and $\Delta h_{i}$ is the deflection of the $i^{\text {th }}$ intermediate piers. The maximum ratio of $\Delta h_{i}$ to $x_{i}$ among the intermediate piers should be used in order to determine the maximum uplift height. When a vehicle leaves the tip point of the uplift end with a high speed, it will become airborne for a very short time until it lands on the approach slab. This travelling process is simplified as a motion of a free-falling body with a horizontal travelling velocity. The airborne time $(\Delta t)$ can be determined by Eq. 5.4 where $g$ is the acceleration of gravity. When the airborne time is too long, it will cause safety problems for the traffic especially in icy road condition. In the case that a vehicle travels toward to a significant uplift, the vehicle could hit on the bridge deck and cause problems ranging from damage to the tires and axis to serious accidents.

$$
\Delta H=\frac{D}{x_{i}} \cdot \Delta h_{i}
$$




$$
\Delta t=\sqrt{\frac{2 \Delta H}{g}}
$$

On the other hand, when the elevation of a contact point on an intermediate pier is below the straight line, the beam will deflect concavely and the abutments will carry more bridge load as shown in Fig. 5.3b. Unless the maximum deflection is large enough to cause damage to the bridge beams and decks, the influence of the concave deflection caused by longwall subsidence on the traffic should be insignificant.

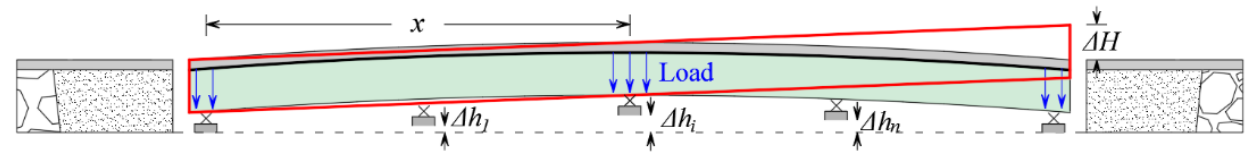

(a)

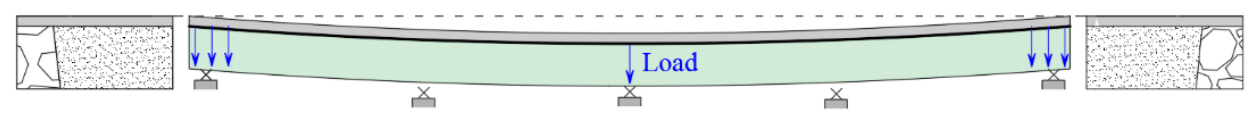

(b)

Figure 5.3 Schematic of bridge beams convex (a) and concave (b) deflections

\subsubsection{Twisting of Bridge Decks}

The subsidence-induced differential vertical movements at the contact points above the abutments and piers would result in twisting condition on bridge decks when the elevations of those contact points are not on a plane. Severe twisting would cause cracks on decks and even collapse. Though not caused by mine subsidence, the collapse of the main span of the Tacoma Narrows Bridge served as an example of effects of twisting. Only after opening for four months, the bridge was collapsed on November 7, 1940 when an unusual twisting mode occurred as shown in Fig. 5.4 (Fuller et al., 2000). 


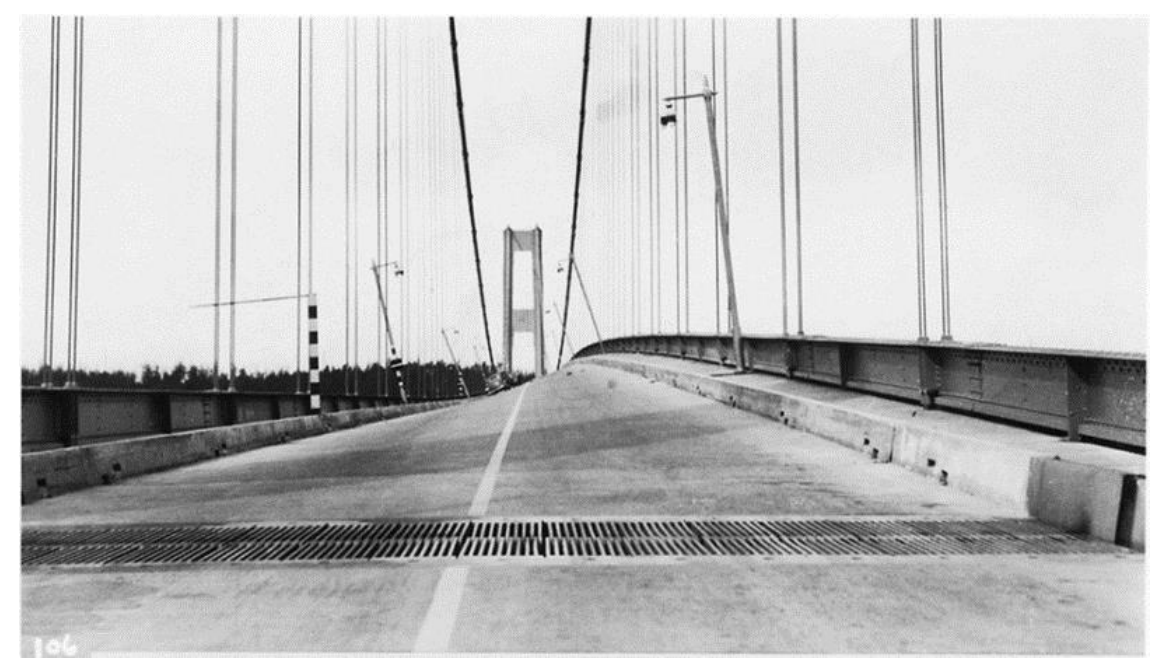

Figure 5.4 Twisting condition that occurred on the bridge deck (Fuller et al., 2000)

During the subsidence process, the twisting condition can be checked by randomly choosing three points at the deck corners at a given time using their subsided elevations (or subsidence) to define a plane first. The subsided elevation at a given contact point other than the three chosen points is checked to see whether it is still on the plane defined by the three chosen points using Eq. 5.5. In the equation, the coordinates and elevations (or subsidence) of the three chosen points are $\left(x_{1}, y_{1}, S_{1}\right),\left(x_{2}, y_{2}, S_{2}\right)$ and $\left(x_{3}, y_{3}, S_{3}\right)$, respectively while that for a point of interest is $\left(x_{i}, y_{i}, S_{i}\right)$. For the point of interest $i$ to be on the defined plane, Eq. 5.5 must be satisfied (Luo, 2020b).

$$
\left|\begin{array}{llll}
x_{1} & y_{1} & S_{1} & 1 \\
x_{2} & y_{2} & S_{2} & 1 \\
x_{3} & y_{3} & S_{3} & 1 \\
x_{i} & y_{i} & S_{i} & 1
\end{array}\right|=0
$$

\subsubsection{Integrity of Abutments}

Due to the differential vertical movements during the subsidence process, each of the end abutments could experience subsidence-induced curvature and strain along its axial direction. The combined effect of the subsidence-induced convex curvature and tensile strain, if strong enough, could create cracks on the concrete poured abutments (Fig. 5.5). However, the concave curvature 
and compressive strain have much less impact to the integrity of the abutments and piers. The total strain to be experienced on the top surface of an abutment $\left(\varepsilon_{T}\right)$ can be estimated using Eq. 5.6. In the equation, $\varepsilon_{+}$is the subsidence-induced tensile strain, $K_{+}$is the convex curvature and $h$ is the height of the abutment above its foundation. Based on our past subsidence monitoring program to study the structural responses to ground subsidence, hairline cracks could be initiated on concrete structures when the tensile strain reaches about $2.0 \times 10^{-3} \mathrm{ft} / \mathrm{ft}(\mathrm{m} / \mathrm{m})($ Peng, 2008).

$$
\varepsilon_{T}=\varepsilon_{+}+K_{+} \times h
$$

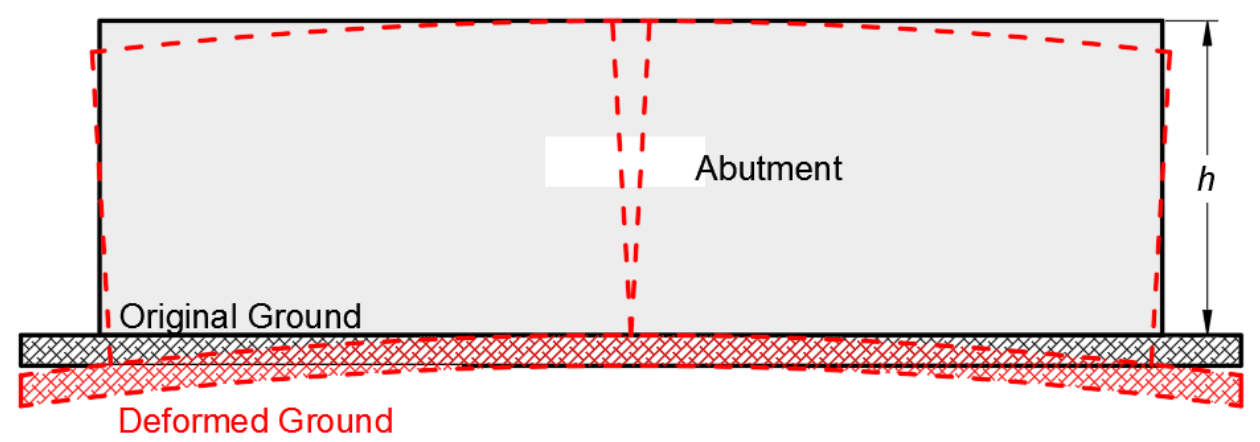

Figure 5.5 Schematic of integrity of abutment

\subsection{Case Study}

A case study is used here to demonstrate the techniques for assessing the subsidence influence to a set of interstate highway overpass bridges over a rural road to be mined under by longwall mining operations. The spatial relation between the bridge and the longwall panel is shown in Fig. 5.6. The rib-to-rib panel width is about $1,026 \mathrm{ft}(313 \mathrm{~m})$. The mining direction is from east to west. The overburden depth at the location of the bridge is about $610 \mathrm{ft}(186 \mathrm{~m})$ while the mining height is about $7.5 \mathrm{ft}(2.3 \mathrm{~m})$. The ratio of the panel width to overburden depth is about 1.68 indicating that a supercritical subsidence basin will be formed over the panel (Peng, 1992). The bridge axial direction forms an angle of 62 degrees with the longitudinal direction of the panel. The nearest and farthermost distances between the panel headentry and the bridge are about 226 and $385 \mathrm{ft}$ (69 and 
$117 \mathrm{~m})$, respectively. Each of the 3-span bridges, with two intermediate piers, is $127 \mathrm{ft}(38.7 \mathrm{~m})$ long as shown in Fig. 5.7. The middle span between the two intermediate piers is about $51 \mathrm{ft}(15.5$ $\mathrm{m})$ while each of the two side spans is about $38 \mathrm{ft}(11.6 \mathrm{~m})$. There are 24 contact points between the piers/abutments and the steel beams on each bound bridge as shown in Fig. 5.6. The contact points on the eastbound bridge are numbered as E1 to E24 while those on the westbound are called W1 to W24 and the subsidence predictions are performed at these contact points.

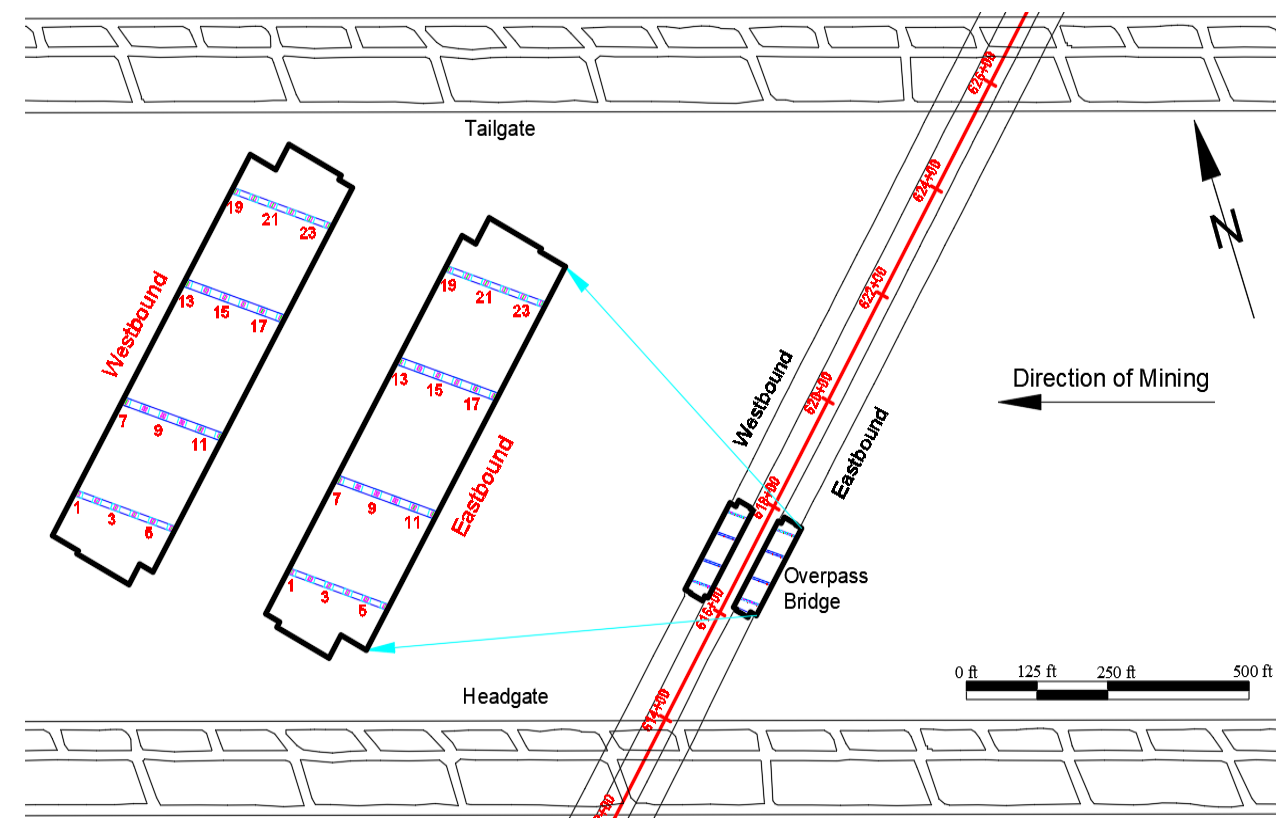

Figure 5.6 Overview of the subsidence study site

\subsubsection{Subsidence Prediction}

In order to assess the potential influence of the ground subsidence process on the bridges, the subsidence prediction program package CISPM (Luo, 1989) is used to predict the final and dynamic surface movements and deformations in the area of study. For the direction dependent surface movements and deformations, their respective components along the axial direction of the bridges are presented in this study. 


\subsubsection{Final Subsidence Prediction}

The final subsidence prediction is used to assess the permanent influence of the subsidence to the bridges as the longwall face has past the area for a sufficient distance - typically 1.2 times of the overburden depth. The prediction shows that the bridges are located between the inflection point and the point of full subsidence of the final subsidence basin. The ranges of the predicted final subsidence indices on the bridges are listed in Table 5.1. Taking the eastbound bridge as an example, it will experience final surface subsidence in the range from 3.85 to $4.78 \mathrm{ft}$ (1.17 to 1.46 m) with average being about $4.32 \mathrm{ft}(1.32 \mathrm{~m})$, horizontal displacement from 0.042 to $0.801 \mathrm{ft}$ ( 0.504 to 9.612 inches or 1.28 to $24.41 \mathrm{~cm}$ ). The final slope ranges from 0.06 to $1.18 \%$. The bridge is located in the compression zone of the final subsidence basin with the surface strain ranging from $-1.59 \times 10^{-3}$ to $-1.06 \times 10^{-2} \mathrm{ft} / \mathrm{ft}(\mathrm{m} / \mathrm{m})$ showing that the maximum compressive strain is very significant. It will also experience convex curvature from $-2.06 \times 10^{-5}\left(-6.76 \times 10^{-5}\right)$ to $-1.37 \times 10^{-4}$ $1 / \mathrm{ft}\left(-4.49 \times 10^{-4} 1 / \mathrm{m}\right)$ which is also very high. Since the westbound bridge is located further away from the panel edge, the maximum surface deformations are smaller than those to be experienced by the eastbound bridge.

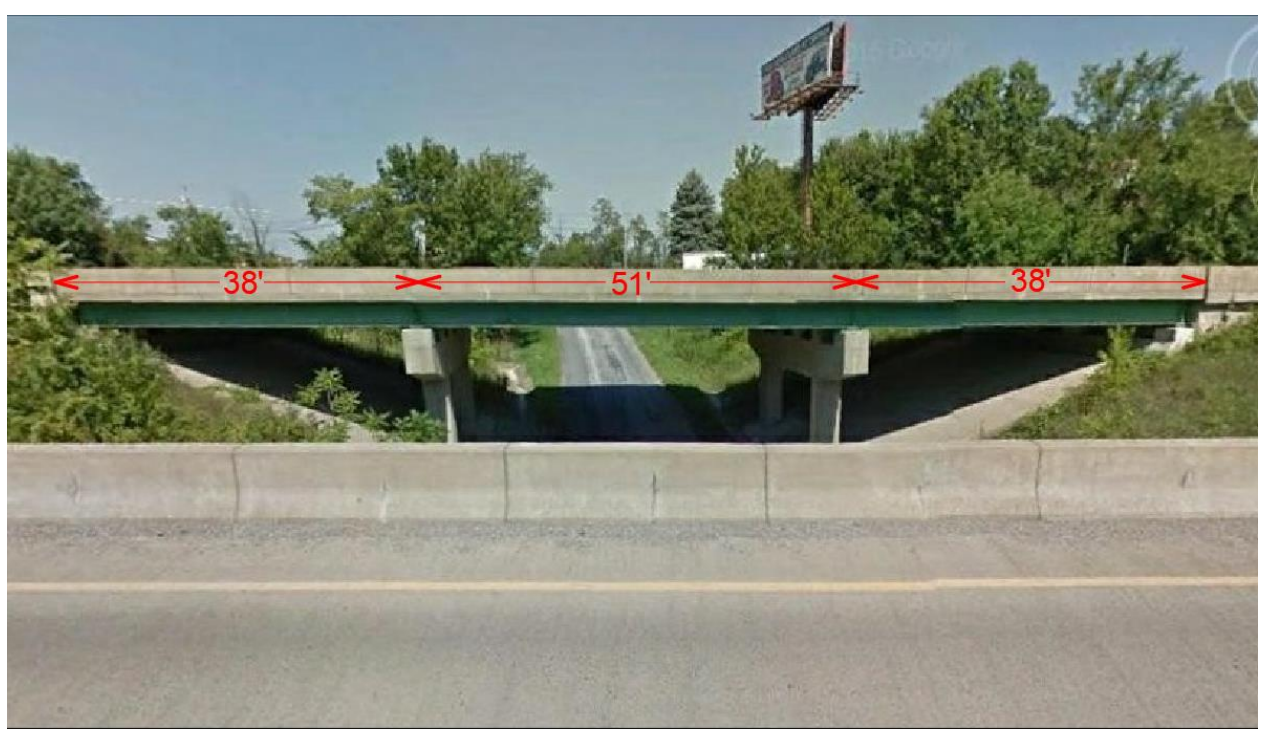

Figure 5.7 Images of the overpass bridge from google earth ${ }^{\circledR}$ 
Table 5.1 Ranges of predicted final surface movements and deformations across the bridge structures

\begin{tabular}{|c|c|c|c|c|c|}
\hline \multirow{2}{*}{ Item } & Subsidence & H.D. & Slope & Strain & Curvature \\
\cline { 2 - 6 } & $\mathrm{ft}$ & $\mathrm{ft}$ & $\%$ & $\mathrm{ft} / \mathrm{ft}$ & $1 / \mathrm{ft}$ \\
\hline \multicolumn{7}{|c|}{ Eastbound Bridge } \\
\hline Min. & 3.85 & 0.042 & 0.06 & $-1.59 \mathrm{E}-03$ & $-2.06 \mathrm{E}-05$ \\
\hline Max. & 4.78 & 0.801 & 1.18 & $-1.06 \mathrm{E}-02$ & $-1.37 \mathrm{E}-04$ \\
\hline Max. diff. & 0.93 & 0.759 & & & \\
\hline Average & 4.32 & 0.422 & 0.62 & $-6.10 \mathrm{E}-03$ & $-7.88 \mathrm{E}-05$ \\
\hline \multicolumn{7}{|c|}{ Westbound Bridge } \\
\hline Min. & 4.25 & 0.013 & 0.02 & $-7.31 \mathrm{E}-04$ & $-9.46 \mathrm{E}-06$ \\
\hline Max. & 4.82 & 0.510 & 0.76 & $-9.10 \mathrm{E}-03$ & $-1.18 \mathrm{E}-04$ \\
\hline Max. diff. & 0.57 & 0.497 & & & \\
\hline Average & 4.54 & 0.262 & 0.39 & $-4.92 \mathrm{E}-03$ & $-6.37 \mathrm{E}-05$ \\
\hline
\end{tabular}

\subsubsection{Dynamic Subsidence Prediction}

As described previously, the bridge structures are very sensitive to the surface movements and deformations during and after the underground longwall mining operation. The potential effects of dynamic subsidence process on the bridges should be accurately assessed. In order to assess the likelihood for the bridges to survive the subsidence process, the dynamic subsidence predictions were performed at all the 48 contact points on the bridges. For this chapter, only the prediction results for the eastbound bridge are presented. A face advance rate of $90 \mathrm{ft} / \mathrm{day}(27.4$ $\mathrm{m}$ /day), easily achievable by the mine, was used in the dynamic subsidence predictions. Higher face advance rate would further reduce the maximum dynamic deformations (i.e., slope, strain and curvature) (Peng, 1992). A total of 11 sets of dynamic subsidence predictions are conducted as the longwall face advances every $100 \mathrm{ft}(30.5 \mathrm{~m})$ from -150 to $950 \mathrm{ft}$ (-46 to $290 \mathrm{~m}$ ) past contact point E24 - the first point to experience subsidence among the 48 points on the bridges.

The development curves of the predicted surface dynamic subsidence at the contact points are shown in Fig. 5.8. There is little subsidence before the longwall face reaches directly under the point of interest. The subsidence process accelerates afterwards and reaches about one half of 
the final subsidence when the longwall face is between 250 and $350 \mathrm{ft}$ (76 and $107 \mathrm{~m}$ ) past reference point E24. At this time, the subsidence process is most active and the subsidence velocity is highest. A decelerating process is followed and the ground surface regains its stable condition when the face is about $750 \mathrm{ft}(229 \mathrm{~m})$ outby the contact point E24. The final surface subsidence at those points range from 4.1 to $4.8 \mathrm{ft}$ (1.25 to $1.46 \mathrm{~m})$.

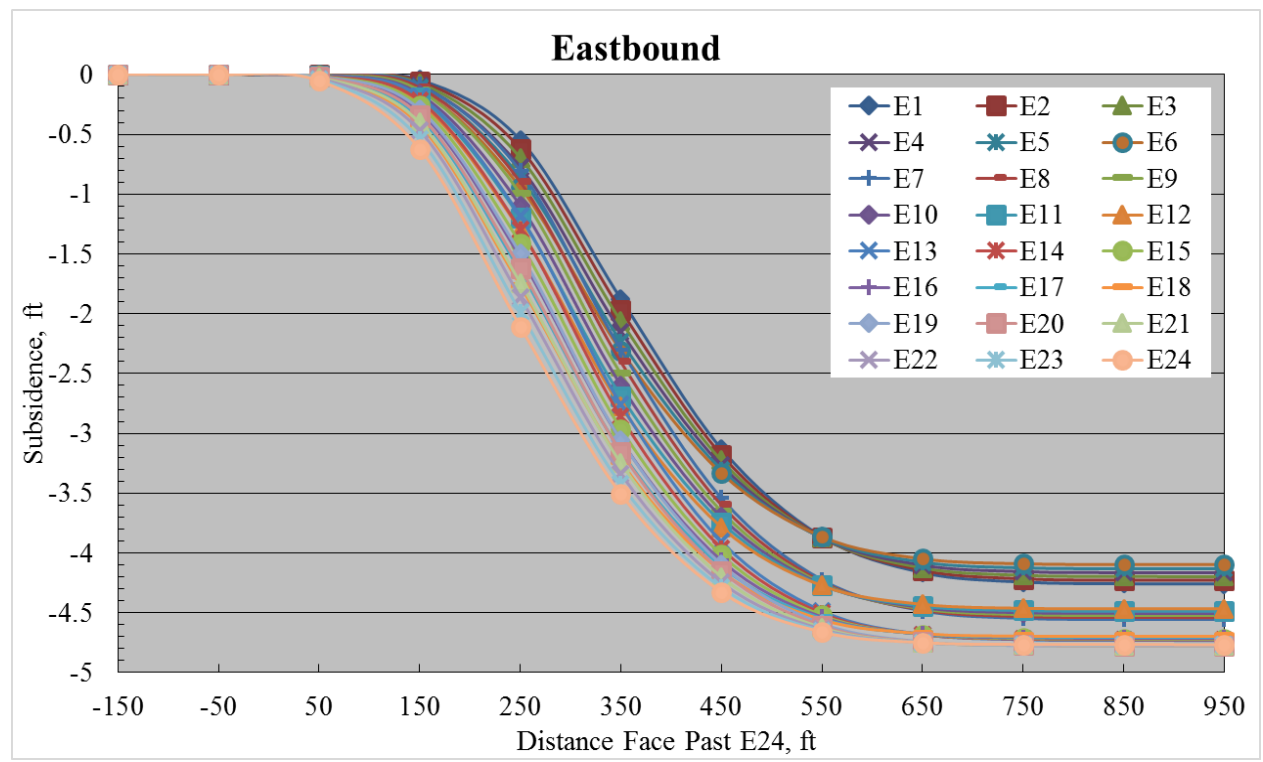

Figure 5.8 Development curves of dynamic subsidence for the eastbound overpass bridge

Based on the predicted subsidence, the differential subsidence across each steel beam marked with paired points (i.e. E1-E19, W1-W19) on bridge abutments can be calculated for different longwall face locations as shown in Fig. 5.9. The positive values in the figure indicate that for a pair of points (a beam), the subsidence on the north end abutment is larger than that on the south end abutment. The maximum differential subsidence is about $1.20 \mathrm{ft}(36.6 \mathrm{~cm})$ for E6-E24 on the eastbound bridge when the longwall face past point E24 a distance of $400 \mathrm{ft}(122 \mathrm{~m})$. Figure 5.9 also shows that the differential subsidence on each paired points (beam) for eastbound bridge 
has the almost same development pattern during the dynamic subsidence process. When the subsidence process is over, the differential subsidence between the paired points on the bridge abutments ranges from 0.52 to $0.67 \mathrm{ft}(6.24$ to 8.04 inches or 15.8 to $20.4 \mathrm{~cm})$.

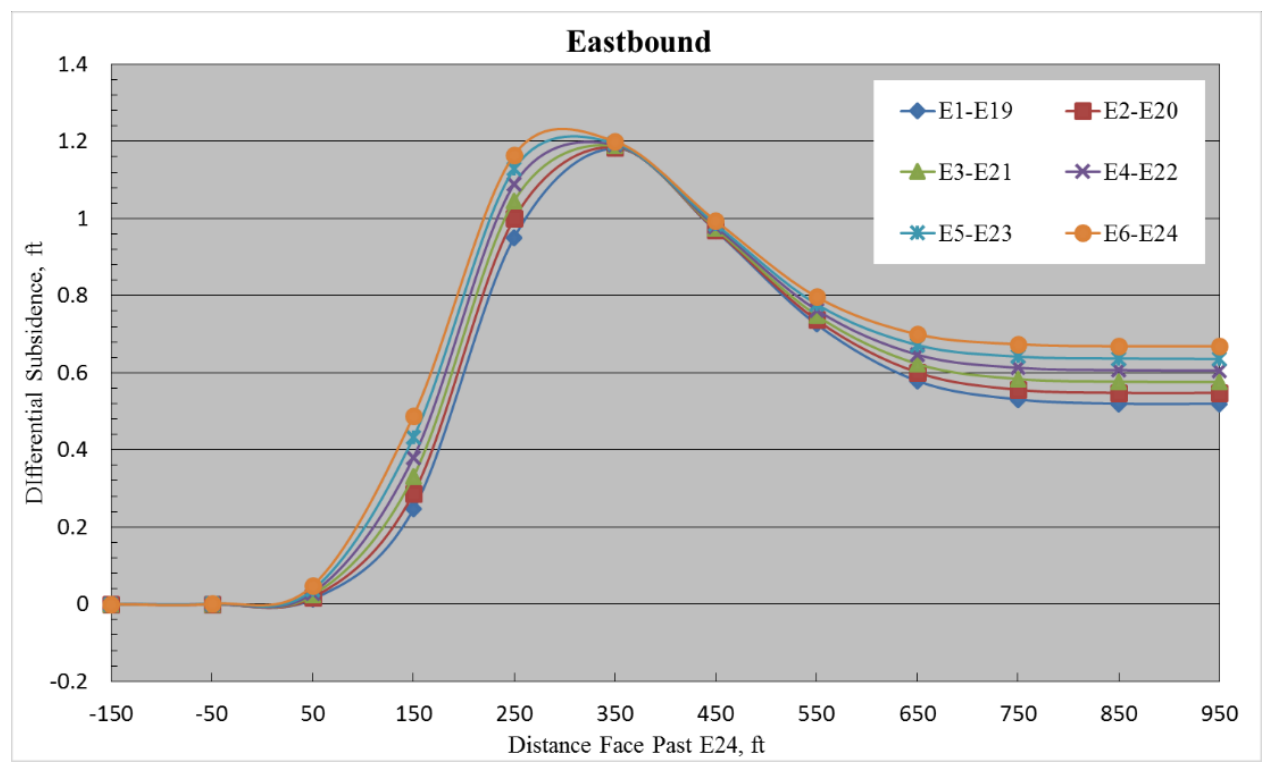

Figure 5.9 Differential subsidence between paired points (steel beams) on the eastbound bridge abutments

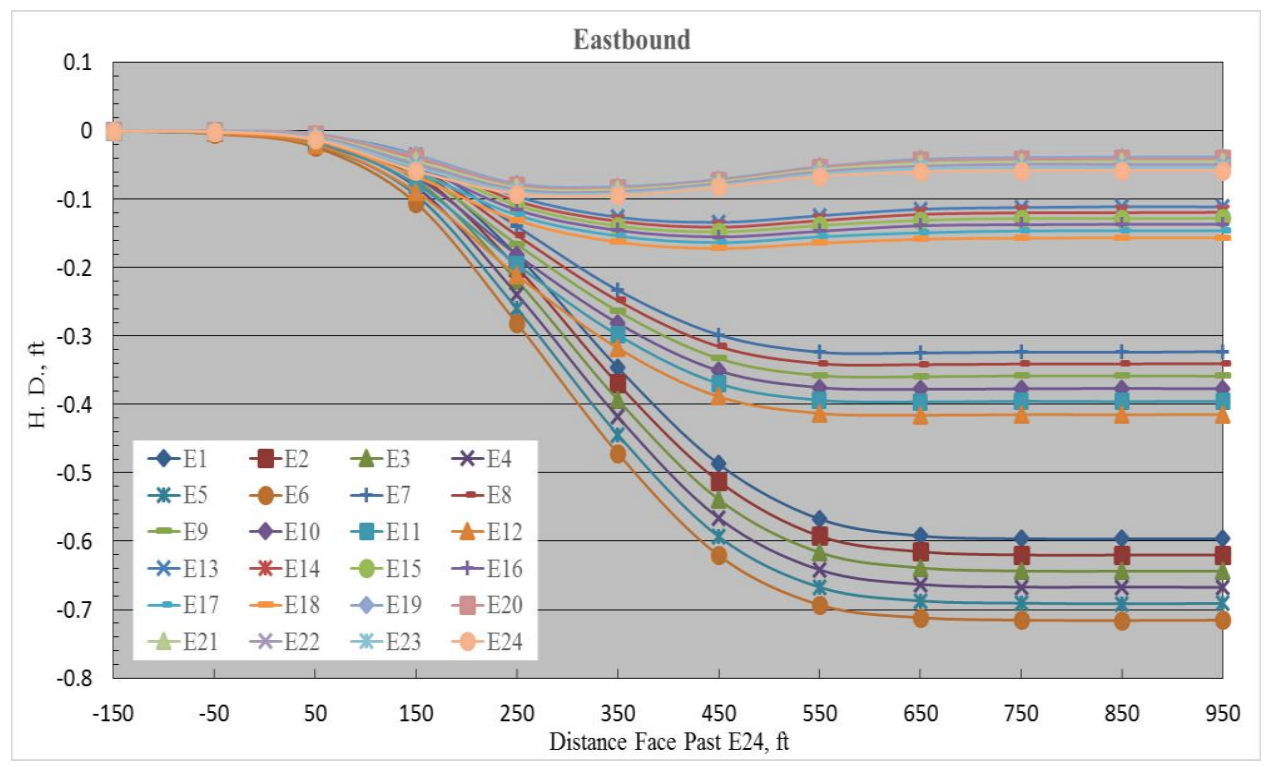

Figure 5.10 Development curves of dynamic horizontal displacement for the eastbound overpass bridge

The development curves of the predicted dynamic horizontal displacement (component along bridge axial direction) at those contact points are plotted in Fig. 5.10. The negative values 
in the figure indicate that the movement is toward the panel center. The maximum dynamic horizontal displacement is about $-0.71 \mathrm{ft}(-8.52$ inches or $-21.6 \mathrm{~cm})$ at point E6. The bridges regain the lateral stability when the longwall face has past point E24 a distance of about $750 \mathrm{ft}(229 \mathrm{~m})$.

Similar to the differential subsidence between the paired points on bridge abutments, the differential horizontal displacement between the paired points on bridge abutments are also calculated and plotted in Fig. 5.11. The negative value in the figure stands for that the horizontal displacement on the north end abutment is less than that on the south and the bridge deck will experience compression. Figure 5.11 shows that the differential horizontal displacement on each paired points has the almost same distribution and magnitude during the dynamic subsidence process. The maximum differential horizontal displacement is about $-0.66 \mathrm{ft}(-7.92$ inches or $-20.1 \mathrm{~cm})$ on the eastbound bridge when the longwall panel subsidence process is over.

The development curves of the predicted dynamic strain (component along abutment axial direction) on abutments are plotted in Fig. 5.12. The abutments begin to experience some minor tension when the longwall face is about $50 \mathrm{ft}(15 \mathrm{~m})$ inby the reference point E24. The tensile strain increases as the face advances with the maximum tensile strains being about $2.47 \times 10^{-3}$ and $4.76 \times 10^{-3} \mathrm{ft} / \mathrm{ft}(\mathrm{m} / \mathrm{m})$ for south and north end abutments, respectively, when the face is about 150 $\mathrm{ft}(46 \mathrm{~m})$ past the point E24. The tensile strain decreases as face advances and then the abutments enter the dynamic compression stage. The maximum dynamic compressive strains are $-4.44 \times 10^{-3}$ and $-2.98 \times 10^{-3} \mathrm{ft} / \mathrm{ft}(\mathrm{m} / \mathrm{m})$ for south and north end abutments, respectively, when the face is about $450 \mathrm{ft}(137 \mathrm{~m})$ past the point E24. Finally, the abutments will be in the minor compression condition. 


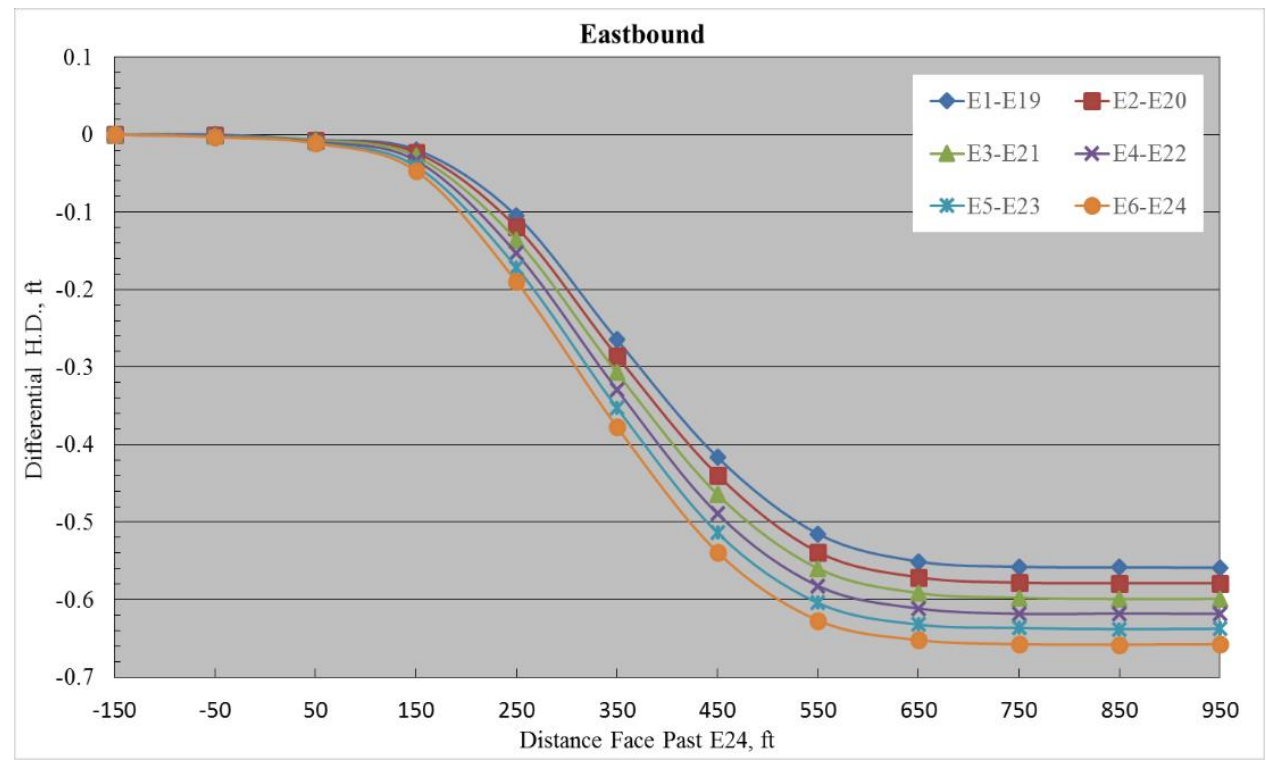

Figure 5.11 Differential horizontal displacement between paired points on end abutments

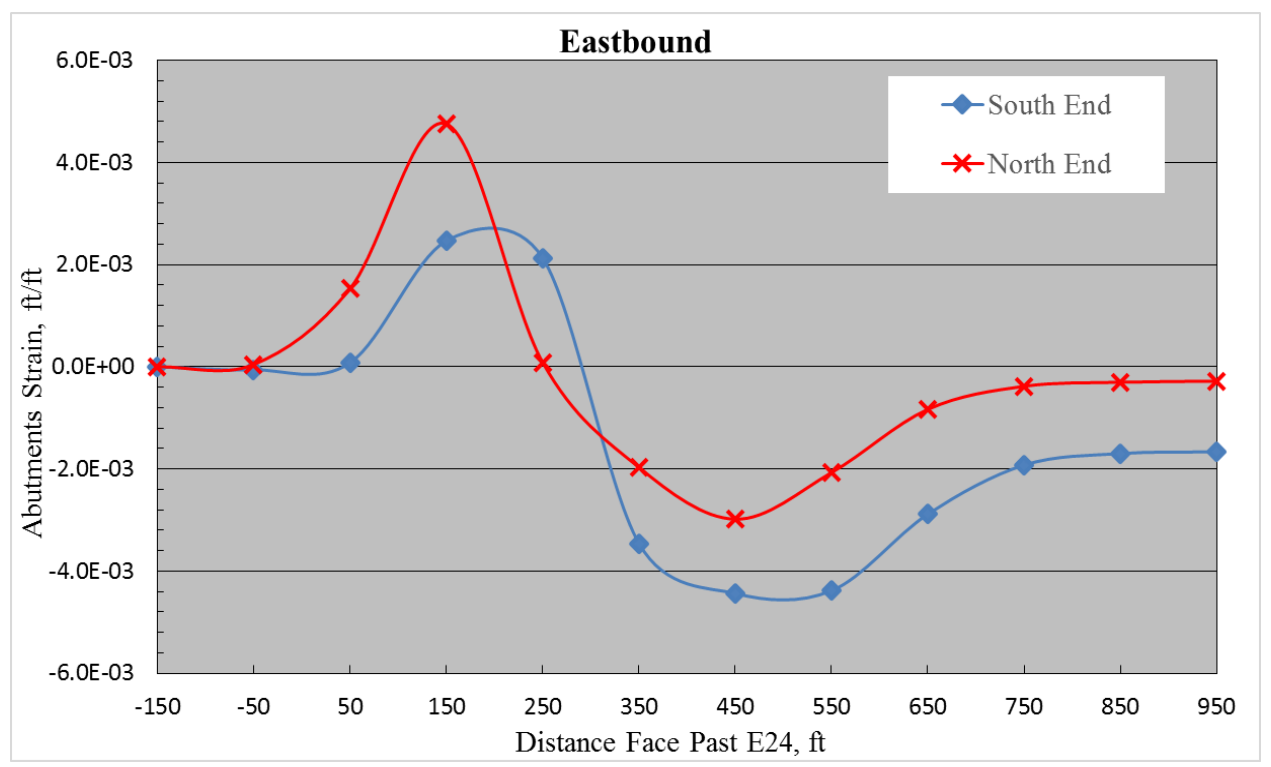

Figure 5.12 Development curves of dynamic strain on abutments for the eastbound overpass bridge

Figure 5.13 shows the dynamic curvature development curves for the end abutments along their axial direction. Their distributions are very similar to those of dynamic strain. A positive value indicates a convex bending while a negative one for concave bending. It shows that abutments will experience convex bending in the first half of the dynamic subsidence process and concave bending in the second half of the dynamic subsidence process. The maximum convex 
curvature, ranging from $4.26 \times 10^{-5}$ to $8.44 \times 10^{-5} 1 / \mathrm{ft}\left(1.40 \times 10^{-4}\right.$ to $\left.2.77 \times 10^{-4} 1 / \mathrm{m}\right)$, is reached when the longwall face is between 150 and $250 \mathrm{ft}$ (46 and $76 \mathrm{~m}$ ) past the point E24 while the maximum concave curvature is ranging from $-4.83 \times 10^{-5}$ to $-6.85 \times 10^{-5} 1 / \mathrm{ft}\left(-1.58 \times 10^{-4}\right.$ to $\left.-2.25 \times 10^{-4} 1 / \mathrm{m}\right)$ when the face passed the point E24 about $400 \mathrm{ft}(122 \mathrm{~m})$.

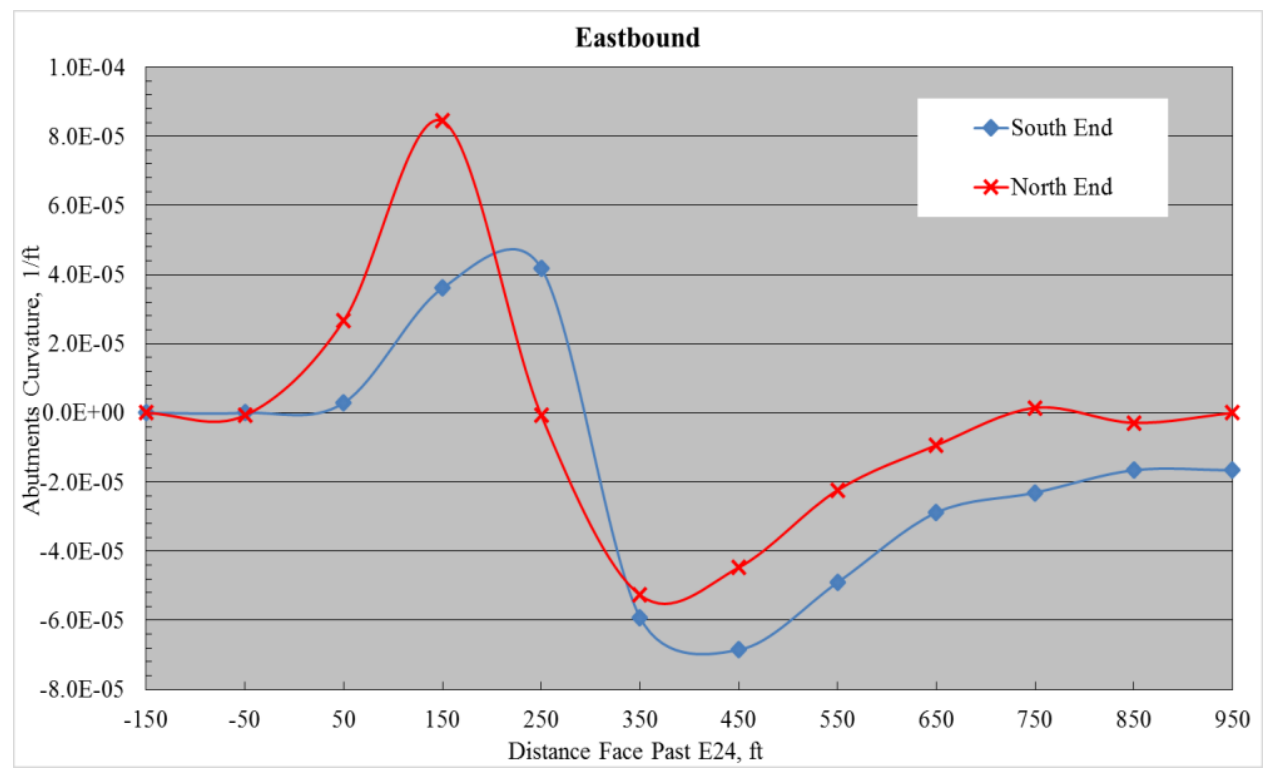

Figure 5.13 Dynamic curvature developed on the end abutments and pier caps

\subsubsection{Assessment of Subsidence Influence on Bridges}

Based on the predicted dynamic subsidence and horizontal displacements at the contact points, the influence of the subsidence process on the structural integrity, functionality of the bridge structures can be assessed. In this chapter, only the subsidence influence on eastbound bridge are accessed and presented.

\subsubsection{Separation or Closure between End Abutments}

Using the subsidence prediction results and the introduced assessment techniques, the development curves of the predicted dynamic separation or closure (component along bridge axial direction) between the paired points on eastbound bridge abutments are determined and plotted in Fig. 5.14. To calculate the separation or closure between the paired points, both the predicted 
dynamic subsidence and horizontal displacements at each mining stages are considered. The predicted movements are superposed on the original elevations and coordinates of these contact points. The original elevations of the points on the end abutments for the eastbound bridge are collected and shown in Table 5.2.

In Fig. 5.14, a negative value indicates the distance between the paired points is decreased. It shows that the distance will be decreasing continuously during the entire subsidence process. When the subsidence process is over, the maximum closure distance is about $0.64 \mathrm{ft}$ ( 7.68 inches or $19.5 \mathrm{~cm}$ ) on the eastbound bridge.

Based on the bridge design, the bridge has two expansion joints and each of the expansion joint is 2 inches $(5.08 \mathrm{~cm})$ wide. Therefore, the bridge decks can tolerate a maximum closure of 4 inches $(10.16 \mathrm{~cm})$. However, the predicted maximum closure is much larger than the total width of expansion joints. The uncompensated closure could induce significant compressive force on the bridge decks. In this case, the subsidence induced compressive strain on the bridge deck could be up to $2.44 \times 10^{-3} \mathrm{ft} / \mathrm{ft}(\mathrm{m} / \mathrm{m})$.

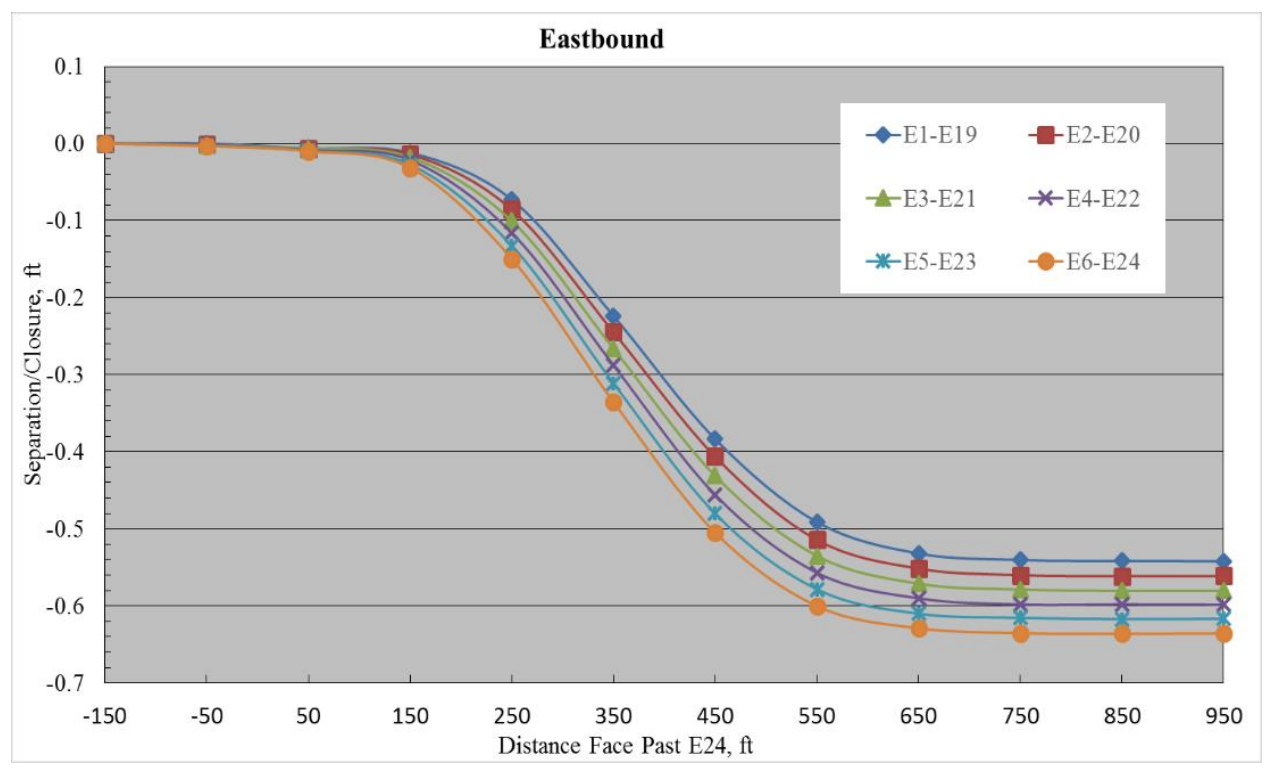

Figure 5.14 Predicted separation/closure between the paired points on eastbound bridge abutments 
Table 5.2 Original elevations of contact points on eastbound bridge abutments

\begin{tabular}{|c|c|c|c|c|c|c|c|c|}
\hline \multirow{4}{*}{ Eastbound } & \multicolumn{2}{|l|}{ Point } & E1 & E2 & E3 & E4 & E5 & E6 \\
\hline & Elevation & $\mathrm{ft}$ & 1282.7 & 1282.6 & 1282.4 & 1282.2 & 1282.0 & 1281.7 \\
\hline & \multicolumn{2}{|l|}{ Point } & E19 & E20 & E21 & E22 & E23 & E24 \\
\hline & Elevation & $\mathrm{ft}$ & 1278.9 & 1278.8 & 1278.6 & 1278.4 & 1278.2 & 1277.9 \\
\hline
\end{tabular}

\subsubsection{Deflections of Steel Beams}

For each of the overpass bridges, each steel beam is supported by two end abutments and two intermediate piers between. Using the introduced method, the development curves of beam deflection on the eastbound bridge at intermediate piers are plotted in Fig. 5.15. A positive value indicates that the elevation of a contact point is higher than the straight line connecting the paired points on abutments. It shows that the steel beams will have positive deflections in the early stage of the dynamic subsidence process. During this period, the intermediate piers will be subjected to higher loads than before subsidence. The maximum positive deflection is about 0.55 inches (1.4 $\mathrm{cm}$ ) at points E12 and E18 (both along the south edge of the bridge as shown in Fig. 5.6) when the longwall face has past reference point E24 a distance of $150 \mathrm{ft}(46 \mathrm{~m})$. Using Eq. 5.3, the maximum possible uplift at the deck end where the support beams sit on flexible bearings could be up to 1.7 inches $(4.2 \mathrm{~cm})$ when the beams are assumed to be rigid. Such a large uplift could create hazardous condition for an approaching vehicle at high speed.

When the longwall face has past point E24 a distance from 250 to $350 \mathrm{ft}$ (76 to $107 \mathrm{~m}$ ), the beams begin to experience negative deflections. The negative deflections increase as the face moves away from the bridge. When the subsidence process is over, the maximum negative deflection is about 2.0 inches $(5.08 \mathrm{~cm})$ at E12. Therefore, the intermediate piers after the early subsidence process will be under-loaded and most of the bridge loads will be carried by the end abutments. 


\subsubsection{Twisting of Bridge Decks}

Based on the predicted dynamic subsidence at the contact points, the twisting condition of the bridge beam-deck system is assessed. Figure 5.16 shows the estimated maximum heights off the planes that are fixed at different three corner points. The maximum uplift height is about 3.0 inches $(7.62 \mathrm{~cm})$ when the longwall face is about $250 \mathrm{ft}(76 \mathrm{~m})$ past the point E24. The amount will decrease to almost zero but increase again. When the subsidence process is over, the gap height is about 1.8 inches $(4.57 \mathrm{~cm})$. It should be noted that the gap height also creates a step between the bridge deck and the approaching platform.

\subsubsection{Integrity of End Abutments}

Using Eq. 5.6 and the predicted dynamic strain and curvature at the end abutment locations, the total strain for the top surface of the $7.5 \mathrm{ft}(2.29 \mathrm{~m})$ tall abutments are estimated and plotted in Fig. 5.17. It shows that the maximum tensile strain, ranging from $2.74 \times 10^{-3}$ to $5.39 \times 10^{-3} \mathrm{ft} / \mathrm{ft}$ $(\mathrm{m} / \mathrm{m})$, occurs when the face passed the point E24 about $150 \mathrm{ft}(46 \mathrm{~m})$. Therefore, it is likely for the dynamic subsidence process to cause cracks on the top surface of the abutments.

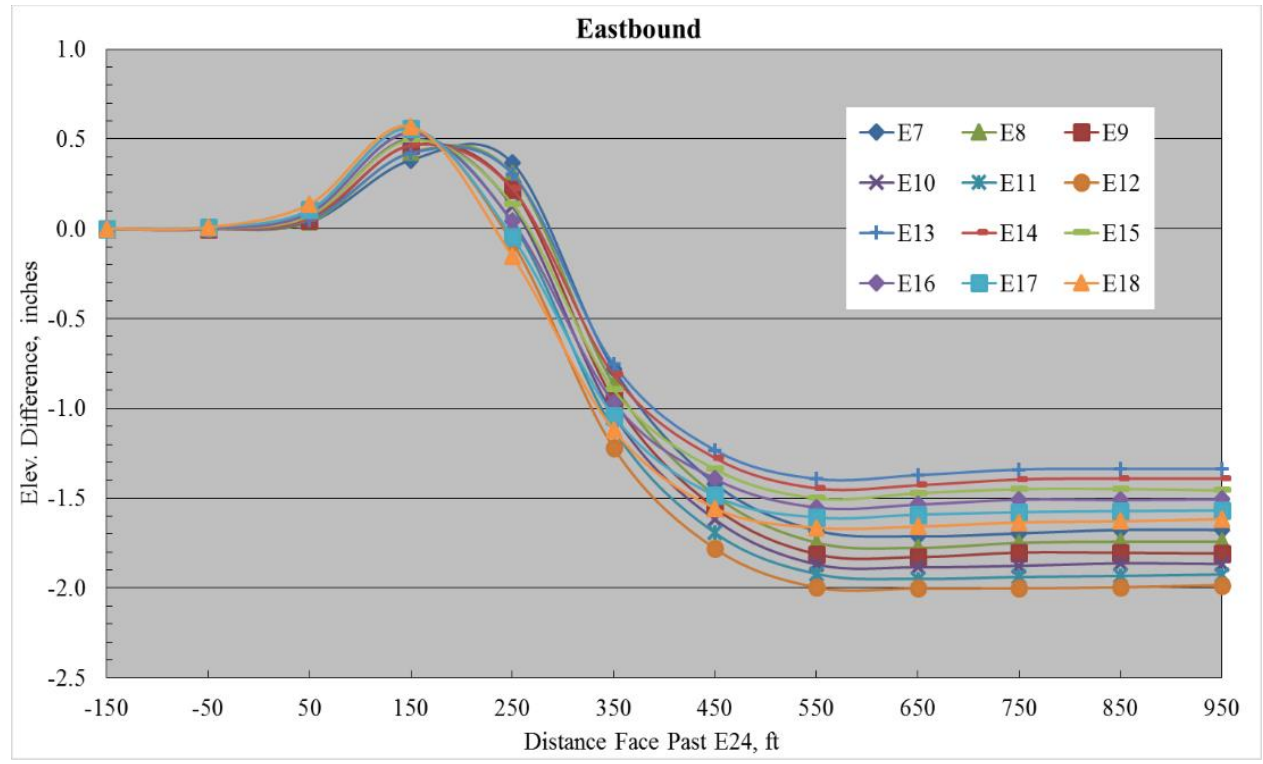

Figure 5.15 Development curves of maximum deflection of steel beam at intermediate piers 


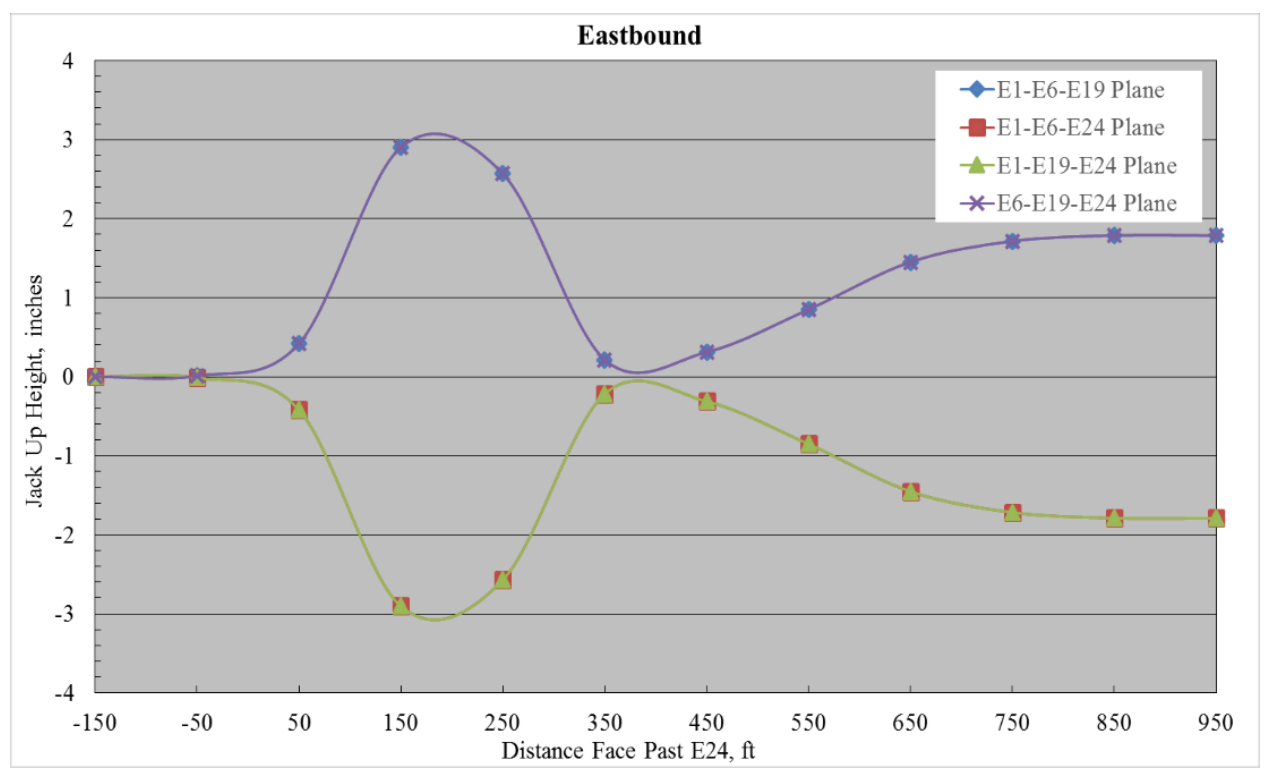

Figure 5.16 Development curves of twisting conditions on the bridge decks

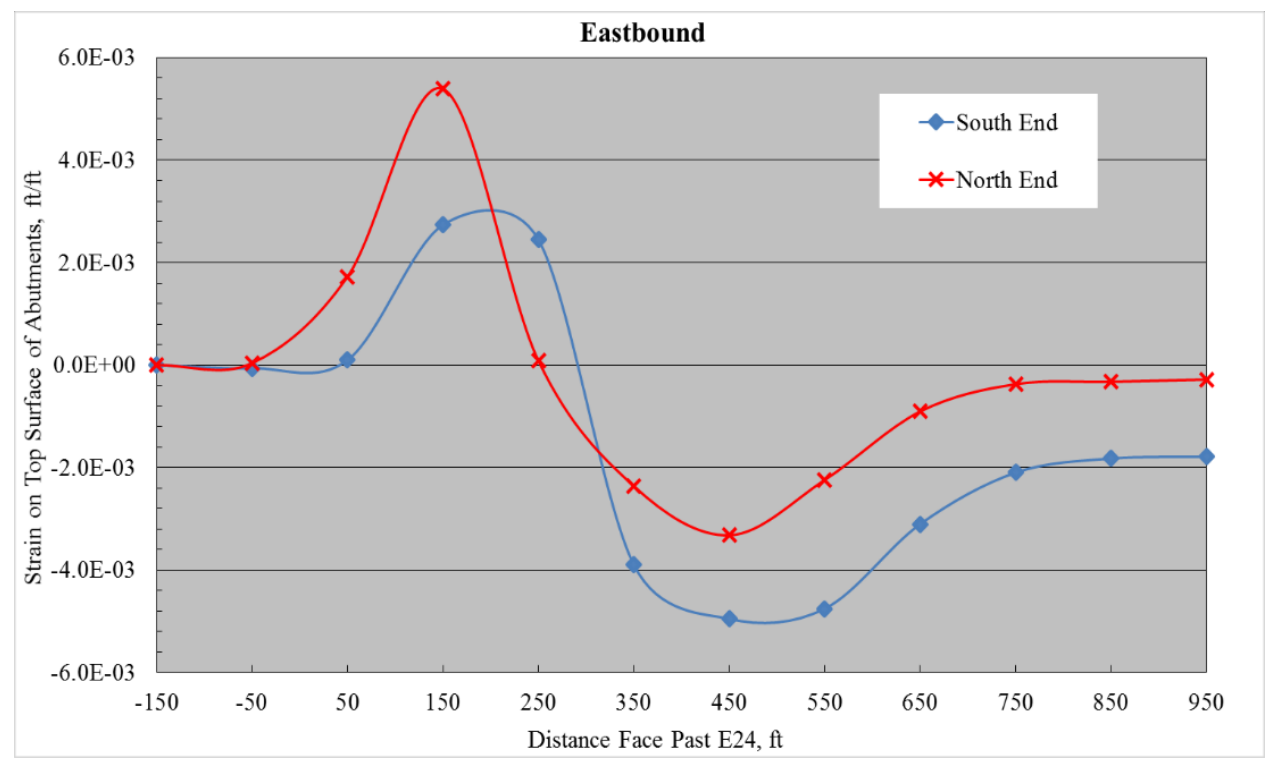

Figure 5.17 Dynamic strain developed on the end abutments

\subsubsection{Recommended Mitigation Measures for Bridges}

In the case study, it is found that the ground subsidence process induced by the longwall mining operation could cause significant closure between the end abutments, significant deflections on bridge beams, twisting conditions on beam-decks system, tensile strain on top surface of the abutments, etc. These influences could significantly affect the integrity and stability of the 
bridge structures such as beams and decks and reduce the functionality of the bridges. However, through the subsidence predictions and influence assessment, the causes and timing of these anticipated problems are identified and their severities are quantified. Using such knowledge, effective mitigation measures could be designed and implemented to significantly reduce the severity of the anticipated influence to the bridges. The following precautionary and mitigation measures should be considered for protecting the bridges when they are mined under by the underground longwall operation.

\subsubsection{Traffic Speed Control}

In order to reduce dynamic load of traffic to the bridge structures, it is recommended to post and enforce a significantly lower speed limit (e.g., $45 \mathrm{mph}$ or $72 \mathrm{~km} / \mathrm{h}$ ) in the section of the interstate highway and the bridges to be subsided and some distance beyond. The slower moving vehicle can significant reduce the dynamic loads on the bridge structures and increase the traffic safety. The speed reduction should be enforced during the preparation of the subsidence mitigation measures, the entire subsidence process and the damage repairs.

\subsubsection{Compensation Gaps on End Abutments}

To reduce the anticipated compressive force in or even possible buckling failure of the bridge decks due to the excessive closure between the abutments, a compensation gap should be cut between the end of the bridge decks (including its support beams) and the abutments on each end of each bridge. For the eastbound bridge, each of the compensation gaps should be about 4 inches $(10.16 \mathrm{~cm})$ wide. After the compensation gaps are created, thick steel plates should be used to cover those gaps, each plate for one lane and its adjacent shoulder. The ends of the plate should be angled for smooth traffic entrance and exit. 


\subsubsection{Temporary Piers Erected Beside the Intermediate Piers}

As discussed in the previous assessment, the intermediate piers during most of the dynamic subsidence process and after the subsidence event will be unable to provide the required supports to the bridge beams and decks. It is recommended to erect one temporary pier beside each of the existing intermediate piers. Hydraulic jacks with stroke distance of 4 inches $(10.16 \mathrm{~cm})$ should be installed between top of the temporary piers and the steel beams. During the subsidence process, the hydraulic pressure should be monitored and adjusted in daily basis so that the required support ability of piers to the bridge super-structures can be adequately maintained.

\subsubsection{Plane Fitting Method}

In order to prevent the twisting condition from being developed on the bridge decks, the plane fitting method (Luo and Peng, 1991) is recommended to be carried out during the dynamic subsidence process. To employ this method for protecting the bridge decks, height-adjustable devices are strategically placed under the bridge decks. Subsidence monuments are installed near these installed height-adjustable devices. During the dynamic subsidence process, daily subsidence survey should be performed on the monuments. The measured ground movements will be analyzed immediately using a computer program to find an inclined plane to place the bridge decks on so that the decks are free of any stresses induced by curvature and twisting during the dynamic subsidence process. The plane fitting program will generate the necessary adjustments on the height-adjustable devices while maintaining the required adjustment to a minimum. The recommended height adjustment after each subsidence survey should be implemented by a mitigation crew immediately. 


\subsubsection{Post-Subsidence Repairs}

After the dynamic subsidence process over the longwall panel is finished, the abutments and intermediate piers should be reconstructed to make the contact point on a straight line and recover their required support abilities. New bearing system should be installed to connecting the piers and bridge beams. After that, the temporary piers and hydraulic jacks can be removed. In addition, the expansion joints should be redesigned by filling or widening the compensation gaps. The approach slabs and bridge decks should be repaved to smooth the transition section between the bridge decks and approach slabs.

\subsection{Summaries}

The effects of surface subsidence caused by underground mining activities, especially longwall mining operations, on bridge structures have been assessed. The assessments indicate that the subsidence events could cause integral, stable and functional problems to the bridge decks and beams. In order to maintain the functionality of the influenced bridges and ensure the safety of traffic, the potential subsidence influence should be correctly assessed and properly mitigated based on accurate subsidence prediction. The movements and deformations of bridge structures are analyzed to determine the integrity and stability related factors such as separation/closure between abutments, deflection of beams, twisting of decks, integrity of abutments, etc. for the bridges. Due to the practical limitation, the mitigation measures can be divided into: (1) temporary mitigation measures to maintain the stability and functionality of bridges during the active subsidence period, and (2) permanent repair of the movements and deformations of the bridge structures for the resumption of normal traffic after the subsidence event. A case study was employed to demonstrate these influence assessments and mitigation measures to protect the bridge structures. 


\section{CHAPTER 6 EFFECTS OF DEWATERING FLOODED INACTIVE ROOM-AND-PILLAR MINES ON SURFACE SUBSIDENCE}

\subsection{Introduction}

For room-and-pillar mining operations, their potential to induce surface subsidence is mainly dependent on the recovery ratio in the underground mines that directly relates to the stability of pillars. Normally, if the recovery ratio is less than $50 \%$, the mine pillars are sufficient to support the overburden strata without their collapse in sufficiently large contiguous area. Consequently, there will be no surface subsidence. However, if the recovery ratio is greater than $70 \%$, the pillars are too small to support the overburden strata and can cause immediate surface subsidence. A mathematical model has been proposed and a program has been developed by Luo and Peng (1993) to predict surface subsidence caused by high extraction room-and-pillar mining method.

When the recovery ratio is between $50 \%$ and $70 \%$, the mine pillars could be loaded near their critical condition and, therefore, the surface subsidence is uncertain to develop. If the surface subsidence did not occur immediately, mine water starts to fill the underground openings. If thick clay type of rock layers present in the mine roof, floor or pillars, they can be considerably weakened by mine water and cause surface subsidence. The techniques to investigate subsidence events over inactive room-and-pillar coal mines caused by the weakening effects of raising mine water to the claystone immediate roof and floor have been presented elsewhere (Luo, 2009 and 2011).

On the other hand, when the accumulated mine water level in a sealed mine is considerably higher than the mining level, the hydrostatic pressure can carry a significant fraction of the overburden load. If the mine water is withdrawn, the mine structures would subject to significantly 
more load and could fail and possibly lead to surface subsidence events. In this chapter, the potential effects of dewatering mine water on causing surface subsidence over inactive room-andpillar mines have been analyzed.

\subsection{Mathematical Models}

Dewatering of a flooded underground coal mine could cause two types of stability problems to the mine pillars and mine roof that could lead to surface subsidence events. The hydrostatic pressure could be reduced or disappeared due to the dewatering operation. The part of overburden load originally supported by hydrostatic pressure could be transferred to the mine pillars and mine roof, and could result in pillar and/or immediate roof failures. To assess the potential influences of dewatering to the mine structures, two models have been developed in the following two sections.

\subsubsection{Pillar Stability Model}

As indicated previously, a trough subsidence event is induced by a subsidence source with its lateral dimension larger than the effective width (typically more than one third of the overburden depth). The subsidence source could commonly be created by the failure of mine pillars in a large contiguous area when the immediate roof and floor strata are competent. Therefore, assessing the pillar stability is the key for investigating those reported subsidence cases over the inactive underground coal mines. The stability of pillar can be quantified by the safety factor (SF) of pillar. Normally, a pillar is considered as stable when its safety factor is greater than 1 . The safety factor is defined as the ratio of pillar strength $\left(S_{p}\right)$ to pillar stress $\left(\sigma_{p}\right)$ as shown in the following equation.

$$
S F=\frac{S_{p}}{\sigma_{p}}
$$


In the Eq. 6.1, the pillar strength can be calculated by the Bieniawski formula as shown in Eq. 6.2 or other pillar strength formulas (Bieniawski, 1968). In this formula, the pillar strength is related to the in-situ coal strength $\left(\sigma_{1}\right)$, equivalent pillar width $\left(W_{e}\right)$, and pillar height $(m)$. The equivalent pillar width is a function of its cross-sectional area $\left(A_{p}\right)$ and perimeter $\left(C_{p}\right)$ as shown in Eq. 6.3 which is useful since pillars in inactive mines are normally in irregular shape.

$$
\begin{aligned}
& S_{p}=\sigma_{1}\left(0.64+0.36 \frac{W_{e}}{m}\right) \\
& W_{e}=4 \frac{A_{p}}{C_{p}}
\end{aligned}
$$

In assessing the pillar stability under the influence of mine water, the tributary load method is used to assess the pillar load. As shown in Fig. 6.1, the overburden load $\left(F_{p}\right)$ on a pillar with its width, length and height being $W, L$ and $m$, respectively, can be determined using the tradition method (Eq. 6.4). In Eq. 6.4, $W_{r}$ stands for the entry or cross-cut width.

$$
F_{p}=h \cdot \gamma \cdot\left(W+W_{r}\right)\left(L+W_{r}\right)
$$
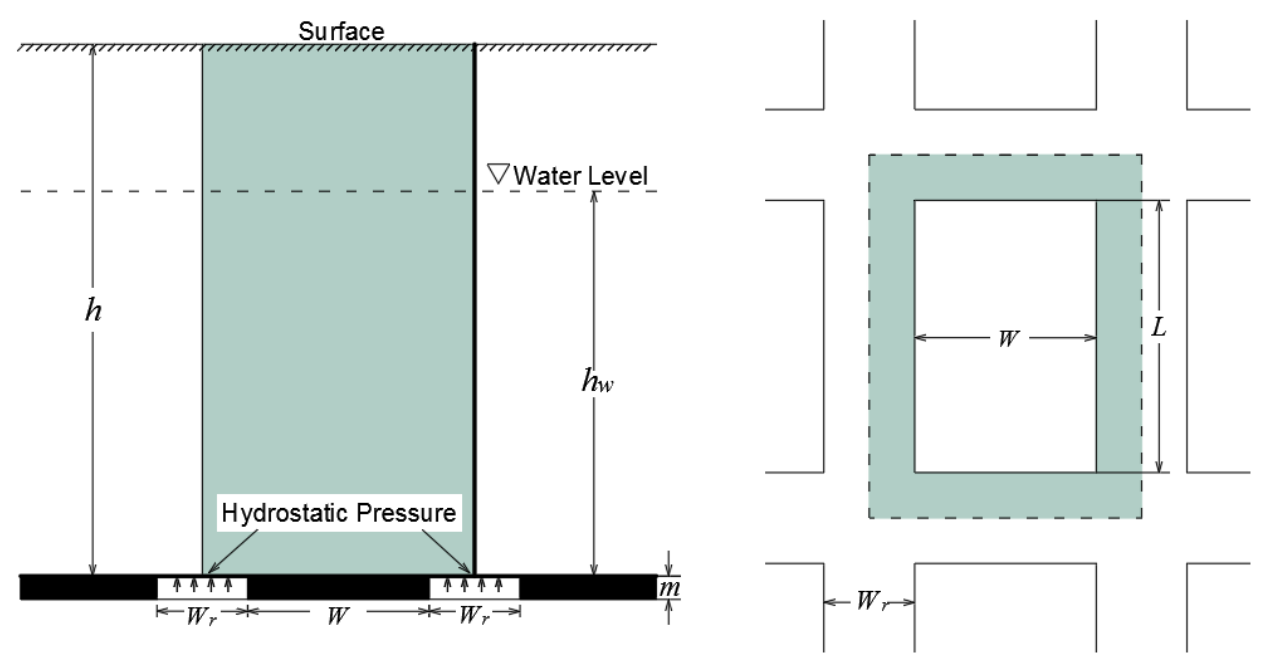

Figure 6.1 Schematic of hydrostatic pressure and tributary load method

However, when the inactive mine is filled with mine water with its water table significantly higher than the mining level, the hydrostatic pressure of the mine water plays a role to support the 
mine roof. The hydrostatic pressure $\left(P_{w}\right)$ is a function of the water level above the coal mine level $\left(h_{w}\right)$ and water density $\left(\gamma_{w}\right)$. The total tributary force $\left(F_{w}\right)$ supporting the mine roof induced by the hydrostatic pressure is the product of the hydrostatic pressure and the shaded area around the pillar as defined by Eq. 6.5.

$$
F_{w}=h_{w} \cdot \gamma_{w} \cdot\left[\left(W+W_{r}\right)\left(L+W_{r}\right)-W \cdot L\right]
$$

Therefore, the effective pillar stress can be estimated as:

$$
\sigma_{p}=\frac{\left(h \cdot \gamma-h_{w} \cdot \gamma_{w}\right)\left(W+W_{r}\right)\left(L+W_{r}\right)+h_{w} \cdot \gamma_{w} \cdot W \cdot L}{W \cdot L}
$$

In this case, it is assumed that underground mine structures such as roof, pillars and floor do not contain thick clay-rich rock layers such as mudstone and claystone or a new equilibrium after the failure of these clay-rich rock layers has been reached.

In an abandoned coal mine, the weathering and water erosion make the shapes of the remnant pillars irregular. Therefore, it is better to use the recovery ratio $(\eta)$ in the formula for pillar stress estimation. For an irregularly shaped pillar, its cross-sectional area $\left(A_{p}\right)$ and perimeter $\left(C_{p}\right)$ can be easily measured using an engineering CAD program and the recovery ratio was calculated. Therefore, the pillar stress can be estimated using Eq. 6.7.

$$
\sigma_{p}=\frac{h \cdot \gamma-h_{w} \cdot \gamma_{w}}{1-\eta}+h_{w} \cdot \gamma_{w}
$$

In order to gain the possible influences of each of the parameters on pillar stability, a sensitivity study has been performed on the five independent variables in Eqs. 6.2 and 6.7 (i.e., $h, h_{w} / h$, $\eta, \sigma_{i}$, and $\left.W_{e} / m\right)$. For the most concerned parameter of this study, the water level above the coal seam $\left(h_{w}\right)$, varies from 0 to $100 \%$ of the overburden depth $(h)$. It is assumed that all strata are permeable up to $h_{w}$. In the sensitivity study, the minimum, mean and maximum values of these 
variables are listed in Table 6.1. The mean values are used as the base and each of the variables varies from its minimum $(-100 \%)$ to it maximum $(+100 \%)$. The results of the sensitivity study are shown in Fig. 6.2. Apparently, the traditional rock mechanics parameters play important roles in pillar stability assessment. Among them, the overburden thickness has the largest impact on the pillar safety factor followed by the ratio of equivalent pillar width to mining height $\left(W_{e} / m\right)$, recovery ratio $(\eta)$ and in-situ coal strength $\left(\sigma_{i}\right)$. The water level above coal seam $\left(h_{w}\right)$ plays a secondary but still important role in pillar stability.

Table 6.1 Ranges of independent variables in sensitivity study

\begin{tabular}{|c|c|c|c|c|}
\hline Variables & Unit & Minimum & Mean & Maximum \\
\hline $\boldsymbol{h}$ & $\mathrm{ft}$ & 100 & 500 & 900 \\
$\boldsymbol{h}_{w} / \boldsymbol{h}$ & $\%$ & 0 & 50 & 100 \\
$\boldsymbol{\eta}$ & $\%$ & 55 & 65 & 75 \\
$\boldsymbol{\sigma}_{i}$ & $\mathrm{psi}$ & 600 & 750 & 900 \\
$\boldsymbol{W}_{e} / \boldsymbol{m}$ & $\%$ & 2 & 3.5 & 5 \\
\hline
\end{tabular}

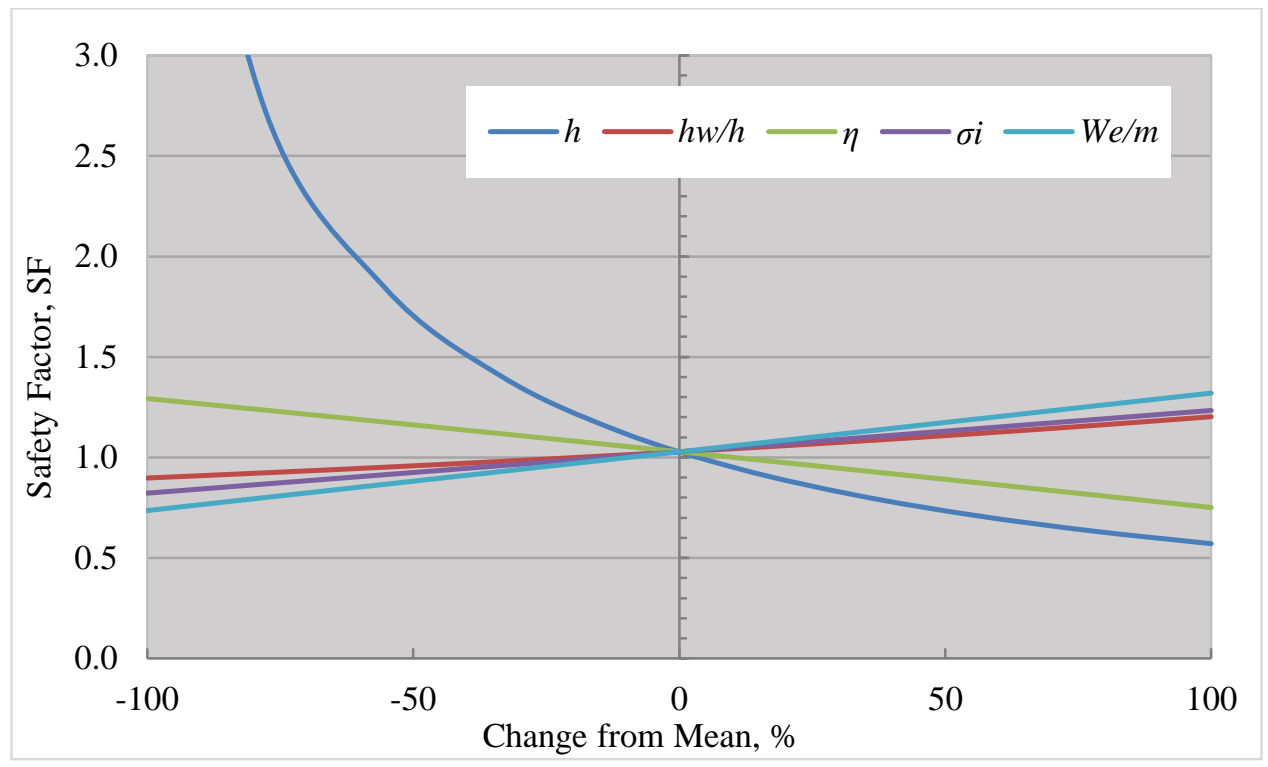

Figure 6.2 Change in safety factor vs. percent change in variables

For example, to analyze the sensitivity of the safety factor to the water head $\left(h_{w}\right)$, the average values of other four parameters were used. In this case, the pillar safety factor varies from 0.9 
to 1.2 when the water head changes from 0 to $500 \mathrm{ft}(152.4 \mathrm{~m})$. Therefore, dewatering an inactive flooded room-and-pillar mine could increases the load on the remnant pillars and consequently cause their failures. When the pillar failure occurs in a sufficiently large area, it could induce surface subsidence.

\subsubsection{Roof Stability Model}

A second mechanical model has been developed for assessing the stability of the immediate roof over the mine rooms that could lead to sinkhole subsidence over shallow mine area. Roof falls are likely to occur in mines with weak and thinly bedded immediate roof strata in the following two forms: (1) tensile failure at the middle part of mine entry due to excessive roof sag and bed separations, and (2) cutter roofs at the edge of the entry. The entry-crosscut intersection is the most possible originating location for the sinkhole subsidence since it has the longest unsupported roof span.

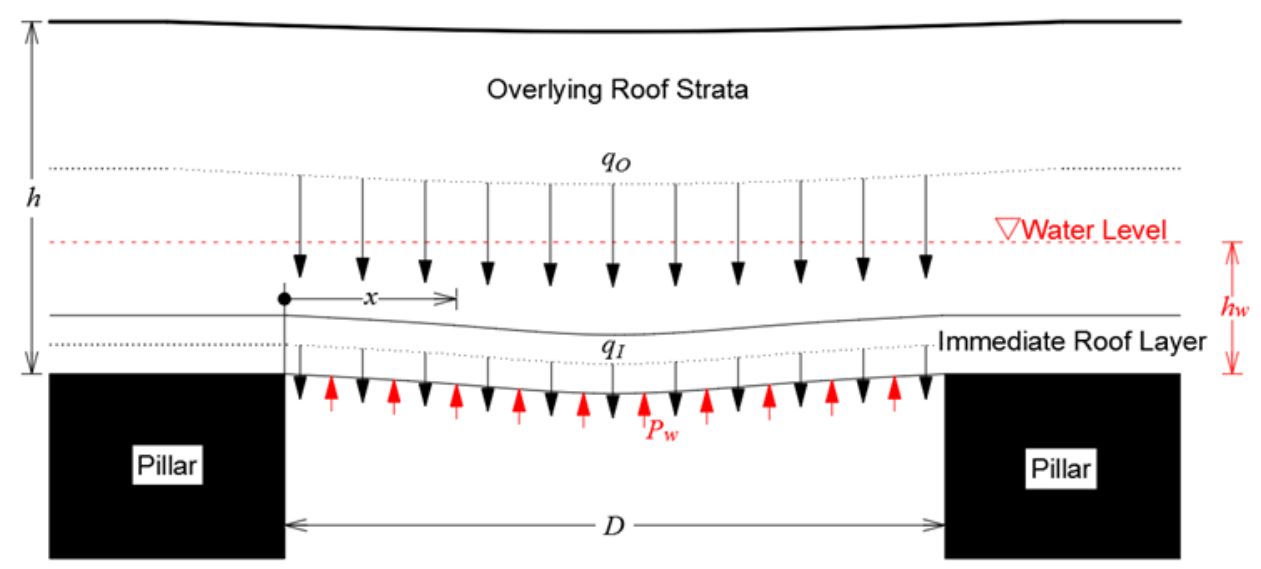

Figure 6.3 A beam with fixed ends for assessing mine roof stability in abandoned room-and-pillar mine

In this model, it is assumed that the roof does not have any type of support or the roof bolts have been eroded to perform their function in order to simplify this model. Similar to the previous model, the abandoned mine was filled with water with a water head of $h_{w}$. The hydrostatic pressure $\left(P_{w}\right)$ of the mine water produces a force $\left(F_{w}\right)$ to support the mine roof. The immediate roof strata 
can be treated as a beam with fixed ends. It is loaded with uniform overburden load $q_{O}$ and its own weight $q_{I}$ as shown in Fig. 6.3.

Using beam theory, the deflection of a bridging roof layer at a given point of interest, $S(x)$, can be determined by Eq. 6.8. In the equation, $E$ and $I$ are the modulus of elasticity and moment of inertia of the beam, respectively.

$$
S(x)=\frac{\left(q_{o}+q_{I}-P_{w}\right) \cdot x^{2}}{24 E I}(D-x)^{2}
$$

As a quick reference, the physical and mechanical properties of a number of common coal measure rocks in dry condition are shown in Table 6.2. However, it should be pointed out that the mechanical properties and strength of mudstone could be greatly affected by its moisture content (Luo, 2015a).

Table 6.2 Physical and mechanical properties of coal measure rocks in dry condition (Zhao, 2020)

\begin{tabular}{|c|c|c|c|c|c|c|c|c|c|c|}
\hline \multirow{2}{*}{ Rock Type } & \multicolumn{2}{|c|}{$\begin{array}{c}\text { Dry Density } \\
\text { lbs/ft }\end{array}$} & \multicolumn{2}{|c|}{$\begin{array}{c}\text { UCS } \\
\text { ksi }\end{array}$} & \multicolumn{2}{c|}{$\begin{array}{c}\text { Tensile } \\
\text { Strength } \\
\text { ksi }\end{array}$} & \multicolumn{2}{|c|}{$\begin{array}{c}\text { Young's } \\
\text { Modulus } \\
\text { Mpsi }\end{array}$} & \multirow{2}{*}{$\begin{array}{c}\text { Poisson's } \\
\text { Ratio }\end{array}$} & $\begin{array}{c}\text { Strain at } \\
\text { Failure, \% }\end{array}$ \\
\cline { 2 - 9 } & Min & Max & Min & Max & Min & Max & Min & Max & & \\
\hline Sandstone & 119 & 161 & 2.90 & 24.65 & 0.58 & 3.63 & 2.18 & 7.25 & 0.14 & 0.20 \\
\hline Shale & 125 & 150 & 0.73 & 14.50 & 0.29 & 1.45 & 0.73 & 4.35 & 0.10 & \\
\hline Mudstone & 113 & 168 & 1.45 & 14.50 & 0.73 & 4.35 & 0.73 & 10.15 & 0.15 & 0.15 \\
\hline Limestone & 167 & 170 & 4.35 & 36.25 & 0.87 & 3.63 & 2.90 & 10.15 & 0.30 & \\
\hline
\end{tabular}

Since it is hard to accurately determine the tensile strength of rock materials, tensile strain is often used as a failure criterion, as shown in Table 6.2. Therefore, it is important to determine the strain distribution on the top and bottom surface of the rock layer. Equation 6.9 can be used to determine the surface strains on a sagging roof layer. In this equation, the first term is the tensile strain caused by the beam elongation due to sagging and the second term is due to beam bending. The positive sign (+) in front of the second term is for the strain on the top surface of the layer 
while the negative sign (-) for the bottom surface. If the resulting strain is a positive one, it is in tension and otherwise in compression. For coal measure rocks, the tensile strain should be more critically examined than the compressive strain (Luo, 2015a).

$$
\varepsilon(x)=\left(\sqrt{1+4\left(\frac{S_{\max }}{D}\right)^{2}}-1\right) \pm \frac{b\left(q_{o}+q_{I}-P_{w}\right)}{24 E I}\left(D^{2}-6 D x+6 x^{2}\right)
$$

The derived equation indicates that the hydrostatic pressure of the mine water plays a role in reducing the tensile strain on the bridging roof layer. Besides, mine water could reduce the elastic modulus $(E)$ and moment of inertia $(I)$ of the immediate roof which will increase the tensile strain developed in the immediate roof. For a bridging layer that has been loaded to a nearly critical condition, withdrawing the mine water could cause the failure of this layer. As it fails, domino effects could occur and eventually lead to a sinkhole subsidence event.

\subsection{Case Study}

The developed mechanical models for assessing the effects of mine water on causing surface subsidence over inactive room-and-pillar mines are applied to analyze the development mechanism of one documented subsidence case. On March 4, 1995, a $10 \mathrm{ft}(3 \mathrm{~m})$ in diameter and $10 \mathrm{ft}$ (3 m) deep subsidence sinkhole was reported on the eastbound lane of I-70 in Guernsey County, Ohio, marked as a shaded square in Fig. 6.4 (Guy et al., 2003). The underground coal mine underneath the affected I-70 section was opened in 1912 and abandoned in 1935. Room-and-pillar mining method was employed to extract the Upper Freeport coal seam of 5 to $7 \mathrm{ft}$ (1.5 to $2.1 \mathrm{~m}$ ) in thickness (Crowell, 1995). The overburden depth at the site is about $66 \mathrm{ft}(20 \mathrm{~m})$. In the local area of the catastrophic sinkhole on the eastbound lane (Fig. 6.4), the mine entries and crosscuts measured from the available mine map are about 20 and $15 \mathrm{ft}(6$ and $4.6 \mathrm{~m})$ wide, respectively. 
The pillars are about $10 \mathrm{ft}(3 \mathrm{~m})$ wide and $60 \mathrm{ft}(18.3 \mathrm{~m})$ long in the area around the sinkhole. Based on these dimensions, the overall recovery ratio at the time of mining is calculated as $73 \%$ while the recovery ratio around pillar \#3 (directly under the sinkhole) is about $83 \%$.

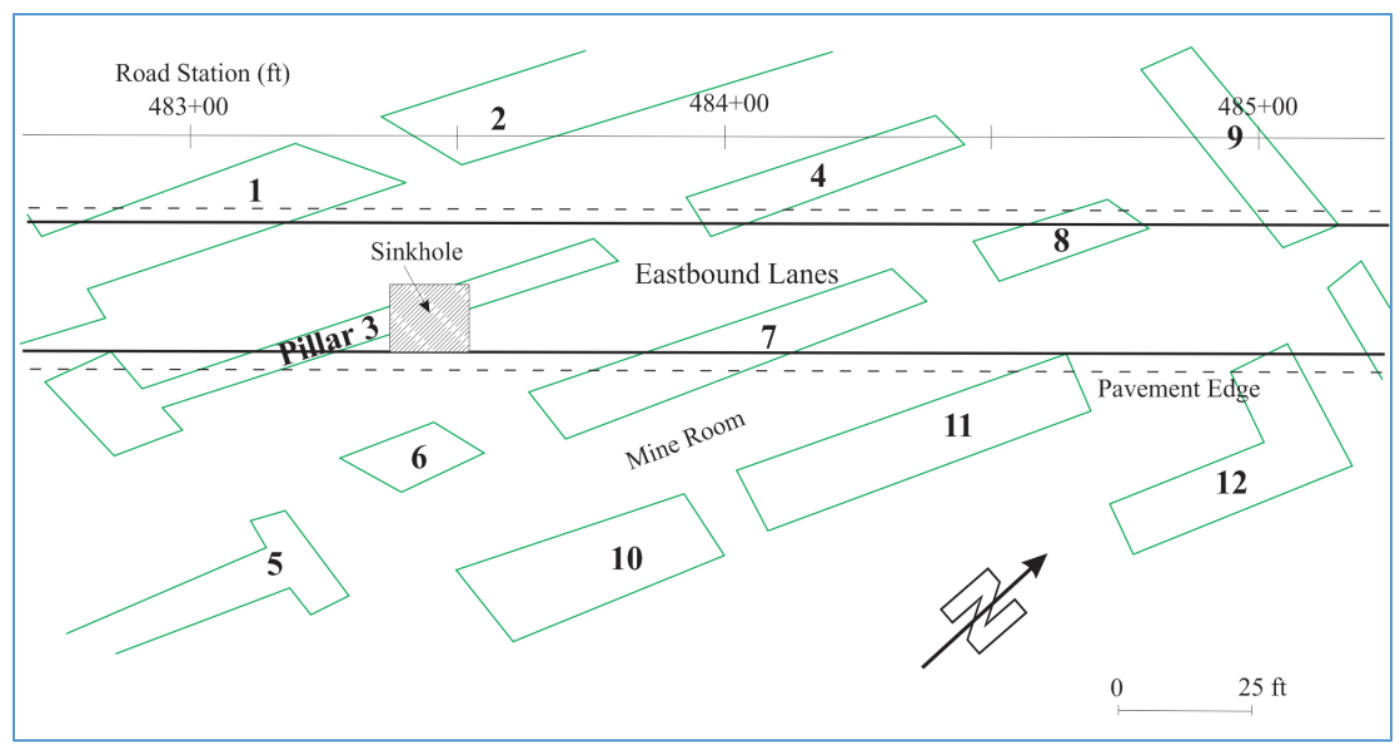

Figure 6.4 Map view of the sinkhole subsidence on the eastbound of I-70 (road stations 48300-48500) in Ohio (after Guy et al., 2003)

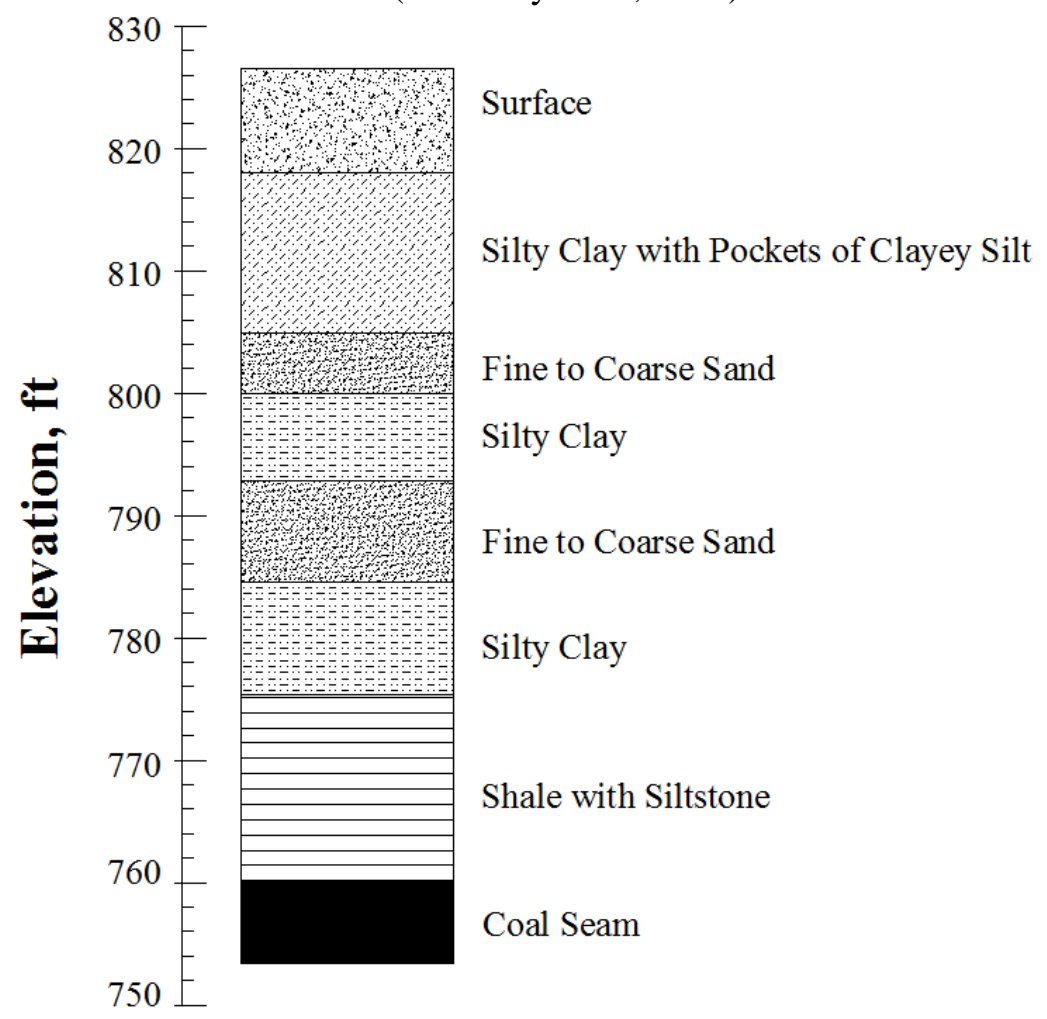

Figure 6.5 A Geologic column constructed from drill log data along the southern edge of the I-70 
Based on the 49 exploration boreholes drilled immediately after the subsidence events started, a geologic cross-section constructed from the drill logs are shown in Fig. 6.5. The geologic information shows that this mine is partly overlain by unconsolidated material ranging from 40 to $50 \mathrm{ft}$ (12.2 to $15.2 \mathrm{~m})$ in thickness from surface downward. Bedrock between the unconsolidated material and the coal seam included fractured shale and siltstone 10 to $20 \mathrm{ft}$ ( 3 to $6 \mathrm{~m}$ ) thick. The coal seam was underlain by soft claystone (Crowell, 1995).

Just before this subsidence event, an auger mining operation of an adjacent surface mine encountered the abandoned workings of the Murray Hill No. 2 mine resulting in prolific water flows into the surface mine excavation. The surface mine had to pump water constantly in order to operate normally. This subsidence began shortly after pumping was started. The mine water is about $20 \mathrm{ft}(6 \mathrm{~m})$ above the mine roof before pumping (Hoffman et al., 1995).

The documented case is analyzed using the model developed in this chapter. A program has been developed in MS Excel to analyze the safety factor of pillars. The collected mining information are used in the analysis. The recovery ratio is as high as $73 \%$ and the average safety factor of pillars in the area is determined as 4.7 while the safety factor of pillar \#3 is about 2.2 by using Eqs. 6.2 and 6.7 when the hydrostatic pressure was still in place. However, when the mine water was withdrawn to the coal seam level, the average safety factor of pillars and the safety factor of pillar \#3 are reduced to 4.3 and 2, respectively. Considering the possible inaccuracy of such old mine map and the weathering and water erosion effects, the effective widths of the pillars could be smaller than the measured ones from the map. Therefore, the safety factor of pillar \#3 could be much lower than the calculated value of 2 and its stability could be jeopardized.

Since the reported sinkhole occurred directly above the pillar \#3, there could be two conditions of the pillar \#3, stable and unstable. If the pillar \#3 was still stable after dewatering, cutter 
roofs at the edge of the pillar \#3 would occur. If pillar \#3 was squeezed during dewatering, a longer beam sitting on pillars \#1 and \#7 would form. These two conditions will be discussed in detail later.

The program developed based on the roof beam mechanical model has been applied to assess the possibility of forming sinkhole subsidence. In this case, all the measured mine structural dimensions are used. The densities of fractured shale and overlying unconsolidated material are 160 and $140 \mathrm{lbs} / \mathrm{ft}^{3}\left(2,563\right.$ and $\left.2,243 \mathrm{~kg} / \mathrm{m}^{3}\right)$, respectively. It is assumed that the presence of water does not affected the mechanical properties of the immediate roof layer. Since the shale beam was fractured, its Young's modulus was selected as $7.25 \times 10^{5} \mathrm{psi}(5 \mathrm{GPa})$. The $15 \mathrm{ft}(4.6 \mathrm{~m})$ thick fractured shale and siltstone rock layers were simplified into one beam to support the overlying unconsolidated materials. Apparently, if this layer fails, the overlying unconsolidated materials would fall into the mine void and sinkhole subsidence event would form on surface. Two different cases are simulated using the beam model for stable and unstable pillar \#3.

If the pillar \#3 was stable, the intersection span was determined as $25 \mathrm{ft}(7.6 \mathrm{~m})$ from pillar \#1 to pillar \#3 (Fig. 6.4). The resulting deflections and strains profiles on the roof layer are shown in Figs. 6.6 and 6.7, respectively. A positive strain is in tension while a negative one for compression. With the hydrostatic pressure, the maximum roof deflection is 0.015 inches $(0.381 \mathrm{~mm})$. On the top surface of the roof layer, the maximum tensile strains, $7.5 \times 10^{-4} \mathrm{ft} / \mathrm{ft}(\mathrm{m} / \mathrm{m})$, are located directly above the pillar edges. On the bottom surface, the maximum tensile strain is $3.0 \times 10^{-4} \mathrm{ft} / \mathrm{ft}$ $(\mathrm{m} / \mathrm{m})$ occurring at the center of the entry. Without the hydrostatic pressure support, the maximum roof deflection increases to 0.017 inches $(0.432 \mathrm{~mm})$. The maximum tensile strains on the top and bottom surface of the roof layer are $8.5 \times 10^{-4}$, and $4.0 \times 10^{-4} \mathrm{ft} / \mathrm{ft}(\mathrm{m} / \mathrm{m})$, respectively. All these maximum tensile strains are much less than the critical value of $2.0 \times 10^{-3} \mathrm{ft} / \mathrm{ft}(\mathrm{m} / \mathrm{m})$ required to 
fracture such rock. The roof layer would not fail and consequently a sinkhole subsidence would be unable to form on surface. Therefore, the pillar \#3 should not be stable.

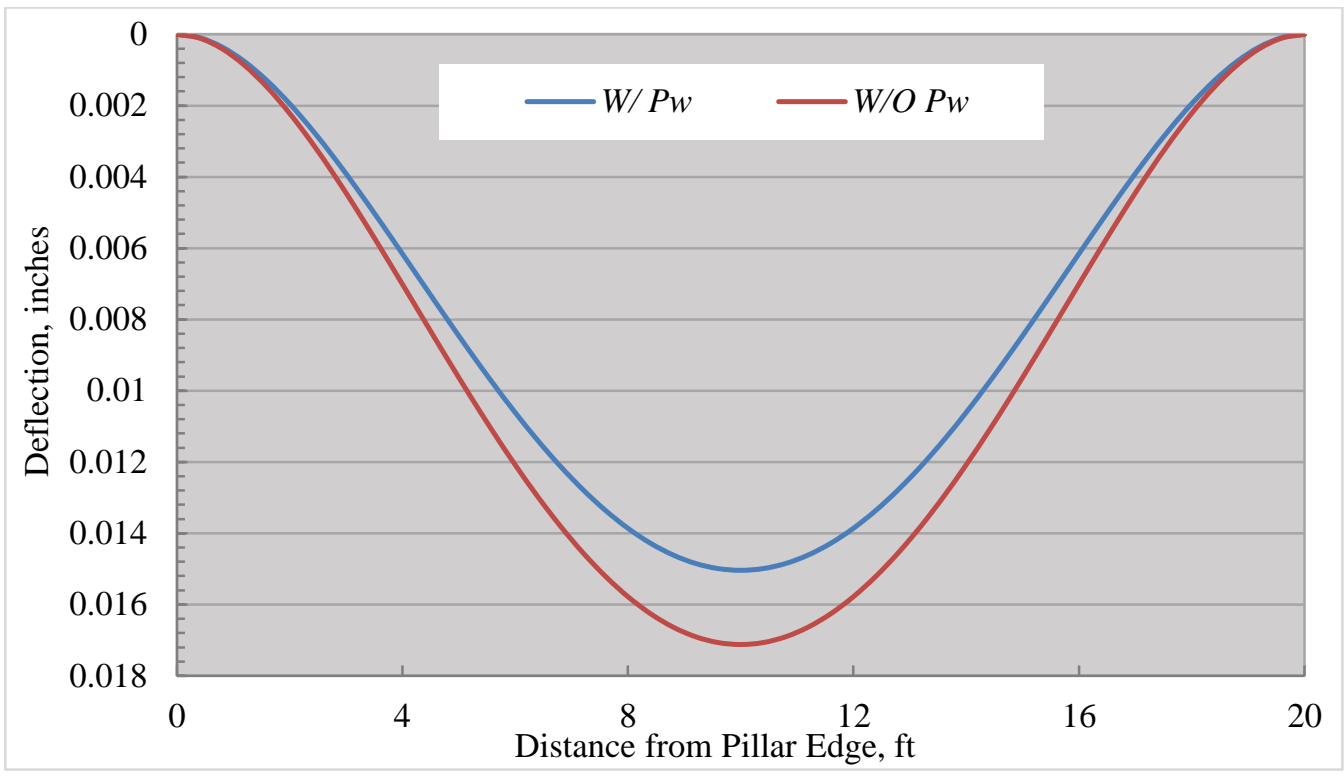

Figure 6.6 Roof deflection profile for the $25-\mathrm{ft}$ long and 15 -ft thick shale layer with and without hydrostatic pressure effect

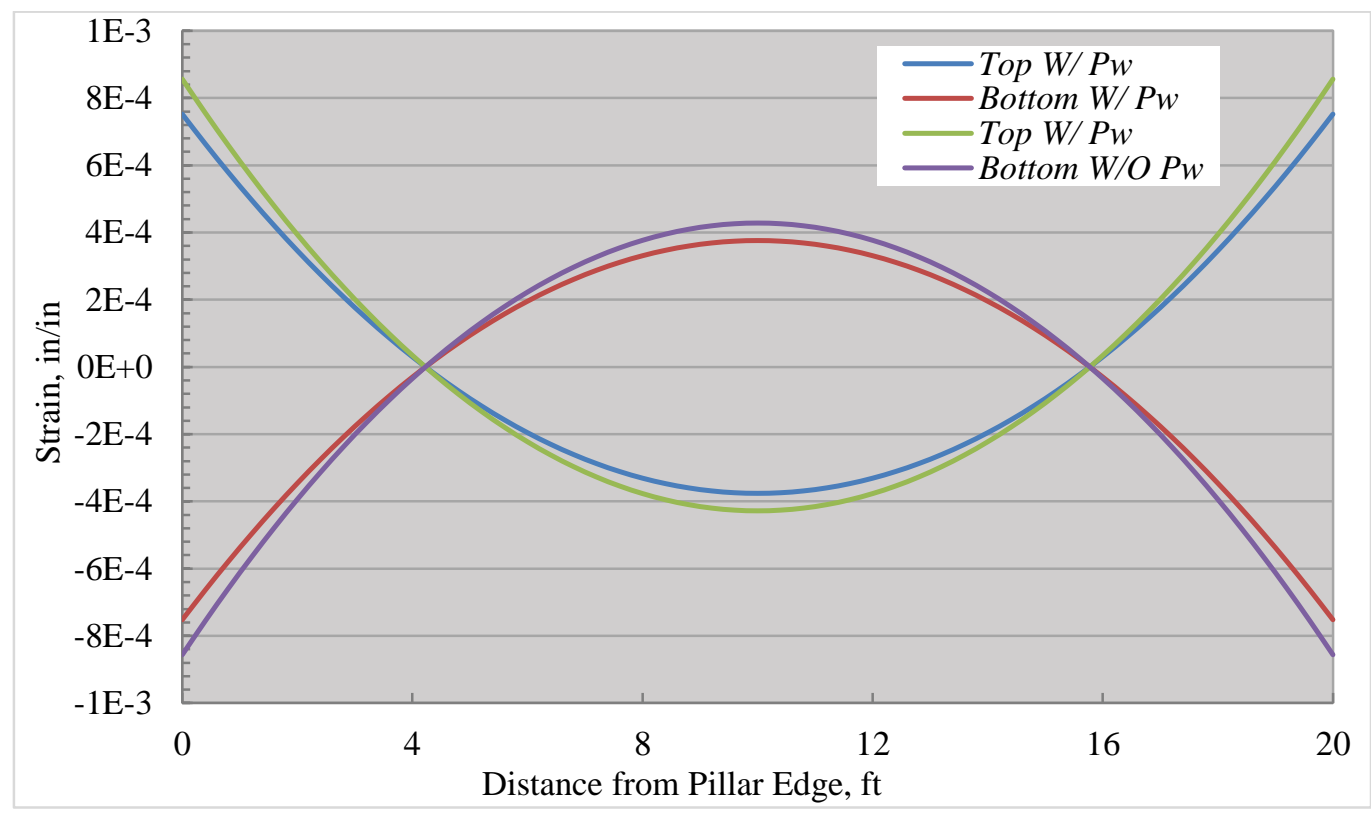

Figure 6.7 Strain profiles for the 25 -ft long and 15 -ft thickness shale layer with and without hydrostatic pressure effect

If the pillar \#3 was squeezed after dewatering, the roof span was determined as $45 \mathrm{ft}(13.7$ m) between pillar \#1 and pillar \#7 (Fig. 6.4). The estimated deflections and strains on the roof 
layer are shown in Figs. 6.8 and 6.9, respectively. With the supporting force from hydrostatic pressure, the maximum roof deflection is 0.385 inches $(9.8 \mathrm{~mm})$.

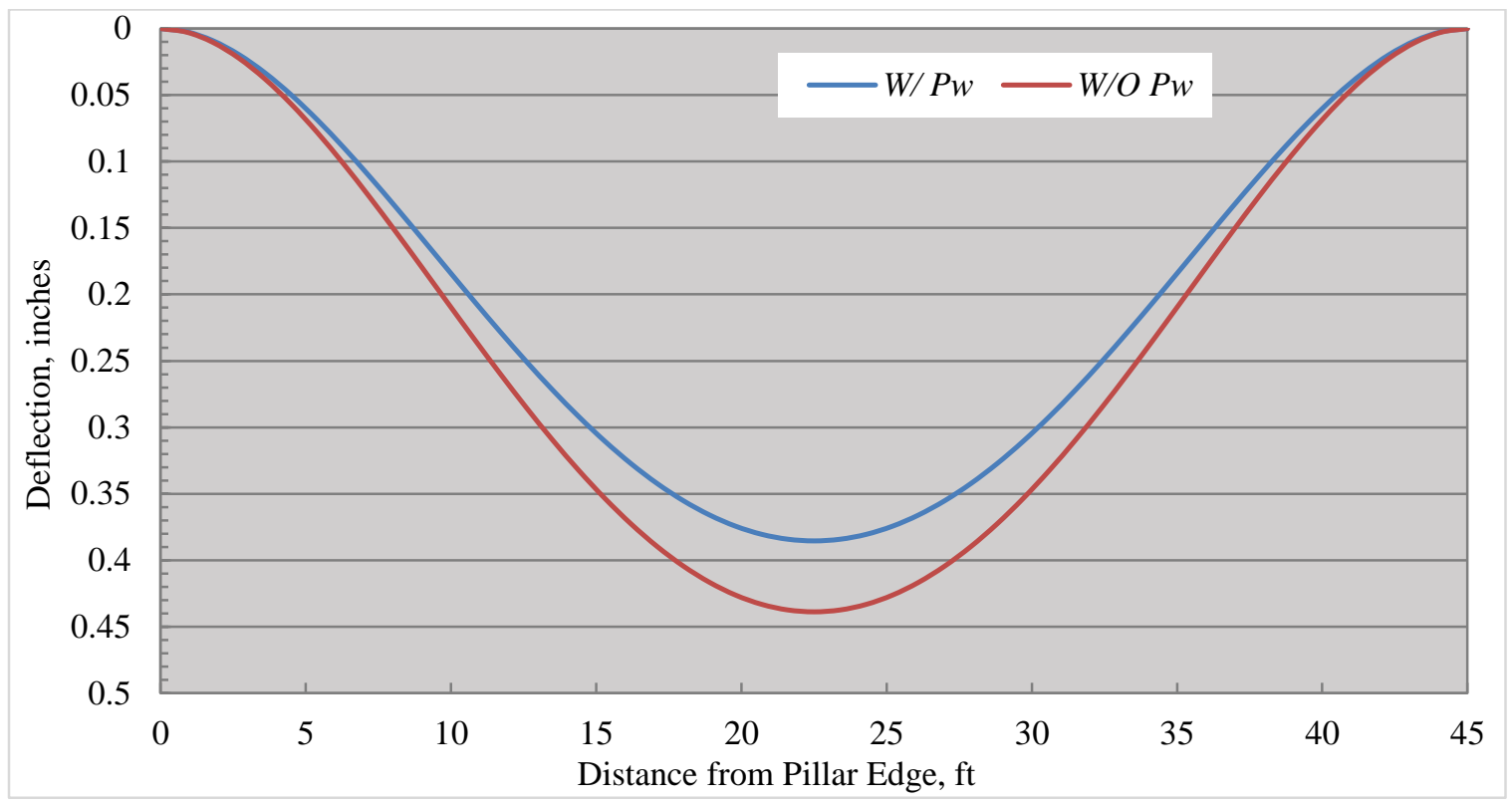

Figure 6.8 Roof deflection profile for the 45 -ft long and 15-ft thick shale layer with and without hydrostatic pressure effect

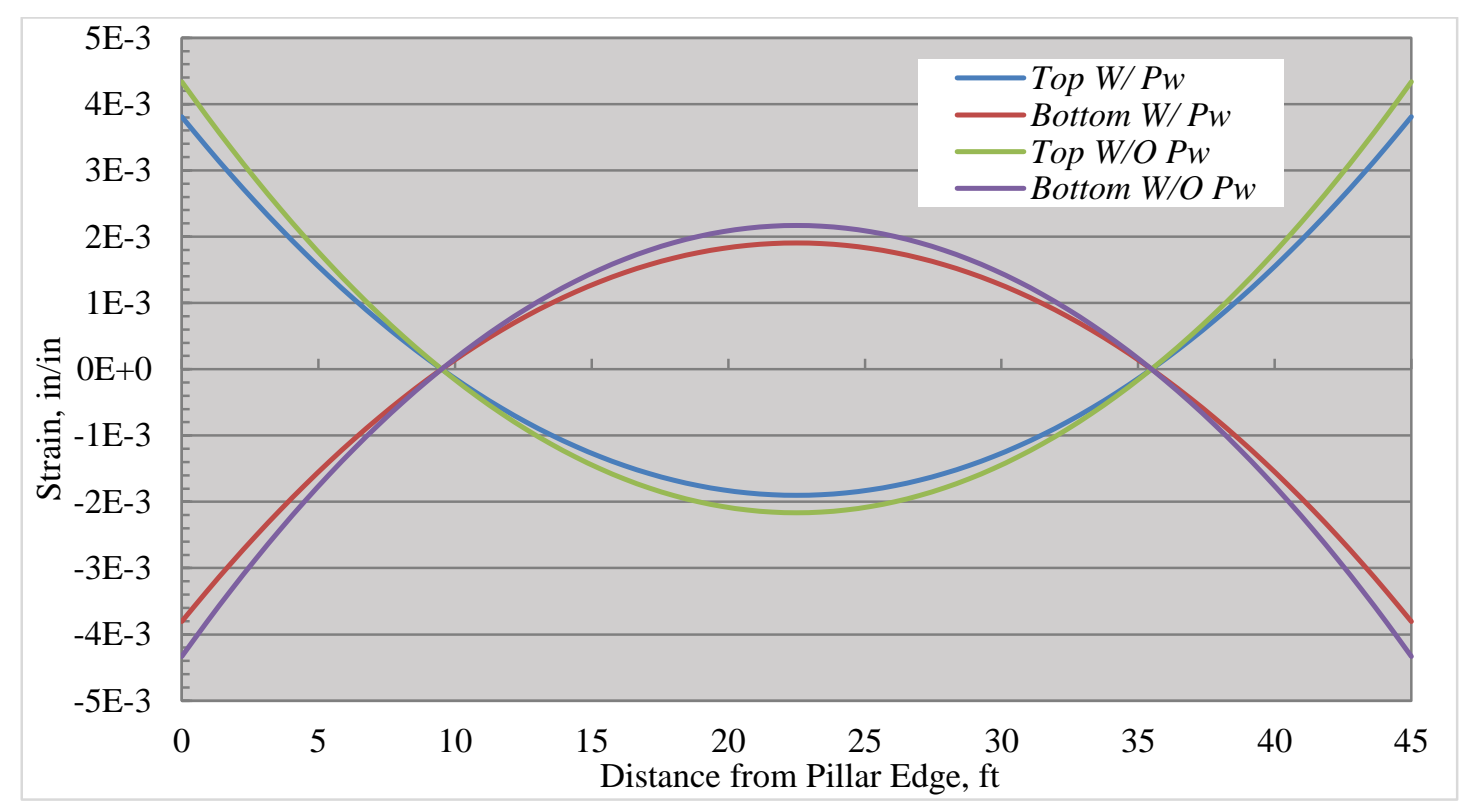

Figure 6.9 Strain profiles for the 45-ft long and 15-ft thickness shale layer with an without hydrostatic pressure effect

The maximum tensile strains on the top and bottom surfaces of the roof layer are $3.8 \times 10^{-3}$ and $1.9 \times 10^{-3} \mathrm{ft} / \mathrm{ft}(\mathrm{m} / \mathrm{m})$, respectively. Without the assistive action of the hydrostatic pressure, the 
maximum roof deflection increases to 0.44 inches $(11.2 \mathrm{~mm})$ while the maximum tensile strains on the top and bottom of the roof layer become $4.4 \times 10^{-3}$ and $2.2 \times 10^{-3} \mathrm{ft} / \mathrm{ft}(\mathrm{m} / \mathrm{m})$, respectively. Therefore, the roof layer would fail in the second case. Without this competent roof layer, the domino failure of the overlying strata would continue and eventually lead the documented sinkhole subsidence.

\subsection{Summaries}

The mechanism of mine water in abandoned underground room-and-pillar mines to prevent surface subsidence under the current assumptions has been explored in this research. It demonstrates that the hydrostatic pressure can reduce the loads on the mine pillars and support the mine roof to certain degrees. Losing of the hydrostatic pressure due to withdrawing the mine water could lead to pillar and/or roof failure. Depending on mining and geological conditions, the failed pillars and/or roof could lead to formation of trough type or sinkhole subsidence events on surface.

Two mechanical models have been developed to consider the effects of hydrostatic pressure on the pillar and roof stability assessments, respectively. The models have been applied to the analysis of the formation mechanism of a documented sinkhole subsidence event. 


\section{CHAPTER 7 \\ CONCLUSIONS AND RECOMMENDATIONS}

\subsection{Conclusions}

The objective of this dissertation is to develop an enhanced subsurface subsidence prediction model by incorporating the key strata theory, to propose techniques for assessing and mitigating longwall subsidence effects on interstate highways and highway bridges, and to develop two mathematical models to quantify the potential effects of mine water on the structural stability of mine pillars and immediate roof, as well as the potential for causing surface subsidence over inactive room-and-pillar mines.

A new subsurface subsidence prediction model considering the key strata effects on subsurface strata movements and deformations is developed. The key strata serve as the backbone of the overburden and control the movements of the weak layers located above them. The versatile influence function method was employed in this model to predict subsurface subsidence layer by layer from the mine level to the ground surface. A set of empirical formulas were derived for determining the required final subsurface subsidence parameters (i.e., subsidence factor, offset distance of inflection point, radius of major influence) at the top surface of each layer. The new program was validated with subsurface subsidence data measured in two boreholes over two longwall panels using multi-wire extensometer method with the anchors being attached to the borehole wall at different levels above the mined coal seam. Other than the apparent measurement errors at four anchors in the caving zone due to lost anchorage, the predicted subsurface subsidence

agreed well with the measured ones for the remaining anchors and ground surface. The total strain distribution field, useful for estimating the mining impacts to subsurface structures, water bodies 
and coalbed methane, in the overburden strata produced by the new prediction model can clearly show the effects of the thick and hard key strata to the ground subsidence process.

The surface subsidence induced by underground mining activities, especially longwall mining operations, can cause significant influence on interstate highways and highway bridges. In order to ensure traffic safety and drivability of the affected highways and bridges, the potential subsidence effects on those structures have been assessed. The highway design criteria and the analysis of vehicle dynamics are applied to determine the driving safety related factors such as minimum stopping distance, superelevation rate, sight distance, etc. for the subsided highway. The predicted surface strain is used to assess the integrity of highway pavements. In addition, the movements and deformations of bridge structures are analyzed to determine the integrity and stability related factors such as separation/closure between abutments, deflection of beams, twisting of decks, integrity of abutments, etc. for the bridges. Due to the practical limitations, the mitigation measures can be divided into: (1) temporary mitigation measures to maintain driving safety during the active subsidence period, and (2) permanent adjustment of the subsided section of highway and permanent repair the movements and deformations of the bridge structures for the resumption of normal traffic after the subsidence event. Two case studies are presented to demonstrate the longwall subsidence influence assessment and mitigation measures to protect the interstate highways and highway bridges, respectively.

Two mechanical models have been developed to quantify the effects of hydrostatic pressure induced by the accumulated mine water in inactive underground room-and-pillar mines on the structural stability of mine pillars and immediate roof, respectively. The mechanism of mine water to prevent surface subsidence has been explored in this research. It demonstrates that the hydrostatic pressure can reduce the loads on the mine pillars and support the mine roof to certain 
degrees. Losing of the hydrostatic pressure due to withdrawing the mine water could lead to pillar and/or roof failure. Depending on mining and geological conditions, the failed pillars and/or roof could lead to formation of trough type or sinkhole subsidence events on surface. The mathematical models have been applied to the analysis of the formation mechanism of a documented sinkhole subsidence event.

\subsection{Research Significance and Outcomes}

The significance and outcomes of this research are:

(1) An enhanced subsurface subsidence prediction model for longwall mining method was developed by incorporating the key strata theory;

(2) The techniques for assessing and mitigating longwall subsidence effects on interstate highways and highway bridges were systematically proposed for the first time;

(3) The potential effects of mine water on the structural stability of mine pillars and immediate roof, as well as the potential for causing surface subsidence were quantified for the first time by two developed mathematical models.

\subsection{Recommendations for Future Research}

Based on the conclusions from this research, the following working is recommended for any future studies:

(1) Calibrating the enhanced subsurface subsidence prediction model with field data. As mentioned previously, the accuracy of the prediction model is heavily depended on the mathematical models and the required subsurface subsidence factors. Most of the work in this dissertation was dedicated to improving the mathematical models. Due to the 
limited subsurface subsidence cases available, the empirical formulas for the required subsurface subsidence factors might not be as accurate as that for surface subsidence factors. Therefore, in the future research, more subsurface subsidence cases should be collected to calibrate the enhanced the prediction model in order to improve its accuracy.

(2) Refining the techniques for assessing and mitigating longwall subsidence effects on interstate highways and highway bridges. In this dissertation, the techniques for assessing and mitigating longwall subsidence effects on interstate highways and highway bridges are mainly focus on theoretical analyses. While the field observations could be different from the theoretical analyses to some degree. In the future, the longwall subsidence effects on interstate highways and highway bridges should be observed and measured as more as possible to refine the proposed techniques in this dissertation.

(3) Improving the mathematical models to quantify the mine water effects on the structural stability of the mine pillars and immediate roof. The two mathematical models in this dissertation were developed by dealing the geologic condition in simplest way and assuming that the mine water has no erosion effect on the surrounding rocks. Therefore, this treatment could compromise the accuracy and applicability of the mathematical models. In the future, the erosion effect of the mine water on the surrounding rocks should be studied. In addition, the mathematical models should be improved by taking more true situations into consideration and by calibrating and validating the mathematical models with more field cases. 


\section{REFERENCES}

Adelsohn, E., Iannacchione, A., and Winn, R., 2019. Investigations on Longwall Mining Subsidence Impacts on Pennsylvania Highway Alignments. Proceedings of the 38th International Conference on Ground Control in Mining. Society for Mining, Metallurgy \& Exploration. pp. 239-250.

Alke, R. B., and Thompson, B. L., 1984. A Case History of the Effect of Mine Subsidence on A Concrete Arch Bridge in Northern West Virginia. In The $25^{\text {th }}$ US Symposium on Rock Mechanics (USRMS), American Rock Mechanics Association.

American Association of State Highway and Transportation Officials (AASHTO), 2001. A Policy on Geometric Design of Highways and Streets. 4th Edition. ISBN 1-56051-156-7. Washington, DC, $905 \mathrm{pp}$.

American Association of State Highway and Transportation Officials (AASHTO), 2012. AASHTO-LRFD Bridge Design Specifications. 6th Edition, Washington, DC.

Bals, R., 1932. A Contribution to the Problem of Precalculating Mining Subsidence. Mitt. Markscheidewesen, Essen, German, Vol. 42, pp. 98-111.

Beyer, F., 1945. On Predicting Ground Deformations due to Mining Flat Seams. Habilitation Theses, Tech Univ Berlin.

Bieniawski, Z. T., 1968. The effect of specimen size on compressive strength of coal. In International Journal of Rock Mechanics and Mining Sciences \& Geomechanics Abstracts, Vol. 5, No. 4, pp. 325-335. Pergamon.

Bridge and Tunnel History (BTH), 2020. History of Bridges. Retrieved 28 April, 2020, from http://www.historyofbridges.com/.

Brook, N., and Misra, B., 1970. A Critical Analysis of the Stamp Mill Method of Determining Protodyakonov Rock Strength and the Development of A Method of Determining A Rock Impact Hardness Number. In Proceedings 12th US Rock Mechanics Symposium, Rolla, Missouri; November 1970. pp. 151-165.

Chien, M. G., 1981. A Study of the Behavior of Overlying Strata in Longwall Mining and Its Application to Strata Control. In Developments in Geotechnical Engineering, Vol. 32, pp. 13-17. DOI:10.1016/B978-0-444-42086-2.50008-9.

Crowell, D. L., 1995, The Hazards of Mine Subsidence, Ohio Geology - A Quarterly Publication of the Ohio Department of Natural Resources (Division of Geological Survey), pp. 1-5. 
Du, X. Z., 2010. The Impacts of Longwall Mining on Groundwater Systems - A Case of Cumberland Mine Panels B5 and B6 . Ph.D. Dissertation, 2010, West Virginia University, Morgantown, WV, 332 pp.

Fuller, R. G., Lang, C. R., Lang, R. H., 2000. Twin Views of the Tacoma Narrows Bridge Collapse. American Association of Physics Teachers, College Park, MD, 27 pp.

Grübl, P., Rühl, M., and Bührer, M., 1999. Evaluation of Modulus of Elasticity of Concrete with Recycled Aggregate. Darmstadt Concrete-Annual Journal.

Guo, H., Adhikary D. P., and Craig M. S., 2009. Simulation of Mine Water Inflow and Gas Emission During Longwall Mining. Rock Mechanics and Rock Engineering, 42(1), pp. 2551. DOI: https://doi.org/10.1007/s00603-008-0168-9.

Gutierrez, J. J., Vallejo, L. E., and Lin, J. S., 2010. A Study of Highway Subsidence due to Longwall Mining Using Data Collected from I-79. Pilttsburgh, Pennsylvania, Pennsylvania Department of Transportation. 402 pp.

Guy, E. D., Nolen-Hoeksema, R. C., Daniels, J. J., and Lefchik, T., 2003, High-Resolution SHWave Seismic Reflection Investigations Near A Coal Mine-Related Roadway Collapse Feature, Journal of Applied Geophysics, pp. 51-70.

Han, H. K., Xu, J. L., Wang, X. Z., Xie, J. L., and Xing, Y. T., 2019. Surface Subsidence Prediction Method for Coal Mines with Ultrathick and Hard Stratum. Advances in Civil Engineering, Vol. 2019. DOI: https://doi.org/10.1155/2019/3714381.

Hoffman, A. G., Clark, D. M., and Bechtel, T. D., 1995, Abandoned Deep Mine Subsidence Investigation and Remedial Design, Interstate 70, Guernsey County, Ohio, Proc. of the 46th Highway Geology Symposium, Charleston, West Virginia, pp. 408-422.

Iannacchione, A., Benner J., Witkowski, M., Miller, H., and Shuler, G., 2010. Observations of Impacts to Pennsylvania's Interstate Highways by Longwall Mining. Proceedings of the 29th International Conference on Ground Control in Mining, Morgantown, WV, pp. 79-88.

Iowa Department of Transportation Office of Design (IDTOD), 2013. Superelevation. Retrieved 20 May, 2020, from https://iowadot.gov/design/dmanual/02a-02.pdf.

Jones, C. J. F. P., 1988. The Effets of Mining Subsidnece on A Motorway Bridge. In 2nd International Conference on Case Histories in Geotechnical Engineering. St Louis, pp $1275-1278$.

Karmis, M., Jarosz, A., Schilizzi, P., 1987. Monitoring and Prediction of Ground Movements above Underground Mines in the Eastern United States. Proceedings of the 6th International Conference on Ground Control in Mining: Department of Mining Engineering, West Virginia University, pp. 184-194. 
Khair, A. W., Chaffins, R. D., and Quinn, M. K., 1987. Study of Ground Movements over A Longwall Mine. Proceedings 6th International Conference on Ground Control in Mining, Department of Mining Engineering, West Virginia University, pp. 141-155.

Knothe, S., 1957. Observations of Surface Movements under Influence of Mining and Their Theoretical Interpretation. Proceedings of the European Congress on Ground Movement, Leeds, UK, pp. 210-218.

Liu T. Q., 1981. Surface Movements, Overburden Failure And Its Applications. Coal Industry Publishing Co., Beijing, China, 369 pp., (in Chinese).

Luo, Y., 1989. Integrated Computer Model for Predicting Surface Subsidence due to Underground Coal Mining - CISPM. Ph.D. Dissertation, West Virginia University, Morgantown, WV, UMI order No.9020385, 168 pp.

Luo, Y., 2008. Assessment and Mitigation of Subsidence Effects on A Tall Self-Supporting and Free-Standing Communication Tower. Proceedings of the 27th International Conference on Ground Control in Mining, Morgantown, WV, pp 153-160.

Luo, Y., 2009. Techniques to Investigate Subsidence Events over Inactive Room-and-Pillar Mines. Proceedings of the 28th International Conference on Ground Control in Mining, West Virginia University, Morgantown, WV, pp. 149-154.

Luo, Y., 2011. Investigation of Subsidence Events over Inactive Room-and-Pillar Mines. Transactions of the Society for Mining, Metallurgy \& Exploration, Vol. 330, pp. 479-489.

Luo, Y., 2015a. A Design Tool for Improving Safety of Highwall Mining Operations. Transactions of the Society for Mining, Metallurgy \& Exploration, Vol. 338, pp. 77-86.

Luo, Y., 2015b. Systematic Approach to Mitigate Longwall Subsidence Influences. 15th Coal Operators' Conference, University of Wollongong, The Australasian Institute of Mining and Metallurgy and Mine Managers Association of Australia, pp. 220-229.

Luo, Y., 2020a. Surface Subsidence Engineering Lecture Notes. West Virginia University, Morgantown, WV.

Luo, Y., 2020b. Surface Subsidence Engineering. Society for Mining, Metallurgy, and Exploration, Littleton, $\mathrm{CO}$, (Publication in process).

Luo, Y., and Peng, S. S., 1989. CISPM - A Subsidence Prediction Model. The 30th U.S. Symposium on Rock Mechanics. Morgantown, WV, USA, pp. 853-860.

Luo, Y., and Peng, S. S., 1991. Protecting A Subsidence Affected House - A Case Study. Lexington, KY, s.n., pp. 297-300. 
Luo, Y., and Peng, S. S., 1992. A Comprehensive Computer Model for Predicting Dynamic Subsidence for Longwall Operations. Proceedings of the 11th International Conference on Ground Control in Mining, Ed. N.I. Aziz and S.S. Peng, University of Wollongong, Australia, pp. 511-516.

Luo, Y., and Peng, S. S., 1993. Using Influence Function Method to Predict Surface Subsidence Caused by High Extraction Room And Pillar Mining," Proceedings of the 7th International FIG Symposium on Deformation Measurements, Banff, Alberta, pp. 342-353.

Luo, Y., and Peng, S. S., 1994. Monitoring Railroad Response to Mining Subsidence And Assessment of Subsidence Influence to Railroad - A Case Study. Morgantown, WV, s.n, pp. 308-319.

Luo, Y., and Peng, S. S., 2000. Prediction of Subsurface Subsidence for Longwall Mining Operations. Proceedings of the 19th International Conference on Ground Control in Mining, West Virginia University, Morgantown, WV, pp. 163-170.

Luo, Y., and Peng, S. S., 2010. Subsurface Subsidence Prediction Model and Its Potential Applications in the Study of Longwall Subsidence Effects on Hydrologic System. SME Transactions, Volume 326, pp. 458-465.

Luo, Y., and Qiu, B., 2012. Enhanced Subsurface Subsidence Prediction Model That Considers Overburden Stratification. Mining Engineering, 64(10), pp. 78-84.

Luo, Y., Kimutis, R., Yang, K., Cheng, J. W., 2010. Mitigation of Longwall Subsidence Effects on Operating Railroad. Proceedings of the 29th International Conference on Ground Control in Mining, Morgantown, WV, pp. 89-96.

Luo, Y., Peng, S. S., and Chen, H., 1997. Protection of Pipelines Affected by Surface Subsidence. SME Transactions, Volume 302, pp. 2202-2207.

Luo, Y., Peng, S. S., and Kudlawiec, R., 2005. Mitigating Longwall Subsidence Effects on A Large Industrial Building. Proceedings of the 24th International Conference on Ground Control in Mining. Morgantown, WV, s.n, pp. $130-136$.

Luo, Y., Peng, S. S., and Miller, B., 2003. Influences of Longwall Subsidence on A Guyed Steel Tower - A Case Study. Proceedings of the 22nd International Conference on Ground Control in Mining. Morgantown, WV, USA, s.n, pp. 360-366. 
Ma, F. S., Yang, Y. S., Yuan, R. M., Yao B. K., and Guo, J., 2011. Effect of Regional Land Subsidence on Engineering Structures: A Case Study of the $6 \mathrm{~km}$ Long Su-tong Yantze River Bridge. Bulletin of Engineering Geology and the Environment. 70(3), pp 449-459.

Mark, C., 2007. Multiple Seam Longwall Mining in the U.S. - Lessons for Ground Control. Paper Presented to the 2007 SME Annual Meeting, Denver, CO, preprint 07-104.

Mark, C., and Barton, T. M., 1997. Pillar Strength and Coal Strength. Preceedings of New Technology for Ground Control in Retreat Mining. NIOSH, IC 9446, pp 49-59.

Matheson, G. M., and Eckert-Clift, A. D., 1986. Characteristics of Chimney Subsidence Sinkhole Development from Abandoned Underground Coal Mines Along the Colorado Front Range. Proceedings of the 2nd Workshop on Surface Subsidence due to Underground Mining, S.S. Peng, ed., West Virginia University, Morgantown, WV, pp. 204-214.

National Association of City Transportation Officials (NACTO), 2020. Vehicle Stopping Distance and Time. Retrieved 2 August, 2020, from https://nacto.org/docs/usdg/vehicle_stopping_distance_and_time_upenn.pdf.

Office of Highway Policy Information (OHPI), 2017. Table HM-20 - Highway Statistics 2016. Federal Highway Administration. Retrieved 28 April, 2020, from https://www.fhwa.dot.gov/policyinformation/statistics/2016/hm20.cfm.

Oglesby, C.H., and Hicks, R. G., 1982. Highway Engineering, 4th Edition. John Wiley \& Sons, New York. 844 pp.

Peng, S. S., 1992. Surface Subsidence Engineering. Society for Mining, Metallurgy, and Exploration, Littleton, CO., 161 pp.

Peng, S. S., 2006. Longwall Mining, Second Edition. West Virginia University, Morgantown, WV. $621 \mathrm{pp}$.

Peng, S. S., 2008. Coal Mine Ground Control. Department of Mining Engineering, West Virginia University, Morgantown, WV, $764 \mathrm{pp}$.

Peng, S. S., 2020. Longwall Mining, Third Edition. Published by CRC Press, Taylor \& Francis Group, London, UK, 546 pp.

Peng, S. S., and Luo, Y., 1988. Monitoring and Prediction of Surface Dynamic Subsidence due to Longwall Coal Mining." Proceedings of the 5th International Symposium on Deformation Measurements, Ed. A. Chrzanowski and W. Wells, Fredericton, NB, Canada., pp. 420-429.

Peng, S. S., and Luo, Y., 1992. Comprehensive and Integrated Subsidence Prediction Model CISPM (V2.0). Proceedings of the 3rd Workshop on Surface Subsidence due to 
Underground Mining, S.S. Peng, ed., West Virginia University, Morgantown, WV, pp. 2231.

Peng, S. S., Luo, Y., and Zhang, Z., 1995. Subsidence Parameters - Their Definitions and Determination. AIME-SME Transactions, Vol. 300, pp. 60-65.

Pennsylvania Department of Environmental Protection (PADEP), 2020a. Effects of Mine $\begin{array}{lllll}\text { Subsidence. } & \text { Retrieved } & 8 & \text { April, } & \text { 2020, from }\end{array}$ https://www.dep.pa.gov/Citizens/MSI/PublishingImages/Pages/What-is-MineSubsidence/Poster_final.pdf.

Pennsylvania Department of Environmental Protection (PADEP), 2020b. Mine Subsidence Insurance - Mine Drainage. Retrieved 28 April, 2020, from http://www.depgis.state.pa.us/pamsi/index.html.

Pennsylvania Department of Transportation (PADOT), 2017. Pennsylvania Highway Statistics2017 Highway Data. Retrieved 28 April, 2020, from https://gis.penndot.gov/BPR_PDF_FILES/Documents/Traffic/Highway_Statistics/Annual _Report/2018/2017_Pub_600.pdf.

Qian, M. G., Miao, X. X., and Xu, J. L., 1996. Theoretical Study of Key Stratum in Ground Control. Journal of China Coal Society 21 (3), 225-230 (in Chinese).

Qiu, B., and Luo, Y., 2013. Improved Model to Assess Stress Condition on Buried Pipelines Affected by Mine Subsidence. In World Mining Congress. Montreal, Canada.

Sun, G. C., and Peng, S. S., 1993. Rock Mechanics Property Data Bank for Coal Measure Strata. Proceeding of the $12^{\text {th }}$ International Conference on Ground Control in Mining. West Virginia University, Morgantown, WV, pp 330-341.

The Constructor, 2019. Bridge Bearings -Types of Bearings for Bridge Structures and Details. Retrieved 10 April, 2020, from https://theconstructor.org/structures/bridge-bearings-typesdetails/18062/.

Virginia Polytechnic Institute and State University (VPI\&SU), 1987. Prediction of Ground Movements due to Underground Mining in the Eastern United States Coalfields. Final report, Contract No. J5140137, Office of Surface Mining, Reclamation and Enforcement, U.S. Department of Interior, Vols I, 205 pp, and II, 112 pp.

Wang, J. A., Liu, H., and Ji, H. G., 2009. Study on Fracture Mechanism of Overlying Super-Thick Rock Layer in Underground Mining. Chinese Journal of Rock Mechanics and Engineering Vol. 28, pp. 2815-2823, (in Chinese).

Xu, J. L., and Qian, M. G., 2000. Method to Distinguish Key Strata in Overburden. Journal of China University of Mining \& Technology, 29(5), pp 463-467. 
Zain, M. F. M., and Mohammed, H. J., 2015. Concrete Road Barriers Subjected to Impact Loads: An Overview. Latin American Journal of Solids and Structures, Vol. 12, No. 10, pp. 18241858.

Zhao, J., 2020. Undated Lecture Notes, Rock Mechanics for Civil Engineers, Swiss Federal Institute of Technology, Lausanne, Switzerland. Retrieved 10 April, 2020, from https://www.scribd.com/document/370425033/ZHAO-XXX-Rock-Mechanics-for-CivilEngineers-pdf. 


\section{VITA}

\section{Education}

Henan Polytechnic University, B.S., 2013

West Virginia University, M.S., 2016

West Virginia University, 2016 - Present

\section{Author's Publication List during Ph.D. Study}

Yang, J., and Luo, Y., 2020. Enhanced Subsurface Subsidence Prediction Model Incorporating Key Strata Theory. Paper accepted by Mining, Metallurgy \& Exploration.

Luo, Y., and Yang, J., 2020. A Comprehensive Investigation of a "Subsidence" Claim. Paper is currently under review by International Journal of Mining Science and Technology.

Luo, Y., and Yang, J., 2020. Photogrammetry Method for Fast and Accurate Measurement of Strata Movements and Deformations for Scale Physical Mining Simulation. Mining, Metallurgy \& Exploration. DOI: https://doi.org/10.1007/s42461-020-00284-9.

Luo, Y., Yang, J., and Jiang, H., 2019. Techniques for Assessing and Mitigating Longwall Subsidence Effects on Highway Bridges. Mining, Metallurgy \& Exploration. 37 (1), pp. 197 210.

Luo, Y., Yang, J., and Jiang, H., 2019. Techniques for Assessing and Mitigating Longwall Subsidence Effects on Interstate Highways. Mining, Metallurgy \& Exploration. 36 (6), pp. $1157-1167$. 
Jiang, H., Luo, Y., and Yang, J., 2018. The Mechanics of Bolt Drilling and Theoretical Analysis of Drilling Parameter Effects on Respirable Dust Generation. Journal of Occupational and Environmental Hygiene. 15(9), pp. 700-713.

Luo, Y., and Yang, J., 2018. Effects of Dewatering Flooded Abandoned Room-and-Pillar Mines on Surface Subsidence. Mining Engineering. 70 (6), pp. 45-50.

\section{Author's Technical Report List during Ph.D. Study}

Luo, Y., and Yang, J., 2016. Rock Mechanics Test Report for Mt. Strom Wind Farm Project. A report submitted to Barr Engineering, Co, 8 pp.

Luo, Y., and Yang, J., 2017. Investigation of Subsidence Claims on Clark's House. A report submitted to Murray Energy Corporation, 20 pp.

Luo, Y., and Yang, J., 2017. Ground Stability Analyses for Selected Sites. A report submitted to Barr Engineering, Co, 27 pp.

Luo, Y., Yang, J., and Jiang, H., 2017. Adequacy Assessment for Placing Cumberland Mine No. 8 Bleeder Shaft in Proximity to Nearby Longwall Panels. A report submitted to Contura Energy Services, LLC, 26 pp.

Luo, Y., Yang, J., and Jiang, H., 2017. Subsidence Prediction, Influence Assessment and Recommended Mitigation Measures for West Alexander Water Tank. A report submitted to Tunnel Ridge, LLC, 30 pp.

Luo, Y., Jiang, H., and Yang, J., 2017. Subsidence Prediction, Influence Assessment and Mitigation Recommendation for Sowers Structures. A report submitted to Consol Pennsylvania Coal Company, LLC, 29 pp. 
Luo, Y., Jiang, H., and Yang, J., 2017. Causational Analysis for the Claimed Structural Damages in Mr. and Mrs. Rohanna Property. A report submitted to Babst, Calland, LLC, 25 pp.

Luo, Y., Yang, J., and Jiang, H., 2018. Feasibility Studies of Longwall Mining under a Section of PA I-70 Highway and Recommended Mitigation Measures. A report submitted to Tunnel Ridge, LLC, 32 pp.

Luo, Y., Yang, J., and Jiang, H., 2018. Preliminary Assessment of the Claimed Subsidence Event in Mr. ColaDonato's Property. A report submitted to Consol Pennsylvania Coal Company, LLC, 20 pp.

Luo, Y., and Yang, J., 2019. Subsidence Prediction, Influence Assessment and Recommended Mitigation Measures for Knottsville Water Tank, Tayler County, WV. A report submitted to Leer Mine Complex, $32 \mathrm{pp}$.

Luo, Y., and Yang, J., 2019. Subsidence Prediction and Influence to the Austin Cemetery. A report submitted to Leer Mine Complex, 15 pp.

Luo, Y., Yang, J., and Zhang, Y. N., 2019. Subsidence Prediction, Influence Assessment and Mitigation Measures for Warne's Structures. A report submitted to Warne Family, 34 pp.

Luo, Y., Yang, J., and Zhang, Y. N., 2019. Subsidence Prediction, Influence Assessment and Mitigation Measures for Warne's Rental No. 1 Structures. A report submitted to Warne Family, 26 pp.

Luo, Y., and Yang, J., 2020. Rock Mechanics Test Report for Indiana Limestone Company. A report submitted to Indiana Limestone Company, $12 \mathrm{pp}$.

Luo, Y., Yang, J., and Jiang, H., 2020. Assessment of Subsidence Influences and Recommended Mitigation Measures for I-70 Overpass Bridges near WV Welcome Center. A report submitted to Tunnel Ridge, LLC, 30 pp. 
Luo, Y., and Yang, J., 2020. Subsidence Prediction, Influence Assessment and Mitigation Recommendation for Bear Rocks Lakes. A report submitted to Tunnel Ridge, LLC, $57 \mathrm{pp}$.

Luo, Y., Yang, J., and Zhang, Y. N., 2020. Subsidence Prediction, Influence Assessment and Mitigation Measures for Structures in Winn's Property. A report submitted to Winn's Family, 34 pp.

Luo, Y., Yang, J., and Zhang, Y. N., 2020. Investigation of Severe Damages on King's Residential Structure and Identification of the Root Cause. A report submitted to King's Family, $29 \mathrm{pp}$. 